Adaptive pores in next generation membranes Adaptieve poriën in membranen van de volgende generatie

\author{
HANIEH BAZYAR
}

University of Twente 


\section{Graduation committee}

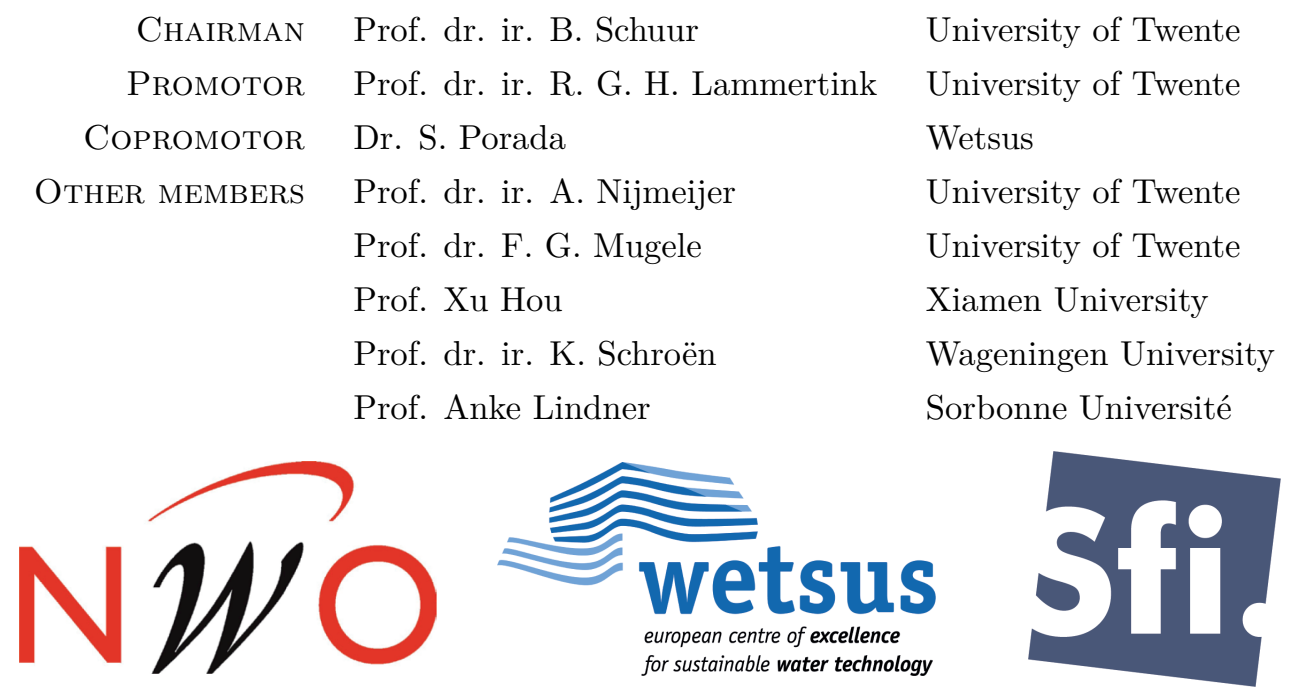

This thesis is part of the Vici project STW 016.160.312 which is financed by The Netherlands Organisation for Scientific Research (NWO). This work was performed in the cooperation framework of Wetsus, European Centre of Excellence for Sustainable Water Technology (www.wetsus.nl).

The work in this thesis was carried out at:

Soft matter, Fluidics and Interfaces

$\mathrm{MESA}^{+}$Institute for Nanotechnology

Faculty of Science and Technology

University of Twente

P.O. Box 217, 7500 AE Enschede, The Netherlands

\section{Adaptive pores in next generation membranes}

ISBN: $978-90-365-4933-2$

DOI: $10.3990 / 1.9789036549332$

URL: https://doi.org/10.3990/1.9789036549332

Cover design by Hanieh Bazyar

Typeset in $\mathrm{LAT}_{\mathrm{E}} \mathrm{X}$ using Overleaf

Copyright () 2020 by Hanieh Bazyar. All rights reserved. 


\title{
Adaptive pores in next generation membranes
}

\author{
DISSERTATION
}

to obtain

the degree of doctor at the University of Twente, on the authority of the rector magnificus,

Prof. dr. T. T. M. Palstra,

on account of the decision of the graduation committee, to be publicly defended

on Wednesday, May 20 $0^{\text {th }}, 2020$ at 12:45

by

Hanieh Bazyar

Born on March 25

in Shiraz, Iran 
This dissertation has been approved by the promotor:

Prof. dr. ir. R. G. H. Lammertink

and the copromotor:

Dr. S. Porada 


Anybody who has been seriously engaged in scientific work of any kind realizes that over the entrance to the gates of the temple of science are written the words "Ye must have faith".

- Max Planck 

Every challenging work needs self efforts as well as guidance of elders especially those who are very close to our heart.

My humble effort is dedicated to my sweet and loving

\section{MOTUER}

whose affection, love, encouragement and prayers of days and nights allow me to achieve such success and honor. 



\section{Contents}

Preface 1

References ............................ 4

\begin{tabular}{ll}
\hline Graphical summary & 7
\end{tabular}

\begin{tabular}{ll}
\hline Grafische samenvatting & 15
\end{tabular}

1 Nature-inspired membranes: a solution to membrane fouling 23

1.1 Introduction . . . . . . . . . . . . . . 25

1.2 Nature-inspired liquid-infused surfaces . . . . . . . . . . . . 28

1.3 How to make liquid-infused surfaces $\ldots \ldots \ldots \ldots$. . . . . . . 32

1.4 Liquid-infused surfaces with membrane technology . . . . . . . 35

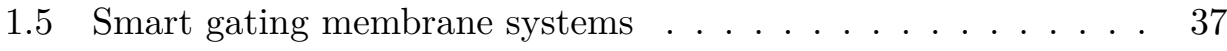

1.5 .1 Design and fabrication scheme . . . . . . . . . . 38

1.5 .2 Gating functionality $\ldots \ldots \ldots \ldots$. . . . . . . . . . . . . . . . . .

1.5.3 Liquid-gated membranes . . . . . . . . . . . . . . . . . 41

1.5.4 Applications of gating membranes . . . . . . . . . . . 44

1.6 Scope and outline of the thesis $\ldots \ldots \ldots \ldots$

References . . . . . . . . . . . . . . . . . . . . . 48

2 On the gating mechanism of slippery liquid-infused porous membranes 65

2.1 Introduction $\ldots \ldots \ldots \ldots \ldots \ldots \ldots$. . . . . . . . . . . . . . 67

2.2 Experimental details $\ldots \ldots \ldots \ldots \ldots \ldots$

$2.2 .1 \quad$ Materials . . . . . . . . . . . . . . . . . . . . 68

2.2 .2 Fabrication of porous PVDF membranes . . . . . . . . 68

2.2 .3 Fabrication of the SLIPS $\ldots \ldots \ldots \ldots$

2.2 .4 Characterization of the membranes . . . . . . . . . 68

2.2 .5 Impregnation experiments . . . . . . . . . . . . . 69 
$2.3 \quad$ Results and discussion $\ldots \ldots \ldots \ldots$

2.3.1 Membrane characterization results . . . . . . . . . . 69

2.3 .2 Observation of the liquid lining . . . . . . . . . . 71

2.3 .3 Liquid film thickness . . . . . . . . . . . . . . . . . 74

2.3.3.1 Experimental measurement . . . . . . . . . . 74

2.3.3.2 Theoretical calculation . . . . . . . . . . . 75

2.3 .4 Dynamics of liquid re-infusion . . . . . . . . . . . 78

2.4 Conclusion $\ldots \ldots \ldots \ldots \ldots$

References ........................ 80

3 Liquid-liquid displacement in slippery liquid-infused mem$\begin{array}{lc}\text { branes (SLIMs) } & \mathbf{8 3}\end{array}$

$3.1 \quad$ Introduction $\ldots \ldots \ldots \ldots \ldots \ldots \ldots$

3.2 Experimental details $\ldots \ldots \ldots \ldots \ldots$. . . . . . . . . . 87

3.2 .1 Materials . . . . . . . . . . . . . . . . 87

3.2 .2 Membrane fabrication . . . . . . . . . . . . . . 87

$3.2 .3 \quad$ Fabrication of dense PVDF . . . . . . . . . . . . . . 88

$3.2 .4 \quad$ Fabrication of SLIM and pre-wet membrane . . . . . . . 88

3.2 .5 Membrane characterization . . . . . . . . . . . 88

3.2 .6 Laser scanning confocal microscopy (LSCM) experiments 88

3.2 .7 Hydrophobization of the microfluidic chip . . . . . . 88

3.3 Results and discussion . . . . . . . . . . . . . . . . . . . 89

3.3.1 Membrane experimental results . . . . . . . . . . . . 89

$3.3 .2 \quad$ Microfluidic experimental results . . . . . . . . . . . . 95

3.4 Conclusion . . . . . . . . . . . . . . . . . . 100

References. . . . . . . . . . . . . . . . . . . 101

\begin{tabular}{|lll}
4 & Liquid-infused membranes with oil-in-water emulsions & 107
\end{tabular}

4.1 Introduction . . . . . . . . . . . . . . . . . . . . 109

4.2 Experimental details $\ldots \ldots \ldots \ldots$

$4.2 .1 \quad$ Materials . . . . . . . . . . . . . . . . . . . . . 113

$4.2 .2 \quad$ Fabrication of membrane and dense PVDF film . . . . . 113

4.2 .3 Membrane characterization . . . . . . . . . . . . . 114

$4.2 .4 \quad$ Fabrication of liquid-infused membranes . . . . . . . . . 114

$4.2 .5 \quad$ Preparation of surfactant solutions . . . . . . . . . . . 115

4.2 .6 Measurement of liquid entry pressure (LEP) . . . . . . . 115

$4.2 .7 \quad$ Measurements of interfacial tension (IFT) . . . . . . . 115

$4.2 .8 \quad$ Preparation and characterization of emulsions . . . . . 116

4.2 .9 Oil permeation from the $\mathrm{O} / \mathrm{W}$ emulsion experiments . . 116 
4.3 Results and discussion . . . . . . . . . . . . . . . . . . . . 117 4.3 .1 LEP and IFT measurement results . . . . . . . . . . . 117

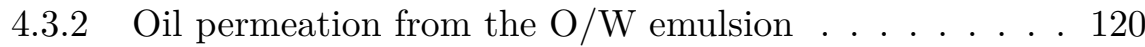

$4.3 .3 \quad$ Contact angle results $\ldots \ldots \ldots \ldots \ldots$

4.4 Conclusion . . . . . . . . . . . . . . . . . . . . . . . 123

References . . . . . . . . . . . . . . . . . . . . . 124

5 Application of liquid-infused membranes to mitigate biofilm growth 131

5.1 Introduction . . . . . . . . . . . . . . . . . . . 133

5.2 Experimental details $\ldots \ldots \ldots \ldots \ldots \ldots$

5.2 .1 Materials . . . . . . . . . . . . . . . . . . 136

5.2 .2 Membranes and spacers . . . . . . . . . . . . 137

5.2 .3 Fabrication of liquid-infused membranes . . . . . . . . . 137

5.2 .4 Membrane characterization . . . . . . . . . . . . 137

$5.2 .5 \quad$ Bacteria nutrient preparation . . . . . . . . . . . 138

$5.2 .6 \quad$ Biofouling experiments . . . . . . . . . . . . . . . . . 138

5.2.7 Process description of biofouling experiment. . . . . . . 139

5.2 .8 Membrane autopsy $\ldots \ldots \ldots \ldots$. . . . . . . . . . 139

5.3 Results and discussion . . . . . . . . . . . . . . . . . . . . . 140

5.3 .1 Membrane biofouling results . . . . . . . . . . . . . 140

5.3 .2 Modeling of bacterial growth . . . . . . . . . . . . . 141

$5.3 .3 \quad$ Membrane autopsy results . . . . . . . . . . . . . . . . 149

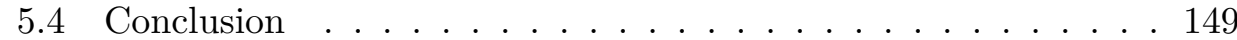

References . . . . . . . . . . . . . . . . . . 150

6 Acoustophoresis of monodisperse oil droplets in water: determining the acoustic energy density 155

6.1 Introduction . . . . . . . . . . . . . . . . . 157

6.2 Experimental details . . . . . . . . . . . . . . . . . . 159

6.2 .1 Materials . . . . . . . . . . . . . . . 160

$6.2 .2 \quad$ Fabrication of monodisperse $\mathrm{O} / \mathrm{W}$ emulsions $\ldots \ldots .160$

$6.2 .3 \quad$ Acoustic experiments . . . . . . . . . . . . . 161

6.2 .4 Analysis of acoustic experiments . . . . . . . . . . 164

6.3 Results and discussion . . . . . . . . . . . . . . . . 165

$6.3 .1 \quad$ Oil droplets in acoustic field . . . . . . . . . . . . . 165

6.3 .2 Acoustophoretic velocity of oil droplets . . . . . . . 166

$6.3 .3 \quad$ Acoustic energy density . . . . . . . . . . . . 168 
6.3.4 Relation between acoustic energy density and the input electric field . . . . . . . . . . . . . 168

6.4 Conclusion . . . . . . . . . . . . . . . . . . . 172

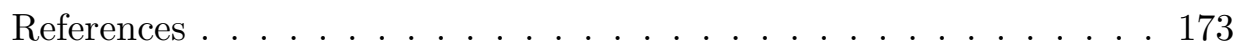

$\begin{array}{lll}7 & \text { On the permeability prediction of porous media } & 179\end{array}$

7.1 Introduction. . . . . . . . . . . . . . . . . 181

7.2 Materials and method . . . . . . . . . . . . . . . . . . 183

7.2.1 Permeability prediction model . . . . . . . . . . . 183

7.2.1.1 Numerical calculation of permeability . . . . . 184

7.2.1.2 Definition of $2^{\text {nd }}$ nearest neighbor distance $\left(\gamma_{2}\right) 184$

7.2.2 Generation of fibrous microstructure . . . . . . . . . . . 184

7.2.2.1 Chosen porosity and $\Delta_{\min }$ values . . . . . . . . 185

7.2.2.2 Statistical analysis of the fibrous microstructure 185

7.2 .3 Fabrication of fibrous microstructure . . . . . . . . . . . 186

$7.2 .4 \quad$ Permeability measurements . . . . . . . . . . . . . . . . 187

7.3 Results and discussion . . . . . . . . . . . . . . . . . . . 187

7.3.1 Analysis of radial distribution function $(g(r))$. . . . . . 188

7.3.2 Comparison between the designed and fabricated fibrous microstructures ................. . 188

7.3.3 Permeability calculation of fibrous microstructures . . . 189

7.3.4 Calculated values of $2^{\text {nd }}$ nearest neighbor distance $\left(\gamma_{2}\right) \cdot 194$

7.3.5 Modification of the numerical model . . . . . . . . . . . 194

7.3.6 Experimental validation of permeability model . . . . . 196

7.4 Conclusion . . . . . . . . . . . . . . . . 197

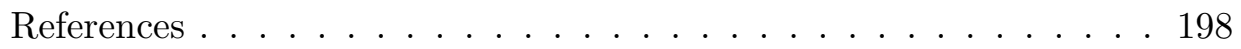

8 Reflections and perspectives 203

8.1 Reflections. . . . . . . . . . . . . . . . . . . 207

8.1.1 Crossflow filtration for oil permeation . . . . . . . . . . 207

$8.1 .2 \quad$ Electrophoresis of oil droplets . . . . . . . . . . . . 209

8.1.3 Cross-flow electro-filtration for oil permeation . . . . . . 214

8.2 Perspectives . . . . . . . . . . . . . . . . 215

References........................ . . 218

\begin{tabular}{|ll}
\hline A Appendix A & 223
\end{tabular}

A.1 $\quad$ Physical properties of the infusion liquids . . . . . . . . . . . 223

A.2 Impregnation experiment and porometry results. . . . . . . . . 223

A.3 Theoretical calculation of liquid film thickness . . . . . . . . . . 223 
A.3.1 Modification of the Lockhart-Martinelli method . . . . . 226 A.3.1.1 Modified Chisholm model . . . . . . . . . . . 226 A.3.1.2 Modified Turner-Wallis model . . . . . . . . . 228 A.3.2 Fourar and Lenormand model . . . . . . . . . . . . . . 230 A.3.3 Calculation of liquid film thickness . . . . . . . . . . . 230 A.3.4 Precision of the liquid film thickness calculation. . . . . 232 A.4 Calculation of the gas flow rate . . . . . . . . . . . . 232 References . . . . . . . . . . . . . . . . . . . . . 232

B Appendix B 235 B.1 SLIM fabrication and characterization . . . . . . . . . . 235

B.2 Contact angle measurements . . . . . . . . . . . . . 238 B.3 Interfacial tension measurements . . . . . . . . . . . . . . 238 B.4 Liquid-liquid displacement porometry (LLDP) experiments . . 239 B.5 $\quad$ Fitting results . . . . . . . . . . . . . . . . 239 B.6 Relation between permeability and porosity (tube model) . . . 241 B.7 Fabrication of the microfluidic chip . . . . . . . . . . . 242 B.8 $\quad$ Liquid-liquid displacement in microfluidic chip . . . . . . . . . 243 B.9 Local saturation of the non-wetting phase . . . . . . . . . . . 243 B.10 Box counting algorithm . . . . . . . . . . . . . 245 B.11 Buckley-Leverett analysis . . . . . . . . . . . . . . . 245 References . . . . . . . . . . . . . . . . . . . . 248

\begin{tabular}{ll}
\hline C Appendix C & $\mathbf{2 5 1}$
\end{tabular} C.1 Membrane characterization . . . . . . . . . . . . . . . 251

C.2 Physical properties of surfactant solutions and oils . . . . . . 254 C.3 Pictures of the fabricated emulsions . . . . . . . . . . . . 254 C.4 LLD analysis of hexadecane through LIM . . . . . . . . . . 256 C.5 Measurement of permeated oil during filtration experiments . . 258

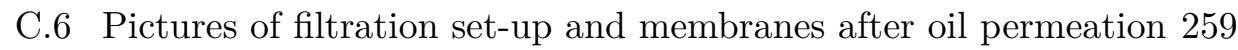
C.7 Permeate pictures of different $\mathrm{O} / \mathrm{W}$ emulsions from dry and liquid-infused membranes $\ldots \ldots \ldots \ldots$. . . . . . . . . . . . . . . . . .

C.8 Droplet size distribution of prepared emulsions . . . . . . . . . 261

C.9 Surfactant adsorption in hexadecane-infused membranes . . . . 261 C.10 Surfactant adsorption in Krytox101-infused membranes . . . . 269 References . . . . . . . . . . . . . . . . . 271 
\begin{tabular}{|ll}
\hline D Appendix D & 277
\end{tabular}

D.1 Membrane characterization . . . . . . . . . . . . 277

D.2 2 Liquid-liquid displacement (LLD) analysis . . . . . . . . . . . . 279

D.3 Results of feed pressure increase $\ldots \ldots \ldots$. . . . . . . . . 282

D.4 Effect of nutrient concentration . . . . . . . . . . . . . . . . 283

D.5 Confocal laser scanning microscope (CLSM) images. . . . . . . 284

D.6 Modification of logistic model . . . . . . . . . . . . . . . . 284

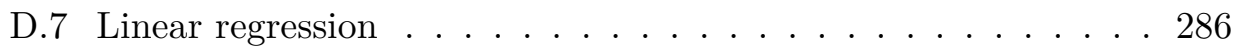

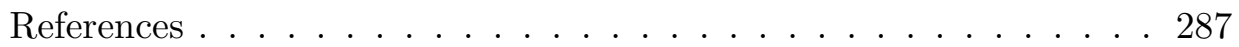

\begin{tabular}{lll}
\hline Appendix E & 289
\end{tabular}

E.1 Monodisperse emulsion fabrication using EDGE set-up . . . . . 289

E.2 $\quad$ Acoustic experimental results $\ldots \ldots \ldots \ldots$. . . . . . . . . . 290

E.3 $\quad$ Particle tracking velocimetry (PTV) results . . . . . . . . . . 292

E.4 Particle image velocimetry (PIV) results . . . . . . . . . . . . . 293

E.5 Effects of secondary acoustic radiation force . . . . . . . . . . . 294

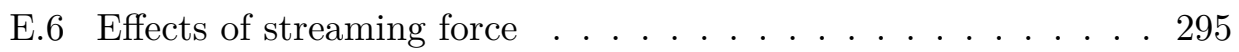

E.7 $\quad$ Fabrication of the microfluidic chip . . . . . . . . . . . . 297

References . . . . . . . . . . . . . . . . . . 298

\begin{tabular}{lll}
\hline Appendix F & 299
\end{tabular}

F.1 Comparison between the designed and fabricated fibrous microstructures . . . . . . . . . . . . . . . . 299

F.2 Algorithm for calculation of $2^{\text {nd }}$ nearest neighbor $\left(\gamma_{2}\right) \quad \ldots \quad \ldots 299$

F.3 $\quad$ Error analysis in calculation of $\gamma_{2} \ldots \ldots \ldots 303$

F.4 Permeation of water and hexadecane through fabricated mi-

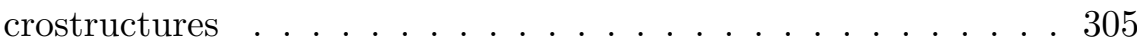

F.5 $\quad$ Fabrication procedure of the microfluidic chip . . . . . . . . 305

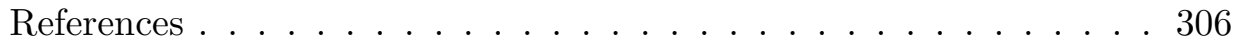

\begin{tabular}{ll}
\hline Acknowledgments & 307
\end{tabular}

\begin{tabular}{|ll}
\hline About the author & 313
\end{tabular}

\begin{tabular}{|l|l|}
\hline About the cover & 315
\end{tabular}

\begin{tabular}{ll}
\hline Scientific output & 317
\end{tabular} 


\section{Preface}

The development of a broad international consensus about the importance of human rights is one of the outstanding achievements of the twentieth century. The concept of human rights may be described as [1]:

There is something about each and every human being, simply as a human being, such that certain choices should be made and certain choices rejected; in particular, certain things ought not to be done to any human being and certain other things ought to be done for every human being.

Human rights discourse continues to develop. Thus, in 2010 a resolution of the General Assembly of the United Nations acknowledged "the importance of equitable access to safe and clean drinking water and sanitation as an integral component of the realization of all human rights", and further recognised [2]:

The right to safe and clean drinking water and sanitation as a human right that is essential for the full enjoyment of life and all human rights.

This resolution provides a very clear statement of the internationally recognised ethical importance of each person's need for access to clean drinking water and sanitation. However, as most of us may know, there are still many people in the world whose rights to clean water and sanitation are not being fulfilled. Lack of access to clean drinking water and sanitation is a clear example of injustice. Remedying this injustice presents a clear opportunity of professional capabilities for engineers 3 .

Around $97 \%$ of the water on earth resides in the oceans. But the salts in that water make it undrinkable, poisonous to crops and destructive for industrial machinery. If the salts could be removed, this source could provide a practically endless supply of fresh water. The removal of salts and other minerals from water is known as desalination. Various techniques have been tested so far for efficient water desalination [4. An innovative step and major breakthrough was the introduction of membrane technology for water and wastewater treatment. A key engineering contribution was the pioneering work 


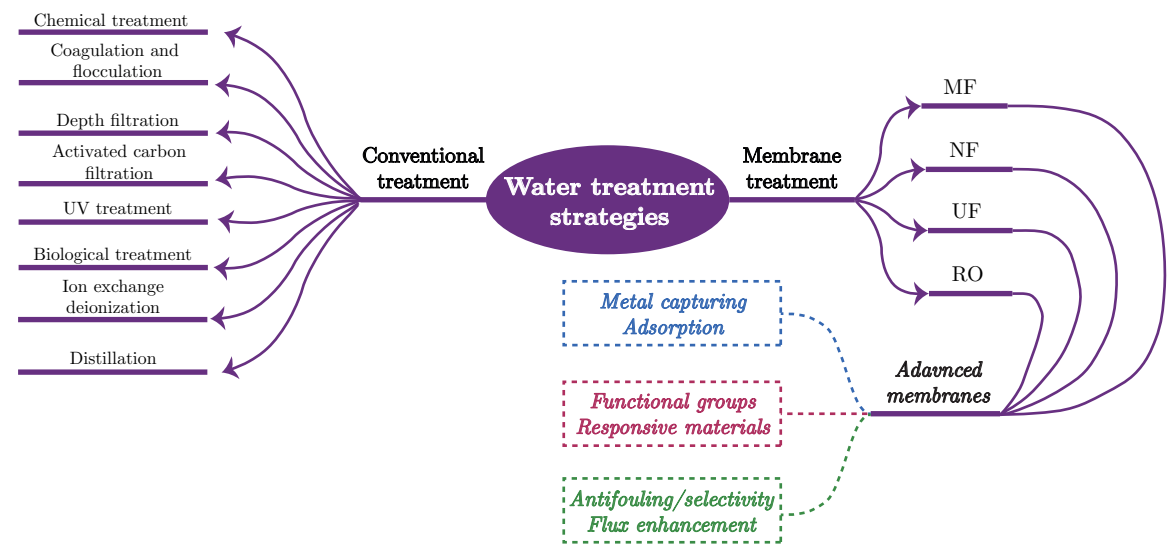

Figure 1: Concept diagram of water treatment strategies currently used in industry (solid lines) and emerging applications (dash lines) (adapted with modification from Ref [8] Copyright(02016, Elsevier B.V.).

of Loeb-Sourirajan in 1963 leading to the development of polymeric anisotropic membranes which is now termed a reverse osmosis ( $\mathrm{RO}$ ) membrane [5, 6]. RO is also known as hyperfiltration which is the most popular form of desalination. The world's first commercial RO system was installed in the town of Coalinga in California in 1965, a development that provided about $20 \mathrm{~m}^{3}$ of drinking water daily for the residents [3, 4].

Membrane processes such as RO, nanofiltration (NF), ultrafiltration (UF), microfiltration (MF), electrodialysis (ED), forward osmosis (FO) and membrane distillation, provide highly flexible separation techniques for selective solute separation/concentration, and permeate water recycling and reuse [7, 8]. Providing access to safe drinking water has been identified as one, and possibly the most important, of the grand challenges facing scientists in the twentyfirst century. Figure 1 shows some existing and emerging technologies for water/wastewater treatment [8].

Although membrane technology, specially polymeric membranes, has gained significant interest for water treatment applications, the inseparable challenge of all membrane processes i.e. "fouling" further curtails the widespread adoption of membranes in commercial systems. Surface fouling and internal fouling are among the most important types of fouling in pressure-driven membrane processes (see Figure 2 for the schematic illustration of these types of fouling). Surface fouling is the deposition of solid material on the membrane that consolidates over time. Internal fouling is caused by penetration of solid material 


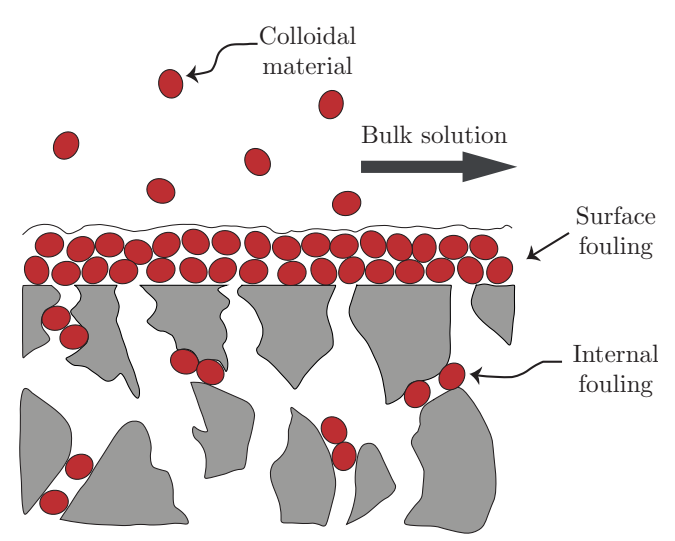

Figure 2: Schematic representation of fouling on a membrane (adapted with modification from Ref [9] Copyright@2004, John Wiley and Sons).

into the membrane, which results in plugging of the pores [9]. Surface fouling is generally reversible and can be controlled by high turbulence, regular cleaning or using membranes with surface characteristics that minimize adhesion. Internal fouling is irreversible and thus difficult to control.

In overall, membrane fouling results in a reduction of permeate flux or an increase in transmembrane pressure (TMP), depending on the mode of operation. Fouling can significantly reduce membrane performance, increase operating costs and shorten membrane life [10, 11. As a consequence, there remains a great need to develop ways to control fouling for the economic development of membrane technologies.

Developing anti-fouling membranes is a hot topic in membrane science. Plenty of research have been focused on developing hydrophilic membranes in order to minimize adhesion to the membrane surface [9, 12. One generallyused method is by adding hydrophilic additives to the membrane polymer. Long-term efficiency of such membranes is of great concern due to the possible release of the additives compromising their functionality [13]. A new research perspective for developing anti-fouling membranes is inspired by $\mathrm{Ne}$ penthes pitcher plant in which the nano/microstructured substrate is used to lock-in an intermediary liquid [14. This idea led to the development of a novel class of functional surfaces known as slippery liquid-infused porous surfaces (SLIPS) [15] which found its application in membrane technology as slippery liquid-infused membranes (SLIMs). The fabrication procedure includes infusion of the membrane or porous surface with a low surface tension liquid that 
has a high affinity to the membrane material. The liquid-infused pore acts like a gate which can open and close in response to the immiscible feed fluid pressure [16]. In the open state, the pore wall is still covered with the infusion liquid forming liquid-lined pores. Presence of liquid-lining prevents direct contact of the permeate fluid with the solid membrane material. The permanent interaction between foulant and membrane material can be inhibited due to the movement of liquid molecules down to the nanometer scale, leading to the reduction in the adhesion with the membrane material [17. Thus, these adaptive pores provide potentially anti-fouling properties as well as selective fluid transport [16, 18].

Further development of any new idea in science is not possible without a thorough fundamental understanding of the system. The work presented in this thesis, focuses on the investigation of the underlying basics of SLIMs and exploring the governing mechanisms such as gating, immiscible displacement mechanisms and infusion liquid retention. The permeability prediction of membranes (in general porous media) is also studied numerically and experimentally in details. The application of these membranes is investigated for oily wastewater treatment to separate oil from oil-in-water emulsions. One approach is employed in which the minor phase, i.e. oil is permeated through the membrane accomplished by gravity-driven creaming. As a relevant topic, application of external fields such as acoustic field, for separation of oil droplets, is also fundamentally studied. The anti-biofouling performance of SLIMs is further investigated through long-term cross flow biofouling experiments.

\section{References}

[1] M. J. Perry, The Idea of Human Rights: Four Inquiries (Oxford University Press USA) (1998).

[2] "The human right to water and sanitation, a/res/64/292, united nations general assembly", https://www.un.org/ga/search/view_doc. asp?symbol=A/RES/64/292 (2010).

[3] W. R. Bowen, "Chapter 1 - ethical and sustainable utilisation of water: Global scenarios and engineering responsibilities", in Emerging Membrane Technology for Sustainable Water Treatment, edited by N. P. Hankins and R. Singh, 3-13 (Elsevier, Boston) (2016).

[4] K. Hendrickson, The Encyclopedia of the Industrial Revolution in World 
History, number v. 3 in The Encyclopedia of the Industrial Revolution in World History (Rowman \& Littlefield Publishers) (2014).

[5] S. Loeb and S. Sourirajan, "Sea water demineralisation by means of an osmotic membrane", Advances in Chemistry Series 38, 117-132 (1963).

[6] S. Loeb, The Loeb-Sourirajan Membrane: How It Came About, chapter 1, 1-9 (1981).

[7] R. Singh and N. P. Hankins, "Chapter 2 - introduction to membrane processes for water treatment", in Emerging Membrane Technology for Sustainable Water Treatment, edited by N. P. Hankins and R. Singh, 15 - 52 (Elsevier, Boston) (2016).

[8] S. Hernández, A. Saad, L. Ormsbee, and D. Bhattacharyya, "Chapter 16 - nanocomposite and responsive membranes for water treatment", in Emerging Membrane Technology for Sustainable Water Treatment, edited by N. P. Hankins and R. Singh, 389 - 431 (Elsevier, Boston) (2016).

[9] R. W. Baker, Ultrafiltration, chapter 6, 237-274 (John Wiley \& Sons, Ltd) (2004).

[10] J. A. Nilson and F. A. DiGiano, "Influence of nom composition on nanofiltration", Journal - AWWA 88, 53-66 (1996).

[11] F. Meng, S.-R. Chae, A. Drews, M. Kraume, H.-S. Shin, and F. Yang, "Recent advances in membrane bioreactors (MBRs): Membrane fouling and membrane material", Water Research 43, 1489-1512 (2009).

[12] J. Dickhout, J. Moreno, P. Biesheuvel, L. Boels, R. Lammertink, and W. de Vos, "Produced water treatment by membranes: A review from a colloidal perspective", Journal of Colloid and Interface Science 487, 523 -534 (2017).

[13] Y. Zhu, D. Wang, L. Jiang, and J. Jin, "Recent progress in developing advanced membranes for emulsified oil/water separation", NPG Asia Materials 6, e101 (1-11) (2014).

[14] H. F. Bohn and W. Federle, "Insect aquaplaning: Nepenthes pitcher plants capture prey with the peristome, a fully wettable water-lubricated anisotropic surface", Proc. Natl. Acad. Sci. U. S. A. 101, 14138-14143 (2004). 
[15] T.-S. Wong, S. H. Kang, S. K. Tang, E. J. Smythe, B. D. Hatton, A. Grinthal, and J. Aizenberg, "Bioinspired self-repairing slippery surfaces with pressure-stable omniphobicity", Nature 477, 443-447 (2011).

[16] X. Hou, Y. Hu, A. Grinthal, M. Khan, and J. Aizenberg, "Liquid-based gating mechanism with tunable multiphase selectivity and antifouling behaviour", Nature 519, 70-73 (2015).

[17] A. K. Epstein, T.-S. Wong, R. A. Belisle, E. M. Boggs, and J. Aizenberg, "Liquid-infused structured surfaces with exceptional anti-biofouling performance", Proc. Natl. Acad. Sci. U. S. A. 109, 13182-13187 (2012).

[18] X. Hou, "Smart gating multi-scale pore/channel-based membranes", Adv. Mater. 28, 7049-7064 (2016). 


\section{Graphical summary}

This thesis combines fundamental and applied studies on slippery liquidinfused membranes (SLIMs). SLIM is a newly introduced concept to membrane science and technology which is inspired by slippery liquid-infused porous surfaces (SLIPS). These surfaces are a novel class of functional surfaces which are introduced to address shortcomings of the well-known materials with non-wetting properties, i. e. superhydrophobic surfaces. Examples of these shortcomings include failure at elevated pressure and temperature as well as inability to repel low surface tension liquids. The fabrication procedure of liquid-infused surfaces includes infusion of the porous structure/membrane with an infusion liquid which has low surface tension. The chemical compatibility between the base material and the infusion liquid is a requisite to ensure a high affinity between these two. Once this criteria is satisfied, the infusion liquid spontaneously infiltrates the surface structure/pores via capillary wicking and forms a smooth lubrication layer on the surface. Presence of this lubrication layer is responsible for important features of these materials such as, low water contact angle hysteresis, self-healing and repelling a variety of liquids. A general introduction about nature-inspired functional materials such as, superhydrophobic, liquid-infused surfaces and their properties are discussed in Chapter One. The idea of smart gating membranes stemming from opening/closing capability of the pores, is further explored in detail.

In this work, SLIM is fabricated by infusing home-made polyvinylidene fluoride (PVDF) membranes using different infusion liquids such as fluorinated oils (perfluoropolyether (PTFE)) with the commercial names of Krytox 101, FC-43, Galpore and silicone oil. In Chapter Two the fabrication and characterization of these membranes are explained in detail. All fabricated membranes show a high advancing water contact angle $\left(\simeq 120^{\circ}\right)$ together with low contact angle hysteresis $\left(<5^{\circ}\right)$ ensuring high droplet mobility (slipperiness). The key working mechanism of SLIM, namely the gating mechanism is further deeply explored. The liquid-infused pore acts like a gate which can open and 


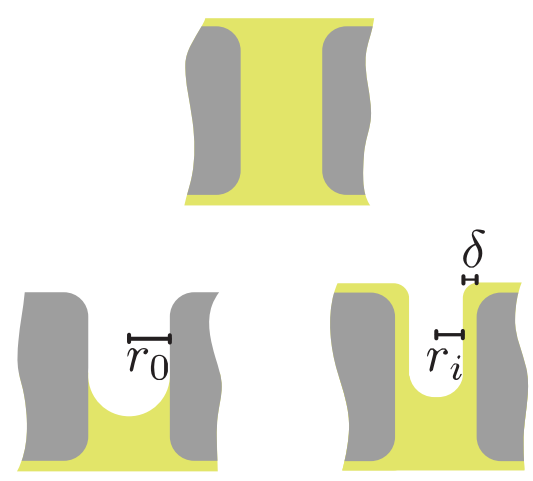

Figure 1: Liquid-infused pores with liquid-lining (right hand side) and without liquid-lining (left hand side) in the open state. $r_{0}$ is the initial pore radius, $r_{\mathrm{i}}$ is the effective pore radius including liquid-lining and $\delta$ is the liquid film thickness (Chapter Two).

close in response to the immiscible feed fluid pressure. In the open state, the pore wall is still covered with the infusion liquid forming liquid-lined pores which are responsible for anti-fouling properties of these membranes. The liquid film thickness lining the pores is experimentally estimated using gas-liquid displacement experiments and theoretically predicted using annular two phase flow models. Figure 1 depicts liquid-infused pores with and without liquidlining in the open state. The repeated ability of the infusion liquid to close the pores (gating) is further studied.

To further investigate the applicability of SLIMs for separation purposes, the retention of the infusion liquid inside the pores are studied in Chapter Three. Liquid-liquid displacement (LLD) experiments are performed using pure water at relatively high flux values and the corresponding pressures are measured. The results reveal the underlying immiscible displacement mechanism, namely capillary fingering which leads to preferential flow pathways for water transport through the membrane. Macroscopic observations using a microfluidic model porous media (micromodel) further confirm the fractal patterns correspond to capillary fingering with trapped infusion liquid. The presence of liquid-lined pores are observed in both LLD and macroscopic observations showing the potential of these membranes for separation processes. The schematic illustration of the displacement mechanism is shown in Figure 2 .

The pressure responsive pores which can be opened and closed in response to the system pressure can be used for efficient sorting of fluids from a mix- 


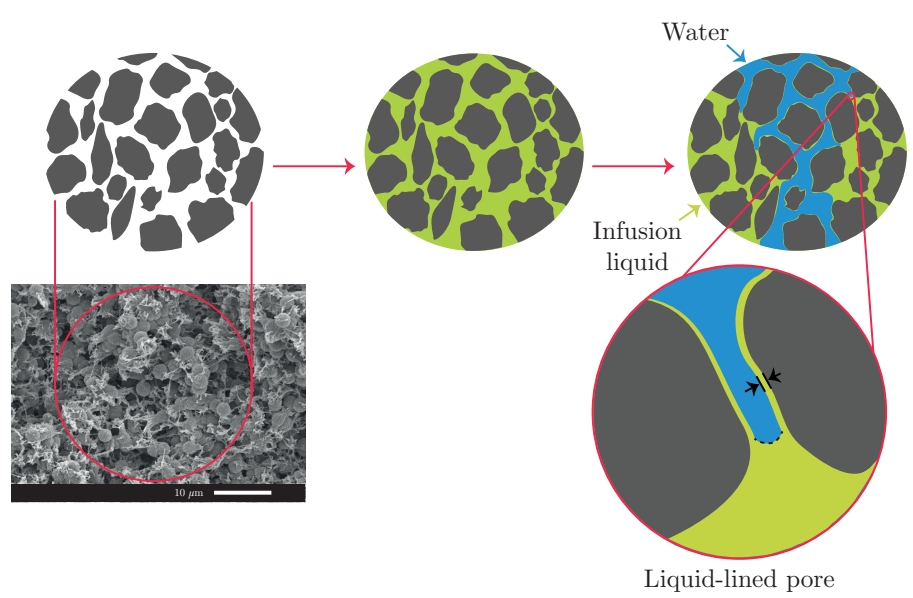

Figure 2: Immiscible displacement in SLIM using pure water showing preferential flow path ways for water transport as well as liquid-lined pores after water permeation (Chapter Three).

ture. In that sense, the capability of liquid-infused membranes (LIMs) are investigated for selective permeation of the dispersed phase (oil) from an oilin-water $(\mathrm{O} / \mathrm{W})$ emulsion (as representative of oily wastewater) in Chapter Four. Unlike normal membrane filtration in which the continuous phase (water) is permeated through the membrane, the challenge here is to permeate the dispersed phase (oil). In order to permeate the oil phase, oil droplets should transport throughout the bulk of the emulsion to reach the membrane surface. This is achieved here by gravity-driven creaming in dead-end filtration mode. The results reveal that by setting the feed pressure between the entry pressure of oil and that of the aqueous surfactant solution, oil can be selectively permeated. At high surfactant concentration, water also permeates partly. The amount of permeated water through liquid-infused membranes is lower than that through non-infused counterparts (dry membrane). The improved performance of LIMs is due to the presence of liquid-lining which leads to the formation of three-phase interfaces in the pore, namely the interface between surfactant solution-oil $\left(\gamma_{12}\right)$ and that between oil-infusion liquid $\left(\gamma_{23}\right)$ (see Figure 3. This additional interface between oil and infusion liquid gives rise to an increase in the total interfacial tension values $\left(\gamma_{12}+\gamma_{23}\right)$ and thus liquid entry pressure for the surfactant solution leading to less water permeation.

The presence of liquid-lining in liquid-infused membranes during permeation prevents the direct contact between permeating fluid and solid membrane ma- 

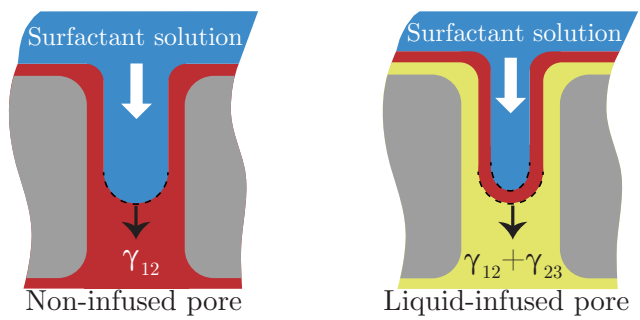

Figure 3: Comparison of liquid-infused and non-infused pore for oil permeation from an $\mathrm{O} / \mathrm{W}$ emulsion containing surfactant solution. $\gamma_{12}$ is the interfacial tension between surfactant solution and oil (red) and $\gamma_{23}$ is that between oil and infusion liquid (yellow) (Chapter Four).

terial. This can subsequently lead to anti-fouling properties which are specifically important to curtail membrane biofouling. If the initial phase of microorganism attachment to the pore wall is inhibited, a remarkable reduction in biofilm formation can be obtained. The anti-biofouling performance of LIMs is studied in Chapter Five by conducting cross flow filtration experiments for approximately 20 days. The results reveal a lower increase in transmembrane pressure (TMP) values for LIMs compared to dry membranes. As a relevant and accessible parameter, the TMP values as a function of time are fitted to growth curve models (logistic model) to obtain the bacterial growth parameters. This type of modeling quantifies the biofouling behaviour of membranes in terms of the lag period $\lambda$, the bacterial growth rate $\left(\mu_{\mathrm{m}}\right)$ and the asymptotic value $A$. The modeling results show an increase in $\lambda$ from approximately 3 days in dry membranes to 10 days in LIMs. A substantial decrease in the growth rate from 0.351 /day for dry membranes to 0.051 /day for LIMs are also observed. These results together with flow cytometry results confirm the ability of LIMs to mitigate biofouling due to the presence of liquid-lining. This is schematically shown in Figure 4.

Membranes have a wide range of application in wastewater treatment, including oily wastewater or produced water. This kind of wastewater is the largest waste stream in the oil and gas industry which mainly contains dispersed oil, dissolved organics/inorganics and suspended solids. As it has been already explained in Preface all the membrane processes suffer from fouling which further limits their widespread applications. To address this issue, in Chapter Four, we presented the idea of oil permeation (instead of water) through the membrane. Oil permeation can suppress surface and internal fouling (see Figure 2 in Preface mainly due to the coalescence of oil droplets 

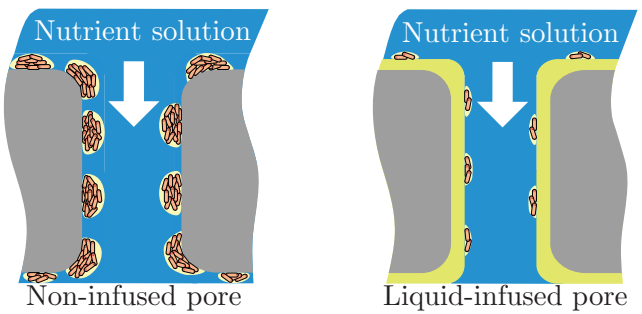

Figure 4: Comparison of anti-biofouling performance of liquid-infused and noninfused pores. Presence of liquid-lining prevents direct contact with the microorganisms and thus mitigate biofilm formation and growth (Chapter Five).

on the membrane surface and the absence of oil droplets as the foulant material. Coalescence of oil droplets on the membrane surface requires movement of oil droplets towards the membrane surface. A simple approach, used in Chapter Four, is the use of intrinsic density difference between oil and water phases leading to gravity-driven creaming. However, this technique is a rather slow process which highly depends on the droplet size (creaming velocity scales with the square of the droplet radius). Additionally, it is not suitable for density matched liquids. Alternatives include the use of an external field such as an acoustic or electric field. In Chapter Six a fundamental study is performed on the movement of oil droplets in an $\mathrm{O} / \mathrm{W}$ emulsion using an acoustic field (acoustophoresis). To avoid the statistical uncertainties arising from polydispersity of oil droplets in an emulsion, monodisperse oil droplets were employed. The monodisperse emulsions were made using hydrocarbon oil (hexadecane) and silicone oil in aqueous surfactant solutions of different concentrations. The acoustophoretic behaviour of monodisperse oil droplets was investigated in a microfluidic chip with one inlet and three outlets (see Figure 5). The acoustic energy density is a key design parameter for acoustic manipulation of particles/droplets. However, due to the energy losses of the acoustic waves, it remains a challenge to theoretically predict or experimentally determine the acoustic energy density. Here, the acoustophoretic velocity of monodisperse oil droplets was measured using particle image velocimetry (PIV) and the corresponding acoustic energy was calculated. The results show no effect of surfactant concentration on acoustophoretic velocity as well as energy density. A general relationship was obtained for the calculation of the acoustic energy density.

Permeability is an important transport property of any porous media which plays an important role in further application processes. Experimental mea- 


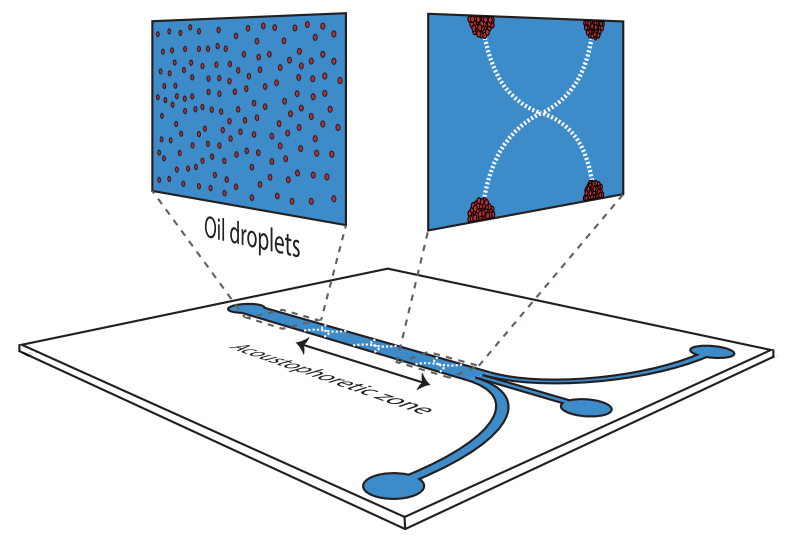

Figure 5: Movement of oil droplets towards pressure anti-nodes in a microfluidic acoustophoresis chip upon application of acoustic field (Chapter Six).

surements of permeability is time-consuming and expensive since new sets of experiments must be performed on a case-by-case basis. Thus, accurate prediction of permeability is of significant importance. Numerical prediction of permeability suggest a universal scaling power-law for normalized permeability. In Chapter Seven we aim to experimentally validate this power-law relation using micromodels with different porosity values. To be more realistic, micromodels consist of random arrays of cylindrical pillars which are designed using Monte Carlo simulations are used (see Figure 6). The micromodels are fabricated in silicon wafer using deep reactive ion etching process. The experiments are performed by pushing pure water or oil (hexadecane), with higher viscosity, through the micromodels at different pressure values and measuring the corresponding flow. The analogous scaling power-law relation is obtained for the normalized permeability which shows good agreement with the numerical prediction.

The overall overview to the work together with reflections and perspectives are presented in Chapter Eight. The idea of gravity-driven oil permeation through the membranes is further discussed in crossflow filtration mode and at low oil concentrations. The applicability of electric field as the external field for the movement of oil droplets, together with the corresponding challenges and the future outlook are touched upon. 


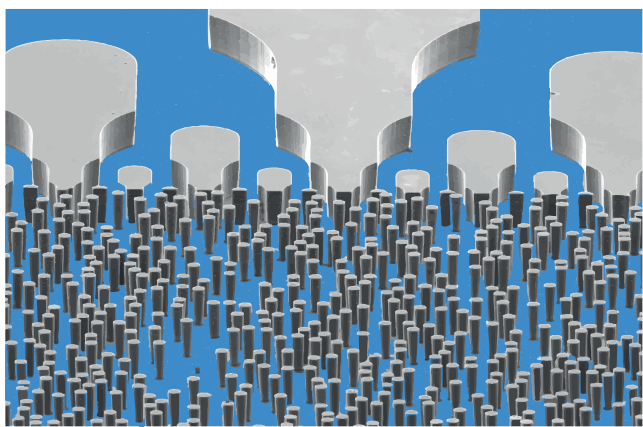

Figure 6: Pure water (blue) has been pushed through a micromodel consisting random arrays of cylindrical pillars as a representation of porous media (Chapter Seven). 



\section{Grafische samenvatting}

Dit proefschrift combineert fundamentele en toegepaste studies over gladde vloeistof geïnfuseerde membranen (GVGM). GVGM is een nieuw geïntroduceerd concept voor membraan wetenschap en technologie dat is geïnspireerd op gladde vloeistof geïnfuseerde poreuze oppervlakken (GVGPO). Deze oppervlakken zijn een nieuwe klasse functionele oppervlakken die worden geïntroduceerd om tekortkomingen van de bekende materialen met niet bevochtigende eigenschappen zoals superhydrofobe oppervlakken, aan te pakken. Voorbeelden van deze tekortkomingen zijn niet functioneren bij verhoogde druk en temperatuur, evenals het onvermogen om vloeistoffen met lage oppervlaktespanning af te stoten. De fabricageprocedure van met vloeistof geïnfuseerde oppervlakken omvat infusie van de poreuze structuur/membraan met een infusievloeistof wat een lage oppervlaktespanning heeft. De chemische compatibiliteit tussen het basismateriaal en de infusievloeistof is een vereiste om een hoge affiniteit tussen deze twee te waarborgen. Zodra aan dit criterium is voldaan, infiltreert de infusievloeistof spontaan de oppervlaktestructuur/poriën via capillaire adsorptie en vormt een gladde smeerlaag op het oppervlak. De aanwezigheid van deze smeerlaag is verantwoordelijk voor belangrijke kenmerken van deze materialen, zoals watercontacthoek met lage hysterese, zelfherstel en het afstoten van verschillende vloeistoffen. Een algemene inleiding over door de natuur geïnspireerde functionele materialen zoals superhydrofobe oppervlakken, vloeistof geïnfuseerde oppervlakken en hun eigenschappen worden besproken in Hoofdstuk Eén. Het idee van slimme poortmembranen, die voortkomen uit het openen en sluiten van de poriën, wordt verder in detail onderzocht.

In dit werk wordt GVGM vervaardigd door infusie van zelfgemaakte polyvinylidene fluoride (PVDF) membranen met verschillende infusievloeistoffen zoals gefluoreerde oliën (perfluorpolyether (PTFE)) met de commerciële namen van Krytox 101, FC-43, Galpore en siliconenolie. In Hoofdstuk Twee worden de fabricage en karakterisatie van deze membranen in detail 


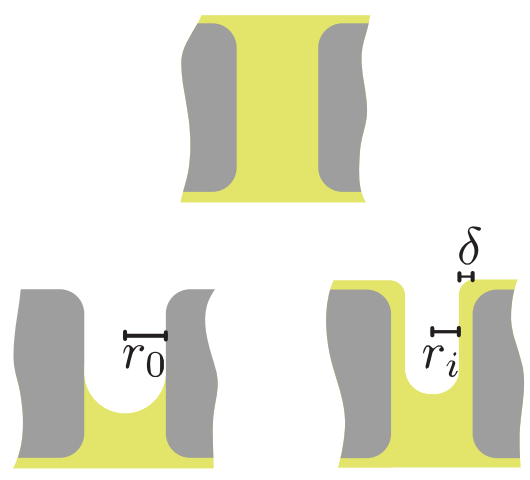

Figuur 1: Vloeistof-geïnfuseerde poriën met vloeistof voering (rechterkant) en zonder vloeistof-voering (linkerkant) in de open toestand. $r_{0}$ is de initiële porieradius, $r_{\mathrm{i}}$ is de effectieve porieradius inclusief vloeistof-voering en $\delta$ is de dikte van de vloeibare film (Hoofdstuk Twee).

uitgelegd. Alle gefabriceerde membranen vertonen een grote watercontacthoek $\left(\simeq 120^{\circ}\right)$ samen met een lage contacthoekhysterese $\left(<5^{\circ}\right)$ die zorgt voor een hoge druppelmobiliteit (gladheid). Het belangrijkste werkingsmechanisme van GVGM, namelijk het poortmechanisme, wordt verder diepgaand onderzocht. De vloeistof geïnfuseerde porie werkt als een poort die kan openen en sluiten in reactie op de vloeistofdruk van de niet mengbare voeding. In de open toestand is de poriewand nog steeds bedekt met de infusie vloeistof die vloeistof gevoerd poriën vormt, die verantwoordelijk zijn voor anti vervuiling eigenschappen van deze membranen. De dikte van de vloeistof film langs de poriën wordt experimenteel geschat met behulp van gas vloeistofverplaatsings experimenten en theoretisch voorspeld met behulp van ringvormige tweefasige stromingsmodellen. Figuur 1 toont vloeistof-geïnfuseerde poriën met en zonder vloeistof-voering in de open toestand. Het herhaalde vermogen van de infusievloeistof om de poriën te sluiten (poorten) wordt verder bestudeerd.

Om de toepasbaarheid van GVGM voor scheidingsdoeleinden verder te onderzoeken, wordt de retentie van de infusievloeistof in de poriën bestudeerd in Hoofdstuk Drie. Vloeistof-vloeistof verplaatsing (VVV) experimenten worden uitgevoerd met zuiver water bij relatief hoge fluxwaarden en de overeenkomstige drukken worden gemeten. De resultaten onthullen het onderliggende niet-mengbare verplaatsingsmechanisme, namelijk capillaire vertakking die leidt tot voorkeurs stroom routes voor watertransport door het membraan. Macroscopische waarnemingen met behulp van een poreus medium van het microfluïdische model (micromodel) bevestigen verder dat 


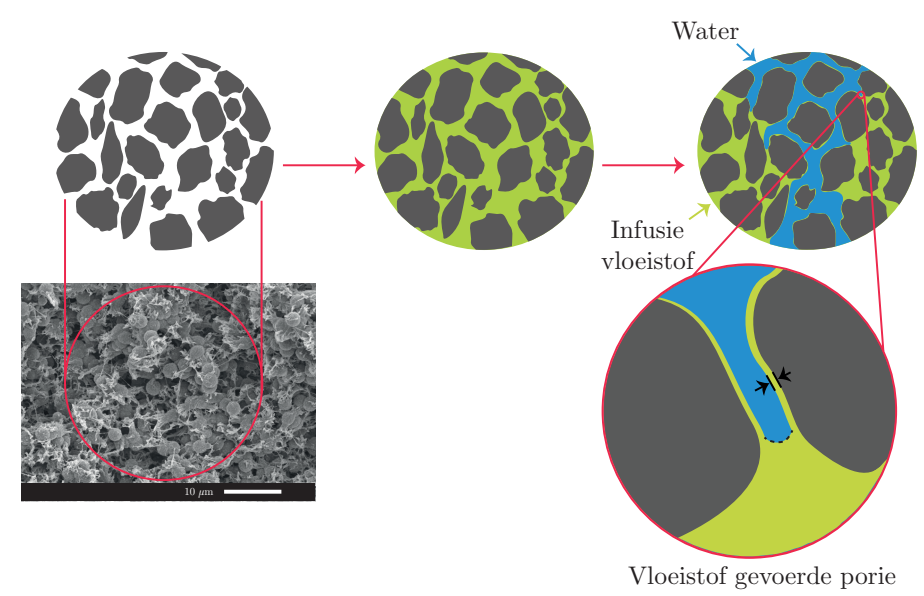

Figuur 2: Niet mengbare verplaatsing in GVGM met zuiver water dat preferentiële stromingspadroutes voor watertransport toont, evenals de vloeistof gevoerde poriën na waterpermeatie (Hoofdstuk Drie).

de fractale patronen overeenkomen met capillaire vertakking met ingesloten infusievloeistof. De aanwezigheid van vloeistof gevoerde poriën wordt waargenomen in zowel VVV als in de macroscopische waarnemingen die het potentieel van deze membranen voor scheidingsprocessen aantonen.

De schematische illustratie van het verplaatsingsmechanisme wordt getoond in Figuur 2,

Op druk reagerende poriën kunnen worden geopend en gesloten in reactie op de systeemdruk, waardoor ze kunnen worden gebruikt voor het efficiënt sorteren van vloeistoffen uit een mengsel. Het vermogen van vloeistof geïnfuseerde membranen (GVGM) wordt onderzocht voor selectieve permeatie van de gedispergeerde fase (olie) uit een olie-in-water $(\mathrm{O} / \mathrm{W})$ emulsie (als vertegenwoordiger van olieachtig afvalwater) in Hoofdstuk Vier. In tegenstelling tot normale membraanfiltratie waarin de continue fase (water) door het membraan is doordrongen, is de uitdaging hier om de gedispergeerde fase (olie) door te dringen. Oliedruppeltjes moeten door het grootste deel van de emulsie worden getransporteerd om het membraanoppervlak te bereiken en de oliefase te doordringen. Dit wordt bereikt door verroming via zwaartekracht in doodlopende filtratiemodus. De resultaten onthullen dat door het instellen van de voedingsdruk tussen de ingangsdruk van olie en de waterige oplossing met oppervlakteactieve stof, olie selectief kan worden doordrongen. Bij hoge concentratie van oppervlakteactieve stoffen dringt ook water gedeeltelijk 

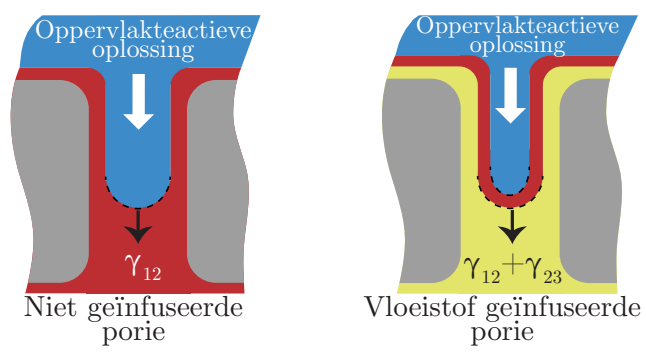

Figuur 3: Vergelijking van vloeistof geïnfuseerde en niet geïnfuseerde poriën voor olie doordringing uit een $\mathrm{O} / \mathrm{W}$ emulsie oppervlakteactieve stoffen in de water fase. $\gamma_{12}$ is de grensvlakspanning tussen oppervlakteactieve oplossing en olie (rood) en $\gamma_{23}$ is dat tussen olie en infusievloeistof (geel) (Hoofdstuk Vier).

door. De hoeveelheid doordrongen water door vloeistof geïnfuseerde membranen is lager dan die door niet geïnfuseerde tegenhangers (droog membraan). De verbeterde prestaties van GVGM zijn te wijten aan de aanwezigheid van vloeistof voering die leidt tot de vorming van driefasige grensvlakken in de porie, namelijk het grensvlak tussen oppervlakteactieve oplossing-olie $\left(\gamma_{12}\right)$ en dat tussen olie-infusievloeistof $\left(\gamma_{23}\right)$ (zie Figuur 3). Dit extra grensvlak tussen olie en infusievloeistof leidt tot een toename van de totale grensvlakspanningswaarden $\left(\gamma_{12}+\gamma_{23}\right)$ en dus vloeistofinvoerdruk voor de oplossing van oppervlakteactieve stof, hetgeen leidt tot minder waterpermeatie.

De aanwezigheid van vloeistof voering in vloeistof geïnfuseerde membranen tijdens permeatie verhindert het directe contact tussen permeaat en vast membraanmateriaal. Dit kan vervolgens leiden tot aangroeiwerende eigenschappen die specifiek van belang zijn om membraan biovervuiling in te perken. Als de begin fase van hechting van micro organismen aan de porie wand wordt geremd, kan een opmerkelijke vermindering van de vorming van biofilm worden bereikt. De anti biovervuiling prestaties van VGM worden in Hoofdstuk Vijf bestudeerd door dwarsstroomfiltratie experimenten uit te voeren gedurende ongeveer 20 dagen. De resultaten laten een lagere toename van transmembraan druk (TMD) waarden voor VGM zien in vergelijking met droge membranen. Als relevante en toegankelijke parameter worden de TMD waarden als functie van tijd aangepast aan groei curve modellen (logistiek model) om de bacteriële groei parameters te verkrijgen. Dit type modellering kwantificeert het biovervuiling gedrag van membranen in termen van de vertragingsperiode $\lambda$, de bacteriegroei $\left(\mu_{\mathrm{m}}\right)$ en de asymptotische waarde $A$. De model resultaten tonen een toename van $\lambda$ aan van ongeveer 3 dagen in 

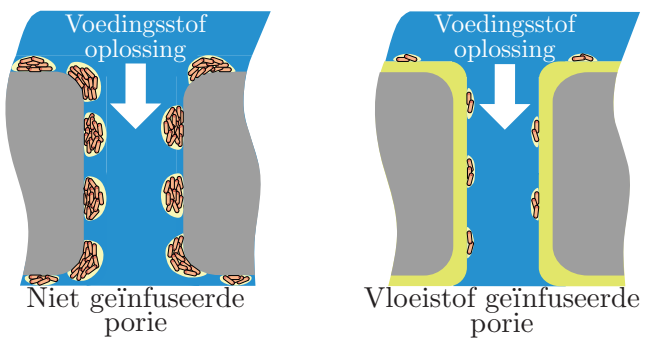

Figuur 4: Vergelijking van de anti biovervuiling prestaties van vloeistof geïnfuseerde en niet geïnfuseerde poriën. Aanwezigheid van vloeistof voering voorkomt direct contact met de microorganismen en vermindert zo de vorming en groei van biofilm (Hoofdstuk Vijf).

droge membranen tot 10 dagen in VGM. Er wordt ook een substantiële afname van de groei snelheid van $0.351 /$ dag voor droge membranen tot $0.051 /$ dag voor VGM waargenomen. Deze resultaten, samen met de resultaten van flow cytometrie, bevestigen het vermogen van VGM om biovervuiling te verminderen als gevolg van de aanwezigheid van vloeistof voering. Dit is schematisch weergegeven in Figuur 4 .

Membranen hebben een breed toepassingsgebied bij de behandeling van afvalwater, waaronder olieachtig afvalwater of geproduceerd water. Dit soort afvalwater is de grootste afvalstroom in de olie en gas industrie die voornamelijk verspreide olie, opgeloste organische/anorganische stoffen en zwevende stoffen bevat. Zoals in het Voorwoord al is uitgelegd, lijden alle membraan processen aan vervuiling, wat hun brede toepassingsmogelijkheden beperkt. Om dit probleem aan te pakken, hebben we in Hoofdstuk Vier het idee van olie permeatie (in plaats van water) door het membraan gepresenteerd. Olie permeatie kan oppervlakte en inwendige vervuiling onderdrukken (zie Figuur 2 in Voorwoord), voornamelijk als gevolg van de samensmelting van olie druppels op het membraan oppervlak en de afwezigheid van olie druppels als vervuiler. Samensmelting van olie druppels op het membraan oppervlak vereist beweging van olie druppels naar het membraan oppervlak. Een eenvoudige benadering, gebruikt in Hoofdstuk Vier, is het gebruik van het intrinsieke dichtheidsverschil tussen olie en water, wat leidt tot verroming door zwaartekracht. Deze techniek is echter een vrij langzaam proces dat sterk afhangt van de druppelgrootte (verromingsnelheid schaalt kwadratisch met de druppelradius). Bovendien is het niet geschikt voor vloeistoffen die op dichtheid zijn afgestemd. Alternatieven zijn het gebruik van een extern veld zoals een akoestisch of elektrisch veld. In Hoofdstuk Zes wordt een fundamentele studie uitgevoerd naar de 


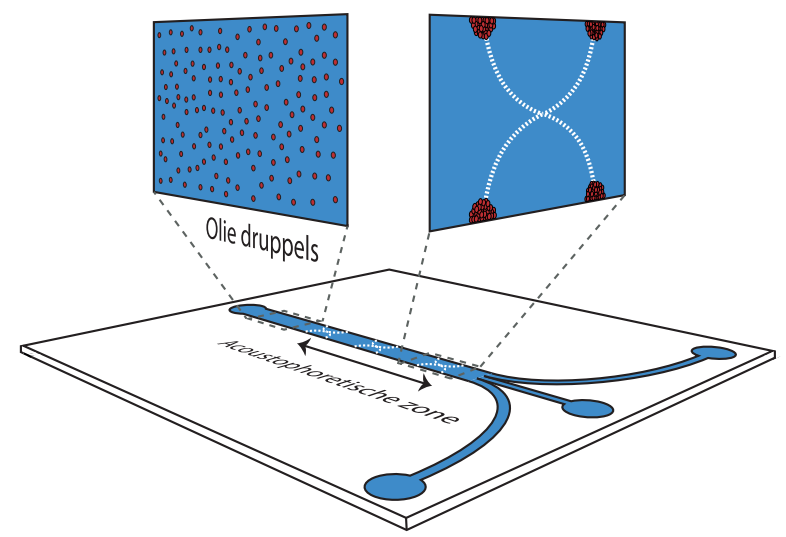

Figuur 5: Beweging van oliedruppels naar druk anti knoop punten in een microfluïdische acoustoporese chip bij toepassing van een akoestisch veld (Hoofdstuk Zes).

beweging van oliedruppels in een $\mathrm{O} / \mathrm{W}$ emulsie met behulp van een akoestisch veld (acoustophorese). Om de statistische onzekerheden als gevolg van polydispersiteit van oliedruppels in een emulsie te vermijden, werden monodisperse oliedruppels gebruikt. De monodisperse emulsies werden gemaakt met koolwaterstof olie (hexadecaan) en siliconen olie in water met oppervlakactieve stoffen van verschillede concentraties. Het acoustophoretisch gedrag van monodisperse oliedruppels werd onderzocht in een microfluïdische chip met één ingang en drie uitgangen (zie Figuur 5). De akoestische energiedichtheid is een belangrijke ontwerpparameter voor akoestische manipulatie van deeltjes/druppels. Vanwege het energieverlies van de akoestische golven blijft het echter een uitdaging om de akoestische energie dichtheid theoretisch te voorspellen of experimenteel te bepalen. Hier werd de acoustophoretische snelheid van monodisperse oliedruppels gemeten met particle image velocimetry (PIV) en de bijbehorende akoestische energie werd berekend. De resultaten laten geen effect zien van de concentratie oppervlakte actieve stof op de acoustophoretische snelheid en de energiedichtheid. Voor de berekening van de akoestische energiedichtheid is een algemene relatie gevonden.

De permeabiliteit is een belangrijke transporteigenschap van alle poreuze media die een belangrijke rol speelt in verdere toepassingsprocessen. Experimentele metingen van permeabiliteit zijn tijdrovend en duur, omdat nieuwe sets experimenten per situatie moeten worden uitgevoerd. Een nauwkeurige voorspelling van permeabiliteit is dus van groot belang. Numerieke voor- 


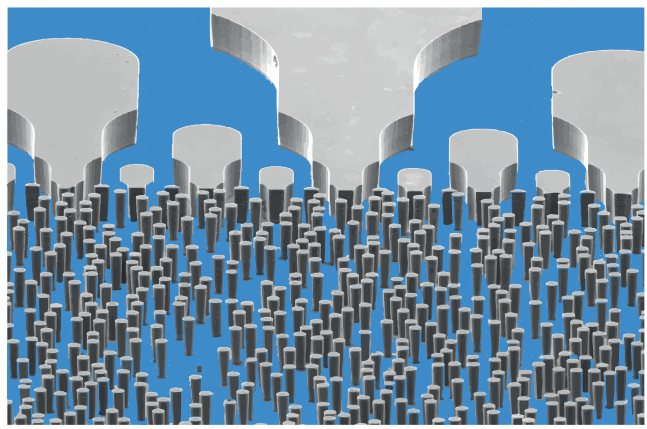

Figuur 6: Zuiver water (blauw) is door een micromodel geduwd dat bestaat uit willekeurige reeksen cilindrische pilaren als vertegenwoordiger van poreuze media (Hoofdstuk Zeven).

spelling van permeabiliteit suggereert een universeel geschaalde machtsfunctie voor genormaliseerde permeabiliteit. In Hoofdstuk Zeven willen we deze geschaalde machtsfunctie experimenteel valideren met behulp van micromodellen met verschillende waarden voor porositeit. Om realistischer te zijn, bestaan micromodellen uit willekeurige reeksen cilindrische pilaren die zijn ontworpen met behulp van Monte Carlo simulaties (zie Figuur 6). De micromodellen zijn vervaardigd in silicium wafer met behulp van een diep reactief ionen ets proces. De experimenten worden uitgevoerd door zuiver water of olie (hexadecaan) met hogere viscositeit door de micromodellen te duwen bij verschillende drukken en de bijbehorende stroming te meten. De analoog geschaalde machtsfunctie wordt verkregen voor de genormaliseerde permeabiliteit, wat een goede overeenkomst vertoont met de numerieke voorspelling.

Het algemene overzicht van het werk samen met reflecties en perspectieven worden gepresenteerd Hoofdstuk Acht. Het idee van olie permeatie via zwaartekracht door de membranen wordt verder besproken in dwarsstroomfiltratiemodus en bij lage olieconcentraties. De toepasbaarheid van elektrisch veld als extern veld voor de verplaatsen van oliedruppeltjes, samen met de bijbehorende uitdagingen en de toekomstperspectieven worden besproken. 



\section{Nature-inspired membranes: a solution to membrane fouling}





\subsection{Introduction}

INCE ancient times, the natural world always acts as the head spring of technological thoughts, engineering principles, and significant inventions in human civilization [1]. Architecture is the most prominent field that benefited from this notion. The remarkable constructions by Eiffel, Gaudí and Paxton are examples where natural structures have provided inspiration for unique and enduring man-made creations. Other examples around the world include the lotus temple in India, The Gherkin in London, the Beijing national stadium in China, the Olympic pavilion in Barcelona and the Eastgate development in Zimbabwe. Some of these examples, like the lotus temple, however, mainly mimic their biological counterparts in appearance, with less attention to nature-inspired function [2]. Nature-inspired engineering is not only based on mimicking nature out of context, but, rather, on taking a scientific approach to uncover fundamental mechanisms underlying desirable traits. These mechanisms are subsequently applied to design and synthesize artificial systems that borrow the traits and features of the natural counterpart [3].

Over the past several decades of development of science, the study on nature-inspired materials has expanded to micro-/nanoscale, which has facilitated new breakthroughs on the design of micro-/nanostructural materials with attractive properties [4-7]. One of these properties, which plays crucial roles in a wide variety of applications, is wettability [8]. It is normally considered that chemical compositions, which determine the surface free energy, are main factors governing the surface wettability of materials. But actually, their influences are limited in many cases. For example, -CF3 terminated surface was reported to possess the lowest free energy and the best hydrophobicity, yet its intrinsic contact angles (CAs) could only reach a largest value of about $120^{\circ}$ [9]. In nature, special wettability phenomena, such as superhydrophobicity $\left(\mathrm{CA}>150^{\circ}\right)$ and superhydrophilicity $\left(\mathrm{CA} \approx 0^{\circ}\right)$, are quite common and can be frequently observed on many plant leaves or insect wings [8, 10]. Surfaces such as lotus leaves and rice leaves [11 13, butterfly wings [14, mosquito compound eyes [15], cicada wings [16], rose petals [17], gecko feet [18, 19] and other insects (desert beetle [20] and water striders [21]) exhibit fascinating superhydrophobicity.

Water does not show any affinity for the superhydrophobic surfaces, causing water drops to behave very extraordinarily, e.g., bouncing and rolling instead of sliding [22 24]. This further gives self-cleaning ability to the surface of many plants including the lotus leaf. In the pioneer work by Neinhuis and Barthlott [12, the micromorphological characteristics of 200 plant species with water- 
repellent property were investigated. They demonstrated that the epidermal (i.e. outermost) cells of the lotus leaves form papillae, which act as microstructure roughness. The papillae are superimposed by a very dense layer of epicuticular waxes (wax tubules) [25, also referred to as hair-like structures [26] or nanostructure roughness 27]. Figure 1.1 shows a lotus leaf and scanning electron microscopy (SEM) images of its upper side at different magnifications together with the schematic illustration of self-cleaning ability due to water rolling on the surface. Epicuticular waxes themselves have hydrophobic properties, which together with micro- and nanostructure roughness, result in reduced contact area between water droplets and the leaf's surface. This combination results in static contact angles exceeding $150^{\circ}$ on lotus leaves. If the surface is tilted, even with a slight angle, water droplets begin to roll off the leaves, and so collect and remove dirt from the surface demonstrating the self-cleaning effect (see Fig 1.1(b)] [28]. Due to the self-cleaning ability and facilitating dirt removal, the lotus leaf is a symbol of purity in some Asian religions [12.

Short after the discovery of superhydrophobic biological materials, a number of efforts have been devoted to fabricate bio-inspired superhydrophobic surfaces. Different methods such as template-based technique, photolithography, chemical vapor deposition, electrochemical deposition and phaseseparation micro molding have been utilized to fabricate various micro- and nano-structures on a wide variety of materials to obtain superhydrophobicity [30 34. The superhydrophobicity and other properties thereof are stemming from the entrapped air between the micro- nano-structures which further reduces the contact area between water and solid. This in turn translates into contact angles $>150^{\circ}$ with favourably low sliding angles $<10^{\circ}$ which makes these special surfaces ideal for applications that demand properties like selfcleaning [35, 36, liquid-repellency [36, icophobicity [37, 38] and anti-fogging [39, 40. These surfaces have been also extensively studied and developed to produce (partial) slip surfaces [41-46]. A nice overview on experimental, numerical and analytical studies of superhydrophobic surfaces for drag-reduction purposes (such as marine environments) is given by Samaha et. al. [28.

The stability of the air-water interface, that is present at a superhydrophobic interface, under hydrostatic pressure is a key working parameter. The entrapped air is ineffective against low surface tension liquids 47, 48, extreme ambient conditions like high humidity [49] and low temperature $\left(<0^{\circ}\right.$ for water) [50. The dissolution of air to the surrounding fluid under elevated pressure leads to the failure of such surfaces specially in submerged applications 


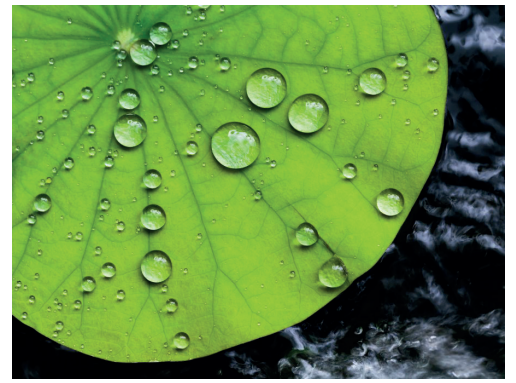

(a)

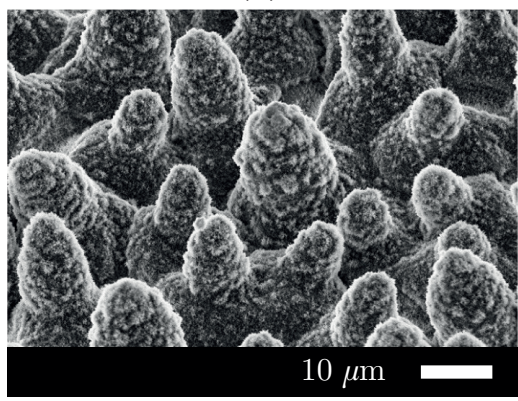

(c)

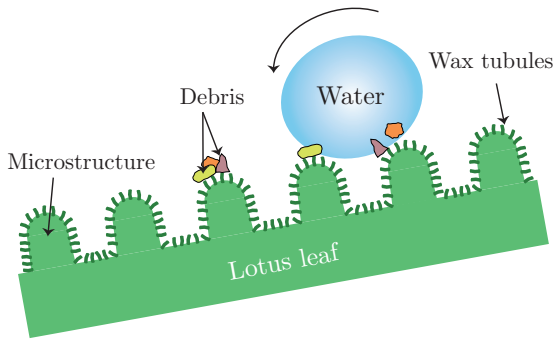

(b)

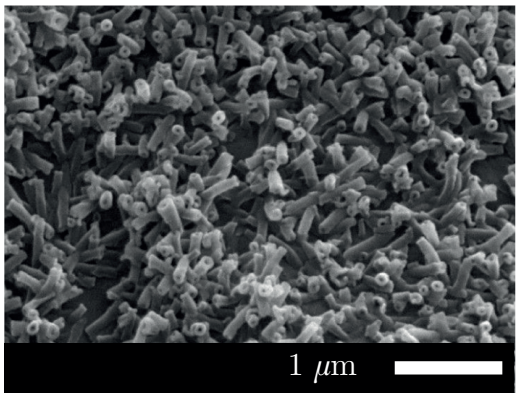

(d)

Figure 1.1: (a) Lotus leaf with extraordinary water repellency on the upper side (adapted from Ref [29]). (b) Schematic illustration of Lotus leaf depicting selfcleaning ability. Scanning electron microscopy (SEM) of (c) the upper side of the leaf showing hierarchical surface structure consisting of papillae, wax clusters and wax tubules (adapted with modification from Ref 25]) and (d) wax tubules covering the leaf (adapted with modification from Ref [25]). 
28, 51, 52. Also, these surfaces have limited stability where droplet impact is involved [53, 54] as their anti-wetting properties are incapable of sustaining for longer duration. Such failures have been attributed to the droplet pinning through the micro- or nano-textured surface which causes the transition of the liquid from the non-wetting Cassie-Baxter [55] state to the wetting Wenzel [56] state [57]. Therefore the need for surfaces with non-wetting properties which posses reasonable longevity and durability to sustain environmental conditions such as water salinity, depth and biofouling is inevitable.

\subsection{Nature-inspired liquid-infused surfaces}

Nature herself has always created a vase panoply of surfaces with non-wetting properties. To address the shortcomings of superhydrophobic surfaces, researchers are inspired by another example in nature, namely carnivorous pitcher plants of the genus Nepenthes. This plant captures prey with a pitfall trap that relies on a micro-structured slippery surface [58. Figure 1.2 demonstrates the macroscopic view of a pitcher plant together with SEM images of the surface at its different functional zones.

A wettable peristome (a collar-shaped structure that surrounds the pitcher opening (see Figure 1.2(a) ) is the location of the major nectaries that attract and trap insects/prey [62]. The surface of the peristome is covered with microscopic radial ridges, arrayed anisotropically (see Figure $1.2(\mathrm{~d})$ to aid traction in the direction of the pitcher mouth [61, 62]. Capillary action between the ridges renders the peristome highly wettable. A wetted peristome provides very little traction for insect feet, effectively causing the prey to slip into the bottom of the pitcher [58, 62.

The upper part of the inner pitcher wall is covered with densely placed crystals of lower wax layer (see Figure 1.2(b) 63. The wax surface is non-wettable which prevents formation of a foothold for the insects 64 67. Additionally, the microscopic roughness of the wax crystal layer further reduces the available effective area for traction by the prey's adhesive pads [60, 68.

Moving toward the pitcher bottom in the slippery zone, platelets of the upper wax layer appear and cover the lower wax layer completely (see Figure 1.2(c) [60. The water-lubricated wax regions make it extremely slippery for insects causing the prey to fall into the bottom part of the pitcher (digestive zone) 68. Most of Nepenthes species produce pitcher fluid with viscoelastic properties. It is impossible for insects falling into this fluid to extricate themselves and quickly drown [69, 70]. 


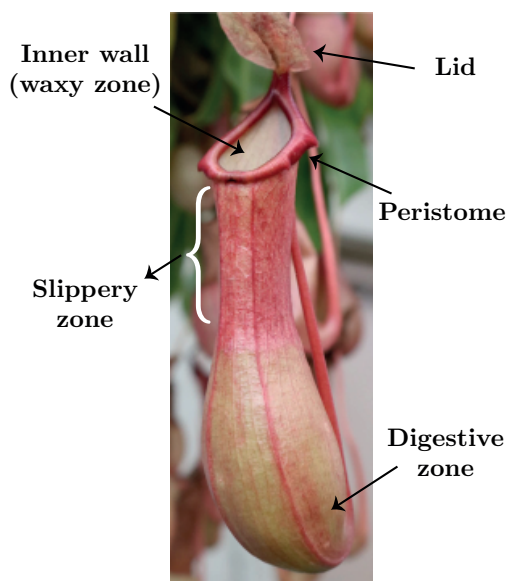

(a)

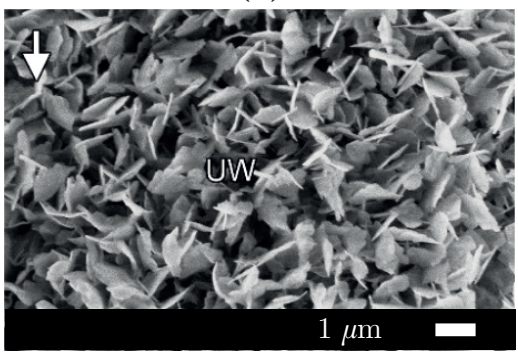

(c)

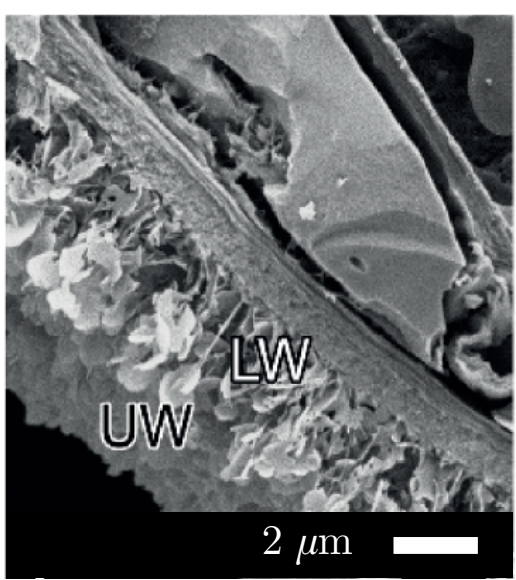

(b)

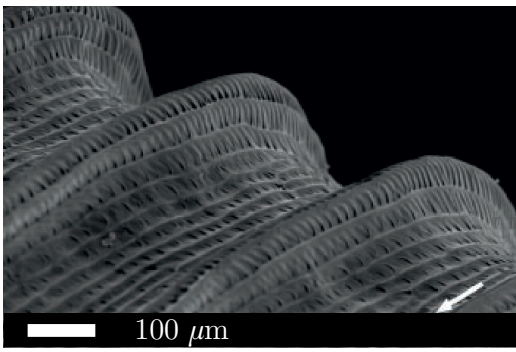

(d)

Figure 1.2: (a) Nepenthes pitcher plant with indicated functional zones (adapted from Ref [59]). SEM images of (b) wall of the internal side in slippery zone showing the wax coverage (LW and UW refer to upper and lower wax respectively) (adapted with modification from Ref [60] Copyright@2009, Springer Science Business Media B.V.), (c) structure of the upper wax layer (adapted with modification from Ref [60] Copyright@2009, Springer Science Business Media B.V.) and (d) peristome surface with first- and second-order radial ridges (adapted with modification from Ref [61] Copyright(02004, National Academy of Sciences, U.S.A.). Arrows in (c) and (d) indicate direction toward the inside of the pitcher body. 
In 2011, the Aizenberg group at Harvard University took inspiration from the Nepenthes pitcher plant and designed a so-called slippery liquid-infused porous surface known as SLIPS [71. These surfaces are composed of microor nano-structures which are used to lock-in an intermediary liquid. The liquid then acts by itself as the repellent surface [71, 72]. From the stand point of "liquid repellency", the most important design criteria is that the infusion liquid must preferentially wet the substrate relative to an immiscible ambient fluid [71, 73]. The choice of infusion liquid must take into account the surface energies of all phases present [74. The infusion liquid wicks then spontaneously into, and stably adheres within the substrate by capillary forces [71]. Once these conditions are satisfied, a thin lubricating liquid layer forms on top of the surface which provides non-wetting and low-hysteresis properties making the surface "slippery". Contact angle hysteresis (the difference between advancing and receding contact angles of a moving droplet) and sliding angle (surface tilt required for droplet motion) are used to directly characterize resistance to mobility [31. The low values of contact angle hysteresis and sliding angle together with high contact angles, prevent pining and therefore provide high droplet mobility [75, 76]. This is consistent with a nearly defect-free surface which is stemming from the liquid layer in the case of SLIPS.

Shortly after the introduction of SLIPS, Smith et. al. 777. performed a fundamental study on the design criteria based on interfacial energy contributions. The physico-chemical hydrodynamics upon placing a drop of an immsicible liquid on a slippery liquid-infused surface, revealed different wetting configurations outside and underneath the drop. They further showed that drops roll across this surface. The shedding velocity of drops from such surfaces has been shown to be inversely dependent upon the viscosity of the infusion liquid 78.

To understand the slipperiness and how the infusion liquid alters the static and dynamic properties of the drop, Schellenberger et. al. observed the shape of the drop using laser scanning confocal microscope [79. Their study shed more light on the main differences between slippery liquid-infused and superhydrophobic surfaces. The differences arise from (1) the formation of a wetting ridge of adjustable height surrounding the drop on liquid-infused surface and (2) replacement of air pockets in superhydrophobic surface with a more viscous and incompressible infusion liquid in liquid-infused surface. This direct observation further helped measuring and estimating the liquid film thickness cloaking the drop. If the interfacial tension between drop and ambient fluid, e.g. air $\left(\gamma_{D A}\right)$ is higher than the summation of that between drop-infusion 
liquid $\left(\gamma_{D L}\right)$ and infusion liquid-air $\left(\gamma_{L A}\right)$ which leads to a positive spreading coefficient $\left(S_{L D(a)}=\gamma_{D A}-\left(\gamma_{D L}+\gamma_{L A}\right)\right)$, the infusion liquid spreads over and "cloaks" the drop [77. Cloaking is important and should be considered in design of a SLIPS, since it can cause progressive loss of infusion liquid through entrainment in the drops as they are shed from the surface. In a recent study, it has been demonstrated that this effect should be taken into account in the design when dealing with both macroscale and ultrasmall nanoscale droplets [80. The combined experimental and computational work provided insights into droplet interfacial phenomena on slippery surfaces.

A nice comparison between superhydrophobic and liquid-infused surfaces in terms of functions and applications is performed by Cao et. al. [81. The advantages and disadvantages of each type of surface are discussed indicating how to select water-repellent surfaces in practical circumstances. Liquid-infused surfaces demonstrate remarkable properties ranging from antiicing [73, 78, 82, 83, anti-frosting [82, 84, enhanced condensation [74] and anti-wetting at high temperature [85], to drag reduction [86 88, self-cleaning [71, 81, 89, self healing by capillary wicking upon damage and repellency to a variety of liquids spanning a broad range of surface tension values [71. The latest property is specifically important in comparison with superhydrophobic surfaces and found its application in biomedical industry as "paper SLIPS" which is capable of repelling liquids with surface tensions as low as $15 \mathrm{mN} / \mathrm{m}$ 90. The foldability of the paper SLIPS allows the fabrication of channels and flow switches to guide the transport of liquid droplets. As stated before, superhydrophobic surfaces fail to repel liquids with low surface tension values such that the contact angle hysteresis increases dramatically upon decrease of surface tension [91]. Such a dependence is absent for SLIPS due to the physical smoothness and chemical homogeneity of the liquid-liquid interface [71. Another interesting property of these surfaces is the enhanced optical transparency in visible or near-infrared wavelengths [71, 92, 93. This requires the proper engineering of SLIPS such that the chosen infusion liquid and substrate match in refractive indices. Maintaining high optical transmittance is a challenge due to the accumulation of airborne dust particles on the surface in applications such as optoelectronics, automobile and construction industry 94. All such cases bring about the importance of optically transparent surfaces that are cost-effective to clean such as SLIPS. The non-adhesive, slippery character of the smooth liquid layer gives rise to anti-biofouling properties as well [72, 95. The mobility of the liquid molecules prevents the permanent interactions of any microorganism with the surface, thereby significantly dis- 
rupting the biological adhesion 95 . The toxicity experiments, using live bacteria species, further confirmed that the anti-biofouling characteristic is not attributed to the toxicity of the infusion liquid [72, 95.

\subsection{How to make liquid-infused surfaces}

Fabrication of SLIPS first requires obtaining a rough, porous and textured solid substrate which can contain the infusion liquid and guarantee formation of a stable liquid film. Such a film should not be displaced by the impinging test liquid, e.g. water. The solid surface must be preferentially wetted by the infusion liquid. To satisfy this design criteria based on interfacial energy arguments [77, the summation of the interfacial tension values between solid-infusion liquid $\left(\gamma_{S L}\right)$ and infusion liquid-water $\left(\gamma_{L W}\right)$ must be smaller than that between solid-water $\left(\gamma_{S W}\right)$ leading to a positive spreading coefficient $\left(S_{L S(W)}=\gamma_{S W}-\left(\gamma_{S L}+\gamma_{L W}\right)\right)$. This prefers a solid surface with a low surface energy value, i.e. possessing surface atoms with nearly complete atomic bonds, which is the characteristic of hydrophobic surfaces [94, 96. If the solid surface is not hydrophobic by its nature, further hydrophobization using low-surface tension silane compounds is a possibility. To fulfil the spontaneous imbibition of the infusion liquid into the solid surface as well as complete wetting of the substrate, liquids with low surface tension values such as fluorocarbons (with surface tension ranging between $10-20 \mathrm{mN} / \mathrm{m}$ [94]) could be employed as the infusion liquid. The choice of fluorocarbon oils as the infusion liquid further satisfied the last design criteria, i.e. immsicibility of the infusion liquid with the majority of impinging test liquids, namely polar, hydrocarbon, alkane liquids and etc. Once all these conditions are met, the liquid-repellency of SLIPS is insensitive to the solid substrate geometry owing to the presence of a stable lubricating layer covering the surface texture [71. Various types of oils ranging from alkanes to different types of silicone oils [89] and fluorinated oils to ionic liquids [74, 77, 79] can be used as the infusion liquid. The most widely used infusion liquids are silicone oil [77, 81, 85, 86, 97] and fluorinated oils such as Fluorinert FC70 [71, 79] and perfluoropolyether (PFPE) with the commercial name of Krytox GPL oils [71, 72, 80, 82, 83, 92, 93, 95, 98 100.

Different solid materials and geometries have been used so far to fabricate slippery liquid-infused surfaces. The very first surfaces were made using fluorinated acrylate textured materials $[89$ and silane-treated periodically ordered/random arrays of nanoposts [71]. The fabrication method includes a two-step soft lithography process using epoxy resin [101]. This technique was 
later used to replicate the surface microstructures of the taro plant leaf using polydimethylsiloxane (PDMS) 102. Photolithography and deep reactive ion etching was used as an alternative method to fabricate micropost/pillar arrays in silicon [74, 77, 95, 99, 100. The silicon surface was further hydrophobized using silane compounds such as octadecyltrichlorosilane (OTS) [74, 77, 100, or (tridecafluoro-1,1,2,2-tetrahydrooctyl)-1-trichlorosilane (TFTS) [99. Cylindrical miropillar arrays were also fabricated in glass using photolithographic techniques and etching followed by further silane treatment [79. In another technique, polished silicon wafers were subjected to a laser ablation process in order to obtain post-like structures having two-fold micro- and nano-features [86. The surface is further silane-treated with OTS while the lubricating oil is later added using dip coating method.

More recent research focused on fabrication of SLIPS using industrially relevant materials such as metals. Aluminium, as the most widely-used light weight structural material, was electro-polished and subsequently anodized to obtain aluminum oxide layers with pore-like and aggregated pillar-like microstructures 72 . Hydrophobization using $(1 \mathrm{H}, 1 \mathrm{H}, 2 \mathrm{H}, 2 \mathrm{H}$-perfluorooctyl)-1trichlorosilane (FOTS) rendered the surface hydrophobic and suitable for liquid infusion. Sand blasting and boehmite treatment of aluminium are another alternative methods [83. Micro and nanoscale textures, stemming from sandblasting and boehmite formation respectively, give rise to a hierarchical aluminium structures. Further surface treatment using fluorinated compounds makes the surface hydrophobic and applicable for SLIPS. Stainless steel was studied as another widely used material which was chemically etched to produce the required rough surface structure [85]. Further cleaning and silane treatment using OTS were performed to obtain the hydrophobic surface for infusion of the liquid. Commercially available oxygen-free copper tubes were also used as a metal substrate [99. Nanostructured CuO films (sharp, knifelike $\mathrm{CuO}$ structures) were obtained on the surface using an oxidation and reoxidation process. TFTS-silane treatment was subsequently applied to coat the surface.

Instead of texturing the solid substrate itself, coating of a structured and rough layer on the substrate is another alternative. This makes fabrication of SLIPS directly possible on commercially available materials/surfaces. Kim et. al. used aluminium as the substrate on which nanostructured polypyrrole was electrochemically coated [82] using an electropolymerization technique 103, 104. Cao et. al. coated glass with a superhydrophobic mesh using a dip coating process into a PDMS solution [81. Spray coating/depositing is an- 
other versatile method that can be applied to a variety of substrate materials. Spray-depositing of carbon nano fibers (CNFs) dispersed in a fluoroacrylic coploymer on glass was studied by Elsharkawy et. al. [84]. The copolymer solution acts as the low surface energy material (providing chemical hydrophobicity) while CNFs provide hierarchal micro-/nanostructures. Recently, a commercially available aerosol solution (functionalized silica nanoparticles suspended in a propanol/liquefied petroleum gas mixture) was spray-coated on glass to make superhydrophobic surface possessing a fractal-like porous network. Upon dip coating of the surface in the infusion liquid, SLIPS can be obtained [97. Sol-gel techniques were also used as another coating method. Flower-like nano-textured alumina sol-gel coatings were introduced by Ma et. al. 93. This coating can be applied on a variety of materials such as silicon, glass, metals and even plastics, irrespective of the shape. Further functionalization using perfluorinated compounds and phosphonic acid was performed to render the film surface hydrophobic and suitable for SLIPS.

For more flexible substrates, various types of mesh structures were investigated. Random networks of polytetrafluoroethylene (PTFE) (Teflon) nanofibers make a hydrophobic mesh without the need of hydrophobization [71. Spray-coated stainless steel meshes, using aerosol solution, allow for the flow of the infusion liquid between two sides providing double-sided flexible conformable meshes [97. Porous architectures with periodically inter connected spherical pores known as inverse opals (IOs) were also studied as substrates for SLIPS [79, 80. Schellenburger et. al. obtained IOs by vertically lifting a glass substrate out of an aqueous dispersion of polystyrene particles and silica nanoparticles [79]. The polystyrene template was then removed via annealing and the surface was cleaned and hydrophobized. A gold-coated silicone substrate was studied by Pham et. al. which was vertically placed in a well containing colloidal suspension of monodispersed polystyrene spheres [80]. The colloidal crystal forms as the suspension evaporates in the ambient environment followed by further annealing at $95^{\circ} \mathrm{C}$ for $3 \mathrm{~h}$. Removing the opal template by immersing in tetrahydrofuran for a minimum of $12 \mathrm{~h}$ revealed an IO structure with interconnected windows for a continuous, fluid-permeable pore network. After IO fabrication, further dispersion of Krytox GPL oil onto the sample, allowed slow permeation of lubricant through the porous network. 


\subsection{Liquid-infused surfaces with membrane technol- ogy}

Most of the fabrication processes of liquid-infused surfaces explained in the previous section "How to make liquid-infused surfaces"] are neither versatile nor suitable for mass production. Examples include, complex, timeconsuming, two-step soft photolithography processes [73, 101, 102, lengthy and high-cost photolithography based on deep reactive ion etching processes [74, 77, 79, 99, 100, chemical etching [85, 99] and anodization of metals [72. Coating techniques provide a more cost-effective and simpler SLIPS fabrication process involving alumina sol-gel [93, spray coating [84, 97, electrolytic polymerization of conductive polymers [82] and dip coating [81]. Yet all these processes require an extra step for reduction of surface energy based mostly on silane treatment methods which causes increase in costs and fabrication time. In summary, for wide spread application of SLIPS, a fast and easy fabrication method is needed.

Porous surfaces, such as polymeric porous membranes, are examples of surfaces which provide the required rough and textured solid substrate to contain the infusion liquid without complex and time consuming fabrication processes. Thanks to the wide availability of porous polymeric membranes, including high-fluorine content polymer with intrinsic low surface energy and hydrophobicity, silane treatment is not required. Examples of such polymers are PTFE [95, 98, polypropylene (PP) [98], polyvinylidene fluoride (PVDF) [92, 98, 105 107] and Nylon [92, 95, 98. The porous structure of such membranes with pore sizes ranging from micrometer 98 , to nanometer [92, 95, can lock-in the infusion liquid. Low surface tension infusion liquid, like silicone oil or fluorinated Krytox, spontaneously infiltrate through the porous structure, as a result of capillary wicking, forming the smooth liquid layer on the surface. The low surface energy of polymer material further ensures the most important design criteria, namely preferential wettability of the solid substrate by the infusion liquid relative to an immiscible ambient fluid such as water. Figure 1.3 illustrates the fabrication steps of liquid-infused surfaces using a porous membrane. All in all, application of polymeric hydrophobic porous membranes as the solid substrate, provide a facile, fast and cheap method for fabrication of liquid-infused surfaces leading to a new class of membranes known as "slippery liquid-infused membranes (SLIMs)" [106] upon addition of the infusion liquid.

Similar to liquid-infused surfaces, liquid-infused membranes also posses the 


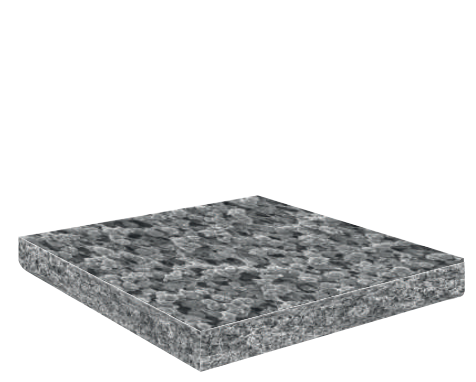

(a)

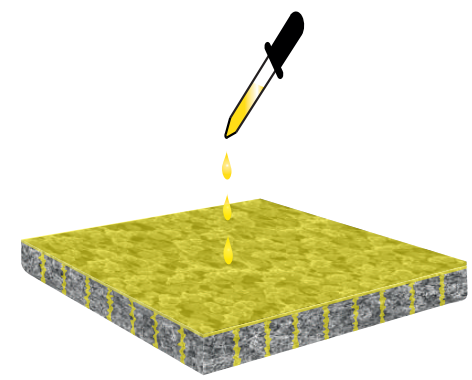

(b)

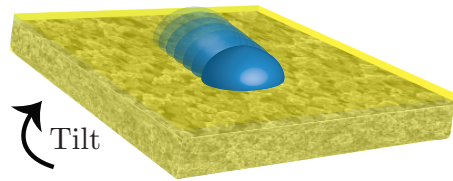

(c)

Figure 1.3: Fabrication steps of SLIM. (a) SEM images of top and cross section of the PVDF membrane used to construct the $3 \mathrm{D}$ view of the membrane (more clear images can be found in Appendix B). (b) Addition of fluorinated Krytox 101 oil to the membrane. (c) Fabricated SLIM with a smooth lubrication layer showing slippery character.

same interesting surface properties, e.g. slipperiness, self-cleaning, self-healing and etc. owing to the presence of a lubricating liquid layer. As a membrane, i.e. a selective barrier regulating the transport of substances between the two compartments [108], these surfaces demonstrate some unique functions and properties for separation applications. The capillary-stabilized liquid in the membrane pores give rise to the formation of a reconfigurable gate which can open and close in response to the system pressure [98. With the unique capability of gating, these membranes belong to the category of "smart membranes" with changing selectivity or adaptive surfaces [108. The properties of such membranes can be changed in a controlled fashion by external stimuli leading to the so-called stimuli-responsive membranes [109, 110]. The external stimuli that modulate membrane performance can be divided into three groups, namely direct stimulation, indirect stimulation and field responsive stimuli [109. Direct stimulation involves a membrane in direct contact with chemical or biological cues, such as $\mathrm{pH}$ [111, electrostatic environment and chemical or biological agents [109. Indirect stimulation involves incorporating responsive sites on the membrane which can respond to the thermodynamic stimuli, e.g. temperature or pressure. For example, temperature responsive groups can 
respond to change in temperature [112. Pressure responsive groups can react to ultrasound. Finally field responsive membranes respond to an external electromagnetic field. Here mass transport or mass and heat transfer between membranes and cues are not required to elicit a response [109.

The gating of a membrane mimics the functionality of biological systems in nature, e.g. electric eel or smell perception in human body [113. The electric eel can generate considerable bio-electricity from the salt content in fluids utilizing highly selective and rectified ion channels. The biological ion channels are membrane protein complexes with various responsive conformational changes regulating ion transport properties [114. Regulation of ionic transport in ion channels is mainly composed of three characteristic features including ionic selectivity, ionic rectification and ionic gating. The gating ion channels open and close in response to ambient stimuli for regulating ion permeation through cell membranes that are significant for implementation of important physiological functions in life processes [115. For instance, in the open state, the ion channel conduct electrical current by allowing ions to pass through. In the closed state, the ions cannot transport through, thus do not conduct electrical current (voltage sensing capability) [114, 116. As another example, the external odorant molecules act as stimuli to specific ion channels in the human nose system leading to the smell perception in the open state 113.

\subsection{Smart gating membrane systems}

Passive transport through membranes occurs as a consequence of a driving force, i.e. a difference in chemical potential by a gradient across the membrane in, e.g. concentration or pressure, or electric potential [117. The barrier structure of membranes can be classified according to their porous character into homogeneous and heterogeneous structures/morphology [118]. Generally, membrane-based mass transfer and separation manifest fantastic characteristics, including a low degree of energy consumption during membrane processes, together with the compactly-structured and less space-occupied membrane equipment [117, 119]. Consequently, membrane technology is essentialial with regard to world-wide sustainable development in various respects ranging from conservancy and renewal of energy [120, decrease in pollutant discharges [121] to water and wastewater treatment [122].

Apart from all the advantages of membrane technology, they suffer from some major disadvantages, such as the unalterable pore size and surface prop- 
erties of the membranes, that restrict their efficient applications 123. As already discussed in the Preface, the performance of membranes will be affected by unavoidable membrane fouling. Additionally, they cannot be applied to cases where self-regulated permeability and selectivity are required [123]. Smart or intelligent membranes possessing self-adjustable permeability and selectivity properties should be developed, which will bring new opportunities for broader membrane utilization [124. Inspired by natural cell membranes with ion channels, artificial stimuli-responsive smart gating membranes are developed by chemically/physically incorporating stimuli-responsive materials as functional gates into traditional porous membranes, to provide advanced functions and enhanced performances for breaking the bottlenecks of traditional membrane technologies [123. Based on the open/close switch capability of smart functional gates in response to the environmental stimuli, the permeability and selectivity of the membrane can be self-regulated via the flexible adjustment of pore sizes and surface properties.

\subsubsection{Design and fabrication scheme}

Smart gating membranes can be designed and fabricated in a variety of styles in which the membrane type, gating style and gating location can be varied [124. Membranes with stimuli-responsive properties have been employed in the form of flat sheet for separation [125, or hollow fibers for water treatment [126] or capsules for controlled release [127] purposes. The gating style highly depends on the type of functional material/molecule used for functionalization of the membrane based on physicochemical modification methods (Figure 1.4). The functional gate can consist of linear polymer chains [128, cross-linked hydrogel networks [129] or microspheres [126] which enables stimuli-responsive swelling/shrinking switches to adjust the effective pore size and surface characteristics. The gating material can be incorporated at different locations, i.e. into the membrane pores (pore-filling form) or on top of the membrane (pore-covering form). The pore-filling form provides robust gating performance [130] while pore-covering form is useful for applications where rapid response is required [131. The latter method can be extended to both sides of the membrane surface with or without fully covering the pore [132].

The fabrication techniques for smart gating membranes can be classified into two categories based on whether the gate materials are introduced after or during the membrane formation [123. Stimuli-responsive gates introduced after membrane formation usually incorporate the gate materials on existing porous membrane substrates using grafting techniques via grafting-from or grafting-to 


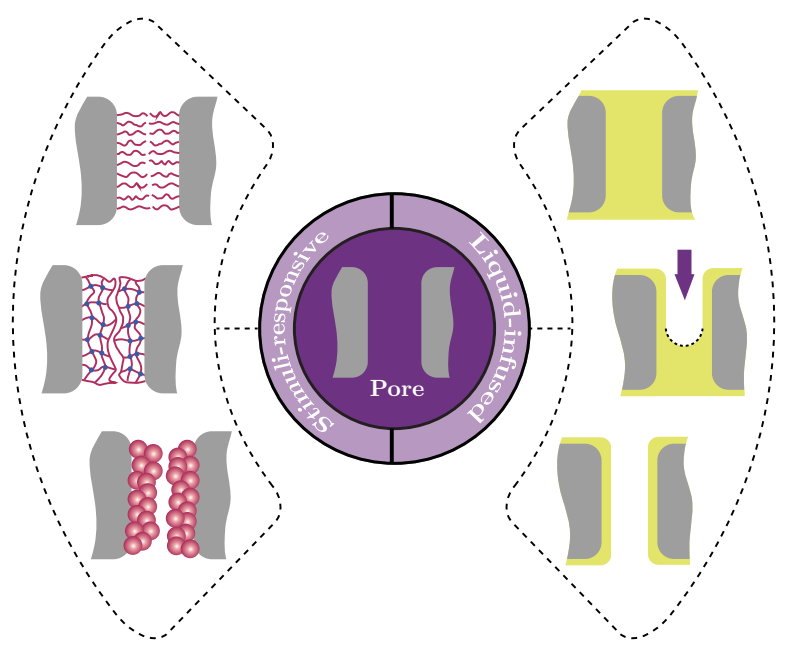

Figure 1.4: Smart gating membranes which can be designed either based on the infusion of the membrane pores with a liquid (right) or incorporation of a functional material into the membrane pores (left). This functional group can be polymer chains (top), hydrogel network (middle) or microspheres (bottom).

methods. In the "grafting-from" method, active sites are induced on the pore surface and functional monomers are polymerized from these active sites constituting linear polymers or cross-linked networks [129, 130]. Various grafting techniques such as plasma-induced grafting [125, 133, chemical grafting [134] and UV-induced grafting [135] can be employed for incorporating functional gates into membranes. In "grafting-to" method, pre-formed functional materials (polymer chains or microspheres) are chemically/physically incorporated on the membrane pore surfaces with pre-treated active sites [126, 128]. This method offers improved control and flexibility for the gate microstructures. The bonding between the gates and the pore surface can be achieved through either physical interactions, e.g. van der Waals' forces [126] or chemical covalent bonds for more robust applications [128]. The most direct approach to prepare smart gating membranes is to utilize the functional materials to make porous membranes without any further modification [110. Although this approach provides great potential for easy scale-up as well as efficient industrial manufacturing strategy of gating membranes, it has been restricted due to the limited functional material options to fabricate membranes. An alternative approach has been introduced which can be achieved by blending the stimuli-responsive materials (block copolymer or microspheres) with the 
membrane forming polymer during membrane formation [136, 137.

Functionalization of membrane pores to obtain smart gating membranes can be achieved via various physicochemical modification method such as atom transfer radical polymerization [136, electroless deposition [138, plasma modification [139] and self-assembly [140]. These methods are sophisticated, time-consuming, in some cases expensive and not easy to access. As an easy and straightforward method, infusing the membrane pores with an infusion liquid (see Figure 1.4 and section "Liquid-infused surfaces with membrane technology") can provide an alternative approach to obtain a reconfigurable gate. This will be discussed further in section "Liquid-gated membranes"

\subsubsection{Gating functionality}

Typically the gating can be divided into two models, namely positively- or negatively-response gating [123, 141. Positively-response gating allows increased membrane permeability through opening membrane pores when the stimulus appears or increases. While in negatively-response gating, the membrane permeability decreases dramatically through closing membrane pores in response to an increase in or the presence of a stimulus [123]. Due to the versatility of stimuli-responsive materials, a wide range of stimuli can be employed as triggers for achieving responsive gating. Temperature and $\mathrm{pH}$ are the most studied stimuli since temperature fluctuations occur naturally in many environmental systems and is well controlled in artificial designs while $\mathrm{pH}$ is an important environmental parameter specially for biomedical applications [141, 142. Among other stimuli, one can consider ions such as potassium $\left(\mathrm{K}^{+}\right)$which is essential for biological metabolism [19], or molecules such as glucose of which the concentration is an important indicator of, for instance, diabetes in blood [143. (UV) light and magnetic fields are usually clean stimuli that can be used for remote control [144, 145. The gating functions are achieved through the shrinking/swelling transitions of stimuli-responsive materials, which can open/close the membrane pores for increased/decreased permeability. Also, the hydrophobic/hydrophilic changes associated with the transitions of certain gates can adjust the surface properties of the pores [124]. As the most common parameters, fabrication and applications of temperatureand $\mathrm{pH}$-responsive gating will be discussed briefly here. More detailed information on other types of stimuli-responsive gates can be found elsewhere [123, 124.

Poly(N-isopropylacrylamide) (PNIPAM) is a popular thermo-responsive polymer used in positively-response gates [141. It shows a distinct and re- 
versible phase transition at the lower critical solution temperature (LCST) around $32^{\circ} \mathrm{C}$ (close to human body temperature) [146, 147]. At temperatures below the LCST, PNIPAM chains are swollen and hydrophilic (due to the hydrogen bonding between the amide groups and water molecules), thus the membrane pores close. With an increase in the temperature above the LCST, the PNIPAM chains shrink and become hydrophobic (due to hydrogen bonding cleavage), and the membrane pores open [148]. The LCST can be tuned by incorporating hydrophilic or hydrophobic groups into the PNIPAM chains providing routes for more flexible applications. Polymers with interpenetrating networks (IPNs) composed of poly(acryl amide) (PAAm) and poly(acrylic acid) PAAc can be used as negatively thermo-responsive gates. The polymeric gates can shrink due to the formation of a PAAm/PAAc complex via hydrogen bonds at temperatures below the upper critical solution temperature (UCST) of IPNs, resulting in pore opening. While at temperatures above the UCST, the IPNs can swell due to their dissociation through the breakage of hydrogen bonds, leading to pore closing. Thus, the membrane pores can switch from an open to a closed state once the temperature increases above the UCST [129].

All pH-responsive materials with $\mathrm{pH}$-responsive swelling or shrinking properties contain either acidic or basic groups, which respond to changes in environmental $\mathrm{pH}$ by gaining or losing protons [149. For example, the $\mathrm{pH}$ responsive volume phase transition of poly(methacrylic acid) (PMAA) and poly(N,N-dimethylaminoethyl methacrylate) (PDM) hydrogels have been verified to be opposite [150]. PMAA hydrogels are featured with a positively $\mathrm{pH}-$ responsive volume phase transition characteristic, i.e. the hydrogel swelling is induced by an increase in the environmental $\mathrm{pH}$. On the contrary, PDM hydrogels show a negatively $\mathrm{pH}-\mathrm{responsive} \mathrm{volume} \mathrm{phase} \mathrm{transition} \mathrm{character-}$ istic, i.e., the hydrogel swelling is induced by a decrease in the environmental $\mathrm{pH}$. When the environmental $\mathrm{pH}$ is higher than the corresponding value of the effective dissociation constant (pKa), the PDM hydrogel shrinks, but the PMAA hydrogel swells. On the other hand, when the ambient $\mathrm{pH}$ is decreased to values lower than the corresponding pKa, the PMAA hydrogel shrinks, but the PDM hydrogel swells. Polymers such as PMAA or PAAc can be used to achieve negatively pH-responsive model [150, 151], while PDM can be used to achieve a positively $\mathrm{pH}$-responsive model for smart gating membranes [136.

\subsubsection{Liquid-gated membranes}

The capillary-stabilized liquid inside micro/nano pores of a liquid-infused membrane brings a unique combination of dynamic and interfacial behaviours 
[98. As it is schematically shown in Figure 1.4 the dynamic gating concept gives rise to the open state of the pore as long as the applied pressure is above the threshold. Once the pressure drops below the threshold, the pore will be thermodynamically primed to the closed state [110]. The pressure threshold value is determined by the balance between pore geometry, surface interactions, and surface tension based on the Young-Laplace equation. Thomas Young and Pierre Simon Laplace in 1805 [152] showed that the pressure difference, $\Delta P$, across a curved fluid interface is directly proportional to its curvature $\kappa$, with the interfacial tension $\gamma$ being the proportionality constant

$$
\Delta P=\gamma \kappa .
$$

The curvature of a sphere or semi-sphere (similar to the liquid interface in liquid-filled pores (see the dashed curvature in Figure 1.4 middle right)) is defined as $\kappa=\frac{2}{R}$ [153. Thus, the Young-Laplace equation, which is also known as capillary pressure, takes the general form of

$$
\Delta P=\frac{2 \gamma}{R}
$$

When the liquid interface is in contact with a solid surface, the wetting state (surface interactions) of the solid by the liquid must be also considered. Surfaces wettability is usually measured by the contact angle $\theta$ of a liquid droplet on a solid surface. For smooth solid surfaces, Thomas Young defined it as the angle formed between the solid/liquid interface and the liquid/vapor interface when a droplet is placed on the surface [154. In another words, it is the angle formed by a liquid at the three-phase boundary where a liquid, gas, and solid intersect [94]. Young's equation is known as

$$
\cos \theta=\frac{\gamma_{S A}-\gamma_{S L}}{\gamma_{L A}}
$$

where $\gamma_{S A}, \gamma_{S L}$ and $\gamma_{L A}$ are the interfacial tension between solid-air, solidliquid and liquid-air respectively. A contact angle of $180^{\circ}$ represents no spreading and the whole droplet is located on the surface as a complete sphere in case of low Bond/Eötvös number $B o=\Delta \rho g L^{2} / \gamma$, where $\Delta \rho$ is density difference between the two phases $\left(\mathrm{kg} / \mathrm{m}^{3}\right), g$ is gravitational acceleration $\left(\mathrm{m} / \mathrm{s}^{2}\right)$ and $L$ is the characteristic length (radii of curvature of the drop (m)). A contact angle of $0^{\circ}$ represents full spreading on the surface and the droplet liquid completely wets the surface [94. Incorporating wetting behaviour of the solid surface by the liquid, in Young-Laplace equation (Equation 1.2) reads 


$$
\Delta P=\frac{2 \gamma \cos \theta}{R},
$$

where $\theta$ is Young's contact angle of the liquid on the solid surface, $\gamma$ is the interfacial tension between fluids and $R$ is the radius of curvature.

In the case of liquid-infused membranes, the infusion liquid completely wets and strongly adheres to the porous solid material of the membrane leading to a contact angle of $0^{\circ}$ between infusion liquid and membrane material. As explained in section "Liquid-infused surfaces with membrane technology", this is an important design criteria which once satisfied, the infusion liquid can completely seal the membrane pores and form a continuous liquid layer along the membrane surface. For transport of any fluid, e.g. gases or liquids through the liquid-infused pores, the infusion liquid must be replaced such that the other fluid can enter the membrane pores. Depending on the type of fluid and its physical characteristics, such as interfacial tension with the infusion liquid, the corresponding threshold/critical pressure (Young-Laplace pressure) is different. Once the system pressure is higher than the critical pressure, the infusion liquid will be partly removed and form a liquid-lined pathway for passage of the transport fluid while remaining adherent to the pore wall (see Figure 1.4 bottom right). This is because the affinity of the infusion liquid for the porous membrane is stronger than that of the transport fluid. As long as the transport fluid is immiscible with the infusion liquid, it would pass through without contacting the solid membrane. Compared to the pristine membrane, without infusion liquid, this can further prevent fouling since there is no direct contact between the transport fluid and solid material of the membrane [95, 98. Once pressurizing is stopped, the liquid-lined pores inside the membrane return to their original closed state (liquid re-infusion) in case sufficient infusion liquid is present [98, 105. Liquid re-infusion highly depends on the type of the transport fluid and it has been shown to be the case for gases [105. The behaviour is different in the case of a more viscous transport fluid such as water [106. The opening and closing ability of the liquid-infused pores in response to the system pressure, makes them responsive gates which can be used for multiphase transport and efficient sorting of immiscible liquids. This will be discussed further in next section. The opening and closing of the liquid-infused pores in response to the system pressure provides a unified approach for achieving the responsive, tunable and selective antifouling multiphase transport 98 . 


\subsubsection{Applications of gating membranes}

As explained in section "Gating functionality", the positively- and negativelyresponsive gating functions, in response to various stimuli, enable the precise control of pore size and surface properties of smart gating membranes, as well as the permeability and selectivity. In liquid-gated membranes, the dynamic reconfiguration of liquid lining is a mean to reversibly open and close micropores. This provides a new tunable gating concept for achieving the physicochemical selectivity for gas and liquid phase transport [98, 110].

Self-adjustment of permeability in gating membranes is a powerful tool for specific ion detection in water, water purification purposes and applications where controlled release is required [150, 155, 156. Negatively $\mathrm{Pb}^{2+}$ responsive gating membranes can reduce their permeability in response to the trace of $\mathrm{Pb}^{2+}$ ions in solution [155]. By combining bioactive membranes with pH-responsive gating membranes, water purification systems can be developed for degrading toxic organics. For instance, degrading toxic organics can be achieved via decomposition of hydrogen peroxide into free radical oxidants via $\mathrm{pH}$-responsive PAAc hydrogel gates with doped iron species [156]. Further degradation of toxic organics into alkali ions increases $\mathrm{pH}$ for pore closing. This leads to a reduced flux of toxic organics and allows a longer time for their efficient degradation. Gating membranes with self-regulated diffusional permeability, which is defined as molecular diffusion driven by a concentration gradient, are promising for regulating the mass transfer of active molecules across the membrane for controlled release [123. As an example, the gating membrane with negatively $\mathrm{pH}$-responsive gates serves as a functional valve for controlling the substance release from enclosed system, while the positively $\mathrm{pH}$-responsive hydrogel inside the system works as a pump for pumping the substances out. Upon request, the membrane pores open and the hydrogel swells and the encapsulated substances can be pumped out through the open pores $[150$. The achieved release rate is further enhanced beyond the limit of concentration-driven diffusion.

Stimuli-responsive separation of substances with different sizes can be achieved by using single gating membranes with self-regulating pore size based on designed stimuli such as $\mathrm{pH}$ or temperature [147, 151. pH-responsive gating membranes can selectively reject molecules with appropriate molecular weights (such as dextran) from mixtures with different molecular weights, depending on the environmental $\mathrm{pH}$ [151. Temperature-responsive gating membranes enable the fast permeation of small molecules (such as $\mathrm{NaCl}$ ) at low temperatures, while larger molecules can only permeate through the membrane 
with opened pores at higher temperatures [147]. With self-regulated surface properties to control the affinity between pore composition and substances, smart gating membranes offer ingenious tools for stimuli-responsive separation or purification of substances such as proteins and chiral molecules [124]. For example, gating membranes with gates that allow a thermo-induced switch between the hydrophilic and hydrophobic states can be used for separating more hydrophobic substances (such as bovine serumalbumin (BSA)) based on adsorption 125. The BSA can be adsorbed when the gates are more hydrophobic, and desorbed when the gates become hydrophilic. This can be simply controlled by varying the operation temperature.

Self-cleaning functionality can be achieved to reduce membrane fouling while retaining the permeability. Polymers that are used for membrane fabrication are usually hydrophobic in nature, facilitating the deposition of organic foulants on the membrane surface due to hydrophobic interactions [117. Grafting hydrophilic polymers on membrane surfaces has been shown to reduce foulant adsorption [157]. The main issue with the grafted polymers is that they reduce the intrinsic permeability of the membrane due to the partial blockage of the pores [158. In smart gating membrane with stimuli-induced self-cleaning function, the shrunk and hydrophobic gates become swollen and hydrophilic upon exposure to the stimulus. Such transitions weaken the interactions between the foulant and membrane surface leading to easy removal of the foulant by washing with water [123. The permeability of the membrane will be preserved by recovering the gates to the shrunken state.

The opening and closing of the liquid-infused pores in response to the system pressure (gating mechanism) can be used for gas/liquid or liquid/liquid separation applications. As explained in section Liquid-gated membranes, gases and liquids must deform the interface of the gating liquid to enter the pore under different critical pressures (Young-Laplace equation 1.3). For example, for gas/liquid separation, there are two critical pressures to gate the gas and liquid through the liquid-gated membranes, namely $\mathrm{P}_{\text {critical, } \mathrm{g}}$ and $\mathrm{P}_{\text {critical, l. }}$ By setting the pressure between the two critical pressure, i.e. higher

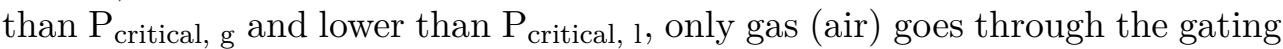
membrane and bubble-free water is obtained [98. Based on the same concept, more complex fluid dispersions can be simply separated. Each component of the multiphase dispersion possesses a distinct critical pressure, via the interfacial tension with the infusion liquid. This can be beneficial in the field of oily wastewater treatment. Oil/water mixtures in oily wastewater discharged from daily life and industrial processes, have caused tremendous threats for 
both environment and human health [121, 159]. Membrane technology has been considered as one of the most efficient methods to treat oil-contaminated water and it has been studied significantly so far [160 164]. Liquid-gated membranes represent a new regime in the development of oil/water separation and wastewater treatment technologies. The minor phase, i.e. oil, can be successfully permeated through the membrane while the continuous water phase is being retained [107. This is economically beneficial specially at low oil concentrations.

Wetting properties of liquid-gated membranes can be regulated by infusing liquids with different surface energies. This helps developing a universal infused-liquid-switchable separation protocol based on polarity interaction between liquids and membranes [165. In this case, no external stimulation or covalent modification is necessary. In addition to above-mentioned applications, the anti-biofouling properties of liquid-gated membranes demonstrate the ability of these membranes to recover flux after both protein and bacterial fouling without the use of harsh chemicals or antibiotics [166]. This further offers a promising potential to reduce costs associated with cleaning in membrane processes.

\subsection{Scope and outline of the thesis}

The main focus of this thesis is on understanding the underlying working mechanisms of liquid-infused membranes. To achieve this goal, the transport behaviour at the pore scale is investigated, clarifying the role of liquid-lining. In this journey, in addition to membrane studies, microfluidic investigations further help observing the fluid displacement behaviour. Using actual membranes and commercial infusion liquids, the applications of these membranes for multiphase separations is investigated. Further related studies such as porous media flow and behaviour of oil droplets in oil-in-water $(\mathrm{O} / \mathrm{W})$ emulsions complement the thesis.

In Chapter Two, the gating mechanism of the liquid-infused membranes is investigated by pushing gas, at different pressure values, through the membrane. The presence of liquid-lining in the open state as well as re-infusion capability of the liquid for recovering the closed state, are further demonstrated. In Chapter Three, the retention of infusion liquid is investigated while pushing a more viscous immiscible liquid, e.g. water through the membranes. The underlying displacement mechanism is revealed based on microscopic observations. The presence of remaining infusion liquid, specially in the form of 
liquid-lining, at high flow rates of transport fluid, shows the potential of these membranes for separation applications. In Chapter Four the applicability of liquid-infused membranes for separation of the minor phase, i.e oil from $\mathrm{O} / \mathrm{W}$ emulsions (as resemblance of oily wastewater), is investigated based on gravity-assisted creaming. The persistent liquid-lining leads to the formation of three-phase interfaces with the permeating oil and continuous water phase giving rise to an increase in the combined interfacial tension value. This further results in an increase in the critical Young-Laplace pressure leading to successful permeation of oil and retention of water. As it has been explained previously, the liquid-lined pores prevent the direct contact between permeating fluid and solid material of the membrane which can potentially decrease fouling. In Chapter Five the anti-biofouling performance of liquid-infused membranes is studied using long-term cross flow filtration. A significantly lower transmembrane pressure (TMP) increase is observed for liquid-infused membranes compared to non-infused counterparts. Further fitting of the results to growth curve models reveal a substantial increase in the lag phase of bacterial growth as well as a decrease in its growth rate.

Permeation of the minor phase (oil) instead of the continuous phase (water) from $\mathrm{O} / \mathrm{W}$ emulsion is a promising alternative for oily wastewater treatment using a membrane. The oil droplets should transport through the bulk of the emulsion to reach the membrane surface. External fields such as electric or acoustic fields can be applied to further accelerate the movement of oil droplets. In Chapter Six, the acoustophoretic behaviour of oil droplets is fundamentally studied. To exclude the size effects and the statistical uncertainties thereof, monodisperse $\mathrm{O} / \mathrm{W}$ emulsions are employed. An experimental as well as theoretical method are presented for measurement and calculation of acoustic energy density as an important design parameter in acoustic separation applications.

Permeability, as the most important transport property of any porous media directly affects the separation functionality of membranes. In Chapter Seven, a numerical prediction model for permeability is introduced. The model is validated experimentally using porous micromodels consisting of random arrays of cylindrical pillars. The results show a unique scaling power-law relation between normalized permeability (permeability/pillar diameter ${ }^{2}$ ) and the second nearest neighbor distance $\left(\gamma_{2}\right)$ which is defined based on pore geometry and pillar arrangements.

Finally in Chapter Eight a general discussion and conclusion of the work together with an outlook for future research directions are presented. The 
application of an electric field as an alternative method for movement of oil droplets towards the membrane surface and the accompanying challenges are touched upon.

\section{References}

[1] C. Wan, Y. Jiao, D. Liang, Y. Wu, and J. Li, "A geologic architecture system-inspired micro-/nano-heterostructure design for highperformance energy storage", Advanced Energy Materials 8, 1802388 (1-7) (2018).

[2] A. S. Perera and M.-O. Coppens, "Re-designing materials for biomedical applications: from biomimicry to nature-inspired chemical engineering", Philosophical Transactions of the Royal Society A: Mathematical, Physical and Engineering Sciences 377, 20180268 (1-21) (2019).

[3] P. Fratzl, "Biomimetic materials research: what can we really learn from nature's structural materials?", Journal of the Royal Society, Interface 4, 637-642 (2007).

[4] J. Peng and Q. Cheng, "High-performance nanocomposites inspired by nature", Advanced Materials 29, 1702959 (2017).

[5] U. G. K. Wegst, H. Bai, E. Saiz, A. P. Tomsia, and R. O. Ritchie, "Bioinspired structural materials", Nature Materials 14, 23-36 (2015).

[6] H.-B. Yao, H.-Y. Fang, X.-H. Wang, and S.-H. Yu, "Hierarchical assembly of micro-/nano-building blocks: bio-inspired rigid structural functional materials", Chem. Soc. Rev. 40, 3764-3785 (2011).

[7] W. Zhang and W. Zheng, "Exsolution-mimic heterogeneous surfaces: Towards unlimited catalyst design", ChemCatChem 7, 48-50 (2015).

[8] T. Sun, L. Feng, X. Gao, and L. Jiang, "Bioinspired surfaces with special wettability", Accounts of Chemical Research 38, 644-652 (2005).

[9] T. Nishino, M. Meguro, K. Nakamae, M. Matsushita, and Y. Ueda, "The lowest surface free energy based on -cf3 alignment", Langmuir 15, 4321-4323 (1999). 
[10] L. Feng, S. Li, Y. Li, H. Li, L. Zhang, J. Zhai, Y. Song, B. Liu, L. Jiang, and D. Zhu, "Super-hydrophobic surfaces: From natural to artificial", Advanced Materials 14, 1857-1860 (2002).

[11] W. Barthlott and C. Neinhuis, "Purity of the sacred lotus, or escape from contamination in biological surfaces", Planta 202, 1-8 (1997).

[12] C. Neinhuis and W. Barthlott, "Characterization and distribution of water-repellent, self-cleaning plant surfaces", Annals of Botany 79, 667 - 677 (1997).

[13] C. Luo, H. Zheng, L. Wang, H. Fang, J. Hu, C. Fan, Y. Cao, and J. Wang, "Direct three-dimensional imaging of the buried interfaces between water and superhydrophobic surfaces", Angewandte Chemie International Edition 49, 9145-9148 (2010).

[14] Y. Zheng, X. Gao, and L. Jiang, "Directional adhesion of superhydrophobic butterfly wings", Soft Matter 3, 178-182 (2007).

[15] X. Gao, X. Yan, X. Yao, L. Xu, K. Zhang, J. Zhang, B. Yang, and L. Jiang, "The dry-style antifogging properties of mosquito compound eyes and artificial analogues prepared by soft lithography", Advanced Materials 19, 2213-2217 (2007).

[16] G. Zhang, J. Zhang, G. Xie, Z. Liu, and H. Shao, "Cicada wings: A stamp from nature for nanoimprint lithography", Small 2, 1440-1443 (2006).

[17] L. Feng, Y. Zhang, J. Xi, Y. Zhu, N. Wang, F. Xia, and L. Jiang, "Petal effect: A superhydrophobic state with high adhesive force", Langmuir 24, 4114-4119 (2008).

[18] W. R. Hansen and K. Autumn, "Evidence for self-cleaning in gecko setae", Proceedings of the National Academy of Sciences 102, 385-389 (2005).

[19] K. Liu, J. Du, J. Wu, and L. Jiang, "Superhydrophobic gecko feet with high adhesive forces towards water and their bio-inspired materials", Nanoscale 4, 768-772 (2012).

[20] A. R. Parker and C. R. Lawrence, "Water capture by a desert beetle", Nature 414, 33-34 (2001). 
[21] X. Gao and L. Jiang, "Water-repellent legs of water striders", Nature 432, 36-36 (2004).

[22] D. Richard and D. Quéré, "Viscous drops rolling on a tilted non-wettable solid", Europhysics Letters (EPL) 48, 286-291 (1999).

[23] D. Richard and D. Quéré, "Bouncing water drops", Europhysics Letters (EPL) 50, 769-775 (2000).

[24] D. Quéré, "Rough ideas on wetting", Physica A: Statistical Mechanics and its Applications 313, 32-46 (2002).

[25] H. J. Ensikat, P. Ditsche-Kuru, C. Neinhuis, and W. Barthlott, "Superhydrophobicity in perfection: the outstanding properties of the lotus leaf", Beilstein journal of nanotechnology 2, 152-161 (2011).

[26] Y. T. Cheng, D. E. Rodak, C. A. Wong, and C. A. Hayden, "Effects of micro- and nano-structures on the self-cleaning behaviour of lotus leaves", Nanotechnology 17, 1359-1362 (2006).

[27] K. Koch, B. Bhushan, Y. C. Jung, and W. Barthlott, "Fabrication of artificial lotus leaves and significance of hierarchical structure for superhydrophobicity and low adhesion", Soft Matter 5, 1386-1393 (2009).

[28] M. A. Samaha, H. V. Tafreshi, and M. G. el Hak, "Superhydrophobic surfaces: From the lotus leaf to the submarine", Comptes Rendus Mécanique 340, 18-34 (2012).

[29] P. U. LTD, "The lotus effect = https://www.properla.co.uk/ lotus-effect/,", .

[30] T. Onda, S. Shibuichi, N. Satoh, and K. Tsujii, "Super-water-repellent fractal surfaces", Langmuir 12, 2125-2127 (1996).

[31] W. Chen, A. Y. Fadeev, M. C. Hsieh, D. Öner, J. Youngblood, and T. J. McCarthy, "Ultrahydrophobic and ultralyophobic surfaces: Some comments and examples", Langmuir 15, 3395-3399 (1999).

[32] H. Li, X. Wang, Y. Song, Y. Liu, Q. Li, L. Jiang, and D. Zhu, "Super"amphiphobic" aligned carbon nanotube films", Angewandte Chemie International Edition 40, 1743-1746 (2001). 
[33] H. Y. Erbil, A. L. Demirel, Y. Avc1, and O. Mert, "Transformation of a simple plastic into a superhydrophobic surface", Science 299, 1377-1380 (2003).

[34] L. Vogelaar, R. G. H. Lammertink, and M. Wessling, "Superhydrophobic surfaces having two-fold adjustable roughness prepared in a single step", Langmuir 22, 3125-3130 (2006).

[35] S. Nishimoto and B. Bhushan, "Bioinspired self-cleaning surfaces with superhydrophobicity, superoleophobicity, and superhydrophilicity", RSC Adv. 3, 671-690 (2013).

[36] K. M. Wisdom, J. A. Watson, X. Qu, F. Liu, G. S. Watson, and C.H. Chen, "Self-cleaning of superhydrophobic surfaces by self-propelled jumping condensate", Proceedings of the National Academy of Sciences 110, 7992-7997 (2013).

[37] P. Guo, Y. Zheng, M. Wen, C. Song, Y. Lin, and L. Jiang, "Icephobic/anti-icing properties of micro/nanostructured surfaces", Advanced Materials 24, 2642-2648 (2012).

[38] S. Bengaluru Subramanyam, V. Kondrashov, J. Rühe, and K. K. Varanasi, "Low ice adhesion on nano-textured superhydrophobic surfaces under supersaturated conditions", ACS Applied Materials \& Interfaces 8, 12583-12587 (2016).

[39] N. K. Mandsberg and R. Taboryski, "Spatial control of condensation on chemically homogeneous pillar-built surfaces", Langmuir 33, 5197-5203 (2017).

[40] J. B. Boreyko and C.-H. Chen, "Self-propelled dropwise condensate on superhydrophobic surfaces", Phys. Rev. Lett. 103, 184501 (2-5) (2009).

[41] J. Ou, B. Perot, and J. P. Rothstein, "Laminar drag reduction in microchannels using ultrahydrophobic surfaces", Physics of Fluids 16, 4635-4643 (2004).

[42] J. Ou and J. P. Rothstein, "Direct velocity measurements of the flow past drag-reducing ultrahydrophobic surfaces", Physics of Fluids 17, 103606 (2005).

[43] C. Lee, C.-H. Choi, and C.-J. Kim, "Structured surfaces for a giant liquid slip", Phys. Rev. Lett. 101, 064501 (1-4) (2008). 
[44] C. Lee and C.-J. Kim, "Maximizing the giant liquid slip on superhydrophobic microstructures by nanostructuring their sidewalls", Langmuir 25, 12812-12818 (2009).

[45] C.-H. Choi and C.-J. Kim, "Large slip of aqueous liquid flow over a nanoengineered superhydrophobic surface", Phys. Rev. Lett. 96, 066001 (1-4) (2006).

[46] E. Karatay, A. S. Haase, C. W. Visser, C. Sun, D. Lohse, P. A. Tsai, and R. G. H. Lammertink, "Control of slippage with tunable bubble mattresses", Proceedings of the National Academy of Sciences 110, 8422-8426 (2013).

[47] E. G. Shafrin and W. A. Zisman, "Constitutive relations in the wetting of low energy surfaces and the theory of the retraction method of preparing monolayers1", The Journal of Physical Chemistry 64, 519-524 (1960).

[48] T. P. N. Nguyen, P. Brunet, Y. Coffinier, and R. Boukherroub, "Quantitative testing of robustness on superomniphobic surfaces by drop impact", Langmuir 26, 18369-18373 (2010).

[49] L. Zheng, R. Shafack, B. Walker, and K. Chan, "The impact of high humidity on the ice-phobicity of copper-based superhydrophobic surfaces", Nanomaterials and Nanotechnology 7, 1847980417707174 (2017).

[50] M. He, H. Li, J. Wang, and Y. Song, "Superhydrophobic surface at low surface temperature", Applied Physics Letters 98, 093118 (2011).

[51] P. Papadopoulos, L. Mammen, X. Deng, D. Vollmer, and H.-J. Butt, "How superhydrophobicity breaks down", Proceedings of the National Academy of Sciences 110, 3254-3258 (2013).

[52] R. Di Mundo, F. Bottiglione, M. Notarnicola, F. Palumbo, and G. Pascazio, "Plasma-textured teflon: Repulsion in air of water droplets and drag reduction underwater", Biomimetics (Basel, Switzerland) 2, 1 (1-13) (2017).

[53] T. Koishi, K. Yasuoka, S. Fujikawa, T. Ebisuzaki, and X. C. Zeng, "Coexistence and transition between cassie and wenzel state on pillared hydrophobic surface", Proceedings of the National Academy of Sciences 106, 8435-8440 (2009). 
[54] T. Deng, K. K. Varanasi, M. Hsu, N. Bhate, C. Keimel, J. Stein, and M. Blohm, "Nonwetting of impinging droplets on textured surfaces", Applied Physics Letters 94, 133109 (2009).

[55] A. B. D. Cassie and S. Baxter, "Wettability of porous surfaces", Trans. Faraday Soc. 40, 546-551 (1944).

[56] R. N. Wenzel, "Resistance of solid surfaces to wetting by water", Industrial \& Engineering Chemistry 28, 988-994 (1936).

[57] M. Sbragaglia, A. M. Peters, C. Pirat, B. M. Borkent, R. G. H. Lammertink, M. Wessling, and D. Lohse, "Spontaneous breakdown of superhydrophobicity", Phys. Rev. Lett. 99, 156001 (1-4) (2007).

[58] U. Bauer and W. Federle, "The insect-trapping rim of nepenthes pitchers: surface structure and function", Plant signaling \& behavior 4, 1019-1023 (2009).

[59] P. World, "Slippery surface inspired by pitcher plant = https://www . dmbotanicalgarden.com/event/carnivorous-plant-terrariums/,",

[60] E. V. Gorb and S. N. Gorb, Functional Surfaces in the Pitcher of the Carnivorous Plant Nepenthes alata: A Cryo-Sem Approach, 205-238 (Springer Netherlands, Dordrecht) (2009).

[61] H. F. Bohn and W. Federle, "Insect aquaplaning: Nepenthes pitcher plants capture prey with the peristome, a fully wettable water-lubricated anisotropic surface", Proceedings of the National Academy of Sciences 101, 14138-14143 (2004).

[62] J. A. Moran, L. K. Gray, C. Clarke, and L. Chin, "Capture mechanism in palaeotropical pitcher plants (nepenthaceae) is constrained by climate", Annals of botany 4, 1279-1291 (2013).

[63] M. Riedel, A. Eichner, and R. Jetter, "Slippery surfaces of carnivorous plants: composition of epicuticular wax crystals in nepenthes alata blanco pitchers", Planta 218, 87-97 (2003).

[64] B. E. Juniper and J. Burras, "How pitcher plants trap insects", New Scientist 13, 75-77 (1962). 
[65] L. Gaume, P. Perret, E. Gorb, S. Gorb, J.-J. Labat, and N. Rowe, "How do plant waxes cause flies to slide? experimental tests of wax-based trapping mechanisms in three pitfall carnivorous plants", Arthropod Structure \& Development 33, 103-111 (2004), attachment Systems of Arthropods.

[66] E. V. Gorb and S. N. Gorb, "Physicochemical properties of functional surfaces in pitchers of the carnivorous plant nepenthes alata blanco (nepenthaceae)", Plant Biology 8, 841-848 (2006).

[67] L. Wang, Q. Zhou, Y. Zheng, and S. Xu, "Composite structure and properties of the pitcher surface of the carnivorous plant nepenthes and its influence on the insect attachment system", Progress in Natural Science 19, 1657-1664 (2009).

[68] I. Scholz, M. Bückins, L. Dolge, T. Erlinghagen, A. Weth, F. Hischen, J. Mayer, S. Hoffmann, M. Riederer, M. Riedel, and W. Baumgartner, "Slippery surfaces of pitcher plants: Nepenthes wax crystals minimize insect attachment via microscopic surface roughness", Journal of Experimental Biology 213, 1115-1125 (2010).

[69] L. Gaume and Y. Forterre, "A viscoelastic deadly fluid in carnivorous pitcher plants", PloS one 2, e1185 (1-7) (2007).

[70] V. Bonhomme, H. Pelloux-Prayer, E. Jousselin, Y. Forterre, J.-J. Labat, and L. Gaume, "Slippery or sticky? functional diversity in the trapping strategy of nepenthes carnivorous plants", New Phytologist 191, 545-554 (2011).

[71] T.-S. Wong, S. H. Kang, S. K. Tang, E. J. Smythe, B. D. Hatton, A. Grinthal, and J. Aizenberg, "Bioinspired self-repairing slippery surfaces with pressure-stable omniphobicity", Nature 477, 443-447 (2011).

[72] P. Wang, D. Zhang, and Z. Lu, "Slippery liquid-infused porous surface bio-inspired by pitcher plant for marine anti-biofouling application", Colloids and Surfaces B: Biointerfaces 136, 240-247 (2015).

[73] H. A. Stone, "Ice-phobic surfaces that are wet", ACS Nano 6, 6536-6540 (2012).

[74] S. Anand, A. T. Paxson, R. Dhiman, J. D. Smith, and K. K. Varanasi, "Enhanced condensation on lubricant-impregnated nanotextured surfaces", ACS Nano 6, 10122-10129 (2012). 
[75] M. Delmas, M. Monthioux, and T. Ondarçuhu, "Contact angle hysteresis at the nanometer scale", Phys. Rev. Lett. 106, 136102 (1-4) (2011).

[76] C. Semprebon, G. McHale, and H. Kusumaatmaja, "Apparent contact angle and contact angle hysteresis on liquid infused surfaces", Soft Matter 13, 101-110 (2017).

[77] J. D. Smith, R. Dhiman, S. Anand, E. Reza-Garduno, R. E. Cohen, G. H. McKinley, and K. K. Varanasi, "Droplet mobility on lubricantimpregnated surfaces", Soft Matter 9, 1772-1780 (2013).

[78] J. D. Smith, R. Dhiman, and K. Varanasi, "Liquid-encapsulating surfaces: overcoming the limitations of superhydrophobic surfaces for robust non-wetting and anti-icing surfaces", in APS Division of Fluid Dynamics Meeting Abstracts, volume 64 of APS Meeting Abstracts, S4.001 (2011).

[79] F. Schellenberger, J. Xie, N. Encinas, A. Hardy, M. Klapper, P. Papadopoulos, H.-J. Butt, and D. Vollmer, "Direct observation of drops on slippery lubricant-infused surfaces", Soft Matter 11, 7617-7626 (2015).

[80] Q. N. Pham, S. Zhang, K. Montazeri, and Y. Won, "Droplets on slippery lubricant-infused porous surfaces: A macroscale to nanoscale perspective", Langmuir 34, 14439-14447 (2018).

[81] M. Cao, D. Guo, C. Yu, K. Li, M. Liu, and L. Jiang, "Water-repellent properties of superhydrophobic and lubricant-infused "slippery" surfaces: A brief study on the functions and applications", ACS Applied Materials \& Interfaces 8, 3615-3623 (2016).

[82] P. Kim, T.-S. Wong, J. Alvarenga, M. J. Kreder, W. E. AdornoMartinez, and J. Aizenberg, "Liquid-infused nanostructured surfaces with extreme anti-ice and anti-frost performance", ACS Nano 6, 6569-6577 (2012).

[83] P. W. Wilson, W. Lu, H. Xu, P. Kim, M. J. Kreder, J. Alvarenga, and J. Aizenberg, "Inhibition of ice nucleation by slippery liquid-infused porous surfaces (slips)", Phys. Chem. Chem. Phys. 15, 581-585 (2013).

[84] M. Elsharkawy, D. Tortorella, S. Kapatral, and C. M. Megaridis, "Combating frosting with joule-heated liquid-infused superhydrophobic coatings", Langmuir 32, 4278-4288 (2016). 
[85] P. Zhang, H. Chen, L. Zhang, Y. Zhang, D. Zhang, and L. Jiang, "Stable slippery liquid-infused anti-wetting surface at high temperatures", J. Mater. Chem. A 4, 12212-12220 (2016).

[86] B. R. Solomon, K. S. Khalil, and K. K. Varanasi, "Drag reduction using lubricant-impregnated surfaces in viscous laminar flow", Langmuir 30, 10970-10976 (2014).

[87] A. A. Hemeda and H. V. Tafreshi, "Liquid-infused surfaces with trapped air (LISTA) for drag force reduction", Langmuir 32, 2955-2962 (2016).

[88] M. K. Fu, I. Arenas, S. Leonardi, and M. Hultmark, "Liquid-infused surfaces as a passive method of turbulent drag reduction", Journal of Fluid Mechanics 824, 688-700 (2017).

[89] A. Lafuma and D. Quéré, "Slippery pre-suffused surfaces", EPL (Europhysics Letters) 96, 56001 (1-4) (2011).

[90] A. C. Glavan, R. V. Martinez, A. B. Subramaniam, H. J. Yoon, R. M. D. Nunes, H. Lange, M. M. Thuo, and G. M. Whitesides, "Omniphobic "rf paper" produced by silanization of paper with fluoroalkyltrichlorosilanes", Advanced Functional Materials 24, 60-70 (2014).

[91] A. Tuteja, W. Choi, J. M. Mabry, G. H. McKinley, and R. E. Cohen, "Robust omniphobic surfaces", Proceedings of the National Academy of Sciences 105, 18200-18205 (2008).

[92] I. Okada and S. Shiratori, "High-transparency, self-standable gel-slips fabricated by a facile nanoscale phase separation", ACS Appl. Mater. Interfaces 6, 1502-1508 (2014).

[93] W. Ma, Y. Higaki, H. Otsuka, and A. Takahara, "Perfluoropolyetherinfused nano-texture: a versatile approach to omniphobic coatings with low hysteresis and high transparency", Chem. Commun. 49, 597-599 (2013).

[94] B. S. Yilbas, A. Al-Sharafi, and H. Ali, "Chapter 2 - wetting characteristics of surfaces", in Self-Cleaning of Surfaces and Water Droplet Mobility, edited by B. S. Yilbas, A. Al-Sharafi, and H. Ali, 11-44 (Elsevier) (2019).

[95] A. K. Epstein, T.-S. Wong, R. A. Belisle, E. M. Boggs, and J. Aizenberg, "Liquid-infused structured surfaces with exceptional anti-biofouling performance", Proc. Natl. Acad. Sci. U. S. A. 109, 13182-13187 (2012). 
[96] P.-G. de Gennes, F. Brochard-Wyart, and D. Quéré, Capillarity: Deformable Interfaces, 1-31 (Springer New York, New York, NY) (2004).

[97] N. R. Geraldi, J. H. Guan, L. E. Dodd, P. Maiello, B. B. Xu, D. Wood, M. I. Newton, G. G. Wells, and G. McHale, "Double-sided slippery liquid-infused porous materials using conformable mesh", Scientific Reports 9, 13280 (1-8) (2019).

[98] X. Hou, Y. Hu, A. Grinthal, M. Khan, and J. Aizenberg, "Liquid-based gating mechanism with tunable multiphase selectivity and antifouling behaviour", Nature 519, 70-73 (2015).

[99] R. Xiao, N. Miljkovic, R. Enright, and E. N. Wang, "Immersion condensation on oil-infused heterogeneous surfaces for enhanced heat transfer", Scientific reports 3, 1988-1988 (2009).

[100] K. Rykaczewski, S. Anand, S. B. Subramanyam, and K. K. Varanasi, "Mechanism of frost formation on lubricant-impregnated surfaces", Langmuir 29, 5230-5238 (2013).

[101] B. Pokroy, A. K. Epstein, M. C. M. Persson-Gulda, and J. Aizenberg, "Fabrication of bioinspired actuated nanostructures with arbitrary geometry and stiffness", Advanced Materials 21, 463-469 (2009).

[102] R. Sharma, S. S. Das, U. U. Ghosh, S. Dasgupta, and S. Chakraborty, "Pitcher plant inspired biomimetic liquid infused slippery surface using taro leaf.", (2018).

[103] P. Kim, W. E. EAdorno-Martinez, M. Khan, and J. Aizenberg, "Enriching libraries of high-aspect-ratio micro- or nanostructures by rapid, lowcost, benchtop nanofabrication", Nature Protocols 7, 311-327 (2012).

[104] P. Kim, A. K. Epstein, M. Khan, L. D. Zarzar, D. J. Lipomi, G. M. Whitesides, and J. Aizenberg, "Structural transformation by electrodeposition on patterned substrates (steps): A new versatile nanofabrication method", Nano Letters 12, 527-533 (2012).

[105] H. Bazyar, S. Javadpour, and R. G. H. Lammertink, "On the gating mechanism of slippery liquid infused porous membranes", Advanced Materials Interfaces 3, 1600025 (1-6) (2016). 
[106] H. Bazyar, P. Lv, J. A. Wood, S. Porada, D. Lohse, and R. G. H. Lammertink, "Liquid-liquid displacement in slippery liquid-infused membranes (slims)", Soft Matter 14, 1780-1788 (2018).

[107] H. Bazyar, N. van de Beek, and R. G. H. Lammertink, "Liquid-infused membranes with oil-in-water emulsions", Langmuir 35, 9513-9520 (2019).

[108] M. Ulbricht, "Advanced functional polymer membranes", Polymer 47, 2217-2262 (2006).

[109] S. Darvishmanesh, X. Qian, and S. R. Wickramasinghe, "Responsive membranes for advanced separations", Current Opinion in Chemical Engineering 8, 98-104 (2015), nanotechnology • Separation engineering.

[110] X. Hou, "Smart gating multi-scale pore/channel-based membranes", Advanced Materials 28, 7049-7064 (2016).

[111] L.-Y. Chu, pH-Responsive Gating Membrane Systems with Pumping Effects, 169-184 (Springer Berlin Heidelberg, Berlin, Heidelberg) (2011).

[112] L.-Y. Chu, Thermo-Responsive Gating Membranes: Design, Microstructures and Performances, 19-68 (Springer Berlin Heidelberg, Berlin, Heidelberg) (2011).

[113] Z. Zhang, L. Wen, and L. Jiang, "Bioinspired smart asymmetric nanochannel membranes", Chem. Soc. Rev. 47, 322-356 (2018).

[114] X. Hou, Bio-inspired Asymmetric Design and Building of Biomimetic Smart Single Nanochannels., Springer Theses (Springer) (2013).

[115] X. Hou, W. Guo, and L. Jiang, "Biomimetic smart nanopores and nanochannels", Chem. Soc. Rev. 40, 2385-2401 (2011).

[116] Z. S. Siwy and S. Howorka, "Engineered voltage-responsive nanopores", Chem. Soc. Rev. 39, 1115-1132 (2010).

[117] M. Mulder, Transport in Membranes, 145-197 (Springer Netherlands, Dordrecht) (1991).

[118] R. W. Baker, Overview of Membrane Science and Technology, chapter 1, 1-14 (John Wiley \& Sons, Ltd) (2004). 
[119] L.-Y. Chu, Introduction, 1-17 (Springer Berlin Heidelberg, Berlin, Heidelberg) (2011).

[120] B. E. Logan and M. Elimelech, "Membrane-based processes for sustainable power generation using water", Nature 488, 313-319 (2012).

[121] M. A. Shannon, P. W. Bohn, M. Elimelech, J. G. Georgiadis, B. J. Mariñas, and A. M. Mayes, "Science and technology for water purification in the coming decades", Nature 452, 301-310 (2008).

[122] S. K. Sikdar and A. Criscuoli, Sustainability and how membrane technologies in water treatment can be a contributor, 1-21 (Springer Singapore, Singapore) (2017).

[123] Z. Liu, W. Wang, R. Xie, X.-J. Ju, and L.-Y. Chu, "Stimuli-responsive smart gating membranes", Chem. Soc. Rev. 45, 460-475 (2016).

[124] L.-Y. Chu, ed., Smart Membranes, Smart Materials Series (The Royal Society of Chemistry) (2019).

[125] T. Meng, R. Xie, Y.-C. Chen, C.-J. Cheng, P.-F. Li, X.-J. Ju, and L.Y. Chu, "A thermo-responsive affinity membrane with nano-structured pores and grafted poly(n-isopropylacrylamide) surface layer for hydrophobic adsorption", Journal of Membrane Science 349, 258-267 (2010).

[126] D. Menne, F. Pitsch, J. E. Wong, A. Pich, and M. Wessling, "Temperature-modulated water filtration using microgel-functionalized hollow-fiber membranes", Angewandte Chemie International Edition 53, 5706-5710 (2014).

[127] L.-Y. Chu, T. Yamaguchi, and S. Nakao, "A molecular-recognition microcapsule for environmental stimuli-responsive controlled release", Advanced Materials 14, 386-389 (2002).

[128] J. I. Clodt, V. Filiz, S. Rangou, K. Buhr, C. Abetz, D. Höche, J. Hahn, A. Jung, and V. Abetz, "Double stimuli-responsive isoporous membranes via post-modification of ph-sensitive self-assembled diblock copolymer membranes", Advanced Functional Materials 23, 731-738 (2013).

[129] L.-Y. Chu, Y. Li, J.-H. Zhu, and W.-M. Chen, "Negatively thermoresponsive membranes with functional gates driven by zipper-type 
hydrogen-bonding interactions", Angewandte Chemie International Edition 44, 2124-2127 (2005).

[130] M. Yang, L.-Y. Chu, H.-D. Wang, R. Xie, H. Song, and C. H. Niu, "A thermoresponsive membrane for chiral resolution", Advanced Functional Materials 18, 652-663 (2008).

[131] B. Yang and W. Yang, "Thermo-sensitive switching membranes regulated by pore-covering polymer brushes", Journal of Membrane Science 218, $247-255$ (2003).

[132] L. Wang, H. Zhang, Z. Yang, J. Zhou, L. Wen, L. Li, and L. Jiang, "Fabrication of hydrogel-coated single conical nanochannels exhibiting controllable ion rectification characteristics", Phys. Chem. Chem. Phys. 17, 6367-6373 (2015).

[133] L.-Y. Chu, Y. Li, J.-H. Zhu, H.-D. Wang, and Y.-J. Liang, "Control of pore size and permeability of a glucose-responsive gating membrane for insulin delivery", Journal of Controlled Release 97, 43-53 (2004).

[134] J. Ran, L. Wu, Z. Zhang, and T. Xu, "Atom transfer radical polymerization (atrp): A versatile and forceful tool for functional membranes", Progress in Polymer Science 39, 124 - 144 (2014).

[135] J. Deng, L. Wang, L. Liu, and W. Yang, "Developments and new applications of uv-induced surface graft polymerizations", Progress in Polymer Science 34, 156 - 193 (2009).

[136] J. Xue, L. Chen, H. L. Wang, Z. B. Zhang, X. L. Zhu, E. T. Kang, and K. G. Neoh, "Stimuli-responsive multifunctional membranes of controllable morphology from poly(vinylidene fluoride)-graft-poly[2-(n,ndimethylamino)ethyl methacrylate] prepared via atom transfer radical polymerization", Langmuir 24, 14151-14158 (2008).

[137] F. Luo, R. Xie, Z. Liu, X.-J. Ju, W. Wang, S. Lin, and L.-Y. Chu, "Smart gating membranes with in situ self-assembled responsive nanogels as functional gates", Scientific Reports 5, 14708 (1-13) (2015).

[138] M. Nishizawa, V. P. Menon, and C. R. Martin, "Metal nanotubule membranes with electrochemically switchable ion-transport selectivity", Science 268, 700-702 (1995). 
[139] X. Hou, Y. Liu, H. Dong, F. Yang, L. Li, and L. Jiang, "A ph-gating ionic transport nanodevice: Asymmetric chemical modification of single nanochannels", Advanced Materials 22, 2440-2443 (2010).

[140] M. Ali, B. Yameen, R. Neumann, W. Ensinger, W. Knoll, and O. Azzaroni, "Biosensing and supramolecular bioconjugation in single conical polymer nanochannels. facile incorporation of biorecognition elements into nanoconfined geometries", Journal of the American Chemical Society 130, 16351-16357 (2008).

[141] C. Liangyin, X. Rui, and J. Xiaojie, "Stimuli-responsive membranes: Smart tools for controllable mass-transfer and separation processes", Chinese Journal of Chemical Engineering 19, 891-903 (2011).

[142] D. Schmaljohann, "Thermo- and ph-responsive polymers in drug delivery", Advanced Drug Delivery Reviews 58, 1655-1670 (2006), 2006 Supplementary Non-Thematic Collection.

[143] E. G. Kelley, J. N. L. Albert, M. O. Sullivan, and T. H. Epps, III, "Stimuli-responsive copolymer solution and surface assemblies for biomedical applications", Chem. Soc. Rev. 42, 7057-7071 (2013).

[144] G. Pasparakis, T. Manouras, P. Argitis, and M. Vamvakaki, "Photodegradable polymers for biotechnological applications", Macromolecular Rapid Communications 33, 183-198 (2012).

[145] J. Thévenot, H. Oliveira, O. Sandre, and S. Lecommandoux, "Magnetic responsive polymer composite materials", Chem. Soc. Rev. 42, 7099-7116 (2013).

[146] H. Schild, "Poly(N-isopropylacrylamide): experiment, theory and application", Progress in Polymer Science 17, 163-249 (1992).

[147] L.-Y. Chu, T. Niitsuma, T. Yamaguchi, and S.-i. Nakao, "Thermoresponsive transport through porous membranes with grafted pnipam gates", AIChE Journal 49, 896-909 (2003).

[148] R. Xie, Y. Li, and L.-Y. Chu, "Preparation of thermo-responsive gating membranes with controllable response temperature", Journal of Membrane Science 289, 76-85 (2007). 
[149] X.-J. Ju, R. Xie, L. Yang, and L.-Y. Chu, "Biodegradable 'intelligent' materials in response to chemical stimuli for biomedical applications", Expert Opinion on Therapeutic Patents 19, 683-696 (2009).

[150] J.-B. Qu, L.-Y. Chu, M. Yang, R. Xie, L. Hu, and W.-M. Chen, "A phresponsive gating membrane system with pumping effects for improved controlled release", Advanced Functional Materials 16, 1865-1872 (2006).

[151] T. Luo, S. Lin, R. Xie, X.-J. Ju, Z. Liu, W. Wang, C.-L. Mou, C. Zhao, Q. Chen, and L.-Y. Chu, "ph-responsive poly(ether sulfone) composite membranes blended with amphiphilic polystyrene-block-poly(acrylic acid) copolymers", Journal of Membrane Science 450, 162-173 (2014).

[152] P. S. Laplace, Traité de mécanique céleste, tome quatriéme (Treatise on Celestial Mechanics, tome 4), Supplément au livre $X$ du Traité de mécanique céleste. Sur l'action capillaire (Supplement to Book 10 of the Treatise on Celestial Mechanics. On the capillary action), P. 349-41\%. (Courcier, Paris, France) (1805).

[153] J. C. Berg, Fluid interfaces AND capillarity, chapter 2, 23-106 (2009).

[154] T. Young, "An essay on the cohesion of fluids", Philosophical Transactions of the Royal Society of London 95, 65-87 (1805).

[155] Z. Liu, F. Luo, X.-J. Ju, R. Xie, Y.-M. Sun, W. Wang, and L.-Y. Chu, "Gating membranes for water treatment: detection and removal of trace pb2+ ions based on molecular recognition and polymer phase transition", J. Mater. Chem. A 1, 9659-9671 (2013).

[156] S. R. Lewis, S. Datta, M. Gui, E. L. Coker, F. E. Huggins, S. Daunert, L. Bachas, and D. Bhattacharyya, "Reactive nanostructured membranes for water purification", Proceedings of the National Academy of Sciences 108, 8577-8582 (2011).

[157] W. Sun, J. Liu, H. Chu, and B. Dong, "Pretreatment and membrane hydrophilic modification to reduce membrane fouling", Membranes 3, 226-241 (2013).

[158] S. J. Zaidi, K. A. Mauritz, and M. K. Hassan, Membrane Surface Modification and Functionalization, 1-26 (Springer International Publishing, Cham) (2018). 
[159] M. M. Pendergast and E. M. Hoek, "A review of water treatment membrane nanotechnologies", Energy Environ. Sci. 4, 1946-1971 (2011).

[160] B. D. McCloskey, H. B. Park, H. Ju, B. W. Rowe, D. J. Miller, and B. D. Freeman, "A bioinspired fouling-resistant surface modification for water purification membranes", Journal of Membrane Science 413-414, 82-90 (2012).

[161] Y. Zhu, W. Xie, J. Li, T. Xing, and J. Jin, "ph-induced non-fouling membrane for effective separation of oil-in-water emulsion", Journal of Membrane Science 477, 131-138 (2015).

[162] W. Zhang, N. Liu, Y. Cao, Y. Chen, L. Xu, X. Lin, and L. Feng, “A solvothermal route decorated on different substrates: Controllable separation of an oil/water mixture to a stabilized nanoscale emulsion", Advanced Materials 27, 7349-7355 (2015).

[163] X. Gao, L.-P. Xu, Z. Xue, L. Feng, J. Peng, Y. Wen, S. Wang, and $\mathrm{X}$. Zhang, "Dual-scaled porous nitrocellulose membranes with underwater superoleophobicity for highly efficient oil/water separation", Advanced Materials 26, 1771-1775 (2014).

[164] L. Zhang, Z. Zhang, and P. Wang, "Smart surfaces with switchable superoleophilicity and superoleophobicity in aqueous media: toward controllable oil/water separation", NPG Asia Materials 4, e8 (1-8) (2012).

[165] Y. Wang, J. Di, L. Wang, X. Li, N. Wang, B. Wang, Y. Tian, L. Jiang, and J. Yu, "Infused-liquid-switchable porous nanofibrous membranes for multiphase liquid separation", Nature Communications 8, 575 (1-7) (2017).

[166] J. C. Overton, A. Weigang, and C. Howell, "Passive flux recovery in protein-fouled liquid-gated membranes", Journal of Membrane Science 539, 257-262 (2017). 



\section{2 \\ On the gating mechanism of slippery liquid-infused porous membranes ${ }^{\circ}$}

In this chapter the gating mechanism of liquid-infused polyvinylidene fluoride (PVDF) membranes is investigated via gas-liquid porometry measurements using different infusion liquids. Liquid-infused porous surfaces owe some remarkable properties such as low fouling characteristics to the presence of a surface covering liquid film. We aim to explore the presence of such liquid films inside the membrane, at the pore surface. The liquid film thickness lining the pores is experimentally obtained and predicted using annular two phase flow models. The film thickness trend as a function of transmembrane pressure gradient for all liquidinfused membranes is well predicted with such models. The pore closing (gating) was studied for different re-infusion times, illustrating the repeated ability of the infusion liquid to seal the pores.

${ }^{\circ}$ Published as: Hanieh Bazyar, Sirus Javadpour, and Rob G. H. Lammertink, On the gating mechanism of slippery liquid infused porous membranes, Advanced Materials Interfaces 2016, 3, 1600025 . 



\subsection{Introduction}

URFACES with remarkable non-wetting properties that repel various liquids can be achieved by the presence of gas or liquid trapped pockets

[1, 2]. These surfaces have broad technological implications for areas ranging from biomedical devices and fuel transport to architecture [3. In a recent study, the function and application of gas and liquid-infused bioinspired materials has been investigated 4. The diminished contact of liquid-repellent microstructured surfaces relies on the formation of a stable air-liquid interface 2, 5, 6. Since maintaining stable air pockets is challenging, liquid-infused surfaces stabilized by capillary forces, have attracted a lot of attention. Different outstanding properties of slippery liquid-infused porous surfaces (SLIPS) include low contact angle hysteresis, self-cleaning, high drop impact stability, self-healing by capillary wicking, repelling a variety of liquids, reduced ice accretion, and anti-biofouling performance have been studied $7-11$. In addition to the mentioned properties, the stability of liquid-infused surfaces under shear conditions was found to be important for maintaining nonwetting properties [12, 13. The capillary-stabilized liquid in the micro- or nanometer-sized pores lead to a reversible, reconfigurable gate which can coordinate multiphase transport in a selective fashion without clogging. Liquid lining further ensures antifouling behavior for these kinds of surfaces [14. Hou et al. showed that the gating liquid fills and seals pores in the closed state and creates a nonfouling liquid-lined pore in the open state. This results in efficient gas-liquid sorting demonstrated for three phase air-water-oil mixtures. The experiments show that the liquid gating strategy can be applied to a variety of pore structures and membrane materials.

In the present chapter we aim to explore the liquid-lined pores gating mechanism via gas-liquid porometry and contact angle measurements on liquidinfused polyvinylidene fluoride (PVDF) membranes. The remaining liquid film thickness on the pore wall is estimated experimentally from gas flow measurements and compared with predicted values using annular two phase flow models. The dynamics of the liquid re-infusion after opening are also investigated.

\subsection{Experimental details}




\subsubsection{Materials}

PVDF (Solef 6020/1001) was received from Solvay Solexis, France. 1-methyl2-pyrrolidinone (NMP) (99\% extra pure) was purchased from Acros Organics, The Netherlands. Ethanol (99.8\%) was supplied from Atlas and Assink chemical company, The Netherlands. Krytox GPL oil 101 was purchased from MAVOM chemical industry, The Netherlands. Krytox 157 FSH was supplied from IKV Tribologie, France. Fluorinert FC-43 was supplied from BASF chemical company, Germany. Galpore was delivered with capillary flow porometer, Porolux-1000, Belgium. Silicone oil AR20 was purchased from Sigma-Aldrich, The Netherlands.

\subsubsection{Fabrication of porous PVDF membranes}

Dope solution was prepared by mixing PVDF (15 wt.\%) in NMP with a mechanical stirrer overnight at $80^{\circ} \mathrm{C}$. The dope solution was cast on a glass plate using a casting knife at an initial thickness of $500 \mu \mathrm{m}$. The cast membrane was immediately submerged in water/NMP (30:70 vol.\%) as the coagulation bath for $60 \mathrm{~min}$. To remove the remaining NMP from the membranes, they were kept in ethanol subsequently for another $60 \mathrm{~min}$. The films were then taped to a piece of paper to prevent curling and left to dry in fume hood (1 h) before placing them in a $30^{\circ} \mathrm{C}$ vacuum oven overnight.

\subsubsection{Fabrication of the SLIPS}

An overcoat layer $\left(15.5 \mu \mathrm{l} \mathrm{cm}^{-2}\right)$ of the low surface tension liquid was added to the membranes using a micropipette. The liquid spontaneously infiltrated the pores via capillary wicking. The samples were further placed vertical for gravity-induced removal of the excess liquid.

\subsubsection{Characterization of the membranes}

Water contact angle measurements on liquid-infused and dry PVDF membranes were performed on a contact angle Goniometer (Dataphysics OCA 20). The static contact angle on surfaces was measured by using drops having a volume of $2 \mu \mathrm{l}$. Advancing and receding contact angles were determined by placing the needle in the drop (sessile drop needle-in mode) and continuously supplying or withdrawing water up to $6 \mu \mathrm{l}$ at $0.5 \mu \mathrm{l} \mathrm{min}{ }^{-1}$ within six cycles. The delay time between each advancing and receding measurement was set to be $2 \mathrm{~s}$. 
The morphology of the fabricated PVDF membrane was characterized by SEM (JEOL $5600 \mathrm{LV}$ ). An acceleration voltage of $5 \mathrm{kV}$ was used. Prior to the imaging, the polymeric membranes were coated with a thin layer of platinum to avoid charging of the samples using a sputter coating machine (JEOL JFC1300).

A capillary flow porometer (Porolux-1000) was used for measuring the pore size distribution and observation of the liquid-lined pores and gating mechanism of the liquid-infused samples by using $\mathrm{N}_{2}$ gas.

Gas pycnometer (AccuPyc II 1340 Pycnometer) was used for measuring the porosity of the fabricated PVDF membrane.

\subsubsection{Impregnation experiments}

For doing impregnation experiments, a $1 \times 2 \mathrm{~cm}^{2}$ strip of the membrane was cut and kept vertical in a beaker containing very thin liquid layer $(400 \mu \mathrm{l})$. The imbibition distance of the liquid was observed and recorded as a function of time.

\subsection{Results and discussion}

\subsubsection{Membrane characterization results}

The results of the pore size and porosity measurements obtained, respectively, from the porometer and the gas pycnometer for PVDF membrane are shown in Table 2.1. The water contact angle measurements of PVDF membrane and different liquid-infused membranes are presented in Table 2.2. Liquid-infused membranes were obtained with different infusion liquids, namely, fluorinert FC-43 and Galpore (as the most commonly used wetting fluorocarbon liquids for the porometer), Krytox GPL oil 101, Krytox 157 FSH, and silicone oil AR20 (SO AR20). The physical properties of these liquids, extracted from the data sheet provided by the manufacturers, are shown in Table A.1 in the Appendix A.

Figure 2.1 shows the cross sectional scanning electron microscopy (SEM) image of the PVDF membrane and a water drop on the surface of the dry and liquid-infused membrane. All the infusion liquids spontaneously wicked in to the porous PVDF membrane.

The contact angle measurements show a low contact angle hysteresis $(\mathrm{CAH})$ for PVDF membranes infused with Krytox GPL oil 101, FC-43, Galpore, and SO AR20 indicating slippery surfaces [7, 15]. It is worth mentioning that due 


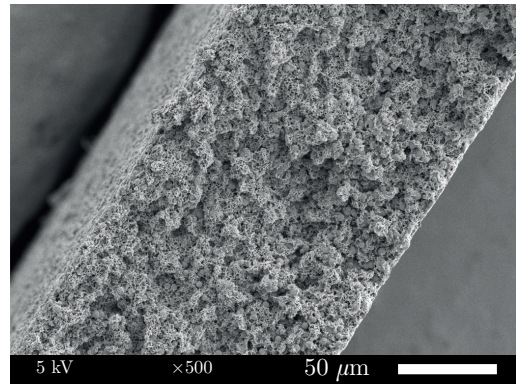

(a)

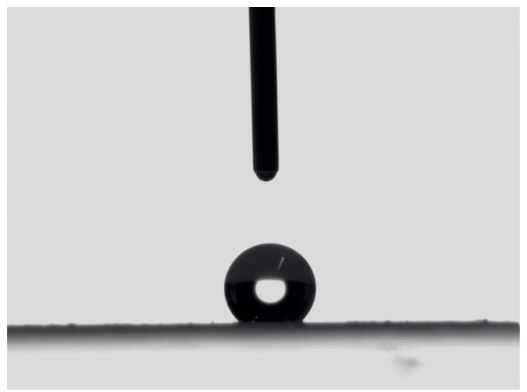

(b)

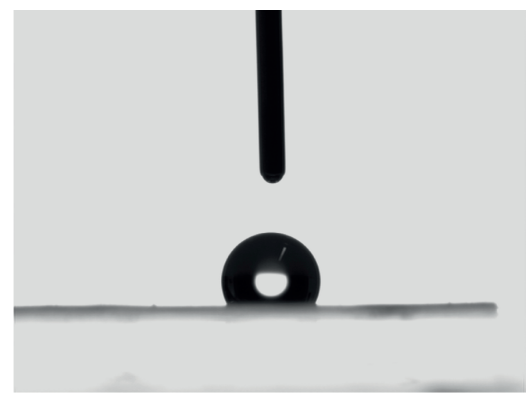

(c)

Figure 2.1: (a) The cross sectional SEM image of the fabricated PVDF membrane. The $2 \mu \mathrm{l}$ water drop on the surface of (b) dry membrane, (c) liquid infiltrated membrane. 
Table 2.1: Porometry and porosity results of the PVDF membrane.

\begin{tabular}{lcccccc}
\hline & Smallest & Mean & Bubble & $95 \%$ of & Approxi- & \\
Membrane & pore & flow pore & point pore & pore \\
& radius & radius & radius & radius & radius \\
{$[\mu \mathrm{m}]$} & {$[\mu \mathrm{m}]$} & {$[\mu \mathrm{m}]$} & {$[\mu \mathrm{m}]$} & {$[\mu \mathrm{m}]$} & $\begin{array}{c}\text { Porosity } \\
{[\%]}\end{array}$ \\
\hline PVDF & 0.8 & 1.04 & 1.07 & 0.85 & 1 & 60 \\
\hline
\end{tabular}

Table 2.2: Water contact angle (CA) measurements on infused membranes.

\begin{tabular}{lcccc}
\hline Infusion liquid & $\begin{array}{c}\text { Advancing CA } \\
\left(\theta_{\text {adv }}\right)\left[^{\circ}\right]\end{array}$ & $\begin{array}{c}\text { Receding CA } \\
\left(\theta_{\text {rec }}\right)\left[^{\circ}\right]\end{array}$ & $\begin{array}{c}\text { Hysteresis } \\
\left.{ }^{\circ}\right]\end{array}$ & $\begin{array}{c}\text { Mean static } \\
\text { CA }\left[^{\circ}\right]\end{array}$ \\
\hline None & $142 \pm 0.3$ & $117 \pm 1.2$ & $25 \pm 1$ & $136 \pm 0.3$ \\
Krytox 101 & $119 \pm 0.1$ & $114 \pm 0.3$ & $5.1 \pm 0.3$ & $117 \pm 0.1$ \\
Krytox 157 & $68 \pm 1.2$ & $46 \pm 1.1$ & $22 \pm 1.7$ & $67 \pm 0.4$ \\
FC-43 & $118 \pm 0$ & $113 \pm 0.3$ & $4.7 \pm 0.3$ & $116 \pm 0.3$ \\
Galpore & $120 \pm 0.2$ & $114 \pm 0.5$ & $6.2 \pm 0.7$ & $117 \pm 0.5$ \\
SO AR20 & $94.2 \pm 0.1$ & $90 \pm 0.2$ & $4.1 \pm 0.2$ & $93 \pm 0.3$ \\
\hline
\end{tabular}

to the presence of carboxylic acid groups $(\mathrm{COOH})$ in Krytox $157 \mathrm{FSH}$, the infused-membrane was somewhat hydrophilic (contact angle values are lower than $90^{\circ}$ ) with high CAH. In contrast, FC-43, Galpore, Krytox GPL oil 101, and SO AR20 infused-membranes present high contact angles combined with very low $\mathrm{CAH}\left(\approx 5^{\circ}\right)$.

\subsubsection{Observation of the liquid lining}

The results of the gas-liquid porometry measurements of Krytox 101 and FC43 infused-membranes are shown in Figure 2.2(a). One can divide the curve in to three sections:

Section I: up to the first bubble point (FBP) pressure when the biggest pores open.

Section II: between FBP and the pressure at which the curves obtained from the first and second run meet (correspond to the smallest pores). More pores increasingly open.

Section III: where the first and second run completely meet. All pores are open.

A remarkable higher gas flow rate for FC-43-infused membrane compared to that of Krytox 101-infused one in section III is noticeable (Figure 2.2(a)). The same behavior was observed for other liquid-infused membranes with approximately the same values of the surface tension (see Table A.1 and Figure 


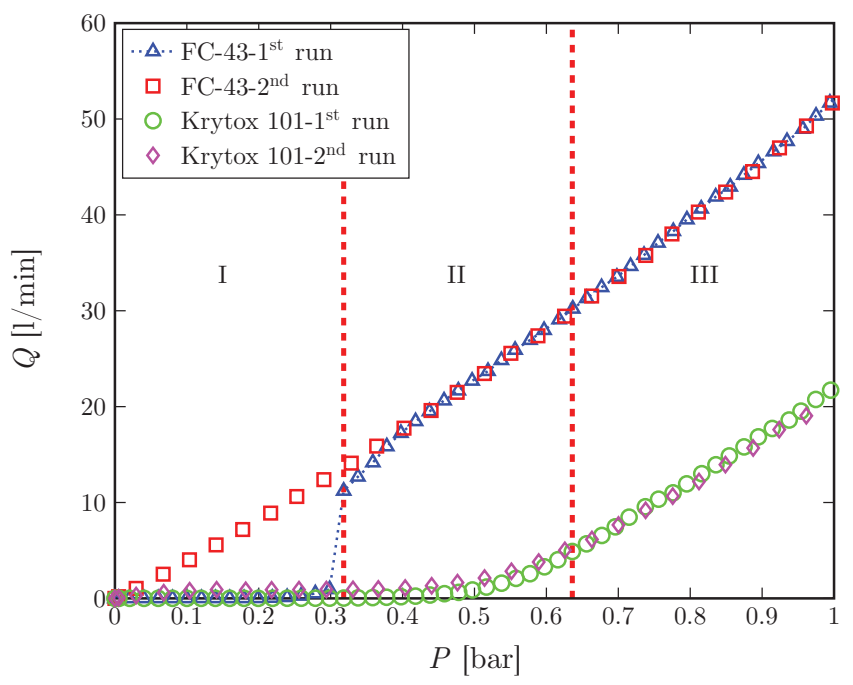

(a)

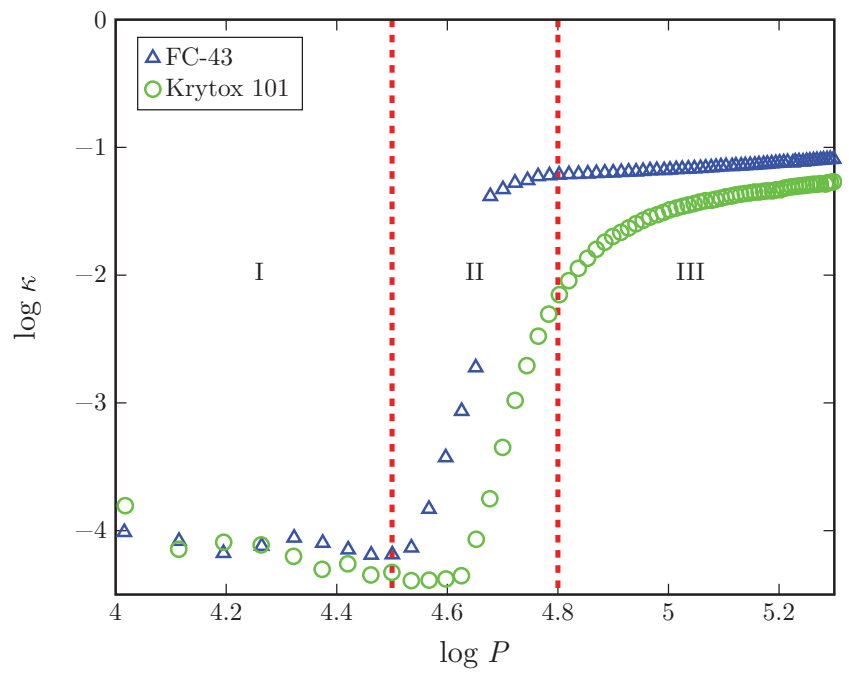

(b)

Figure 2.2: (a) Comparison of the porometry results of FC-43 and Krytox 101infused PVDF membranes.(b) The logarithmic plot of permeability as a function of pressure for Krytox 101 and FC-43-infused membranes. 
A.2 in Appendix A). This shows that the surface tension of the infusion liquid does not account for the observed difference and other physical property of the liquids, namely, viscosity is of significant importance. The effect of the liquid viscosity on the impregnation process and re-infusion of the pores will be discussed later. The difference indicates the presence of the liquid-lined pores for Krytox 101, SO AR 20, Krytox 157 FSH, and Galpore-infused membranes. The liquid lining effectively reduces the pore radius.

The permeability of the mentioned liquid-infused membranes was calculated according to Darcy's law 16

$$
Q=-\frac{\kappa A}{\mu} \frac{d p}{d x},
$$

where $Q\left(\mathrm{~m}^{3} / \mathrm{s}\right)$ is the volumetric flow of the permeating fluid (in this case $\mathrm{N}_{2}$ gas), $\kappa\left(\mathrm{m}^{2}\right)$ is the permeability, $A\left(\mathrm{~m}^{2}\right)$ is the total cross sectional area of the sample, $\mu$ ( $\mathrm{Pa} \mathrm{s})$ is the dynamic viscosity of the transport fluid, and $d p / d x$ is the pressure gradient across the membrane thickness $(\mathrm{Pa} / \mathrm{m})$.

In Figure 2.2(b) permeability as a function of pressure is represented for FC-43 and Krytox 101-infused membranes. The permeability of the FC-43infused membrane reaches a constant value in section III which indicates the complete removal of this liquid from the membrane. However, the permeability of the Krytox 101-infused membrane is still gradually increasing with increasing pressure and eventually saturates at pressure higher than 2 bar. The lower permeability of this membrane as well as that of SO AR20, Krytox 157 FSH, and Galpore-infused membranes compared to the FC-43-infused one, is expected to be caused by the presence of liquid-lined pores. It is worth mentioning that the indicated sections II and III in Figure 2.2(b) belong to Krytox 101 and are liquid specific. The narrower section II for FC-43-infused membrane can be understood by the absence of liquid lining compared to the Krytox 101-infused membrane.

Where Darcy's law (Equation 2.1) predicts a linear relation between pressure and flow, we obtained a much stronger relation, expressed as the exponent of pressure with respect to flow $\left(\Delta P^{\mathrm{n}} \approx Q\right.$ ) (Table 2.3).

It is already known that when the balance between air flow and pressure becomes linear, all pores have been opened [17. This behavior was observed for FC-43 infiltrated membranes. The quadratic relationship between flow and pressure for other infused samples, illustrates the variation of the pore radius with pressure. Hence, an effective pore radius and consequently a liquid film thickness can be obtained experimentally as a function of pressure. Such liquid 
Table 2.3: The exponent values of pressure with respect to the flow $\left(\Delta P^{\mathrm{n}} \approx Q\right)$.

\begin{tabular}{lr}
\hline Infusion liquid & Exponent of pressure \\
\hline Krytox 101 & 2.21 \\
SO AR20 & 2.38 \\
Krytox 157 & 2.02 \\
Galpore & 1.68 \\
FC-43 & 1.23 \\
\hline
\end{tabular}

lined pores were not observed for FC-43-infused membranes, possibly due to the higher volatility.

\subsubsection{Liquid film thickness}

\subsubsection{Experimental measurement}

Since the membrane is completely emptied at section III for FC-43 infiltrated membrane, the pore radius in this case can be considered as the intrinsic pore radius of the membrane. Hagen-Poiseuille law 18, 19

$$
Q=\frac{\pi r^{4}}{8 \mu} \frac{d p}{d x}
$$

can be used to determine the experimental liquid film thickness on the pore wall using

$$
\frac{Q_{\text {lined }}}{Q_{0}}=\left(\frac{r_{\mathrm{i}}}{r_{0}}\right)^{4},
$$

where $\mu(\mathrm{Pa} \mathrm{s})$ is the dynamic viscosity of the permeating fluid (in this case $\mathrm{N}_{2}$ gas), $Q\left(\mathrm{~m}^{3} / \mathrm{s}\right)$ is the volumetric flow of the gas at the outlet, $d p / d x(\mathrm{~Pa} / \mathrm{m})$ is the pressure gradient across the membrane, and $r_{\mathrm{i}}$ and $r_{0}(\mathrm{~m})$ are the effective (liquid-lined pore) and initial (empty) pore radius, respectively. $Q_{\text {lined }}$ and $Q_{0}$ $\left(\mathrm{m}^{3} \mathrm{~s}^{-1}\right)$ correspond to the gas flow rate through the liquid-lined and empty pore, respectively. In section III the sealed pores have been already opened and as it will be shown later, the interfacial liquid velocity is negligible compared to the average gas velocity. Consequently, the measured flow rate is that of the $\mathrm{N}_{2}$ gas and its viscosity has to be considered. We consider the pores as uniform cylinders with an initial pore radius of $1 \mu \mathrm{m}$. (see Table 2.1).

The remarkable higher gas flow rates through FC-43-infused membranes compared to that of other liquid-infused membranes can be attributed to the high volatility of this liquid. The vapor pressure of FC- 43 at $20^{\circ} \mathrm{C}$ is $137.72 \mathrm{~Pa}$, 
whereas that of Galpore is only 3.33 Pa. SO AR20 also has a non-significant vapor pressure at room temperature. Consequently, in the time scale of the experiments, Krytox 101 and SO AR 20 can be considered to be nonvolatile.

\subsubsection{Theoretical calculation}

Apparently, the liquid film on the pore surface is a function of the gas flow. We now discuss several models that predict the relation between these two parameters. The liquid film thickness was calculated based on annular two phase flow models. Three models were used, including the modified Chisholm [20-22], Turner-Walis [23 26] and Fourar-Lenormand [27.

The first two models are derived based on the original Lockhart-Martinelli method for two phase flows in pipes [28] and the third model is derived for two phase flow through porous media. The calculations from here after are done for one pore (see Appendix A section "Theoretical calculation of liquid film thickness" for full explanation of the models).

The final expression to obtain the liquid film thickness is

$$
\delta^{2}=\frac{2 G(1-x) r_{0} \mu_{\mathrm{L}}}{2 \rho_{\mathrm{L}} \tau_{\mathrm{i}}},
$$

where $G\left(\mathrm{~kg} / \mathrm{m}^{2} \mathrm{~s}\right)$ is the total mass flux, $x$ is the flow quality which is defined as the ratio between gas mass flow rate and the total mass flow rate (Equations A.9 and A.10 in Appendix A), $r_{0}(\mathrm{~m})$ is the pore radius, $\mu_{\mathrm{L}}(\mathrm{Pa} \mathrm{s})$ and $\rho_{\mathrm{L}}$ $\left(\mathrm{kg} / \mathrm{m}^{3}\right)$ are the viscosity and density of the liquid respectively. $\tau_{\mathrm{i}}(\mathrm{Pa})$ is the interfacial shear stress calculated as

$$
\tau_{\mathrm{i}}=\left(\frac{d p}{d z}\right)_{\mathrm{g}} \phi_{\mathrm{G}}^{2} \frac{r_{0}}{2}=\frac{\Delta P_{\mathrm{G}}}{L} \phi_{\mathrm{G}}^{2} \frac{r_{0}}{2},
$$

where $\Delta P_{\mathrm{G}}(\mathrm{Pa})$ is the pressure drop in the gas phase and can be calculated by considering gas compressibility and $\phi_{\mathrm{G}}$ is the two phase flow multiplier in the gas phase which can be calculated according to the different models as follows.

The models can be categorized based on the original Lockhart-Martinelli model for annular two phase flow 28] and $\phi_{\mathrm{G}}$ can be calculated subsequently.

The modified Chisholm model [20 22 ] leads to the following equation for $\phi_{\mathrm{G}}$

$$
\phi_{\mathrm{G}}^{2}=1+C X+X^{2},
$$


where $X$ is the Martinelli parameter and $C$ is a constant which are defined based on the corresponding expressions (see Appendix A section "Modified Chisholm model").

The modified Turner-Wallis model can be used for two phase flow through porous media [23 26]. The corresponding two phase flow multiplier in the gas phase is

$$
\phi_{\mathrm{G}}^{2}=\left[1+\left(X^{2}\right)^{q}\right]^{\frac{1}{q}},
$$

where $q$ is 0.5 for microchannels, minichannels, and capillaries [25] (see section "Modified Turner-Wallis model").

The Fourar-Lenormand model is based on the relative permeability and the two phase flow multiplier. A new approach for calculation of $\phi_{\mathrm{G}}$ was employed [27] leading to

$$
\phi_{\mathrm{G}}=\sqrt{F_{\mathrm{G}}},
$$

where $F_{\mathrm{G}}$ can be calculated according to the relative permeability of the gas phase (see Equations A.18 and A.19 in Appendix A).

By calculation of all required parameters in Equations 2.4 and 2.5 based on the mentioned models, the liquid film thickness was calculated using the experimental obtained value for $r_{0}$.

In Figure 2.3. the experimental and predicted values of the liquid film thickness for Krytox 101 and Galpore-infused membranes are shown as a function of pressure. The film thickness trend is well predicted by the models for all liquid-infused membranes. In Table A.4 in Appendix A, the standard deviation of the predicted to the experimental values of the liquid film thickness and the mean relative error in calculation of the film thickness is presented. Models that are used for two phase flow through porous media, namely, modified Turner-Wallis and Fourar-Lenormand models show good agreement with the experimental values. Additionally, the modified Chisholm model includes the effect of surface tension and gap size, which is of significant importance in micro- or minichannels [21, 22].

In some cases over or under estimation is observed. In the proposed models, pores are considered as uniform cylindrical tubes. Pore size distribution and especially larger pores have some effect on our estimation. Prediction of the remaining liquid film thickness by the mentioned models is done by considering smooth and flat interface between gas and liquid phase. In this case, the pressure drops in both liquid and gas phase are the same and when the flow quality is close to unity, the interface shear stress becomes very close to the 


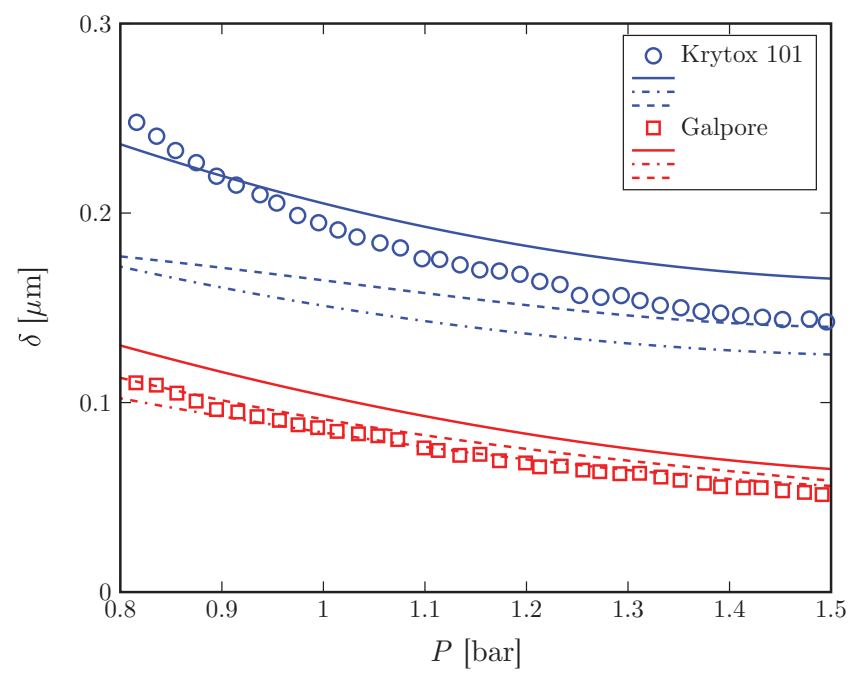

Figure 2.3: Comparison between the experimental and predicted values of the liquid film thickness on the pore wall for Krytox 101 and Galpore-infused membranes (solid, dashed-dotted, and dashed lines, respectively, correspond to modified Chisholm, Turner-Wallis, and Fourar-Lenormand models).

value of the wall shear stress. This will subsequently predict smaller values for liquid film thickness [29].

These models predict approximately a linear variation of film thickness with pressure for all liquid-infused membranes. Because in all cases the flow quality, $x$, is close to unity and the liquid velocity is very low (see Table A.3 in Appendix A). As a result, the liquid film thickness is almost stationary. This is in agreement with two phase flow analysis through a microtube [29].

By comparing the results of the gas-liquid porometry measurements with those of the contact angle measurements, it can be concluded that FC-43infused membrane with initially slippery behavior (see Table 2.2), did not show pore liquid lining due to the complete removal of the liquid at high pressures. Liquid lining on the pore wall was observed for slippery Galpore, SO AR 20, and Krytox 101-infused membranes. Krytox 157-infused membranes with no slippery behavior did show liquid lining. Consequently, slipperiness is not required for the gating mechanism of the liquid-infused membranes and vice versa. Physical properties of the liquid, namely, vapor pressure and viscosity are also crucial, besides the low liquid-solid interfacial energy. 
Table 2.4: Re-infusion time, surface tension, and viscosity for different infusion liquids.

\begin{tabular}{lccc}
\hline Infusion liquid & $\begin{array}{c}\text { Re-infusion time } \\
{[\mathrm{min}]}\end{array}$ & $\begin{array}{c}\text { Surface tension } \\
{[\mathrm{mN} / \mathrm{m}]}\end{array}$ & $\begin{array}{c}\text { Viscosity at } 20^{\circ} \mathrm{C} \\
{[\mathrm{mPa} \mathrm{s}]}\end{array}$ \\
\hline Krytox 101 & 15 & 17 & 17.4 \\
SO AR20 & 5 & 20.6 & 20 \\
Krytox 157 & 12.5 & 17 & 800 \\
Galpore & 30 & 15.9 & 4.4 \\
\hline
\end{tabular}

\subsubsection{Dynamics of liquid re-infusion}

Before discussing the re-infusion mechanism, liquid impregnation into dried membranes was studied first. For this, liquid impregnation was determined as a function of time, and compared to Washburn's law 30.

$$
z^{2}(t)=\frac{1}{2} \frac{\gamma R \cos \theta_{\mathrm{E}}}{\mu} t
$$

where $z(\mathrm{~m})$ is the imbibing distance of the liquid in porous medium, $\gamma(\mathrm{N} / \mathrm{m})$ and $\mu(\mathrm{Pa} \mathrm{s})$ are the surface tension and viscosity of the infusion liquid, respectively, $\theta_{\mathrm{E}}$ is the equilibrium contact angle, $R(\mathrm{~m})$ characteristic radius of the porous medium, and $t(\mathrm{~s})$ is time of liquid impregnation to the porous medium. According to the experimental findings, the imbibition distance of all liquids follows the expected square root dependency with time. The values of the proportional coefficient for all liquids and the values obtained based on Washburn's law are shown in Table A.2 in Appendix A.

After observation of the liquid-lined pores for the infused PVDF membranes, gas-liquid porometry measurements were done successively on all liquid-infused membranes in order to further elucidate the re-infusion dynamics. Experiments with different time intervals between pressure sweeps were performed on liquid-infused membranes to find the re-infusion time. A comparison between section I and section II for $5 \mathrm{~min}$ and $15 \mathrm{~min}$ re-infusion times for Krytox 101-infused membrane is shown in Figure 2.4. A higher gas flow rate after 5 min re-infusion time compared to that of the first experiment and $15 \mathrm{~min}$ re-infusion time is evident. Apparently, $5 \mathrm{~min}$ re-infusion time is not enough for complete restoration of the sealed pores. The results for the other liquid-infused membranes are shown in Table 2.4 .

The re-infusion time for the liquid-lined pores to reseal the pores after opening, mostly depends on the liquid film thickness on the pore wall and, unlike the impregnation rate, it is less affected by the viscosity of the liquid. SO 


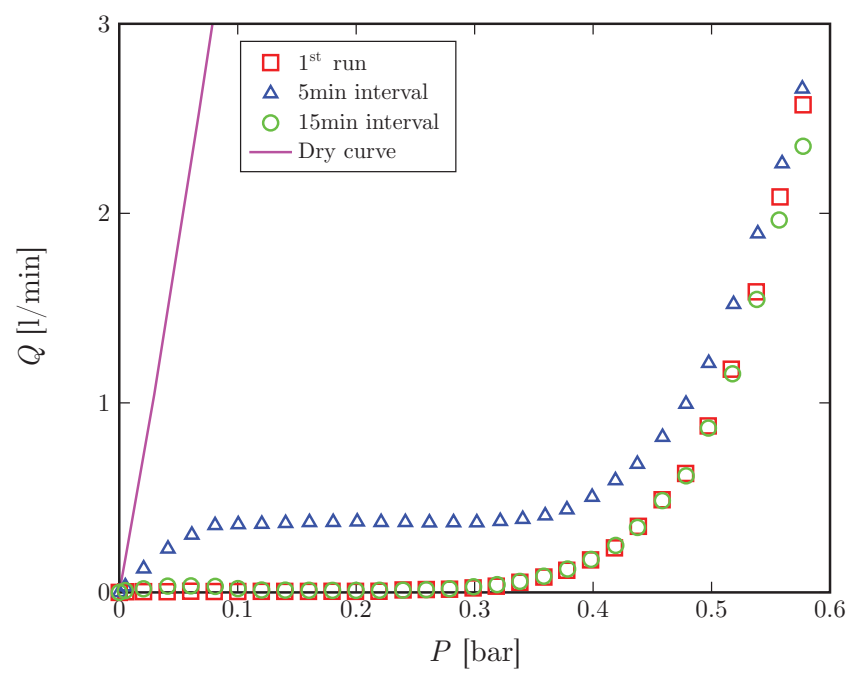

Figure 2.4: Comparison between the successive measurements on the same Krytox 101-infused membrane with different re-infusion times.

AR20 and Krytox 157 FSH show smaller re-infusion times although they have a higher viscosity compared to the other liquids. The reason is the thicker liquid film thickness on the pore wall (see Figure A.2 in Appendix A). Galpore, with a relatively small viscosity value shows the highest re-infusion time because of the small liquid film thickness lining the pores.

\subsection{Conclusion}

The gating mechanism of liquid-infused PVDF membranes and the ability of the remaining liquid film to seal the pores was investigated via gas-liquid porometry measurements by using different infusion liquids. The results accompanied with the contact angle measurements showed that the slipperiness is not necessarily indicative for the gating to be observed. Other factors such as liquid physical properties and low liquid-solid interfacial energy play important roles as well. The liquid film thickness lining the pore was predicted using annular two phase flow models. The film thickness trend as a function of pressure for all liquid-infused membranes was well predicted with the models. The effect of time was also studied by doing successive gas-liquid porometry measurements with different time intervals, i.e., re-infusion time. The results showed the quick restoration of the sealed pores after opening via re-flow of 
the remaining liquid. Consequently, repeated ability of the infusion liquid to seal the pores depends on the re-infusion time which is a function of liquid film thickness on the pore wall.

This novel type of membrane with adaptive pores provides separation of different types of emulsions by simply adjusting the system pressure which is interesting in petroleum industry. Additionally, anti-fouling behavior of this type of membranes, due to the presence of a surface that possesses dynamic features down to the nanometer scale, is of great importance in membrane separation technology.

\section{References}

[1] A. Lafuma and D. Quéré, "Superhydrophobic states", Nature Materials 2, 457-460 (2003).

[2] D. Quéré, "Non-sticking drops", Reports on Progress in Physics 68, 2495-2532 (2005).

[3] D. Quéré, "Wetting and roughness", Annual Review of Materials Research 38, 71-99 (2008).

[4] M. Cao, D. Guo, C. Yu, K. Li, M. Liu, and L. Jiang, "Water-repellent properties of superhydrophobic and lubricant-infused "slippery" surfaces: A brief study on the functions and applications", ACS Applied Materials \& Interfaces 8, 3615-3623 (2016).

[5] A. Tuteja, W. Choi, M. Ma, J. M. Mabry, S. A. Mazzella, G. C. Rutledge, G. H. McKinley, and R. E. Cohen, "Designing superoleophobic surfaces", Science 318, 1618-1622 (2007).

[6] A. Tuteja, W. Choi, J. M. Mabry, G. H. McKinley, and R. E. Cohen, "Robust omniphobic surfaces", Proceedings of the National Academy of Sciences 105, 18200-18205 (2008).

[7] T.-S. Wong, S. H. Kang, S. K. Tang, E. J. Smythe, B. D. Hatton, A. Grinthal, and J. Aizenberg, "Bioinspired self-repairing slippery surfaces with pressure-stable omniphobicity", Nature 477, 443-447 (2011).

[8] P. Kim, T.-S. Wong, J. Alvarenga, M. J. Kreder, W. E. Adorno-Martinez, and J. Aizenberg, "Liquid-infused nanostructured surfaces with extreme anti-ice and anti-frost performance", ACS Nano 6, 6569-6577 (2012). 
[9] J. D. Smith, R. Dhiman, and K. Varanasi, "Liquid-encapsulating surfaces: overcoming the limitations of superhydrophobic surfaces for robust non-wetting and anti-icing surfaces", in APS Division of Fluid Dynamics Meeting Abstracts, volume 64 of APS Meeting Abstracts, S4.001 (2011).

[10] A. K. Epstein, T.-S. Wong, R. A. Belisle, E. M. Boggs, and J. Aizenberg, "Liquid-infused structured surfaces with exceptional anti-biofouling performance", Proc. Natl. Acad. Sci. U. S. A. 109, 13182-13187 (2012).

[11] S. Ozbay, C. Yuceel, and H. Y. Erbil, "Improved icephobic properties on surfaces with a hydrophilic lubricating liquid", ACS Applied Materials \& Interfaces 7, 22067-22077 (2015).

[12] P. Kim, M. J. Kreder, J. Alvarenga, and J. Aizenberg, "Hierarchical or not? effect of the length scale and hierarchy of the surface roughness on omniphobicity of lubricant-infused substrates", Nano Letters 13, 1793-1799 (2013).

[13] J. S. Wexler, I. Jacobi, and H. A. Stone, "Shear-driven failure of liquidinfused surfaces", Phys. Rev. Lett. 114, 168301 (2015).

[14] X. Hou, Y. Hu, A. Grinthal, M. Khan, and J. Aizenberg, "Liquid-based gating mechanism with tunable multiphase selectivity and antifouling behaviour", Nature 519, 70-73 (2015).

[15] J. D. Smith, R. Dhiman, S. Anand, E. Reza-Garduno, R. E. Cohen, G. H. McKinley, and K. K. Varanasi, "Droplet mobility on lubricantimpregnated surfaces", Soft Matter 9, 1772-1780 (2013).

[16] H. Darcy, Les Fontaines Publiques de la Ville de Dijon (Victor Dalmont, Paris, Paris) (1856).

[17] M. Mietton-Peuchot, C. Condat, and T. Courtois, "Use of gas-liquid porometry measurements for selection of microfiltration membranes", J. Membr. Sci. 133, 73-82 (1997).

[18] G. Hagen, "Ueber die bewegung des wassers in engen cylindrischen röhren", Annalen der Physik 122, 423-442 (1839).

[19] J. L. Poiseuille, "Experimental researches on the movement of liquids in tubes of small diameter", Compt. Rend 11, 1041 (1841). 
[20] D. Chisholm, "A theoretical basis for the lockhart-martinelli correlation for two-phase flow", International Journal of Heat and Mass Transfer 10, $1767-1778$ (1967).

[21] W. Zhang, "Study on constitutive equations for flow boiling in minichannels", Ph.D. thesis, Kyoto University, Japan (2005).

[22] L. Sun and K. Mishima, "Evaluation analysis of prediction methods for two-phase flow pressure drop in mini-channels", International Journal of Multiphase Flow 35, 47 - 54 (2009).

[23] G. B. Wallis, One dimensional two phase flow (McGraw-Huill, New York, USA) (1969).

[24] A Simple Asymptotic Compact Model for Two-Phase Frictional Pressure Gradient in Horizontal Pipes, volume Fluids Engineering of ASME International Mechanical Engineering Congress and Exposition (2004).

[25] M. M. Awad, "Two-phase flow modeling in pipes", Ph.D. thesis, Memorial University of Newfoundland, Canada (2005).

[26] M. M. Awad and S. D. Butt, "A robust asymptotically based modeling approach for two-phase flow in porous media", Journal of Heat Transfer 131, 101014(1-12) (2009).

[27] M. Fourar and R. Lenormand, "A new model for two-phase flows at high velocities through porous media and fractures", Journal of Petroleum Science and Engineering 30, 121 - 127 (2001).

[28] R. Lockhart and R. Martinelli, "Proposed correlation of data for isothermal two phase flow, two component flow in pipes", Chemical engineering progress 45, 39-48 (1949).

[29] Y. Han, H. Kanno, Y.-J. Ahn, and N. Shikazono, "Measurement of liquid film thickness in micro tube annular flow", International Journal of Multiphase Flow 73, $264-274$ (2015).

[30] de Gennes P. G., B.-W. F., and D. Quéré, Capillarity and Wetting Phenomena: Drops, Bubbles, Pearls, Waves (Springer, New York, USA) (2004). 


\section{3 \\ Liquid-liquid displacement in slippery liquid-infused membranes (SLIMs) ${ }^{\circ}$}

The gating mechanism of liquid-infused membranes is expected to give rise to antifouling properties and multi-phase transport capabilities. However, the long-term retention of the infusion liquid has not yet been explored. To address this issue, we investigate the retention of the infusion liquid in slippery liquid-infused membranes (SLIMs) via liquid-liquid displacement porometry (LLDP) experiments combined with microscopic observations of the displacement mechanism. Our results reveal that pores will be opened corresponding to the capillary pressure, leading to preferential flow pathways for water transport. The LLDP results further suggest the presence of liquid-lined pores in SLIM. This hypothesis is analyzed theoretically using an interfacial pore flow model. We find that the displacement patterns correspond to capillary fingering in immiscible displacement in porous media. The related physics regarding two-phase flow in porous media is used to confirm the permeation mechanism appearing in SLIMs. In order to experimentally observe liquid-liquid displacement, a microfluidic chip mimicking a porous medium is designed and a highly ramified structure with trapped infusion liquid is observed. The remaining infusion liquid is retained as pools, bridges and thin films around pillar structures in the chip, which further confirms liquid lining. Fractal dimension analysis, along with evaluation of the fluid (non-wetting phase) saturation, further confirms that the fractal patterns correspond to capillary fingering, which is consistent with an invasion percolation with trapping (IPT) model.

${ }^{\circ}$ Published as: Hanieh Bazyar, Pengyu Lv, Jeffery A. Wood, Slawomir Porada, Detlef Lohse and Rob G. H. Lammertink, Liquid-liquid displacement in slippery liquid-infused membranes (SLIMs), Soft Matter 2018, 14, 1780-1788. 



\subsection{Introduction}

2. IO-INSPIRED interfacial materials with non-wetting properties have broad 1) technological implications for areas ranging from biomedical devices and fuel transport to architecture [1]. Lotus-leaf inspired superhydrophobic surfaces are well-known, owing to properties such as drag reduction, anti-icing, anti-frosting and self-cleaning [2]. However, superhydrophobic surfaces are prone to failure due to elevated pressures and temperatures and by dissolution of the trapped air into the surrounding fluid [4, 9]. This is particularly significant for low surface tension liquids [10]. Recently, a novel class of functional surfaces known as slippery liquid-infused porous surfaces (SLIPS) has been introduced [11]. Inspired by Nepenthes pitcher plants [12, the nano/microstructured substrate is used to lock-in an intermediary liquid. This liquid, stabilized by capillary forces, forms a smooth, low hysteresis lubrication layer which is responsible for the non-wetting properties [13-15]. In comparison with superhydrophobic surfaces, SLIPS can potentially improve anti-icing or suppress frost accretion [5, 13, 16], operate at high pressures and temperatures [9. 11, and possibly reduce drag [7, 17]. Self-healing by capillary wicking, repelling a variety of liquids, and anti-biofouling are other potentially advantageous properties of SLIPS [11, 15]. Recently, it has been shown that the capillary-stabilized liquid in a membrane pore can form a reconfigurable gate which can selectively let fluids pass through. This so-called gating mechanism gives SLIPS the capability of multiphase transport without clogging [14. The liquid-lined gating mechanism was explored previously in Chapter Two via gas-liquid porometry where the remaining liquid film thickness on the pore wall was estimated experimentally and theoretically [18].

In previous studies, the fabrication methods of liquid infused surfaces were complex, time-consuming and the substrate selectivity to match solid and liquid chemistry was limited. Some methods required multi-step processing, high temperatures and drying [16, 19]. Using well-matched membrane-liquid combinations with low surface energies for water, e.g. membranes prepared from fluorinated polymers, avoids the extra step of solid surface energy reduction. Examples of these membranes are polyvinylidene fluoride (PVDF) and polytetrafluoroethylene (PTFE). [9, 14, 18.

Introduction of SLIPS to membranes provides potentially anti-fouling properties (see Chapter Five), as well as pressure responsive pores for selective fluid transport [14, 20] (see Chapter Four). These properties are attractive for separation applications. The capability of these membranes in efficient gas-liquid sorting for three phase air-water-oil mixtures [14, for example, is relevant for 
oily waste water treatment (see Chapter Four). Before the potential of slippery liquid-infused membranes (SLIM) can be realized, a thorough understanding of the retention of the infusion liquid under dynamic conditions of transport of the immiscible fluid is required.

Two-phase flow or immiscible displacement in any porous media, such as porous membranes, is typically governed by viscous and capillary forces, characterized by two dimensionless numbers, the viscosity ratio

$$
\mathrm{M}=\frac{\mu_{\mathrm{i}}}{\mu_{\mathrm{d}}},
$$

and the capillary number

$$
\mathrm{Ca}=\frac{\mu_{\mathrm{i}} v}{\gamma} .
$$

Here $\mu_{\mathrm{i}}$ and $\mu_{\mathrm{d}}$ are the viscosity values of invading (water) and defending (oil) fluids respectively ( $\mathrm{Pa} \mathrm{s}), v$ is the superficial velocity $(\mathrm{m} / \mathrm{s})$ and $\gamma$ is the interfacial tension between the two immiscible fluids $(\mathrm{N} / \mathrm{m})$. The domain of validity of different basic mechanisms, i.e. capillary fingering, viscous fingering, or stable displacement, can be mapped on to a phase diagram [21]. The displacement can also be classified according to drainage or imbibition, where the defending (displaced) or invading (displacing) fluid preferentially wets the solid surface, respectively [21, 22. Microfluidic techniques have been used to investigate the displacement mechanisms. These techniques offer the opportunity to fabricate micromodels resembling a porous medium with regular as well as irregular pore shapes, anisotropy and pore sizes. Pore-scale multi-phase displacement phenomena have been experimentally observed in pore network patterns fabricated in materials such as silicon [23, 24], glass [25], PDMS [26 29, polyester and thiolene-based resin [21, 30, 31] (see Chapter Seven on application of micromodels for prediction of porous media permeability).

Liquid-gated membranes are expected to possess anti-fouling characteristics and multi-phase transport capabilities [14]. However, knowledge regarding the retention of the infusion liquid within these membranes is still limited. To address this issue, we report on retention of the infusion liquid in SLIM and microscopic observation of the displacement mechanism. Liquid-liquid displacement porometry (LLDP) is done in a flux-controlled mode by pushing pure water through PVDF membranes infused with perfluoropolyether oil (Krytox 101). The results are further analyzed theoretically using an interfacial pore flow model. Finally, a microfluidic chip resembling the porous medium has been used to microscopically investigate the displacement mechanism under 
identical capillary number and viscosity ratio. The observed flow pattern is characterized using fractal dimension analysis and fluid (non-wetting phase) saturation, methods known from porous media analysis. Here, the permeation through SLIMs is related to two-phase flow in porous media to confirm the observed displacement mechanisms that are crucial for their promising membrane applications.

\subsection{Experimental details}

\subsubsection{Materials}

PVDF (Solef 6020/1001) was received from Solvay Solexis, France. 1-methyl2-pyrrolidinone (NMP) (99\% extra pure) was purchased from Acros Organics, The Netherlands. Ethanol (99.8\%) was supplied from Atlas and Assink chemical company, The Netherlands. Krytox GPL oil 101 was purchased from MAVOM chemical industry, The Netherlands. Silicone oil AR20 was purchased from Sigma-Aldrich, The Netherlands. Trichloro $(1 \mathrm{H}, 1 \mathrm{H}, 2 \mathrm{H}, 2 \mathrm{H}-$ perfluorooctyl) silane (FOTS, 97\%) was purchased from Sigma-Aldrich, The Netherlands. Perylene (sublimed grade, 99.5\%) and Rhodamine 6G (dye content $99 \%$ ) as fluorescent dyes for oil and water phases respectively were purchased from Sigma-Aldrich, The Netherlands. n-Hexane and 2-propanol (analysis grade) were purchased from Merck milipore, The Netherlands. Sulfuric acid $\left(\mathrm{H}_{2} \mathrm{SO}_{4}\right.$ 95-98\%) was purchased from Merck milipore, The Netherlands. Hydrogen peroxide $\left(\mathrm{H}_{2} \mathrm{O}_{2}\right)$ solution $30 \%(\mathrm{w} / \mathrm{w})$ in $\mathrm{H}_{2} \mathrm{O}$ was supplied from Sigma-Aldrich, The Netherlands.

\subsubsection{Membrane fabrication}

The polymer solution was prepared by mixing 15 wt.\% PVDF in NMP with a mechanical stirrer overnight at $80^{\circ} \mathrm{C}$. The solution was cast on a glass plate using a casting knife at an initial thickness of $500 \mu \mathrm{m}$. The cast membrane was immediately submerged in water/NMP (30:70 vol.\%) as the coagulation bath for $60 \mathrm{~min}$. To remove the remaining NMP from the membranes, they were kept in ethanol subsequently for another $60 \mathrm{~min}$. The films were then taped to a piece of paper to prevent curling and left to dry in fume hood (60 min) before placing them in a $30^{\circ} \mathrm{C}$ vacuum oven overnight. 


\subsubsection{Fabrication of dense PVDF}

Dense PVDF was made by casting the polymer dope solution on a glass plate using the same procedure as described for membrane fabrication. The cast polymer solution was placed in a box and dried with a flow of nitrogen for two days.

\subsubsection{Fabrication of SLIM and pre-wet membrane}

An overcoat layer $\left(15.5 \mu \mathrm{l} / \mathrm{cm}^{2}\right)$ of the low surface tension liquid (Krytox 101) was added to the membranes using a micropipette. The liquid spontaneously infiltrated the pores via capillary wicking. The samples were further placed vertical (2-3 h) for gravity-induced removal of the excess liquid.

The pre-wet membrane was prepared using the same procedure by adding ethanol to the membrane. To replace ethanol with water in membrane pores, the sample was placed in a beaker of water $(200 \mathrm{ml})$ and left overnight.

\subsubsection{Membrane characterization}

The membrane was characterized using contact angle Goniometer (Dataphysics OCA20), capillary flow porometer (Porolux-1000), and scanning electron microscope (SEM) (JEOL 5600 LV). See Appendix B section "SLIM fabrication and characterization" for details on the techniques.

\subsubsection{Laser scanning confocal microscopy (LSCM) experi- ments}

The liquid-liquid displacement in the microfluidic chip is observed using an inverted laser scanning confocal microscope (LSCM) (A1 system, Nikon Corporation, Japan) with a 4x dry objective (CFI Plan Fluor 4x/0.13, numerical aperture $(\mathrm{NA})=0.13$, working distance $(\mathrm{WD})=17.2 \mathrm{~mm})$. The scanning area is chosen the same as the area of the pillar structure in the microfluidic chip, i.e. $5 \times 2.5 \mathrm{~mm}^{2}$.

\subsubsection{Hydrophobization of the microfluidic chip}

In order to render the microfluidic chip hydrophobic, it was hydrophobized using deposition of trichloro $(1 \mathrm{H}, 1 \mathrm{H}, 2 \mathrm{H}, 2 \mathrm{H}$-perfluorooctyl)silane (FOTS) via vapor-induced method. To achieve this, a glass bottle with gas inlet and outlet was filled with $12 \mu \mathrm{l}$ of FOTS. The inlet was connected to nitrogen gas and the 
Table 3.1: Physical properties of different infusion liquids (viscosity and density are measured at $20^{\circ} \mathrm{C}$ and $24^{\circ} \mathrm{C}$ respectively).

\begin{tabular}{lcccc}
\hline Infusion liquids & $\begin{array}{c}\text { Surface tension } \\
{[\mathrm{mN} / \mathrm{m}]}\end{array}$ & $\begin{array}{c}\text { Absolute viscosity } \\
{[\mathrm{mPa} \mathrm{s}]}\end{array}$ & $\begin{array}{c}\text { Kinematic viscosity } \\
{\left[\mathrm{mm}^{2} / \mathrm{s}\right]}\end{array}$ & $\begin{array}{c}\text { Density } \\
{\left[\mathrm{g} / \mathrm{cm}^{3}\right]}\end{array}$ \\
\hline Fluorinert FC-43 & $16.3 \pm 0.05$ & $5.6 \pm 0.08$ & 3.0 & $1.88 \pm 0.01$ \\
Galpore & $15.5 \pm 0.05$ & $8.6 \pm 0.08$ & 4.8 & $1.83 \pm 0.01$ \\
Krytox GPL oil 101 & $16.3 \pm 0.13$ & $25 \pm 0.1$ & 13.5 & $1.85 \pm 0.01$ \\
Silicone oil AR20 & $21.8 \pm 0.03$ & $19.6 \pm 0.1$ & 19.4 & $1.00 \pm 0.002$ \\
\hline
\end{tabular}

outlet was connected to the chip using a chip holder. The whole set-up was then placed in oven at temperature of $100^{\circ} \mathrm{C}$. The outflow from the chip was directed to a beaker containing water to neutralize and absorb the permeate gas. The acidity of water was checked to further ensure the presence of FOTS vapor in the chip via formation of hydrochloric acid $(\mathrm{HCl})$ in water. Before hydrophobization, the chip was cleaned with piranha solution $\left(\mathrm{H}_{2} \mathrm{SO}_{4}: \mathrm{H}_{2} \mathrm{O}_{2}\right.$ (3:1) vol.) and rinsed with pure water. Since the chip should be completely dry before hydrophobization, water was replaced with 2-propanol and then n-hexane. The chip was dried in oven (temperature of $100^{\circ} \mathrm{C}$ ) overnight while having a flow of nitrogen gas through the channels.

\subsection{Results and discussion}

\subsubsection{Membrane experimental results}

Liquid-infused membranes are made by infusing different types of liquids (fluorinated or hydrocarbon) into dry PVDF membranes (see section Experimental details. The physical properties of the used liquids are shown in Table 3.1 (see Appendix B section "SLIM fabrication and characterization" for more information on the measurements methods).

All liquid-infused membranes display hydrophobic behavior with a static contact angle of about $120^{\circ}$ and contact angle hysteresis $<5^{\circ}$ using standard contact angle Goniometer (the water contact angle values on liquid infused PVDF membranes are shown in Appendix B Table B.1. These are the key design parameters, since a high contact angle and a low contact angle hysteresis are desirable for high droplet mobility [32. Liquid-liquid displacement experiments are done successively in a flux-controlled mode by pushing pure water (displacing fluid) through the liquid infused membrane. The schematic illustration of the set-up is shown in Figure 3.1 


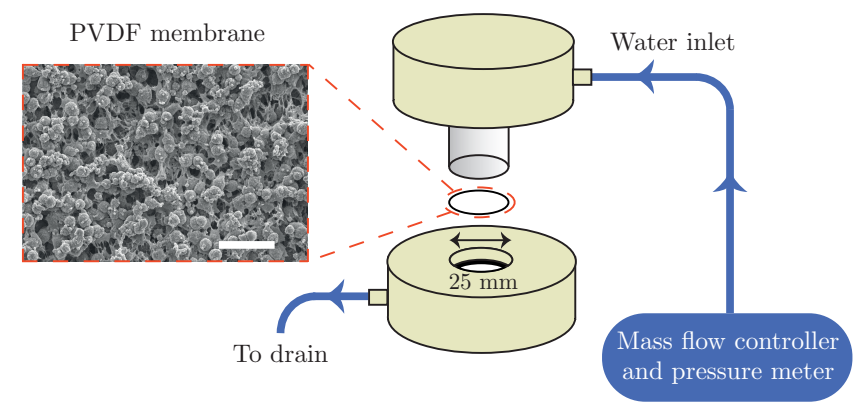

Figure 3.1: Schematic illustration of the membrane experiment and SEM image of the PVDF membrane (scale bar is $10 \mu \mathrm{m}$ ).

The result of LLDP on infused PVDF membrane with perfluoropolyether oil (Krytox 101) is shown in Figure 3.2. The results of other liquid infused membranes are shown in Appendix B Figure B.4. The LLDP experiment is performed in five different cycles. Each cycle is carried out in a flux-increasing mode, which is done twice starting from zero up to a certain flux value, i.e. the cycle consists of two runs ( $1^{\text {st }}$ run and $2^{\text {nd }}$ run). In each run, the flux is increased step-wise and pressure is measured simultaneously. At each step, flux is kept constant for $100 \mathrm{~s}$ and the pressure is reported for the last $40 \mathrm{~s}$ of each step.

In each cycle, a certain number of pores have been opened in the $1^{\text {st }}$ run corresponding to the Laplace pressure

$$
\Delta P=\frac{2 \gamma\left|\cos \theta_{\mathrm{E}}\right|}{r},
$$

leading to preferential flow pathways. Here $\Delta P$ is the transmembrane pressure $(\mathrm{Pa}), r$ is the pore radius $(\mathrm{m}), \gamma$ is the interfacial tension between displacing and displaced fluid $(\mathrm{N} / \mathrm{m})$, and $\theta_{\mathrm{E}}$ is the advancing contact angle of the displacing fluid on a surface of smooth and dense PVDF (total non-wetting $\left(\theta_{\mathrm{E}}=180^{\circ}\right)$ with displacing fluid is considered for liquid-infused membranes).

The opened pores remain open during the $2^{\text {nd }}$ run, confirmed by the linear relation between flux and pressure [33. An initial critical pressure of approximately $0.57 \times 10^{5} \mathrm{~Pa}$ is required to open the biggest pore sizes. Based on the pore size distribution of the membrane obtained from capillary flow porometer (see Appendix B Figure B.2), the largest pore radius is $1.77 \pm 0.11$ $\mu \mathrm{m}$. According to Young-Laplace equation (Equation 3.3) and by considering total non-wetting, the corresponding pressure to open the largest pores is 


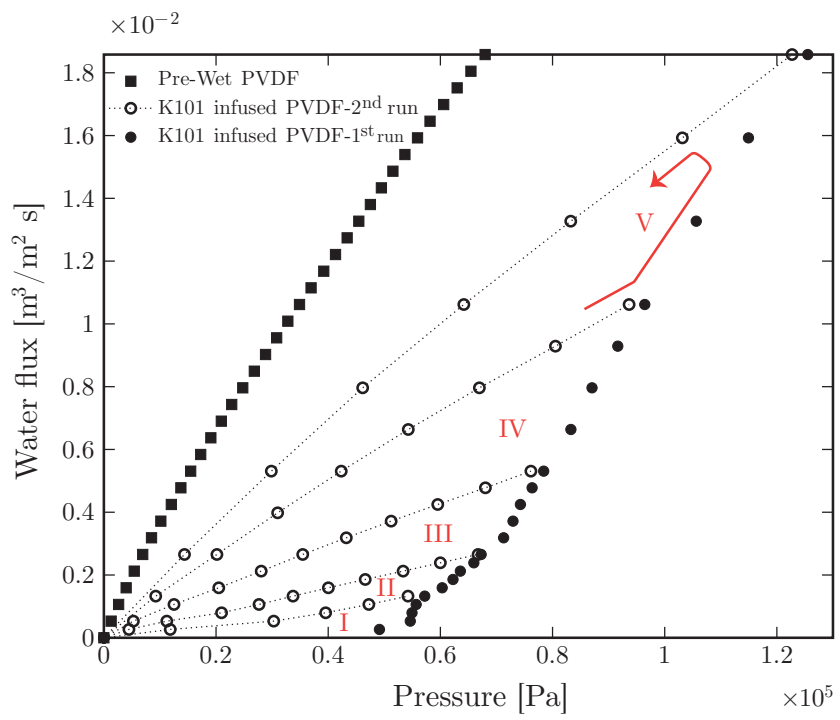

Figure 3.2: Successive liquid-liquid displacement porometry (LLDP) experiment in a flux-controlled mode on Krytox 101-infused PVDF membrane. LLDP is done in five different cycles (I-V) and each cycle consists of a $1^{\text {st }}$ (filled symbols) and a $2^{\text {nd }}$ run (open symbols). In each run flux is increased step-wise from zero up to a certain maximum value and pressure is measured correspondingly. A typical sequence of the measurement is shown for cycle $\mathrm{V}$. 
Table 3.2: Comparison of permeability and fraction of active pores for five different cycles of liquid infused membrane and for the pre-wetted case.

\begin{tabular}{lcc}
\hline Membrane & $\begin{array}{c}\text { Permeability }(\kappa) \\
(\text { Darcy })\end{array}$ & $\begin{array}{c}\text { Estimated fraction } \\
\text { of active pores }\end{array}$ \\
\hline SLIM-cycle 1 & $3.12 \times 10^{-3}$ & 0.09 \\
SLIM-cycle 2 & $5.23 \times 10^{-3}$ & 0.15 \\
SLIM-cycle 3 & $9.19 \times 10^{-3}$ & 0.26 \\
SLIM-cycle 4 & $1.51 \times 10^{-2}$ & 0.43 \\
SLIM-cycle 5 & $2.01 \times 10^{-2}$ & 0.57 \\
Pre-wet & $3.54 \times 10^{-2}$ & 1 \\
${ }^{*}$ 1 Darcy $=0.987 \times 10^{-12} \mathrm{~m}^{2}$. &
\end{tabular}

$0.61 \times 10^{5} \mathrm{~Pa}$ (see Appendix B, Table B.2 for surface and interfacial tension values), which is in good agreement with the LLDP experiments.

In order to check for the presence of the infusion liquid in the membrane after the experiment, the obtained results are compared with the results of the pre-wetted membrane (see Figure 3.2). The permeability of pre-wetted as well as liquid-infused membranes is calculated using Darcy's law 34.

$$
Q=-\frac{\kappa A}{\mu} \frac{d p}{d x} .
$$

Here and in the following, $Q$ is the volumetric flow of the permeating fluid (in this case water) $\left(\mathrm{m}^{3} / \mathrm{s}\right), \kappa$ is permeability $\left(\mathrm{m}^{2}\right), A$ is the total area of the membrane $\left(\mathrm{m}^{2}\right), \mu$ is the viscosity of the displacing fluid $(\mathrm{Pa} \mathrm{s}), \frac{d p}{d x}$ is the pressure gradient across the membrane thickness $(\mathrm{Pa} / \mathrm{m}), r$ is the mean pore radius $(\mathrm{m})$, and $\phi$ is porosity.

A simple model is then used to relate permeability to porosity $\phi$ (see Appendix B section "Relation between permeability and porosity (tube model)" for derivation), namely

$$
\kappa=\frac{\phi r^{2}}{24} .
$$

The calculated porosity is a measure of opened and active pores for water transport in the membrane. The results of the calculated permeability and the estimated fraction of the active pores are shown in Table 3.2 .

This fraction is the ratio between the calculated porosity for the liquid infused membrane in each cycle and that of the pre-wetted membrane. The permeability of the liquid-infused membrane increases in each cycle, revealing 
that new pores are opened for water transport. The lower permeability values of SLIM in comparison with pre-wetted membranes suggests incomplete removal of the infusion liquid with around $43 \%$ of retained infusion liquid in the membrane. Direct observations using the microfluidic chip shows that $27 \%$ of the infused liquid remained in the chip at the corresponding flux value $\left(1.8 \times 10^{-2} \mathrm{~m}^{3} / \mathrm{m}^{2} \mathrm{~s}\right)$ (see Table 3.3 ).

The average pore radius of the membrane based on its pore size distribution is $1.65 \pm 0.11 \mu \mathrm{m}$ (Figure B.3 in Appendix B). Based on the Young-Laplace equation (Equation 3.3) and by assuming total non-wetting, all the pores should be opened at pressures beyond $0.61 \times 10^{5} \mathrm{~Pa}$. As the used membranes are tortuous porous media with interconnected pores and areas, infusion liquid can be trapped. The trapped liquid will not be removed by further flux or pressure increase and thus leads to a lower permeability compared to the prewet one.

In order to observe the re-infusion of the opened pores, long-term experiments are performed. In these experiments the pause time between each cycle was set to $12 \mathrm{~h}$. However, re-infusion is not observed at the high flux values in which the experiments have been already conducted. This is evident from the linear flux-pressure relation, that would be different when re-infused.

The experimental results are analyzed theoretically using an interfacial pore flow model to relate the flux $(J)$ to pressure $(\Delta P)$, namely [35]

$$
J(\Delta P)=\frac{N \pi \Delta P}{8 \sqrt{2 \pi} \ln (S) \mu l} \int_{r_{\min }}^{r_{\max }} r^{3} \exp \left(-\frac{1}{2}\left(\frac{\ln (r / R)}{\ln (S)}\right)^{2}\right) \mathrm{d} r .
$$

Here $N$ is the total number of the pores per unit area, $R$ is the geometric mean radius $(\mathrm{m})$, and $S$ is the geometric standard deviation. $J$ is the volumetric flux of displacing fluid per membrane area through the membrane $\left(\mathrm{m}^{3} / \mathrm{m}^{2} \mathrm{~s}\right)$, $l$ is the membrane thickness $(\mathrm{m}) \cdot r_{\min }$ is the equilibrium radius of curvature $(\mathrm{m})$, i.e. Kelvin radius, which can be calculated using Young-Laplace equation (Equation 3.3). $r_{\max }$ is taken at least one order of magnitude larger than the largest pore size corresponding to the lowest measurable pressure by the setup. A log-normal pore size distribution is considered for this model [35, 36] and was found to describe the measurements well (see Appendix B section "Fitting results" for more details on fitting). The pore size distribution of the PVDF membrane is shown in Figure B.3 in Appendix B.

Figure 3.3 shows good agreement between experimental values and fitted curves using the interfacial pore flow model (Equation 3.6). It accurately 


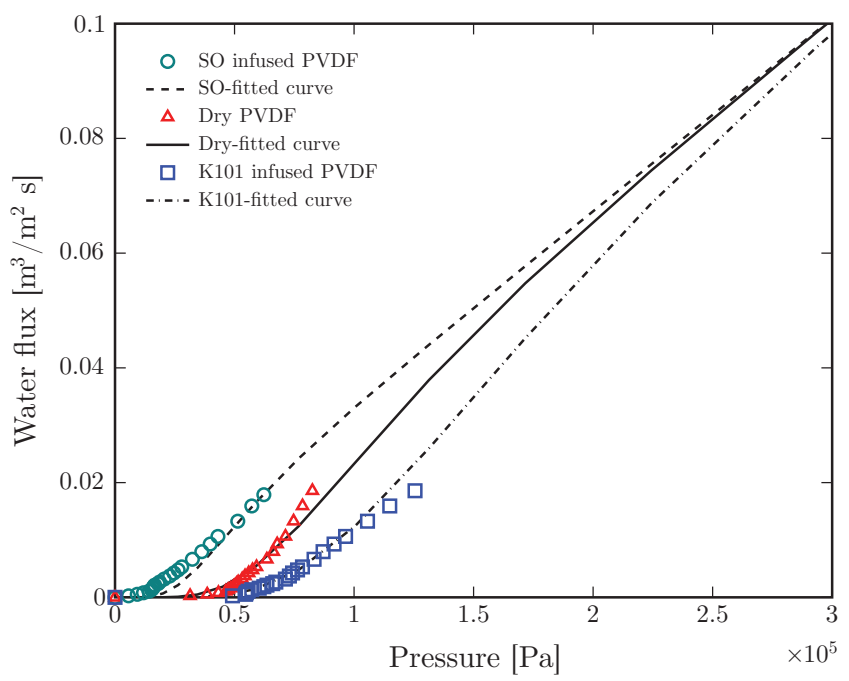

Figure 3.3: Fitting of experimental results of LLDP to the interfacial pore flow model (Equation 2.4 of reference [35]). Symbols and lines show the experimental and fitting results respectively. Fitting parameter are $N=10^{7}$ pore $/ \mathrm{m}^{2}$ (total number of pores per unit area), $R=1.65 \mu \mathrm{m}$ (geometric mean radius) and $S=1.2$ (geometric standard deviation)).

describes the flux behavior in both liquid-infused and dry membranes. The result for a silicone oil (SO AR20)-infused membrane is also shown.

The difference in pressure at a given flux arises purely from different Laplace pressures due to the corresponding interfacial tension values (Table B.2 in Appendix B). Since the liquid-infused membrane is preferentially wetted by the infusion liquid (this is one of the criteria for fabrication of SLIM [11]), total non-wetting can be assumed for the invading liquid $\left(\theta_{\mathrm{E}}=180^{\circ}\right)$ (see Figure 3.4). For validation, the advancing contact angle of water on a dense membrane which was immersed in the oil was measured. $\theta_{\mathrm{Adv}}=175^{\circ}$ and $\theta_{\mathrm{Adv}}=160^{\circ}$ were obtained respectively for K101 and SO AR20 (Table B.1 in Appendix B).

In a dry membrane due to the absence of the wetting layer and hydrophobic character of the pore wall, partial wetting occurs. In this case, the advancing contact angle of water on smooth and dense membrane should be considered $\left(\theta_{\mathrm{Adv}}=122^{\circ}\right)$ (Table B.1 in Appendix B). Thus, the numerator of Equation 3.3 for a dry pore $\left(\gamma\left|\cos \theta_{\mathrm{E}}\right|=38 \mathrm{mN} / \mathrm{m}\right)$ is between that of $\mathrm{K} 101$ and that of SO AR20 infused pores $\left(\gamma_{\text {K101-water }}=54 \mathrm{mN} / \mathrm{m}\right.$ and $\gamma_{\text {SO-water }}=18 \mathrm{mN} / \mathrm{m}$ [37). As it is schematically shown in Figure 3.4(b), this further suggests the presence of remaining liquid film on the pore wall (liquid-lined pores) in SLIM. 


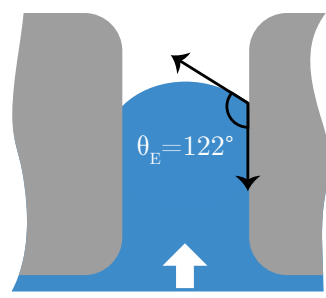

(a)

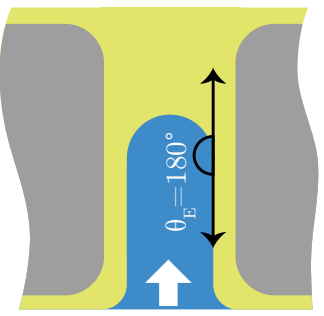

(b)

Figure 3.4: Schematic illustration of water pushing through (a) dry membrane pore and (b) liquid-infused pore.

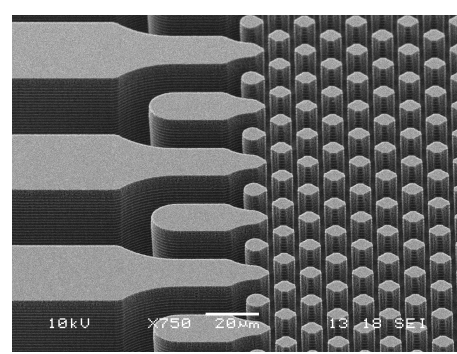

(a)

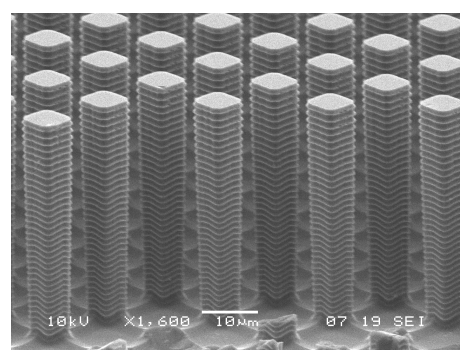

(b)

Figure 3.5: Scanning electron microscopy (SEM) images of (a) the inlet of the microfluidic chip, (b) pillars.

\subsubsection{Microfluidic experimental results}

In order to observe the displacement mechanism and the resulting flow paths, a microfluidic chip has been used as a mimic of the porous medium (Figure 3.5. The chip is fabricated in silicon using standard photolithography and reactive ion etching (see Appendix B section "Fabrication of the microfluidic chip" for detailed fabrication procedure). The pore network contains a uniform distribution of square pillars with $20 \mu \mathrm{m}$ center to center spacing, $8 \mu \mathrm{m}$ diameter and $50 \mu \mathrm{m}$ height giving a porosity of 0.84 .

To mimic the experimental conditions of the membrane experiments, the chip is further hydrophobized with perfluorinated silane and filled with SO AR20 labeled with $8.7 \mathrm{mM}$ fluorescent dye (Perylene). Water (labeled with $17.7 \mu \mathrm{M}$ fluorescent dye (Rhodamine 6G)) is pushed through the chip from the right side using a syringe pump (Harvard apparatus PHD 2000 infuse/withdraw). The addition of the aforementioned dyes neither changed the surface 


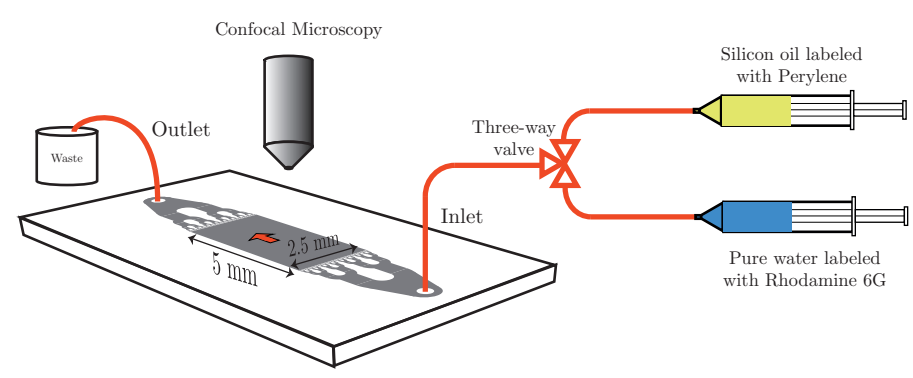

Figure 3.6: Schematic illustration of the microfluidic experiment.

Table 3.3: Irreducible water saturation values $\left(\mathrm{S}_{\mathrm{nwr}}\right)$ for the microfluidic experiment done at different flow rates.

\begin{tabular}{cccc}
\hline $\begin{array}{c}\text { Microfluidic } Q \\
(\mu \mathrm{l} / \mathrm{s})\end{array}$ & $\begin{array}{c}\text { Membrane flux } \\
\left(\mathrm{m}^{3} / \mathrm{m}^{2} \mathrm{~s}\right)\end{array}$ & $\mathrm{Ca}$ & $\mathrm{S}_{\mathrm{nwr}}$ \\
\hline 0.2 & 0.0013 & $1.23 \times 10^{-4}$ & 0.56 \\
0.4 & 0.0026 & $2.46 \times 10^{-4}$ & 0.62 \\
0.8 & 0.0053 & $4.91 \times 10^{-4}$ & 0.63 \\
1.6 & 0.011 & $9.28 \times 10^{-4}$ & 0.69 \\
2.9 & 0.018 & $1.72 \times 10^{-3}$ & 0.73 \\
\hline
\end{tabular}

tension of water nor SO AR20 considerably (see Table B.3 in Appendix B). Laser scanning confocal microscope (LSCM) is used for observation of liquidliquid displacement. The schematic of the experimental set-up is shown in Figure 3.6 .

The viscosity ratio (Equation 3.1) is kept the same as in membrane experiments by using similar fluid pairs. The experiment is done at different flow rates, corresponding to the same capillary number (Equation 3.2 as the membrane experiments (Table 3.3).

A typical result of the microfluidic displacement is shown in Figure 3.7 Figure 3.7(a) displays the last time frame of the corresponding movie (see Appendix B Movie B1). In this figure, yellow and blue colors correspond to the infused liquid (SO AR20) and water, respectively. A highly ramified pattern with trapped infusion liquid is observed (Figure 3.7(b)). Based on the used capillary number $\left(C a \simeq 10^{-4}\right.$ see Table 3.3$)$ and viscosity ratio $(M=0.05)$, the displacement pattern corresponds to the capillary fingering invasion regime in drainage. Fingers in capillary fingering show spreading across considerable part of the chip and growth is seen in all directions. When capillary fingering occurs some wetting fluid becomes entrapped due to the complex displacement 


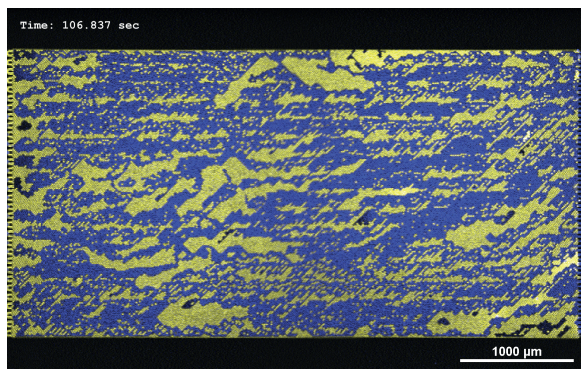

(a)

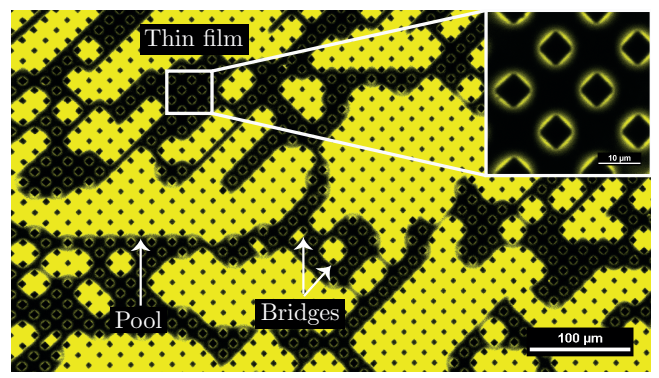

(b)

Figure 3.7: Experiment using laser scanning confocal microscope (LSCM). (a) Image after water transport through the liquid infused chip at $Q=0.2 \mu \mathrm{l} / \mathrm{s}$ $\left(\mathrm{Ca}=1.23 \times 10^{-4}\right)$ (yellow color is the oil phase and blue color is the water phase).

(b) Image at $20 \times$ magnification showing different configurations of the residual wetting fluid.

pattern [24]. The residual wetting fluid can be observed as pools, bridges and thin films around the pillars (Figure $3.7(\mathrm{~b})$. Observation of thin films around pillars (inset of Figure 3.7(b) further confirms liquid-lining after displacing with water (Figure 3.4(b)]. The three-dimensional image of the chip and its cross section after the displacement experiment, is shown in Appendix B Figure B.6 showing the presence of thin liquid films along the pillars). The presence of this liquid layer is crucial for any potential anti-fouling properties of liquid-infused surfaces due to minimum contact of foulants with solid material of the surface [14.

For quantitative description of the observed patterns and better understanding of the displacement mechanism, the patterns are analyzed in terms of total saturation $\mathrm{S}_{\mathrm{nw}}$ of the non-wetting phase (water in this case), the local saturation (and their evolution over time) and the fractal dimension $D$. The total saturation $\mathrm{S}_{\mathrm{nw}}$ is the ratio of the total area of the non-wetting phase to the total available area of the chip [24, 26. For measuring the local saturation, each image is divided vertically into 33 slices and $\mathrm{S}_{\mathrm{nw}}$ is calculated for each slice. The MATLAB bio-format toolbox is used for image processing [38].

The fractal dimension $D$ is given by

$$
D=\frac{\log B}{\log a} .
$$

Here, $B$ is the number of boxes that cover the pattern and $a$ is the magnification factor which is the inverse of the box size. A box counting algorithm is 


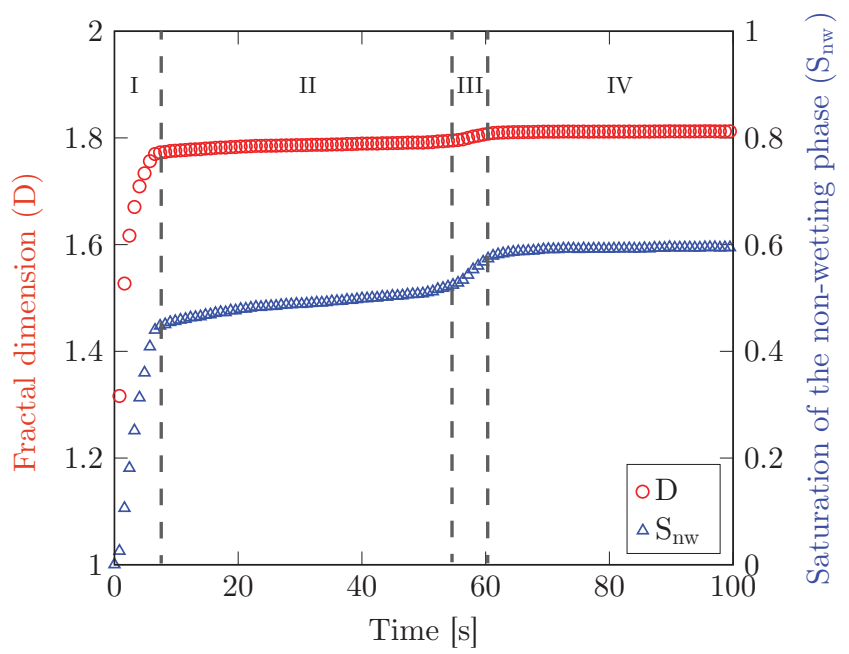

Figure 3.8: Total Saturation of the non-wetting phase $\left(\mathrm{S}_{\mathrm{nw}}\right)$ and fractal dimension $(D)$ as a function of time for the corresponding displacement movie. During phase (I) formation of the fingers takes place. During phase (II) the saturation profile is evolving. Phase (III) corresponds to the breakthrough point and phase (IV) corresponds to the steady-state regime where the saturation profile is preserved.

used to calculate $D$ (Hausdorff (Box-Counting) fractal dimension code) (See Appendix B section "Box counting algorithm" for more details). $D$ for this kind of analysis is a non-integer value which ranges between 1 and 2. $D=1$ for a straight line and $D=2$ for a fractal pattern which completely fills up a $2 \mathrm{D}$ plane [39].

Figure 3.8 shows the total saturation $\mathrm{S}_{\mathrm{nw}}$ and the fractal dimension $D$ as a function of time. There are four distinct phases in the total saturation plot. In phase I, a sharp increase is observed corresponding to the formation of the fingers. Phase II corresponds to the evolution of the formed fingers before the breakthrough point. During phase III the breakthrough point has been reached. At this point a decrease in specific interfacial length for the boundary between two phases is observed corresponds to the removal of the larger mobile oil blobs (Figure B.5(b) in Appendix B). In phase IV, $\mathrm{S}_{\mathrm{nw}}$ reaches a constant water saturation value of 0.6 after the breakthrough point where the oil blobs are completely immobile. The corresponding saturation value for the displacing liquid is the saturation at which the displaced liquid goes from being mobile to being immobile, i.e. irreducible saturation $\left(S_{n w r}\right)$ [40].

The irreducible saturation values $\left(\mathrm{S}_{\mathrm{nwr}}\right)$ of other experiments done at higher 
flow rates are shown in Table 3.3 . The results show that at the highest flow rate which corresponds to the highest flux value of the membrane experiment $(1.8 \times$ $\left.10^{-2} \mathrm{~m}^{3} / \mathrm{m}^{2} \mathrm{~s}\right), 27 \%$ of the infused liquid will remain in the chip. This is lower than the amount of remaining infused liquid in the membrane experiments (Table 3.2). The reason can be attributed to the presence of interconnected pores and irregular shaped pores in the membrane where more infusion liquid can be trapped.

The fractal dimension $D$ reaches its steady state value $\left(D_{s}\right)$ of 1.8 at the breakthrough point. This confirms that the displacement mechanism falls within the flow regime of invasion percolation with trapping (IPT), a statistical model which is used to describe capillary fingering. It is established that IPT patterns can be identified with fractal dimension between 1.8 and 1.83 [21, 41.

In order to better quantify the formation of the fingers in phase I, local saturation of the non-wetting phase is plotted as a function of time and location (see Figure B.7 in Appendix B). Local saturation provides a detailed description of the dynamics of liquid-liquid displacement during the invasion. The initial formation of the fingers corresponds to the movement of a shock front toward the outlet (Figure 3.9p). In order to model the displacement behaviour and movement of the shock front, the Buckley-Leverett model is used [42],

$$
\frac{\phi}{u} \frac{\partial S_{\mathrm{nw}}}{\partial t}+\frac{d f_{\mathrm{nw}}}{d S_{\mathrm{nw}}} \frac{\partial S_{\mathrm{nw}}}{\partial x}=0
$$

Here $\phi$ is the porosity, and $u$ is the total fluid velocity in the direction of the flow $(\mathrm{m} / \mathrm{s}) . \quad f_{\mathrm{nw}}$ is fractional flow of the non-wetting phase, which is defined as the ratio of the non-wetting phase velocity to the total velocity, i.e., $f_{\mathrm{nw}}=u_{\mathrm{nw}} / u$. This model is the best known analytical approach for investigation and modelling of two-phase flow in porous media [43 45] (see Appendix B "Buckley-Leverett analysis" for derivation and solution details).

The modelling result is shown in Figure 3.9. The model can predict the experimental results for the movement of the shock front. The differences may originate from the simplifications in the model as well as experimental accuracy. The displacement observations using LSCM is done at 4x magnification and each time frame of the corresponding movie is divided to 33 slices to obtain the local saturation plot. This is the smallest achievable slice size in order to avoid noticeable experimental noise. 


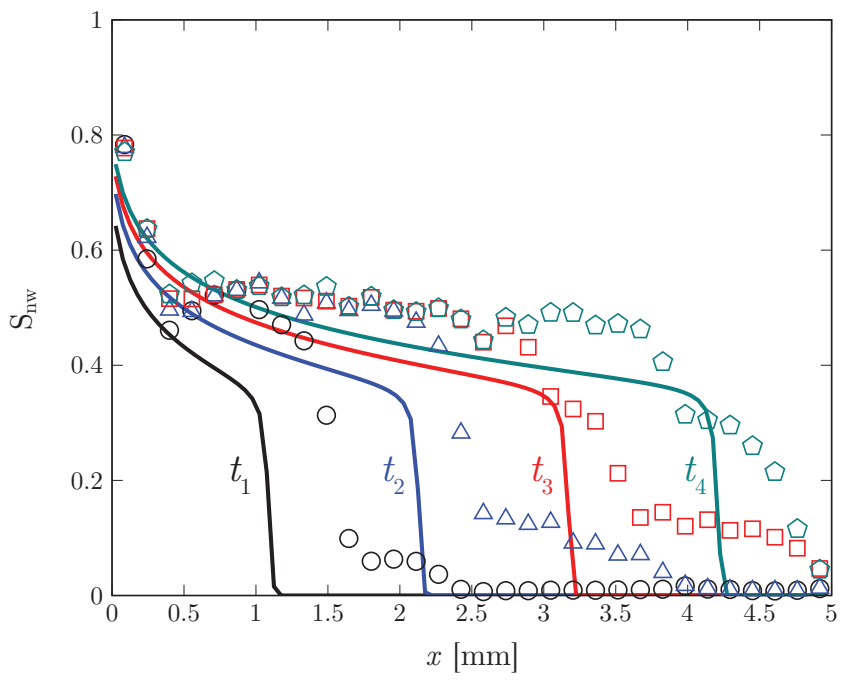

Figure 3.9: Buckley-Leverett experimental results (symbols) and modelling results (solid line) of the shock front movement for four different times, i.e., $t_{1}=1 \mathrm{~s}$ (black), $t_{2}=2 \mathrm{~s}$ (blue), $t_{3}=3 \mathrm{~s}$ (red), and $t_{4}=4 \mathrm{~s}$ (green).

\subsection{Conclusion}

We have reported on the retention of the infusion liquid in slippery liquid infused membranes (SLIM) during water permeation and microscopic observation of the displacement mechanism. The membrane experiments have been done via liquid-liquid displacement porometry (LLDP) by pushing pure water through SLIM in a flux-controlled mode. The pressure-flux results confirmed the presence of remaining infusion liquid (43\%) after displacing with water. Comparison of different liquid-infused membranes with a dry one further indicates the presence of liquid-lined pores. Infused pores were displaced according to the corresponding capillary pressure and remained open once flow was stopped. This suggested the preferential flow path ways for water transport through the membranes which corresponds to the capillary fingering displacement regime. The related physics regarding two-phase flow in porous media was used to confirm the observed displacement mechanism in SLIMs. In order to better understand the physical displacement process, a microfluidic chip was used for direct visualization using laser scanning confocal microscope (LSCM). A highly ramified structure with trapped infusion liquid was observed. Residual wetting structures were observed in the form of pools, bridges, and thin films around pillars. The presence of thin films further confirmed liquid-lining 
after displacing with water. Fractal breakthrough patterns were analyzed in terms of total and local saturation $\left(\mathrm{S}_{\mathrm{nw}}\right)$ and fractal dimension $(D)$. The saturation profiles indicated the dynamic distribution of the infusion liquid during the displacement process. Local saturation provides details on the formation of the fingers which corresponds to the movement of a shock front toward the outlet. Buckley-Leverett model was used to predict the experimental results of the shock front movement. The observed patterns along with the fractal analysis confirmed that the experiment falls within the flow regime of capillary fingering which can be described by an invasion percolation with trapping (IPT) model. The saturation of the water phase reached the steady-state value of 0.73 at the same capillary number as membrane experiments corresponds to the highest flux value. This showed that $27 \%$ of the oil still remains in the chip. This study showed the retention of liquid-lining under cyclic pressure-flux testing during immiscible displacement process. The presence of the liquid-lined pores after displacement with water is crucial for anti-fouling characteristics of SLIM, which makes it a potential candidate for separation processes.

\section{References}

[1] D. Quéré, "Wetting and roughness", Annu. Rev. Mater. Res. 38, 71-99 (2008).

[2] T. Darmanina and F. Guittard, "Recent advances in the potential applications of bioinspired superhydrophobic materials", J. Mater. Chem. A 2, 16319-16359 (2014).

[3] J. Lv, Y. Song, L. Jiang, and J. Wang, "Bio-inspired strategies for antiicing", ACS Nano 8, 3152-3169 (2014).

[4] A. A. Hemeda and H. V. Tafreshi, "Liquid-infused surfaces with trapped air (lista) for drag force reduction", Langmuir 32, 2955-2962 (2016).

[5] M. Elsharkawy, D. Tortorella, S. Kapatral, and C. M. Megaridis, "Combating frosting with joule-heated liquid-infused superhydrophobic coatings", Langmuir 32, 4278-4288 (2016).

[6] M. Cao, D. Guo, C. Yu, K. Li, M. Liu, and L. Jiang, "Water-repellent properties of superhydrophobic and lubricant-infused "slippery" surfaces: A brief study on the functions and applications", ACS Appl. Mater. Interfaces 8, 3615-3623 (2016). 
[7] B. R. Solomon, K. S. Khalil, and K. K. Varanasi, "Drag reduction using lubricant-impregnated surfaces in viscous laminar flow", Langmuir 30, 10970-10976 (2014).

[8] S. B. Subramanyam, V. Kondrashov, J. Rühe, and K. K. Varanasi, "Low ice adhesion on nano-textured superhydrophobic surfaces under supersaturated conditions", ACS Appl. Mater. Interfaces 8, 12583-12587 (2016).

[9] I. Okada and S. Shiratori, "High-transparency, self-standable gel-slips fabricated by a facile nanoscale phase separation", ACS Appl. Mater. Interfaces 6, 1502-1508 (2014).

[10] T. P. N. Nguyen, P. Brunet, Y. Coffinier, and R. Boukherroub, "Quantitative testing of robustness on superomniphobic surfaces by drop impact", Langmuir 26, 18369-18373 (2010).

[11] T.-S. Wong, S. H. Kang, S. K. Tang, E. J. Smythe, B. D. Hatton, A. Grinthal, and J. Aizenberg, "Bioinspired self-repairing slippery surfaces with pressure-stable omniphobicity", Nature 477, 443-447 (2011).

[12] H. F. Bohn and W. Federle, "Insect aquaplaning: Nepenthes pitcher plants capture prey with the peristome, a fully wettable water-lubricated anisotropic surface", Proc. Natl. Acad. Sci. U. S. A. 101, 14138-14143 (2004).

[13] P. Kim, T.-S. Wong, J. Alvarenga, M. J. Kreder, W. E. Adorno-Martinez, and J. Aizenberg, "Liquid-infused nanostructured surfaces with extreme anti-ice and anti-frost performance", ACS Nano 6, 6569-6577 (2012).

[14] X. Hou, Y. Hu, A. Grinthal, M. Khan, and J. Aizenberg, "Liquid-based gating mechanism with tunable multiphase selectivity and antifouling behaviour", Nature 519, 70-73 (2015).

[15] A. K. Epstein, T.-S. Wong, R. A. Belisle, E. M. Boggs, and J. Aizenberg, "Liquid-infused structured surfaces with exceptional anti-biofouling performance", Proc. Natl. Acad. Sci. U. S. A. 109, 13182-13187 (2012).

[16] H. A. Stone, "Ice-phobic surfaces that are wet", ACS Nano 6, 6536-6540 (2012).

[17] M. K. Fu, I. Arenas, S. Leonardi, and M. Hultmark, "Liquid-infused surfaces as a passive method of turbulent drag reduction", J. Fluid Mech. 824, 688-700 (2017). 
[18] H. Bazyar, S. Javadpour, and R. G. H. Lammertink, "On the gating mechanism of slippery liquid infused porous membranes", Adv. Mater. Interfaces 3, 1600025 (1-6) (2016).

[19] S. Anand, A. T. Paxson, R. Dhiman, J. D. Smith, and K. K. Varanasi, "Enhanced condensation on lubricant-impregnated nanotextured surfaces", ACS Nano 6, 10122-10129 (2012).

[20] X. Hou, "Smart gating multi-scale pore/channel-based membranes", Adv. Mater. 28, 7049-7064 (2016).

[21] R. Lenormand, E. Touboul, and C. Zarcone, "Numerical models and experiments on immiscible displacements in porous media", J. Fluid Mech. 189, 165-187 (1988).

[22] R. Holtzman and E. Segre, "Wettability stabilizes fluid invasion into porous media via nonlocal, cooperative pore filling", Phys. Rev. Lett. 115, 164501 (2015).

[23] C. Chomsurin and C. J. Werth, "Analysis of pore-scale nonaqueous phase liquid dissolution in etched silicon pore networks", Water Resour. Res. 39, 1265 (2003).

[24] C. Zhang, M. Oostrom, T. W. Wietsma, J. W. Grate, and M. G. Warner, "Influence of viscous and capillary forces on immiscible fluid displacement: Pore-scale experimental study in a water-wet micromodel demonstrating viscous and capillary fingering", Energ. Fuel 25, 3493-3505 (2011).

[25] M. Ferer, C. Ji, G. S. Bromhal, J. Cook, G. Ahmadi, and D. H. Smith, "Crossover from capillary fingering to viscous fingering for immiscible unstable flow: Experiment and modeling", Phys. Rev. E 70, 016303 (2004).

[26] V. Berejnovz, A. Bazylaka, D. Sinton, and N. Djilali, "Fractal flow patterns in hydrophobic microfluidic pore networks: experimental modeling of two-phase flow in porous electrodes", J. Electrochem. Soc. 157, B760-B767 (2010).

[27] C. Cottin, H. Bodiguel, and A. Colin, "Influence of wetting conditions on drainage in porous media: A microfluidic study", Phys. Rev. E 84, 026311 (2011). 
[28] V. Berejnov, N. Djilali, and D. Sinton, "Lab-on-chip methodologies for the study of transport in porous media: energy applications", Lab Chip 8, 689-693 (2008).

[29] C. Cottin, H. Bodiguel, and A. Colin, "Drainage in two-dimensional porous media: From capillary fingering to viscous flow", Phys. Rev. E 82, 046315 (2010).

[30] R. Lenormand, "Liquids in porous media", J. Phys.: Condens. Matter 2, SA79-SA88 (1990).

[31] C. Odier, B. Levaché, E. Santanach-Carreras, and D. Bartolo, "Forced imbibition in porous media: A fourfold scenario", Phys. Rev. Lett. 119, 208005 (2017).

[32] C. Semprebon, G. McHale, and H. Kusumaatmaja, "Apparent contact angle and contact angle hysteresis on liquid infused surfaces", Soft Matter 13, 101-110 (2017).

[33] M. Mietton-Peuchot, C. Condat, and T. Courtois, "Use of gas-liquid porometry measurements for selection of microfiltration membranes", J. Membr. Sci. 133, 73-82 (1997).

[34] H. Darcy, Les Fontaines Publiques de la Ville de Dijon (Victor Dalmont, Paris, Paris) (1856).

[35] E. Antón, J. I. Calvo, J. R. Álvarez, A. Hernández, and S. Luque, "Fitting approach to liquid-liquid displacement porosimetry based on the log-normal pore size distribution”, J. Membr. Sci. 470, 219-228 (2014).

[36] K. R. Morison, "A comparison of liquid-liquid porosimetry equations for evaluation of pore size distribution", J. Membr. Sci. 325, 301-310 (2008).

[37] M. Kobayashi, Y. Terayama, H. Yamaguchi, M. Terada, D. Murakami, K. Ishihara, and A. Takahara, "Wettability and antifouling behavior on the surfaces of superhydrophilic polymer brushes", Langmuir 28, $7212-7222$ (2012).

[38] T. S. G. Olsson and M. Hartley, "jicbioimage: a tool for automated and reproducible bioimage analysis", PeerJ 4, e2674 (2016).

[39] J. Feder, Fractals (Plenum press, New York, New York) (1988). 
[40] K.-A. Lie, An introduction to reservoir simulation using MATLAB: User guide for the Matlab Reservoir Simulation Toolbox (MRST) (SINTEF ICT, December 2016, http://www.sintef.no/Projectweb/MRST/Publications, SINTEF ICT, Department of applied mathematics, Oslo, Norway) (2016).

[41] R. Lenormand and C. Zarcone, "Capillary fingering: Percolation and fractal dimension", Transport Porous Media 4, 599-612 (1989).

[42] S. E. Buckley and M. C. Leverett, "Mechanism of fluid displacement in sands", Trans. AIME 146, 107-116 (1942).

[43] G. F. Pinder and W. G. Gray, Essentials of Multiphase Flow and Transport in Porous Media, 83-164 (John Wiley and Sons, Inc., Hoboken, New Jersey) (2008).

[44] M. Sahimi, Flow and Transport in Porous Media and Fractured Rock, 519-573 (Wiley-VCH Verlag GmbH and Co. KGaA, Weinheim, Germany) (2011).

[45] C. Marle, Multiphase Flow in Porous Media (Gulf Publishing Company, Houston, Texas) (1981). 



\section{4 \\ Liquid-infused membranes with oil-in-water emulsions ${ }^{\circ}$}

The infusion liquid in liquid-infused membranes can be expelled in response to an immiscible feed liquid pressure, forming liquid-lined pores. The pressure responsive pores can be used for efficient sorting of fluids from a mixture. For example in a two-phase mixture of immiscible liquids, the required liquid entry pressure is different for the constituent liquids. In this Chapter, we investigate the capability of liquid-infused membranes for selective permeation of the dispersed phase, i.e. oil from an oil-in-water $(\mathrm{O} / \mathrm{W})$ emulsion. The separation experiments are conducted in a dead-end pressure controlled filtration cell using liquid-infused and non-infused membranes. In order to permeate the dispersed phase, oil droplets should come in contact with the membrane surface which is accomplished here by gravity-driven creaming. Our results reveal that by setting the feed pressure between the entry pressure of oil and that of the surfactant solution, oil can be successfully permeated. For high concentrations of surfactant, water also permeated partly. The amount of water permeated through liquid-infused membranes is lower than that through non-infused membranes, caused by the corresponding interfacial tensions. The results suggest that the presence of the infusion liquid in the membrane gives rise to the formation of three-phase interfaces in the pore, namely the interface between surfactant solution-oil $\left(\gamma_{12}\right)$ and that between oil-infusion liquid $\left(\gamma_{23}\right)$. Based on the interfacial energy contributions, the additional interface between oil and the infusion liquid gives rise to an increase in the liquid entry pressure for the surfactant solution based on the combined interfacial tension $\left(\gamma_{12}+\gamma_{23}\right)$ leading to less water permeation.

${ }^{\circ}$ Published as: Hanieh Bazyar, Noor van de Beek, and Rob G. H. Lammertink, Liquid-infused membranes with oil-in-water emulsions, Langmuir 2019, 35, 9513-9520. 



\subsection{Introduction}

HE rapid industrial growth in the field of oil and gas has led to the production of large amount of oily waste water [1. Oil-containing waste water is also produced in industries related to edible oil and detergent processing, textile (scouring water), pharmacy, and metallurgy [1, 2]. These waste water streams can be either reused or discharged into coastal water or municipal sewage systems. Purification before discharge is of evident importance. Regulations require that the maximum total oil and grease concentration in discharge waters should be less than $10 \mathrm{mg} / 1$ [3].

Several methods to remove oil from waste water include conventional physical and chemical methods. Adsorption using activated carbon or resins, sand filters, and evaporation of water are examples of physical treatments. Chemical treatment methods include oxidation, electrochemical conversion, and photocatalytic degradation. High cost, using toxic compounds, large space for installation, and generation of secondary pollutants are severe drawbacks of the aforementioned conventional methods [4]. Membrane separation methods involving polymeric as well as ceramic membranes have been recently introduced as an efficient technique to treat oily waste water [4, 5. The advantages of membrane processes include lower capital cost, facile fabrication processes, no necessity for chemical additives while generating permeate of acceptable quality [6]. The porous structure of the membrane can act as a conventional coalescer. Permeation of the emulsion through the membrane pores promotes coalescence of micron and submicron oil droplets resulting in destabilization of the emulsion [7. The coalesced large oil droplets can be further separated from the aqueous phase by the use of gravity for instance [8].

The methods for oily waste water treatment based on membrane separation processes rely on reverse osmosis (RO) [9, microfiltration (MF) [10, 11], membrane distillation [12, and ultrafiltration (UF) [6, 13, 14. UF is considered to be one of the most effective treatment techniques for oil/water separation [7. 15. Surface modified Polyethersulfone (PES) and Polysulfone (PSf) UF membranes showed oil retention of $100 \%$ and $90 \%$, respectively, reducing the oil concentration below $10 \mathrm{mg} / \mathrm{l}$ in the aqueous permeate [6, 16]. Ceramic MF membranes exhibited $98.8 \%$ oil rejection efficiency which yielded permeate streams with environmentally acceptable oil concentration [5].

Electrospun fiber membranes were also used for separation of $\mathrm{O} / \mathrm{W}$ emulsions [17-20]. The membranes were tested in both dead-end and cross flow filtration modes showing around $93 \%$ oil rejection [17. It was shown that further surface modification of electrospun fiber membranes can lead to hierar- 
chal superhydrophilic structures with underwater superolephobicity. Surface modification methods include coating by graphene oxide [18, formation of nanoclusters on crosslinked membranes [19, and electrospraying of nanoparticles [20]. These membranes showed good separation efficiency $(>98 \%)$ with high water flux values.

Membranes with peculiar superwetting properties, i.e. in-air superamphiphilic, underwater superoleophobic, and underoil superhydrophobic, showed their potential in separation of both micrometer and nanometer-size $\mathrm{O} / \mathrm{W}$ and water-in-oil (W/O) emulsion with separation efficiency of more than 99\% 21 24]. These membranes are mainly hybrid/composite porous membranes with hierarchal micro/nano-structural surface that are achieved by embedding nano/micro particles to the membrane structure [25, 26]. Huang et. al. showed that combining silica nanofibers and in situ polymerized fluorinated polybenzoxazine (F-PBZ) can be used to fabricate a superhydrophobic superoleophilic nanofibrous membrane. This membrane is further used for gravity-driven separation of oil from $\mathrm{W} / \mathrm{O}$ emulsions in which no external driving force is needed. High flux values with good anti-fouling properties and thermal stability were observed [27]. Recently Janus membranes, i.e. membranes with asymmetric properties on each side have been used for unidirectional oil/water separation [28, 29. A hydrophilic-hydrophobic Janus membrane was used to separate oil from $\mathrm{O} / \mathrm{W}$ emulsion. The hydrophilic side was exposed to the emulsion which facilitated the coalescence of oil droplets. The oil-filled superhydrophobic pores further prevented water permeation [29].

Materials with superwetting properties have found their applications in absorbents as well. "Smart sorbents" in which materials' adsorption properties can be controlled electrically, thermally or magnetically are gaining popularity in $\mathrm{O} / \mathrm{W}$ separation field [30]. Abdulhussein et. al. newly developed a superhydrophobic, superoleophilic magnetic, porous material based on polydimethylsiloxane (PDMS) and steel wool (SW). The PDMS-modified SW can be magnetically guided and is capable of absorbing and separating oils and organic solvents from water. Gravity-driven oil-water separation results showed permeate flux as high as $\sim 32,000 \mathrm{~L} / \mathrm{m}^{2} \mathrm{~h}$ with separation efficiency over $99 \%$ [31.

Limited strength, durability, and unsatisfactory performance are the main drawbacks of membranes with superwetting/antiwetting properties [21. Multiple-step fabrication procedure and in some cases requirement of special chemical or sophisticated techniques further limit wide spread application of the aforementioned membranes. Additionally, in all these membrane processes, 
$\mathrm{O} / \mathrm{W}$ emulsion

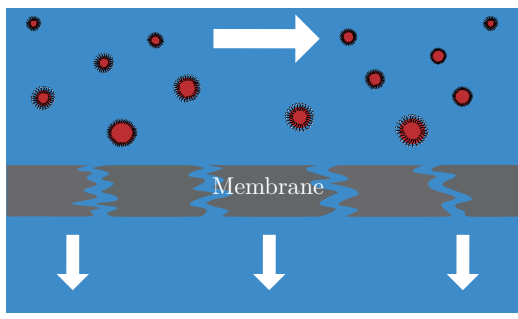

(a)
$\mathrm{O} / \mathrm{W}$ emulsion

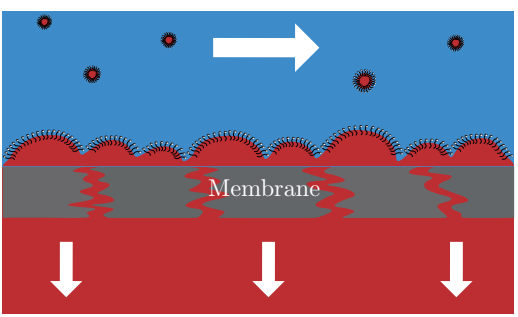

(b)

Figure 4.1: Membrane process for oil separation from $\mathrm{O} / \mathrm{W}$ emulsion by (a) permeation of the continuous water phase (blue) and (b) permeation of the dispersed oil phase (red).

the continuous aqueous phase permeates through the membrane providing a concentrated retentate and purified water as permeate (Figure 4.1(a)). The consequence of this is that a large volume of continuous water phase has to permeate, with accompanying fouling challenges. A method to reduce the permeating volume is to permeate the dispersed phase instead of the continuous phase (Figure 4.1(b) . Permeation of the dispersed phase from an $\mathrm{O} / \mathrm{W}$ emulsion using a membrane requires two steps. Firstly, the dispersed phase must come in contact with the membrane, and likely coalesce on the surface. Secondly, the oil should permeate through the membrane with little or no water, requiring some degree of affinity between the oil and membrane phase [32].

Here, we report on the application of a novel type of membrane, i.e. a liquid-infused membrane, for selective permeation of the dispersed phase from an $\mathrm{O} / \mathrm{W}$ emulsions. An additional liquid phase that is present in the membrane concerns an alternative approach to oil-water separation using membranes. These membranes are inspired by a new class of functional surfaces, known as slippery liquid-infused porous surfaces (SLIPS) [33. The capillarystabilized liquid in the nano/microstructured surface forms a smooth lubrication layer on the surface responsible for its low water contact angle hysteresis and low-fouling properties [34 36]. Other important features of these surfaces include self-healing by capillary wicking, repelling a variety of liquids, and anti-biofouling [33, 34]. Fabrication of SLIPS often requires multi-step processing, high temperatures and drying mainly to render the substrate hydrophobic and match the chemistry between solid and infusion liquid [37, 38. Porous polymeric membranes with low surface energies may provide effective alternatives. These membranes are typically prepared from fluorinated 
polymers, e.g. polyvinylidene fluoride (PVDF) and polytetrafluoroethylene (PTFE) [36, 39, 40.

Liquid infusion has been proved to be a good technique to improve the water sliding properties of surfaces. Hu et. al. demonstrated that infusion of silicone oil into antismudge polyurethane-based coatings (SINP-GLIDE) can decrease the sliding angle of water and various organic liquids. Water sliding properties did not degrade after subjecting to violent simulated rain cycles [41]. Recently, it was demonstrated that liquid-filled pores can form a reconfigurable gate which allow liquid permeation based on interfacial tension. This gating mechanism gives liquid-infused membranes the capability of multiphase transport without clogging [36, 42]. In for example a two-phase mixture of immiscible fluids, like $\mathrm{O} / \mathrm{W}$ emulsions, the selective permeation of one fluid and retention of the other one can be achieved by setting the feed pressure between the entry pressure of the permeating fluid and that of the retained fluid. The entry pressure is set by the Laplace pressure [43]

$$
\Delta P=\frac{2 \gamma\left|\cos \theta_{\mathrm{E}}\right|}{r},
$$

where $r$ is the pore radius $(\mathrm{m}), \gamma$ is the interfacial tension $(\mathrm{N} / \mathrm{m})$ between permeating fluid and liquid, and $\theta_{\mathrm{E}}$ is the advancing contact angle (larger than $90^{\circ}$ ) of the permeating fluid with respect to the pore wall.

The gating mechanism of liquid-infused membranes was previously explored via gas-liquid displacement porometry [40], (see Chapter Two). The liquid film thickness on the pore wall (liquid-lining) was estimated experimentally and theoretically. Liquid-liquid displacement porometry (LLDP) measurements showed the presence of liquid-lined pores even after pushing pure water through liquid infused membranes at high flux values [44] (see Chapter Three). The observed displacement mechanism, visualized using microfluidics, revealed liquid-lining and preferential flow pathways for water transport. The presence of an additional liquid layer on the pore wall prevents direct contact between the permeating fluid and the solid material of the membrane giving rise to the potential anti-fouling properties [36] (see Chapter Five). The anti-fouling properties of liquid-infused membranes as well as pressure responsive pores for selective fluid transport are attractive for separation applications. The good performance of these membranes in efficient sorting of a three-phase airwater-oil mixture [36] makes them a potential candidate for oily wastewater treatment.

In this work, the performance of liquid-infused membranes for oil permeation from $\mathrm{O} / \mathrm{W}$ emulsions is investigated and compared to non-infused coun- 
terparts (dry membrane). The underlying mechanism for the improved performance of the liquid-infused membranes for selective oil permeation is further explored in detail. This work shows the potential application of liquid-infused membranes to treat oily wastewater.

\subsection{Experimental details}

\subsubsection{Materials}

Polyvinylidene fluoride (PVDF) (Solef 6020/1001) was received from Solvay Solexis, France. 1-methyl-2-pyrrolidinone (NMP) (99\% extra pure) was purchased from Acros Organics, The Netherlands. Ethanol (100\% v/v) technical grade was supplied from Boom chemical company, The Netherlands. Krytox GPL oil 101 was purchased from MAVOM chemical industry, The Netherlands. Hydrochloric acid (ACS reagent grade, fuming $\geq 37 \%$ ) was supplied from Merck Millipore, The Netherlands. Hexadecane (reagent plus 99\%), 2-propanol (anhydrous, 99.5\%), sudan IV (dye content $\geq 80 \%$ ), perylene fluorescent dye (sublimed grade $\geq 99.5 \%$ ), sodium dodecyl sulfate (SDS) (ACS reagent, $\geq 99.0 \%$ ), hexadecetyltrimethylammonium bromide (CTAB) ( $\geq 99 \%$ ), sodium hydroxide (reagent grade, $\geq 98 \%$ pellets (anhydrous)), potassium chloride (bioXtra, $\geq 99.0 \%$ ) were purchased from Sigma-Aldrich, The Netherlands.

\subsubsection{Fabrication of membrane and dense PVDF film}

The polymer solution was prepared by mixing 15 wt.\% PVDF in NMP with a mechanical stirrer overnight at $80^{\circ} \mathrm{C}$. The solution was cast on a glass plate using a casting knife at an initial thickness of $500 \mu \mathrm{m}$. The cast membrane was immediately submerged in water/NMP (25:75 vol.\%) as the coagulation bath for $60 \mathrm{~min}$. The remaining NMP was removed from the membrane by subsequently keeping it in ethanol for another $60 \mathrm{~min}$. The cast membrane was then attached to a piece of paper using paper clips to prevent curling and left to dry in a fume hood $(60 \mathrm{~min})$ before placing it in a $30^{\circ} \mathrm{C}$ vacuum oven overnight.

Dense PVDF film was made by casting the polymer dope solution on a glass plate using the same procedure as described for membrane fabrication. The cast polymer solution was placed in a box and dried with a flow of nitrogen for two days. 


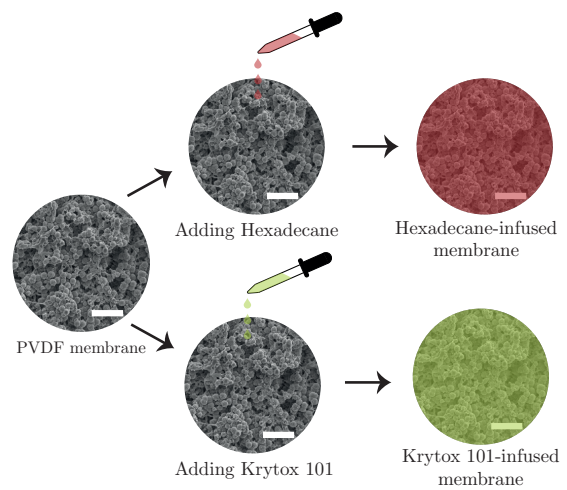

(a)

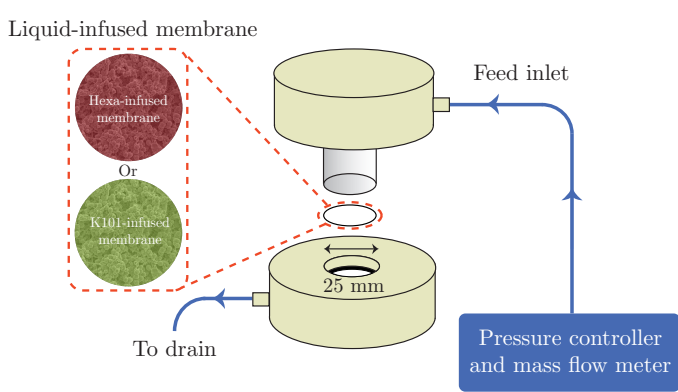

(b)

Figure 4.2: (a) SEM image of the membrane (scale bar is $10 \mu \mathrm{m}$ ) with schematic illustration of fabrication of liquid-infused membranes. (b) Schematic illustration of the LEP measurement set-up.

\subsubsection{Membrane characterization}

The pore size distribution of the membrane was characterized using capillary flow porometer (Porolux-1000) (see Appendix C, Figure C.2). The morphology of the top, bottom, and the cross section of the membranes were observed using scanning electron microscope (SEM) (JEOL 5600 LV) (see Appendix C Figure C.1. The surface wetting properties of the fabricated membranes were investigated using contact angle Goniometer (Dataphysics OCA20) (see Table 4.4).

\subsubsection{Fabrication of liquid-infused membranes}

Liquid-infused membranes were prepared by adding an over coat layer $(15.5 \mu \mathrm{l}$ $\mathrm{cm}^{-2}$ ) of perfluoropolyether (PFPE) oil, i.e. Krytox GPL 101 oil (K101), on the membranes using a micropipette. In order to have a high affinity between the infusion liquid and the PVDF membrane, a fluorinated oil, i.e. K101, was used as the infusion liquid. This is an important criteria for design and fabrication of liquid-infused surfaces [33. Hexadecane-infused membranes were prepared using the same procedure by adding hexadecane to the membrane. Both oils spontaneously infiltrated the pores via capillary wicking (Figure $4.2(\mathrm{a})$. 
Table 4.1: Overview of the used surfactants and the corresponding critical micelle concentration (CMC) values measured experimentally (see Appendix CFigures C.11 and C.16.

\begin{tabular}{lcc}
\hline Surfactant & Charge & CMC (mM) \\
\hline Sodium dodecyl sulfate (SDS) & Anionic & $8.1\left(\right.$ at $\left.20-25^{\circ} \mathrm{C}\right)$ \\
Cetyl trimethyl ammonium bromide (CTAB) & Cationic & $0.92($ at 20-25 C) \\
\hline
\end{tabular}

\subsubsection{Preparation of surfactant solutions}

Two different surfactants (anionic SDS, and cationic CTAB) were used to prepare the surfactant solutions (see Table 2.1). Four solutions have been prepared by dissolving $10 \%$ and $50 \%$ CMC of each surfactant in pure water (Milli-Q grade). A period of more than $12 \mathrm{~h}$ was given for all surfactants to completely dissolve in water.

\subsubsection{Measurement of liquid entry pressure (LEP)}

The liquid entry pressures of all the aforementioned surfactant solutions (see Table 4.1) through K101-infused and hexadecane-infused membranes were measured. The measurement was performed by increasing the pressure stepwise, while measuring the permeate flux using a Bronkhorst pressure controller (IN-PRESS P-502CI) and mass flow meter (mini CORI-FLOW M14) which were connected using a control valve (COMBI-FLOW Mass flow C5I). Depending on the surfactant type and the infusion liquid, pressure steps of 22 mbar or 5.5 mbar were used. The small steps ( 5.5 mbar, which is the accuracy of the pressure controller) were considered for surfactant solutions with low interfacial tension values with hexadecane, i.e. CTAB 10 and 50 (see Figure 4.4(a) . At each step, the pressure was kept constant for $200 \mathrm{~s}$. The pressure at which the solution started permeating through the membrane and a stable flux was measured, was defined as the liquid entry pressure, LEP. The schematic illustration of the set-up is shown in Figure 4.2(b)

\subsubsection{Measurements of interfacial tension (IFT)}

The interfacial tension (IFT) values between different surfactant solutions and oils, Krytox 101 and hexadecane, were measured using a contact angle goniometer (Dataphysics OCA20). The pendant drop method was used for this measurements based on the drop shape analysis (see Figure 4.4(a) and Appendix C for more information on the procedure and Table C.2. . 


\subsubsection{Preparation and characterization of emulsions}

The $\mathrm{O} / \mathrm{W}$ emulsions have been prepared by dispersing 5 wt.\% of hexadecane in the surfactant solution. A mechanical dispersing instrument (IKA Ultra Turrax T18 digital) was used for emulsification. The emulsion was prepared by slowly adding the oil using a long needle (stainless steel 304 syringe needle, noncoding point (Z117056-1EA)) and a syringe to a 11 Schott Duran glass bottle containing the surfactant solution. The mixing was done at $14000 \mathrm{rpm}$ for $15 \mathrm{~min}$. All the used devices including dispensing instrument, syringe, and the needle were cleaned thoroughly with 2-propanol and rinsed with pure water (Milli-Q grade) before preparation of the new emulsions. In order to better distinguish between oil and water in oil permeation experiments, hexadecane was dyed red using sudan IV dye (see Appendix C, Figure C.3(a). The observation of the emulsion was done using an inverted laser scanning confocal microscope (LSCM) (A1 system, Nikon Corporation, Japan) with a $40 \times$ dry objective (Plan Fluor, $40 \times$ DIC M N2, numerical aperture (NA) $=0.75$, calibration $0.62 \mu \mathrm{m} / \mathrm{px}$ ). For this purpose, an oil-soluble fluorescent dye (Perylene) was added to hexadecane (see Appendix C Figures C.3(b) and C.3(c) for the picture and the 3D image of the prepared emulsion respectively). The droplet size distribution of the $\mathrm{O} / \mathrm{W}$ emulsion was measured using dynamic light scattering (Mastersizer 2000) (see Figure 4.5 and Appendix C section "Droplet size distribution of prepared emulsions").

\subsubsection{Oil permeation from the $\mathrm{O} / \mathrm{W}$ emulsion experiments}

Unlike normal filtration in which the continuous phase is permeating through the membrane, the challenge here is to permeate the dispersed phase while retaining the continuous phase. To achieve this, oil droplets should come in contact with the membrane which was obtained by placing the filtration cell up side down. A schematic illustration of the set-up together with the LSCM image of the emulsion made with $10 \%$ CMC of SDS is shown in Figure 4.3 To observe the fabricated emulsion in the cell, the liquid chamber of the cell has been made out of transparent polymethyl methacrylate (PMMA).

Oil (hexadecane) permeability of the non-infused (dry) and K101-infused membranes was measured based on liquid-liquid displacement (LLD) experimental results (see Appendix C, section "LLD analysis of hexadecane through liquid-infused membrane"). In LLD experiments, pure hexadecane was pushed through the membrane at increasing flux while measuring pressure. Permeability was measured according to Darcy's law Appendix C, Euqation C.1 


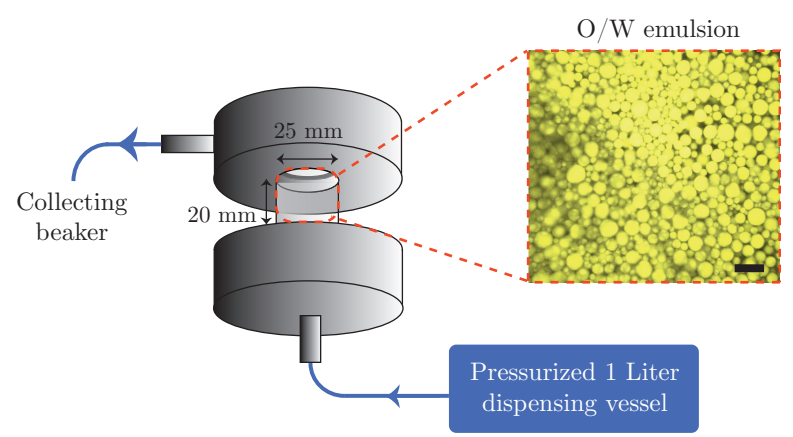

Figure 4.3: Schematic illustration of the dead-end filtration set-up and LSCM image of the emulsion (scale bar is $25 \mu \mathrm{m}$ ). The dispensing vessel was filled with $500 \mathrm{ml}$ of emulsion and pressurized with nitrogen gas. The pressure was controlled using a pressure regulator.

based on the corresponding linear relation between oil flux and pressure.

\subsection{Results and discussion}

\subsubsection{LEP and IFT measurement results}

The IFT values between surfactant solutions and oils, Krytox 101 (K101) and hexadecane, were measured using the pendant drop method (see Appendix C for more information on the procedure and Figures C.11 and C.16). The results up to $50 \%$ of the corresponding $\mathrm{CMC}$ values are shown in Figure 4.4(a). The experimental data points are fitted to the Szyszkowski equation where the relation between IFT and surfactant concentration is defined as 45 .

$$
\gamma=\gamma^{*}-b \gamma^{*} \ln \left(1+\frac{C}{a}\right)
$$

Here, $C$ is the surfactant concentration $\left(\mathrm{mol} / \mathrm{m}^{3}\right), a$ and $b$ are the fitting parameters, $\gamma$ is the interfacial tension (IFT) between oil and the surfactant solution $(\mathrm{N} / \mathrm{m})$, and $\gamma^{*}$ is the IFT value between pure water and pure oil $(\mathrm{N} / \mathrm{m}$ ) (see Appendix C Table C.2. Fitting was done using the least square fitting method in MATLAB. The fitting parameters $a$ and $b$ are summarized in Table 4.2 (see Appendix C Figures C.12 and C.17 for the fitting results together with the corresponding $95 \%$ confidence intervals bounds).

The LEP results of all the surfactant solutions through K101 and hexadecane-infused membranes are shown in Figure 4.4(b). The LEP data 


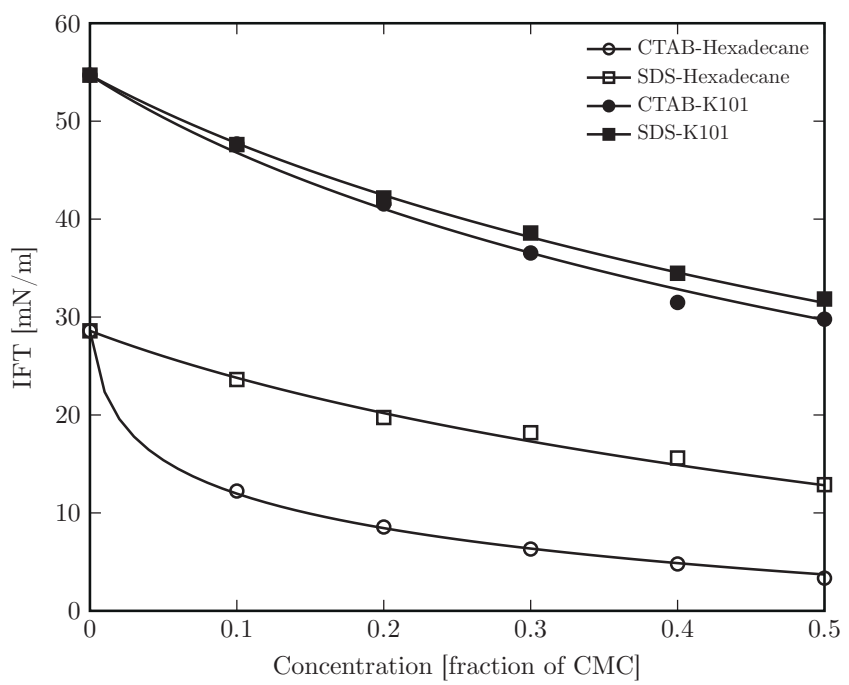

(a)

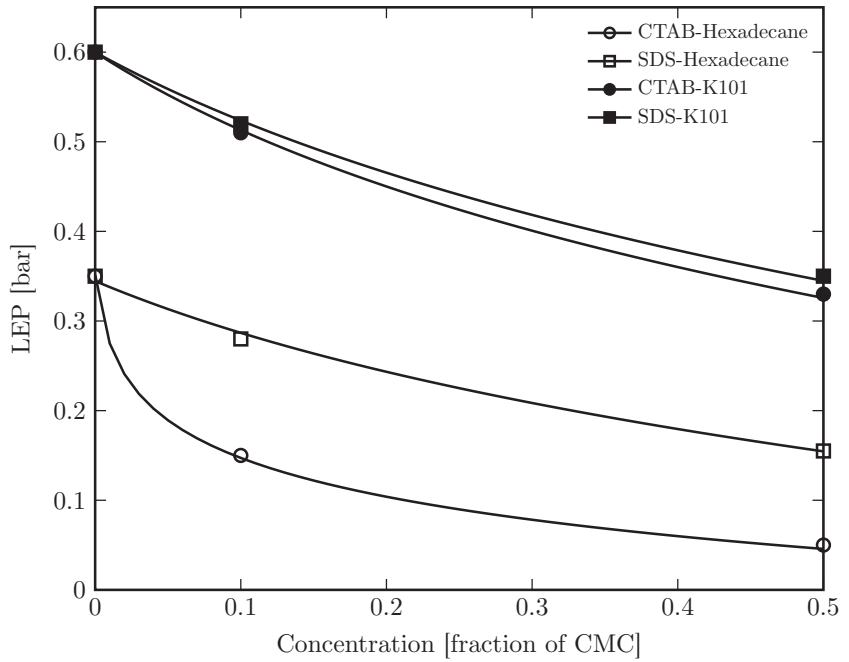

(b)

Figure 4.4: (a) Interfacial tension (IFT) values between surfactant solutions, hexadecane, and K101 as a function of surfactant concentration (symbols are experiments, lines are fitted to Szyszkowski equation (Equation 4.2p). (b) LEP values of surfactant solutions through K101 and hexadecane infused membranes (symbols are experiments, lines are fitted to Equation 4.3) 
Table 4.2: Fitting parameters of fitted experimental data points of IFT and LEP to Szyszkowski equation (Equation 4.2) and Laplace equation (Equation 4.1) by considering Szyszkowski relation for the IFT value (Equation 4.3 respectively (all the values after \pm are half of the the confidence interval limits ((Upper CI - Lower CI) $/ 2)$ )

\begin{tabular}{lccc}
\hline \multirow{2}{*}{ Surfactant solution-oil } & \multicolumn{3}{c}{ Fitting parameters } \\
\cline { 2 - 4 } & $a\left(\mathrm{~mol} / \mathrm{m}^{3}\right)$ & $b(-)$ & $r(\mu \mathrm{m})$ \\
\hline CTAB-Hexadecane & $4.02 \times 10^{-3} \pm 1.75 \times 10^{-3}$ & $1.83 \times 10^{-1} \pm 1.66 \times 10^{-2}$ & $1.63 \pm 6.96 \times 10^{-2}$ \\
CTAB-K101 & $2.01 \times 10^{-1} \pm 4.93 \times 10^{-2}$ & $3.83 \times 10^{-1} \pm 5.13 \times 10^{-2}$ & $1.82 \pm 3.41 \times 10^{-2}$ \\
SDS-Hexadecane & $2.08 \pm 8.31 \times 10^{-1}$ & $5.11 \times 10^{-1} \pm 1.16 \times 10^{-1}$ & $1.66 \pm 9.25 \times 10^{-2}$ \\
SDS-K101 & $2.24 \pm 2.64 \times 10^{-1}$ & $4.12 \times 10^{-1} \pm 2.81 \times 10^{-2}$ & $1.82 \pm 4.06 \times 10^{-2}$ \\
\hline
\end{tabular}

points are fitted to the Laplace equation (Equation 4.1) by considering complete non-wetting $\left(\theta_{\mathrm{E}}=180^{\circ}\right)$ and the Szyszkowski relation (Equation 4.2) for the corresponding IFT value. The surfactant concentration in Equation 4.2 is considered to be the concentration in the bulk solution, i.e. $C_{0}$ leading to

$$
\Delta P=\frac{2 \gamma^{*}}{r}\left(1-b \ln \left(1+\frac{C_{0}}{a}\right)\right) .
$$

Equation 4.3 relates the LEP of each surfactant solution to the surfactant concentration and radius of curvature $r$. The fitted values for the curvature radii (see Table 4.2 are smaller than the largest pore radius of the membrane, $1.92 \mu \mathrm{m}$, suggesting some pore-narrowing due to liquid-lining.

It is worth mentioning that as the surfactant solution is pushed through the membrane pore, surfactant can get adsorbed on the liquid-lined pore leading to a lower local concentration in the pore $\left(C_{P}\right)$ compared to that of the bulk concentration $\left(C_{0}\right)$. In Equation 4.3, adsorption is considered in equilibrium with the bulk concentration $C_{0}$. By including surfactant adsorption on the liquid-lined pore, the surfactant concentration in the pore $\left(C_{P}\right)$ should be used in Equation 4.3. $C_{P}$ values highly depend on pore radius $r$ (see Appendix $\mathrm{C}$ section "Surfactant adsorption on the liquid-lined pore in hexadecane-infused membranes" for more information on the relation between $C_{0}$ and $C_{P}$ ). We observed that using $C_{0}$ matched with the experimental liquid entry pressure. This suggests that the initial entry interface contains adsorbed surfactant in equilibrium with the bulk concentration which is not significantly affected by any surfactant depletion due to adsorption.

In order to further choose the proper operating pressure for dead-end filtration, the LEP of pure hexadecane through dry and K101-infused membranes 


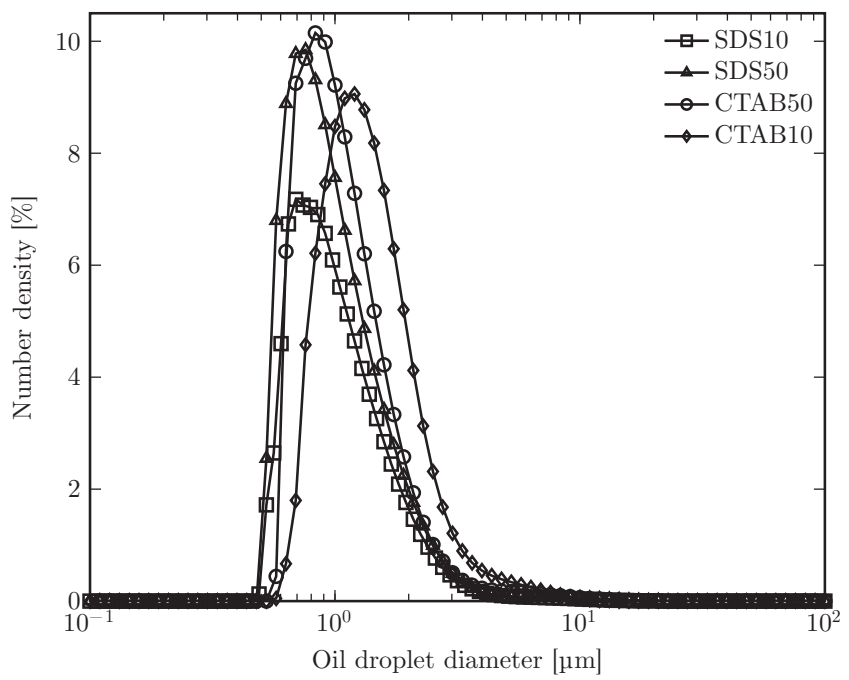

Figure 4.5: Comparison of the number density droplet size distribution of all the prepared hexadecane in water emulsions, with indicated surfactant concentration.

have been also measured. As expected, hexadecane wicks spontaneously through dry membrane and therefore the LEP is zero. For a K101-infused membrane, a LEP for hexadecane of 0.08 bar was measured corresponding to an interfacial tension of $8.7 \pm 0.08 \mathrm{mN} / \mathrm{m}$ (see Appendix C Table C.1).

\subsubsection{Oil permeation from the $\mathrm{O} / \mathrm{W}$ emulsion}

The comparison of the number-averaged droplet size distribution of all the prepared emulsions are shown in Figure 4.5 (see Appendix C Figure C.10 for the number and volume-averaged droplet size distribution of each emulsion separately).

One can calculate the creaming rate for each emulsion according to Stokes's law,

$$
u=\frac{2 a^{2}\left(\rho-\rho_{0}\right) g}{9 \mu},
$$

where $a$ is the droplet radius $(\mathrm{m}),\left(\rho-\rho_{0}\right)$ is the density difference between continuous and dispersed phases $\left(\mathrm{kg} / \mathrm{m}^{3}\right), g$ is the gravitational acceleration $\left(\mathrm{m} / \mathrm{s}^{2}\right)$, and $\mu$ is the dynamic viscosity of the continuous phase (Pa s) [46]. For example, the creaming rate of the emulsion made with SDS 10 is between 0.06 
Table 4.3: The amount of water permeated through dry and K101-infused membranes as a function of surfactant concentration during oil permeation experiments at TMP $\leq 0.1$ bar.

\begin{tabular}{lcc}
\hline \multirow{2}{*}{ Emulsion } & Fraction of water in the permeate \\
\cline { 2 - 3 } & K101-infused & Dry \\
\hline SDS 10 & 0 & 0 \\
SDS 50 & 0.05 & 0.2 \\
CTAB 10 & 0 & 0 \\
CTAB 50 & 0.25 & 0.5 \\
\hline
\end{tabular}

and $19.85 \mu \mathrm{m} / \mathrm{s}$, corresponding to the smallest and largest droplets respectively. Once the droplets reach the membrane surface, they will coalesce and subsequently form a hexadecane oil layer (see Appendix CFigure C.6(d)) on the membrane surface. By applying a transmembrane pressure (TMP) which is higher than the LEP of hexadecane and lower than that of the surfactant solutions (see section LEP and IFT measurement results), oil can selectively permeate through the membrane. The applied TMP for all the experiments was smaller than 0.1 bar. Dry membranes as well as K101-infused membranes were tested for selective oil permeation using all prepared $\mathrm{O} / \mathrm{W}$ emulsions. The performance of these two membranes were compared and the results are summarized in Table 4.3. The amount of water in each permeate was estimated from the corresponding collected permeate (see Appendix C Figures C.7 C.9.

It is worth mentioning that in the dead-end filtration experiments the flux is mainly set by the concentration of the minor phase. As a result, oil permeation in dead-end filtration mode is a discontinuous process and limited by the amount of loaded oil droplets. Calculation of the corresponding permeability based on Figure C.5 in Appendix C shows lower oil permeability through K101-infused membrane compared to that from LLD analysis (see Table C.3). This can be explained based on the fewer active (opened) pores in the emulsion separation experiments compared to the LLD experiments.

According to Table 4.3 , at low concentration of surfactants (10\% CMC), no water was observed in the permeate of both membranes. The applied TMP ( $\leq 0.1$ bar) is lower than the LEP for the corresponding surfactant solutions through both liquid-infused membranes (see Figure 4.4(b). During oil permeation experiments, the dry membrane becomes completely infused with hexadecane (see Appendix C Figure C.6(b)). The K101-infused membrane shows some regions of hexadecane with about $45 \%$ remaining infusion 


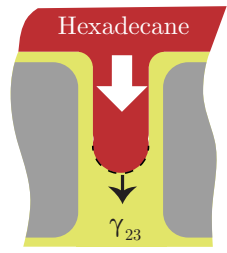

Low Surfactant Conc.

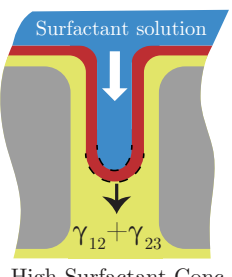

(a)
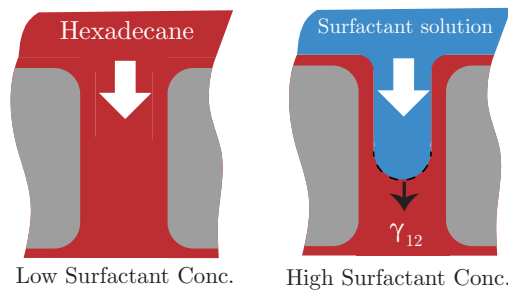

High Surfactant Conc.

(b)

Figure 4.6: Schematic illustration of the interfaces in (a) K101-infused pore, and (b) dry pore at low and high concentrations of surfactants. Yellow colour shows K101 infusion liquid $\left(\gamma_{12}\right.$ and $\gamma_{23}$ are the IFT between surfactant solution-hexadecane and hexadecane-K101 respectively).

liquid (see Appendix CFigure C.6(c) and section"LLD analysis of hexadecane through liquid-infused membrane" .

At a higher concentration of surfactants $(50 \% \mathrm{CMC})$, water was observed in the permeate from both membranes (see Appendix CFigures C.8 and C.9(c) and C.9(d) for pictures of the permeates). This observation was expected for the dry membrane since the applied TMP is slightly higher than the LEP of CTAB 50 (0.05 bar) and very close to that of SDS 50 (0.15 bar) for a hexadecane-infused membrane. Because the TMP is lower than the LEP of the aforementioned surfactant solutions for K101-infused membranes (Figure 4.4(b), no water was expected in the permeate. The LEP values were measured when pure surfactant solutions were pushed through K101-infused membranes. However, in the oil permeation experiments, hexadecane forms a layer on the K101-infused membrane (Figure 4.6(a) . Therefore, the surfactant solution is in contact with a hexadecane layer rather than with K101, resulting in a lower interfacial tension (IFT) compared to K101 only (Figure 4.4(a)).

The presence of three liquids leads to two interfaces that have their corresponding IFT, i.e. surfactant solution-hexadecane $\left(\gamma_{12}\right)$ and hexadecane-K101 $\left(\gamma_{23}\right)$ (see Figure 4.6(a)). This leads to a higher combined liquid entry pressure by the addition of interfacial tensions, i.e. surfactant solution-hexadecaneK101 $\left(\gamma_{12}+\gamma_{23}\right)$ compared to that of the dry pore without liquid-lining, i.e. surfactant solution-hexadecane $\left(\gamma_{12}\right)$ (Figure 4.6(b)) . By considering the IFT value between K101-hexadecane $\left(\gamma_{23}=8.7 \pm 0.08 \mathrm{mN} / \mathrm{m}\right.$ (see Appendix CTable C.1), the LEP for SDS and CTAB solutions with concentration of 50\% CMC would increase to 0.26 bar and 0.15 bar respectively, resulting in less water permeation. 
Table 4.4: Static and ARCA measurements on dry and K101-infused membranes before and after oil separation from emulsions containing SDS (SDS 10 and SDS 50).

\begin{tabular}{lcccc}
\hline \multirow{2}{*}{ Membrane } & \multicolumn{4}{c}{ Contact angle $\left(^{\circ}\right)$} \\
\cline { 2 - 5 } & Mean static & $\begin{array}{c}\text { Advancing } \\
\left(\theta_{\text {Adv }}\right)\end{array}$ & $\begin{array}{c}\text { Receding } \\
\left(\theta_{\text {Rec }}\right)\end{array}$ & Hysteresis \\
\hline K101-infused (Before) & $117 \pm 0.1$ & $119 \pm 0.1$ & $114 \pm 0.3$ & $5.1 \pm 0.3$ \\
K101-infused (SDS 10) & $102.81 \pm 1.98$ & $104.12 \pm 0.35$ & $93.90 \pm 0.51$ & $10.21 \pm 0.26$ \\
K101-infused (SDS 50) & $102.42 \pm 0.65$ & $94.47 \pm 0.11$ & $91.46 \pm 0.39$ & $8.02 \pm 0.45$ \\
Dry (Before) & $136 \pm 0.3$ & $142.3 \pm 0.26$ & $117 \pm 1.2$ & $25 \pm 1$ \\
Dry (SDS 10) & $103 \pm 0.68$ & $103.15 \pm 0.26$ & $88.25 \pm 0.51$ & $14.90 \pm 0.30$ \\
Dry (SDS 50) & $103.21 \pm 0.43$ & $98.32 \pm 0.14$ & $87.68 \pm 1.69$ & $10.64 \pm 1.60$ \\
\hline
\end{tabular}

\subsubsection{Contact angle results}

In order to have a better understanding regarding the membrane surface properties, contact angle measurements have been performed on dry and K101infused membranes before and after oil permeation. The results of static as well as advancing receding contact angle (ARCA) measurements performed on dry and K101-infused membrane before and after oil permeation from $\mathrm{O} / \mathrm{W}$ emulsions containing SDS are shown in Table 4.4 .

As can be seen in Table 4.4, K101-infused membranes still display slippery behaviour after oil permeation indicated by the low contact angle hysteresis. The larger hysteresis compared to the fresh K101-infused membrane reveals likely some reduced K101 coverage on the membrane. The dry membrane showed a decrease in hysteresis upon oil permeation due to the infusion of hexadecane in the membrane after oil permeation (see Appendix C Figure C.6 (b)).

A decrease in the water contact angle (static as well as dynamic, $\theta_{\mathrm{Adv}}$ and $\left.\theta_{\text {Rec }}\right)$ is observed after oil permeation for both membranes which can be explained by surfactant adsorption on the membrane surface.

\subsection{Conclusion}

In this work we have reported on the permeation of oil droplets from oil-inwater $(\mathrm{O} / \mathrm{W})$ emulsions, containing water soluble surfactants through liquidinfused and non-infused (dry) PVDF membranes. A fluorinated oil, perfluoropolyether (Krytox 101), has been used to fabricate liquid-infused membranes (K101-infused). To permeate a hexadecane oil phase, dead-end filtration has been conducted. Four O/W emulsions were made by dispersing 5 wt. $\%$ hexade- 
cane in surfactant solutions containing $10 \%$ and $50 \%$ CMC of two water-soluble surfactants (SDS and CTAB). Based on the liquid entry pressure (LEP) of the surfactant solutions and hexadecane through dry and K101-infused membranes, a transmembrane pressure (TMP) smaller than 0.1 bar is sufficient for selective oil permeation. The results revealed that both membranes could selectively permeate oil and retain water from the $\mathrm{O} / \mathrm{W}$ emulsions containing low concentration of surfactants (10\% CMC). At high surfactant concentrations $(50 \% \mathrm{CMC})$ water was also observed in the permeate from both membranes. The amount of permeated water through a dry membrane was greater than that through a K101-infused membrane using the same surfactant. This can be explained by the presence of two interfaces, i.e., surfactant-hexadecane $\left(\gamma_{12}\right)$ and hexadecane-K101 $\left(\gamma_{23}\right)$. The combined interfacial tension $\left(\gamma_{12}+\gamma_{23}\right)$, and thus the Laplace pressure, will be higher compared to that for a dry membrane with only the IFT of $\gamma_{12}$. This leads to an increase in the required liquid entry pressure of the surfactant solution in case of the K101-infused membrane. This work demonstrates the potential of liquid-infused membranes for emulsion separations. The separation mechanism is governed by the corresponding interfacial tensions between liquid phases involved. Much lower fluxes are required in case of selective permeation of the dispersed phase, providing routes to energy efficient and low fouling membrane separation processes.

\section{References}

[1] M. A. Shannon, P. W. Bohn, M. Elimelech, J. G. Georgiadis, B. J. Mariñas, and A. M. Mayes, "Science and technology for water purification in the coming decades", Nature 452, 301-310 (2008).

[2] G. Anderson, C. Saw, and M. Le, "Oil/water separation with surface modified membranes", Environmental Technology Letters 8, 121-132 (1987).

[3] "Standards for discharge of effluent into water or on land, s. i. no 5", Technical Report, Uganda (1999).

[4] M. Padaki, R. S. Murali, M. Abdullah, N. Misdan, A. Moslehyani, M. Kassim, N. Hilal, and A. Ismail, "Membrane technology enhancement in oil-water separation. a review", Desalination 357, 197-207 (2015).

[5] B. Nandi, A. Moparthi, R. Uppaluri, and M. Purkait, "Treatment of oily wastewater using low cost ceramic membrane: Comparative assessment 
of pore blocking and artificial neural network models", Chemical Engineering Research and Design 88, 881-892 (2010).

[6] B. Chakrabarty, A. Ghoshal, and M. Purkait, "Ultrafiltration of stable oil-in-water emulsion by polysulfone membrane", Journal of Membrane Science 325, 427-437 (2008).

[7] M. Hlavacek, "Break-up of oil-in-water emulsions induced by permeation through a microfiltration membrane", Journal of Membrane Science 102, 1-7 (1995), engineering of Membrane Processes II Environmental Applications.

[8] D. F. Sherony, R. C. Kintner, and D. T. Wassan, "Coalescence of secondary emulsions in fibrous beds", Surface and Colloid Science 10, 99-161 (1978).

[9] T. Mohammadi, M. Kazemimoghadam, and M. Saadabadi, "Modeling of membrane fouling and flux decline in reverse osmosis during separation of oil in water emulsions", Desalination 157, 369-375 (2003), desalination and the Environment: Fresh Water for all.

[10] J. Zhong, X. Sun, and C. Wang, "Treatment of oily wastewater produced from refinery processes using flocculation and ceramic membrane filtration", Separation and Purification Technology 32, 93-98 (2003), seventh International Conference on Inorganic Membranes.

[11] H. Ohya, J. Kim, A. Chinen, M. Aihara, S. Semenova, Y. Negishi, O. Mori, and M. Yasuda, "Effects of pore size on separation mechanisms of microfiltration of oily water, using porous glass tubular membrane", Journal of Membrane Science 145, 1-14 (1998).

[12] M. Gryta and K. Karakulski, "The application of membrane distillation for the concentration of oil-water emulsions", Desalination 121, 23-29 (1999).

[13] K. Karakulski, A. Kozlowski, and A. Morawski, "Purification of oily wastewater by ultrafiltration", Separations Technology 5, 197-205 (1995).

[14] Y. He and Z.-W. Jiang, "Technology review: Treating oilfield wastewater", Filtration and Separation 45, 14-16 (2008). 
[15] M. Bodzek and K. Konieczny, "The use of ultrafiltration membranes made of various polymers in the treatment of oil-emulsion wastewaters", Waste Management 12, 75-84 (1992).

[16] W. Chen, J. Peng, Y. Su, L. Zheng, L. Wang, and Z. Jiang, "Separation of oil/water emulsion using pluronic f127 modified polyethersulfone ultrafiltration membranes", Separation and Purification Technology 66, 591 597 (2009).

[17] Y.-M. Lin and G. C. Rutledge, "Separation of oil-in-water emulsions stabilized by different types of surfactants using electrospun fiber membranes", Journal of Membrane Science 563, 247 - 258 (2018).

[18] J. Zhang, Q. Xue, X. Pan, Y. Jin, W. Lu, D. Ding, and Q. Guo, "Graphene oxide/polyacrylonitrile fiber hierarchical-structured membrane for ultrafast microfiltration of oil-water emulsion", Chemical Engineering Journal 307, 643 - 649 (2017).

[19] J. Wang, L. Hou, K. Yan, L. Zhang, and Q. J. Yu, "Polydopamine nanocluster decorated electrospun nanofibrous membrane for separation of oil/water emulsions", Journal of Membrane Science 547, 156 - 162 (2018).

[20] J. Ge, J. Zhang, F. Wang, Z. Li, J. Yu, and B. Ding, "Superhydrophilic and underwater superoleophobic nanofibrous membrane with hierarchical structured skin for effective oil-in-water emulsion separation", J. Mater. Chem. A 5, 497-502 (2017).

[21] Y. Liao, M. Tian, and R. Wang, "A high-performance and robust membrane with switchable super-wettability for oil/water separation under ultralow pressure", Journal of Membrane Science 543, 123 - 132 (2017).

[22] C. Yang, N. Han, W. Wang, W. Zhang, C. Han, Z. Cui, and X. Zhang, "Fabrication of a pps microporous membrane for efficient water-in-oil emulsion separation", Langmuir 34, 10580-10590 (2018).

[23] Y. Xiang, Y. Wang, H. Lin, Y. Wang, Z. Xiong, and F. Liu, "Efficient separation of $\mathrm{o} / \mathrm{w}$ and $\mathrm{w} / \mathrm{o}$ micro-emulsion by thermally responsive superantiwetting pvdf membrane", Reactive and Functional Polymers 97, $86-95$ (2015).

[24] M. Tao, L. Xue, F. Liu, and L. Jiang, "An intelligent superwetting pvdf membrane showing switchable transport performance for oil/water separation", Advanced Materials 26, 2943-2948 (2014). 
[25] J. Pan, C. Xiao, Q. Huang, H. Liu, and T. Zhang, "Ectfe hybrid porous membrane with hierarchical micro/nano-structural surface for efficient oil/water separation", Journal of Membrane Science 524, 623 - 630 (2017).

[26] Z. Chu, Y. Feng, and S. Seeger, "Oil/water separation with selective superantiwetting/superwetting surface materials", Angewandte Chemie International Edition 54, 2328-2338 (2015).

[27] M. Huang, Y. Si, X. Tang, Z. Zhu, B. Ding, L. Liu, G. Zheng, W. Luo, and J. Yu, "Gravity driven separation of emulsified oil-water mixtures utilizing in situ polymerized superhydrophobic and superoleophilic nanofibrous membranes", J. Mater. Chem. A 1, 14071-14074 (2013).

[28] H.-C. Yang, J. Hou, V. Chen, and Z.-K. Xu, "Janus membranes: Exploring duality for advanced separation", Angewandte Chemie International Edition 55, 13398-13407 (2016).

[29] Z. Wang, Y. Wang, and G. Liu, "Rapid and efficient separation of oil from oil-in-water emulsions using a janus cotton fabric", Angewandte Chemie International Edition 55, 1291-1294 (2016).

[30] A. Turco, C. Malitesta, G. Barillaro, A. Greco, A. Maffezzoli, and E. Mazzotta, "A magnetic and highly reusable macroporous superhydrophobic/superoleophilic pdms/mwnt nanocomposite for oil sorption from water", J. Mater. Chem. A 3, 17685-17696 (2015).

[31] A. T. Abdulhussein, G. K. Kannarpady, and A. S. Biris, "One-step synthesis of a steel-polymer wool for oil-water separation and absorption", npj Clean Water 2, 10 (2019).

[32] A. G. Lefferts, "Membranes as separators of dispersed emulsion phases", Ph.D. thesis, Wageningen University (1997).

[33] T.-S. Wong, S. H. Kang, S. K. Tang, E. J. Smythe, B. D. Hatton, A. Grinthal, and J. Aizenberg, "Bioinspired self-repairing slippery surfaces with pressure-stable omniphobicity", Nature 477, 443-447 (2011).

[34] A. K. Epstein, T.-S. Wong, R. A. Belisle, E. M. Boggs, and J. Aizenberg, "Liquid-infused structured surfaces with exceptional anti-biofouling performance", Proc. Natl. Acad. Sci. U. S. A. 109, 13182-13187 (2012). 
[35] P. Kim, T.-S. Wong, J. Alvarenga, M. J. Kreder, W. E. Adorno-Martinez, and J. Aizenberg, "Liquid-infused nanostructured surfaces with extreme anti-ice and anti-frost performance", ACS Nano 6, 6569-6577 (2012).

[36] X. Hou, Y. Hu, A. Grinthal, M. Khan, and J. Aizenberg, "Liquid-based gating mechanism with tunable multiphase selectivity and antifouling behaviour", Nature 519, 70-73 (2015).

[37] H. A. Stone, "Ice-phobic surfaces that are wet", ACS Nano 6, 6536-6540 (2012).

[38] S. Anand, A. T. Paxson, R. Dhiman, J. D. Smith, and K. K. Varanasi, "Enhanced condensation on lubricant-impregnated nanotextured surfaces", ACS Nano 6, 10122-10129 (2012).

[39] I. Okada and S. Shiratori, "High-transparency, self-standable gel-slips fabricated by a facile nanoscale phase separation", ACS Appl. Mater. Interfaces 6, 1502-1508 (2014).

[40] H. Bazyar, S. Javadpour, and R. G. H. Lammertink, "On the gating mechanism of slippery liquid infused porous membranes", Advanced materials Interfaces 3, 1600025 (1-6) (2016), 1600025.

[41] H. Hu, J. Wang, Y. Wang, E. Gee, and G. Liu, "Silicone-infused antismudge nanocoatings", ACS Applied Materials \& Interfaces 9, 9029-9037 (2017), pMID: 28225251.

[42] X. Hou, "Smart gating multi-scale pore/channel-based membranes", Adv. Mater. 28, 7049-7064 (2016).

[43] P. S. Laplace, Traité de mécanique céleste, tome quatriéme (Treatise on Celestial Mechanics, tome 4), Supplément au livre $X$ du Traité de mécanique céleste. Sur l'action capillaire (Supplement to Book 10 of the Treatise on Celestial Mechanics. On the capillary action), P. 349-417. (Courcier, Paris, France) (1805).

[44] H. Bazyar, P. Lv, J. A. Wood, S. Porada, D. Lohse, and R. G. H. Lammertink, "Liquid-liquid displacement in slippery liquid-infused membranes (SLIMs)", Soft Matter 14, 1780-1788 (2018).

[45] B. von Szyszkowski, "Experimentelle studien über kapillare eigenschaften der wässerigen lösungen von fettsäuren. (experimental studies of the 
capillary properties of aqueous solutions of fatty acids)", Zeitschrift für Physikalische Chemie 64, 385-414 (1908).

[46] S. H. Lamb, Hydrodynamics, 6 edition (Cambridge university press, Cambridge university, United Kingdom) (1945). 



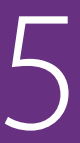

\section{Application of liquid-infused membranes to mitigate biofilm growth ${ }^{\circ}$}

Among different types of membrane fouling, biofouling is a critical issue which can significantly reduce the process productivity. If the initial phase of the microorganism attachment to the pore wall is prevented, a remarkable reduction in biofilm formation can be obtained. A novel approach to achieve this goal is the infusion of the porous membrane with an infusion liquid (oil) forming liquid-infused membranes (LIMs). We have shown in Chapter Three that the pore wall during permeation is still covered with the infusion liquid forming so-called liquid-lined pores. The liquid-lining can enhance anti-biofouling performance by preventing direct contact between the microorganisms and pore wall. Here, we investigate the capability of LIMs in mitigation of biofouling by conducting long-term crossflow filtration experiments at constant flow rate for approximately 20 days. The results show significantly lower increase in transmembrane pressure (TMP) values for LIMs compared to non-infused counterparts (dry membranes). The bacterial growth curves are further investigated by fitting a sigmoidal function (logistic model). Approximately 4 times increase in the lag period $\lambda$ and 7 times decrease in the bacterial growth rate $\mu_{\mathrm{m}}$ are observed for LIMs compared to dry membranes revealing improved anti-biofouling performance of LIMs.

'Submitted as: Hanieh Bazyar, Linya Xu, Hendrik Jan de Vries, Slawomir Porada, and Rob G. H. Lammertink, Application of liquid-infused membranes to mitigate biofilm growth, 2020. 



\subsection{Introduction}

EMBRANE fouling is a major problem in membrane filtration processes which curtails long-term operation. Biofouling, i.e. the accumulation of living material (or remnants of the decomposition thereof) on the membrane surface, has been known as a contributing factor to more than $45 \%$ of all membrane fouling [1, 2]. Controlling and monitoring biofouling are of great importance due to its adverse effects such as membrane flux decline, increased feed and transmembrane pressure (TMP), membrane biodegradation, and increased energy consumption [3. Membrane biofouling is related to the interaction of biosolids with the membrane. This interaction mainly consists of formation of biofilms or the accumulation of bioorganic materials including extracellular polymeric substances (EPS) on the membrane surface [4, 5]. So far, three fouling mechanisms are recognized for membrane biofouling. These mechanisms include adsorption of EPS to the membrane surface, pore clogging by cells, and sludge cake or film formation arising from the deposition of cells or aggregates. The relative importance of each mechanism is site-specific and depends on a number of factors [6]. The attachment of microbial cells to the membrane surface is the first step of membrane biofouling leading to the formation of the biofilm layer [7.

Passive and active strategies have been developed to mitigate biofilm by minimizing the deposition and growth of microorganisms on membrane surfaces [8 10]. The passive strategies generally involve membrane surface modification by grafting [11, 12, polymer brushes [13], zwitterions [14] and hydrophilic or superhydrophilic materials [15, 16]. The passive strategy performs well against fouling under low or mild fouling conditions. Under severe conditions this strategy may lose its efficiency due to the quick coverage of the membrane surface by the foulant layer [17. An active strategy could be to incorporate biocides on the membrane surface to deactivate bacteria and prevent biofilm formation [15, 18]. Long-term efficiency of active strategies is limited due to the eventual depletion of biocides or accumulation of dead cells on the membrane surface which will shield the antimicrobial material 19. An ideal anti-biofouling membrane should have both passive and active functions to minimize bacterial absorption and deactivate bacterial growth on the membrane surface [20. Recently, combination of both active and passive strategies have been used to improve anti-biofouling properties of thin-film composite forward osmosis (TFC-FO) membranes. Polydopamine coating and silver nanoparticles (Ag NPs) were used as the passive and active antibacterial moieties respectively. Ag NPs were stable and active on membrane surfaces 
after $24 \mathrm{~h}$ of cross-flow operation [21].

Combining antifouling and antimicrobial strategies has been highlighted as the most effective approach to mitigate membrane biofouling [15]. Requirement of special chemicals, use of sophisticated techniques, a more complex and multi-step membrane functionalization are the main drawbacks of this method to mitigate membrane biofouling. Additionally, the passive methods fail in dynamic cross flow conditions due to their inability to inactivate the attached bacterial growth [21. Recently a chemical-free approach has been introduced for bacteria inactivation. In these techniques, UV is generated internally inside the membrane module by using embedded radioluminescent particles which are excited by an external X-ray source. However, application of this method is limited to reactors and open areas that can accommodate lamps/LEDs and wiring [22. Therefore, the necessity for a new and simple method to mitigate biofouling during membrane processes still exists.

Here we report on the application of a novel type of membrane, i.e. a liquidinfused membrane (LIM), for mitigation of biofilm formation and growth. These membranes are inspired by a new class of functional surfaces, known as slippery liquid-infused porous surfaces (SLIPS) [23]. The capillary-stabilized liquid in the nano/microstructured surface forms a smooth lubrication layer on the surface responsible for its low water contact angle hysteresis and lowfouling properties [24 26]. Other important features of these surfaces include self-healing by capillary wicking, repelling a variety of liquids, and antibiofouling [23, 24]. Fabrication procedure of liquid-infused membrane includes infusion of the membrane with a low surface tension liquid that has a high affinity to the membrane material [23]. Porous polymeric membranes with low surface energies, which are typically prepared from fluorinated polymers such as polyvinylidene fluoride (PVDF) and polytetrafluoroethylene (PTFE), can be used [26-28]. The liquid-infused pore acts like a gate which can open and close in response to the immiscible feed fluid pressure [26]. In the open state, the pore wall is still covered with the infusion liquid forming liquid-lined pores [26, 28, 29. The gating mechanism was previously explored by pushing nitrogen gas through liquid-infused pores [28]. The liquid film thickness on the pore wall (liquid-lining) was estimated experimentally and theoretically. The presence of liquid-lining was further studied when water was pushed through via liquid-liquid displacement porometry (LLDP) [29. The application of liquid-infused membranes was further investigated for separation of oil from oil-in-water $(\mathrm{O} / \mathrm{W})$ emulsions [30]. The dispersed phase, i.e. oil from $\mathrm{O} / \mathrm{W}$ emulsion was successfully permeated through the membrane while the contin- 
uous phase, i.e. water was being retained.

The anti-biofouling performance of SLIPS was first investigated by Epstein et. al. [24]. It was shown that SLIPS is capable of preventing $99.6 \%$ of Pseudomonas aeruginosa biofilm over a period of 7 days as well as Staphylococcusaureus (97.2\%) and Escherichia coli (96\%). Both static and dynamic experiments were performed where liquid was flowing over the surface. In contrast to SLIPS, nanostructured superhydrophobic surfaces accumulate biofilm within hours. SLIPS showed approximately 35 times reduction of the attached biofilm compared to the best case scenario for improvement of anti-biofouling performance, i.e. PEGylated surface over a far longer time frame. The inability of biofilms to firmly attach to the surface of SLIPS is a result of the non-adhesive "slippery" character of the smooth liquid interface. The growth of $P$. aeruginosa in the presence of $1 \%$ concentration of different infusion liquids, confirmed that inhibition of biofilm attachment on SLIPS was not a result of cytotoxicity of the infusion liquid. Overton et. al. demonstrated the ability of the liquid-gated PTFE membranes to recover flux after both protein and bacteria fouling without the use of harsh chemicals or antibiotics [31. Flux recovery of liquid-gated membranes (LGMs, that are similar to LIMs) occurred during a 15- or 30-min cessation of flow or rest. A maximum of $60 \%$ recovery of clean-membrane flux was observed compared to $10 \%$ in membranes with no lubricant layer. The refilling of the pores with the lubricant forces the foulants from the pore wall. The flux recovery process was repeatable for at least 12 consecutive cycles although decreases with each subsequent cycles. This was mainly due to the accumulation of the cake layer combined with the loss of lubricant during filtration. The flux recovery of LGMs were also investigated after fouling with $S$. epidermidis biofilms. Since bacteria are able to grow on lubricated surfaces [32, LGMs demonstrated neither reduced surface biofilm formation nor recovered flux after a similar resting step. However, preformed S. epidermidis biofilms could be removed by exposure of the LGM to an airwater interface, resulting in a significant recovery of flux when compared to non-lubricated controls. Recently, the formation of Pseudomonas aeruginosa biofilms on Fluoropor-SLIPS has been investigated [33]. Fluoropor are highly fluorinated polymer foams with adjustable porosity which are made via radical emulsion polymerization. It has been shown that Fluoropor-SLIPS can significantly reduce the formation of a biofilm on the substrates over a time period of seven days in a flow chamber experiment. It was also demonstrated that lower surface roughness resulted in a more effective reduction of biofilm attachment. This was attributed to the attachment of biofilm on topographi- 
cal features penetrating the lubricant layer which form preferred locations for bacteria adhesion.

In all the mentioned works, the biofouling properties of liquid-infused surfaces were investigated via flowing the liquid over the surface, without actual permeate flow. The anti-biofouling performance was then related to the slipperiness of the surface. In our previous work, we have shown that the after filtration using liquid-infused membranes, the coverage of the liquid on the membrane surface is reduced confirmed by a larger contact angle hysteresis [30]. The loss of lubricant during filtration was also observed by Overton et. al. 31. This can lead to less or no slippery behaviour on the membrane surface during filtration which can cause penetration of bacteria through the membrane pores. These effects are of great importance specially in long-term filtration processes which have been not yet studied.

In this work, we investigate the long-term performance of liquid-infused membranes (LIMs) in cross flow filtration in which bacteria are capable of penetrating through the liquid-filled pores. The performance of LIMs are compared to that of non-infused counterparts (dry membranes). The feed solution is tap water which permeates through the membranes together with the nutrient solution over a period of 20 days. The development of biofouling is monitored by measuring the increase in transmembrane pressure (TMP) over time. The change in TMP is utilized for the first time as an indication of bacterial population on the liquid-infused membrane surface to obtain bacterial growth curve during filtration. The obtained growth curves for both liquidinfused and dry membranes are modelled using a sigmoidal logistic model and linear regression. Three individual biological phases, i.e. lag phase, exponential phase and stationary phase are determined which illustrate the antibiofouling performance of the corresponding membranes. The results show an increase in lag period and substantial decrease in bacterial growth rate for liquid-infused compared to dry membranes. These results together with those of flow cytometry, further confirm the capability of liquid-infused membranes to mitigate biofilm formation and growth.

\subsection{Experimental details}

\subsubsection{Materials}

Sodium acetate $\left(\mathrm{CH}_{3} \mathrm{COONa}\right)$ and sodium phosphate monobasic dihydrate $\left(\mathrm{NaH}_{2} \mathrm{PO}_{4} \cdot 2 \mathrm{H}_{2} \mathrm{O}\right)$ were purchased from VWR international. Sodium nitrate $\left(\mathrm{NaNO}_{3}\right)$ was supplied from Sigma Aldrich, The Netherlands. Disinfectant 
tablets (Suma tab D4) were purchased from Sealed air diversey care, The Netherlands. Dulbecco's powder was purchased from Panreac Applichem ITW Reagents, Germany. Krytox GPL oil 101 (K101) was purchased from MAVOM chemical industry, The Netherlands. Commercial polyvinylidene fluoride (PVDF) membrane (HVHP00010, Durapore) was supplied from Merck, The Netherlands. Propidium iodide, SYBR green, and LIVE/DEAD BacLight kit were purchased from Invitrogen, USA.

\subsubsection{Membranes and spacers}

A commercial PVDF microfiltartion membrane (HVHP00010) was used in this study. The average pore radius of the membrane is $0.51 \mu \mathrm{m}$ with size distribution of $0.043 \mu \mathrm{m}$ (full width at half $\max / 2$ ) (see Appendix D Figure D.2p. The feed and permeate spacer were obtained from DOW FILMTEC (NF270-400/34i) membrane module, The Netherlands.

\subsubsection{Fabrication of liquid-infused membranes}

The proper size of the membrane $(22.5 \times 11 \mathrm{~cm})$ was cut from the membrane roll. Liquid-infused membrane was then prepared by adding an over coat layer $\left(15.5 \mu \mathrm{l} \mathrm{cm}^{-2}\right)$ of perfluoropolyether (PFPE) oil, i.e. Krytox GPL 101 oil (K101), on the membranes using a micropipette. In order to have a high affinity between the infusion liquid and the PVDF membrane, a fluorinated oil, i.e. K101, was used as the infusion liquid. This is an important criteria for design and fabrication of liquid-infused surfaces [23]. The infusion liquid spontaneously infiltrated the pores via capillary wicking. The liquid-infused membranes were used approximately $1 \mathrm{hr}$ after preparation.

\subsubsection{Membrane characterization}

The pore size distribution of the membrane was characterized using capillary flow porometer (Porolux-1000) (see Appendix D, Figure D.2). The morphology of the top, bottom, and the cross section of the membranes were observed using scanning electron microscope (SEM) (JEOL 5600 LV) (see Appendix D, Figure D.1). The surface wetting properties of both dry and liquid-infused membranes were investigated using contact angle Goniometer (Dataphysics OCA20) (see Appendix D Table D.1). The water permeability of the membranes was measured using liquid-liquid displacement experiments (LLD) (see Appendix D section "LLD analysis" and Table D.2. In LLD experiments, 
pure water (MQ-grade) was pushed through the membrane at increasing flux while measuring pressure. Permeability was measured according to Darcy's law (Equation D.2 in Appendix D) based on the corresponding linear relation between water flux and pressure.

\subsubsection{Bacteria nutrient preparation}

A solution of $\mathrm{CH}_{3} \mathrm{COONa}, \mathrm{NaNO}_{3}$ and $\mathrm{NaH}_{2} \mathrm{PO}_{4} \cdot 2 \mathrm{H}_{2} \mathrm{O}$ was prepared as the nutrient solution. In total four bottles of nutrient solutions, each with volume of $10 \mathrm{l}$ were required. The nutrient solutions were prepared by dissolving $3.6 \mathrm{~g}$ of $\mathrm{CH}_{3} \mathrm{COONa}, 0.55 \mathrm{~g}$ of $\mathrm{NaH}_{2} \mathrm{PO}_{4} \cdot 2 \mathrm{H}_{2} \mathrm{O}$ and $1.3 \mathrm{~g}$ of $\mathrm{NaNO}_{3}$ in pure water (MQ-grade). All solutions were autoclaved at $121^{\circ} \mathrm{C}$ for $1.5 \mathrm{hr}$. The effect of higher concentration of nutrients, namely $7.4 \mathrm{~g} \mathrm{CH}_{3} \mathrm{COONa}, 1.1 \mathrm{~g}$ $\mathrm{NaH}_{2} \mathrm{PO}_{4} .2 \mathrm{H}_{2} \mathrm{O}$, and $2.6 \mathrm{~g} \mathrm{NaNO} 3$ on bacterial growth were also investigated (see Appendix D section "Effect of nutrient concentration").

\subsubsection{Biofouling experiments}

The biofouling experiment was performed in a cross flow cell called transparent membrane biofouling monitor (tMBM). The schematic of the set-up is shown in Figure 5.1. The membrane module is made of transparent polymethylmethacrylate (PMMA). The module includes one feed, one concentrate and one permeate connection. The external dimensions of the module are $300 \times 170 \times 0.787 \mathrm{~mm}$. The total area of the permeate spacer is $185 \mathrm{~cm}^{2}$. The feed channel dimension is $200 \times 100 \times 0.787 \mathrm{~mm}$. The module can withstand pressures up to 5 bars. The pressure development over the feed channel and the membrane was measured via external connections at the feed, concentrate, and permeate sides. During the fouling experiments, the tMBMs were covered in non-transparent boxes to prevent growth of phototrophic organisms. The height of the feed channel is equivalent to the height of the feed spacer ( 787 $\mu \mathrm{m})$ which enables operating the system in two configurations, i.e. with or without the presence of the feed spacer. The membrane is fixed in place by a frame on the edge of the feed channel and is sealed by an O-ring. This construction prevents shifting of the membrane even without the presence of the feed spacer. The membrane area allows harvesting of a sufficient amount of biomass for analyses. More information on setup configuration for operation of the membrane module can be found elsewhere [34]. 


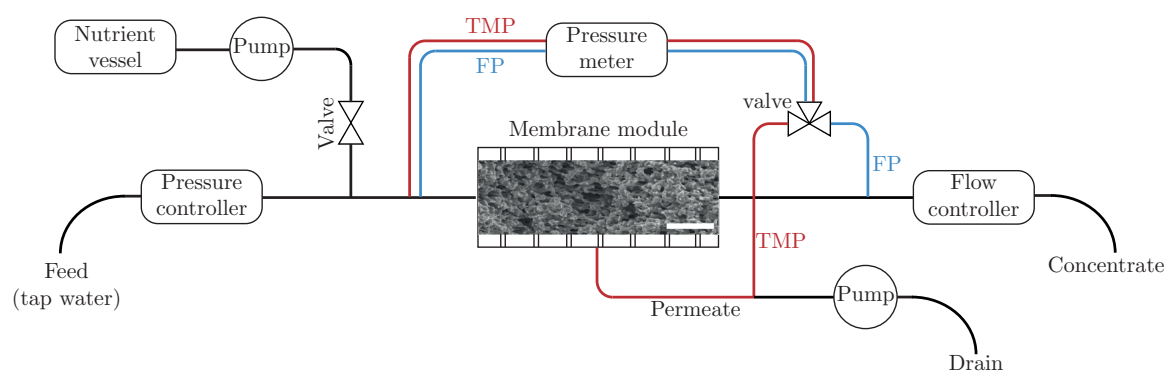

Figure 5.1: Schematic illustration of the cross flow filtration set-up and SEM image of the membrane cross section (scale bar is $10 \mu \mathrm{m}$ ). TMP and FP respectively show transmembrane pressure and feed pressure lines.

\subsubsection{Process description of biofouling experiment}

All biofouling growth experiments were carried out using an experimental system described in [34] and schematically shown in Figure 5.1. The feedwater was first filtered through two $10 \mu \mathrm{m}$ pore size cartridge filters and its pressure was adjusted to 1.7 bar using a pressure reducer (V782, Vink Kunststoffen B.V., Didam, The Netherlands). Before feed water entered the tMBM, nutrients were added using a peristaltic pump (Masterflex L/S pumps, Cole-Palmer Instrument Company, Vernon Hills, Illinois, USA) at constant flow rate of 0.5 $\mathrm{ml} / \mathrm{min}$. The linear flow velocity was monitored and controlled by a flow controller for each tMBM which was installed at the outlet of each monitor. The concentrate flow rate was fixed at $320 \mathrm{ml} / \mathrm{min}$. The permeate rate was maintained by a peristaltic pump (Masterflex L/S pumps, Cole-Palmer instrument Company, Vernon Hills, Illinois, USA) and was equal to $250 \mathrm{ml} / \mathrm{hr}$. The fouling development was monitored by measuring the pressure drop over the feed channel and over the membrane, using a differential pressure transmitter (Deltabar S PMD70, Endress+Hauser, Maulburg, Germany). The concentrate and permeate flow rate, TMP, feed channel pressure drop (FCP), were logged twice a day.

\subsubsection{Membrane autopsy}

Membrane autopsy was performed on membranes obtained from the transparent membrane biofouling monitors (size of each membrane was $2 \times 5 \mathrm{~cm}$ ). Samples of the membrane and spacer were collected from different locations over the length of the membrane. Structure of the biofilm was visualized using a confocal laser scanning microscope, CLSM (Zeiss LSM, Oberkochen, 
Germany). Flow cytometry was performed to determine the viability of the bacterial community. Vitality of the bacterial community of the membrane biofilm was quantified by flow cytometry (easyCyte flow cytometer systems, EMD Millipore) after the cells were stained with a mixture of propidium iodide and SYBR green to a final concentration of $4 \mu \mathrm{M}$ and $1 \mathrm{x}$, respectively. Counting was performed using a benchtop flow cytometer (Guava easyCyte; Merck Millipore). Data were recorded for 5,000 events gated in the bivariate side scatter (SSC-H log) versus green-H log dot plot with a flow rate of 0.24 $\mathrm{mL} / \mathrm{s}$. The biofilm was observed with CLSM using an oil 40x 1.3 NA objective lens. The samples were stained using LIVE/DEAD BacLight kit with mixture of green-fluorescent nucleic acid stain (SYTO 9) and the red-fluorescent nucleic acid stain (propidium iodide) in 1:1 proportion. $15 \mu \mathrm{l}$ of the dye mixture was added to the biofilm and incubated at room temperature in the dark for 15 minutes. Finally, the biofilm was mounted with Vectashield H-1000 media, and coverslip.

\subsection{Results and discussion}

\subsubsection{Membrane biofouling results}

Two cross flow configurations with and without the presence of the feed spacer in the membrane module (tMBM) have been tested for biofouling assessment of liquid-infused and dry membranes. The initial transmembrane pressure (TMP) values are shown in Table 5.1. The initial pressure values for permeating water through the membrane was also measured in liquid-liquid displacement (LLD) experiments while pushing MQ water through the membranes (see Appendix D, section "LLD analysis"). According to Table 5.1, the initial TMP values are quite similar for these two methods. The initial TMP value for the dry membrane is lower in the biofouling experiment compared to that measured in LLD experiment. This is because in the biofouling experimental set-up (see Figure 5.1) the membrane pores have been already opened and filled with water leading to lower TMP values. It is important to note that a dead-end filtration module is used in LLD experiment (see Figure D.3(a) in Appendix D in which spacer does not exist and only the TMP is measured.

The TMP increase over time was measured twice a day. The TMP development in time for both membranes with and without the feed spacer are shown in Figure 5.2. It is evident that the presence of the feed spacer leads to earlier biofilm growth for both dry and liquid-infused membranes. Vrouwenvelder et. al. also observed a much faster feed channel pressure drop increase in the 
Table 5.1: Initial values of transmembrane pressure (TMP) for tested membranes and different cell configurations in biofouling and liquid-liquid displacement (LLD) experiments.

\begin{tabular}{lcc}
\hline \multirow{2}{*}{ Membrane and cell configuration } & \multicolumn{2}{c}{ Initial TMP (bar) } \\
\cline { 2 - 3 } & Biofouling & LLD $^{*}$ \\
\hline Dry-without spacer & $2.2 \times 10^{-2} \pm 0.1 \times 10^{-2}$ & $6.4 \times 10^{-1}$ \\
Dry-with spacer & $4.7 \times 10^{-2} \pm 0.1 \times 10^{-2}$ & $6.4 \times 10^{-1}$ \\
LIM-without spacer & $1.26 \pm 5.5 \times 10^{-2}$ & $8.4 \times 10^{-1}$ \\
LIM-with spacer & $1.21 \pm 5.5 \times 10^{-2}$ & $8.4 \times 10^{-1}$ \\
\hline
\end{tabular}

*Accuracy of the measured pressure is 5.5 mbar

presence of a feed spacer [35].

For both cell configurations, we observe steeper curves (faster TMP growth) and higher TMP for dry membranes compared to liquid-infused counterparts. The final TMP increase for LIM is approximately 2 times lower than that of dry membrane. The similar ratio is observed between the population density of bacteria on both membranes without the presence of the feed spacer (see section Membrane autopsy results). Thus, we have used the TMP values as an indication of the number of bacteria on the membrane surface for further modeling and comparison of the anti-biofouling performance of both membranes.

\subsubsection{Modeling of bacterial growth}

Normally, bacterial growth curve is presented by the logarithm of the number of organisms $\left(\ln \left(\frac{\mathrm{N}}{\mathrm{N}_{0}}\right)\right)$ as a function of time. The changes of growth rate results in a Sigmoidal curve with a lag phase, an exponential phase and a stationary phase. By determining these three phases, one can define the lag period $(\lambda)$, the specific growth rate $\left(\mu_{\mathrm{m}}\right)$, and the asymptotic value $(A)$ respectively [36]. There are two methods that can be used to define the three phases of a growth curve, i.e. linear regression and growth model. In linear regression, $\mu_{\mathrm{m}}$ is estimated by defining the most linear part of the growth curve and calculating the slope using linear regression. A better method is to describe the entire set of data with a growth model and estimating $\mu_{\mathrm{m}}, \lambda$, and $A$ from the model. Examples of growth models are the Gompertz, Logistic, Richards, Stannard, and Schunte models [36].

To obtain the bacterial growth curves, we used the values of TMP increase over time. Gaveau et. al. proposed a strong correlation between membrane efficiency (ratio between bacterial concentration in the feed to that in the per- 


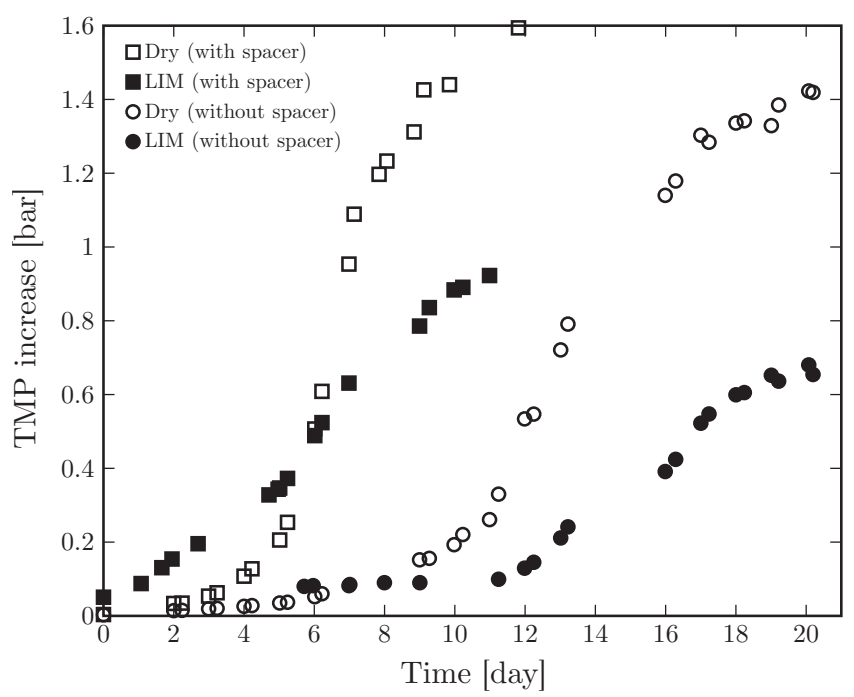

Figure 5.2: Transmembrane pressure (TMP) increase as a function of time for dry and liquid-infused membrane with and without spacer in the cross flow membrane module (tMBM).

meate) and the driving force, as the ratio between applied force by TMP and tension force, based on numerical models [37. They showed that for Gramnegative bacteria strains such as $E$. coli and $P$. aeruginosa, the higher the driving force, the lower the separation efficiency due to the increased transmission of bacteria through membrane pores via deformation of bacteria cell (stretching mechanism). Based on their results, the TMP is directly related to the ratio between bacterial concentration in the feed and that in the permeate. As a relevant and accessible parameter, we have fitted the TMP value as a function of time to growth curve models. We present the fit parameters in terms of biological parameters, i. e. $\lambda, \mu_{\mathrm{m}}$ and $A$. Although the pressure response is not necessarily correlated linearly to the bacterial growth, this type of modeling does quantify the biofouling behaviour of membranes.

The growth curve is plotted as logarithm of the ratio between TMP values $(P)$ and initial pressure $\left(P_{0}\right)\left(\ln \left(\frac{\mathrm{P}}{\mathrm{P}_{0}}\right)\right)$ as a function of time. $P_{0}$ corresponds to the initial TMP values (see Table 5.1). Both linear regression and the logistic growth model have been used to further analyze the growth curves. The logistic model is represented by

$$
y=\frac{a}{1+\exp (b-c t)}
$$


Table 5.2: Biological parameters calculated based on fitting parameters of fitted experimental data points of $\ln \left(\frac{\mathrm{P}}{\mathrm{P}_{0}}\right)$ as a function of time to logistic model (Equation 5.1) (all the values after \pm are half of the $95 \%$ confidence interval limits ((Upper CI - Lower CI)/2)).

\begin{tabular}{lccc}
\hline \multirow{2}{*}{ Membrane and cell configuration } & \multicolumn{3}{c}{ Biological parameters } \\
\cline { 2 - 4 } & $\lambda($ day $)$ & $\mu_{m}(1 /$ day $)$ & $A(-)$ \\
\hline Dry-without spacer & $2.70 \pm 0.35$ & $0.34 \pm 0.03$ & $4.41 \pm 0.12$ \\
Dry-with spacer & $2.17 \pm 0.24$ & $0.65 \pm 0.10$ & $3.64 \pm 0.13$ \\
LIM-without spacer & $10.29 \pm 0.37$ & $0.05 \pm 0.01$ & $0.48 \pm 0.04$ \\
LIM-with spacer & $1.08 \pm 0.29$ & $0.07 \pm 0.01$ & $0.64 \pm 0.04$ \\
\hline
\end{tabular}

where $a, b$ and $c$ are the fitting parameters [38. It is one of the models proposed by Verhulst in 1838 as possible description of the succession of age frequencies in human populations [39]. In order to define the logistic model based on the biological parameters, the model is determined as

$$
y=\frac{A}{1+\exp \left(\frac{4 \mu_{m}}{A}(\lambda-t)+2\right)},
$$

where $A=a, \mu_{m}=\frac{a c}{4}$, and $\lambda=\frac{b-2}{c}$ (see Appendix D section "Modification of logistic model" for the corresponding mathematical analysis).

The fitting results of $\ln \left(\frac{\mathrm{P}}{\mathrm{P}_{0}}\right)$ as a function of time to the logistic model (Equation 5.1) for dry and liquid-infused membranes without the presence of the feed spacer in the membrane module are shown in Figure 5.3. The same results for both membrane in the presence of the spacer are shown in Figure 5.4 .

The fitting parameters $(a, b$, and $c)$ for both membranes with different cell configurations are shown in Appendix D Table D.3. The biological parameters $A, \mu_{m}$ and $\lambda$ are calculated based on the fitting parameters using the corresponding equations (see Appendix D section "Modification of logistic model") and the results are shown in Table 5.2 .

The biological parameters are also calculated based on linear regression. In linear regression, first the most linear part of the curve is determined which defines the exponential phase. The t-axis intercept of the linear fit to the exponential phase defines the duration of the lag phase. The stationary phase is characterized by an asymptotic (horizontal) line which starts at the end of the exponential phase. The results of linear regression of $\ln \left(\frac{\mathrm{P}}{\mathrm{P}_{0}}\right)$ as a function of time for dry and liquid-infused membranes without and with the presence of the feed spacer are respectively shown in Figures 5.5 and 5.6. By defining 


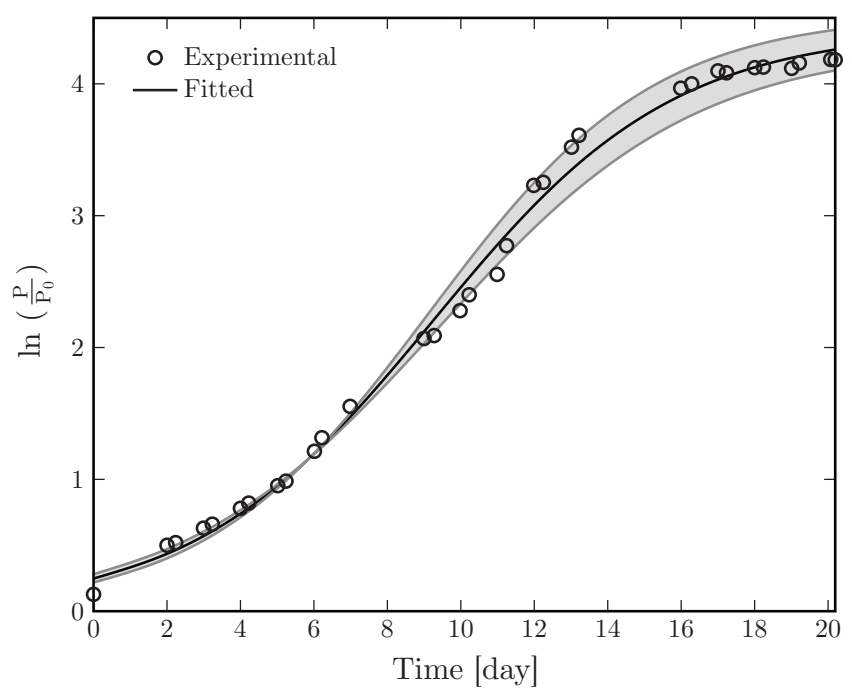

(a)

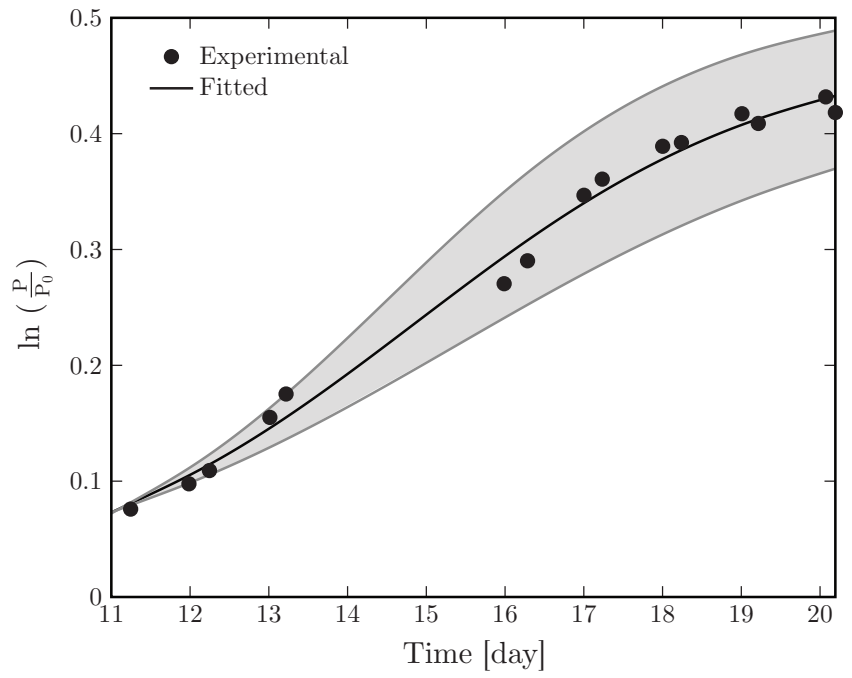

(b)

Figure 5.3: The fitting results of $\ln \left(\frac{\mathrm{P}}{\mathrm{P}_{0}}\right)$ as a function of time to the logistic model for (a) dry membrane and (b) liquid-infused membrane without the feed spacer in the cross flow module. 


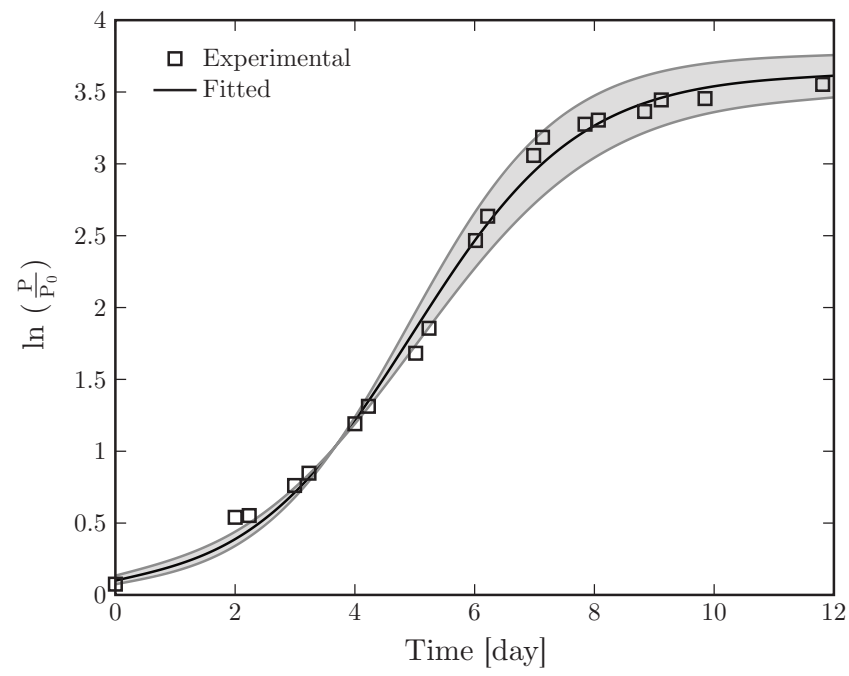

(a)

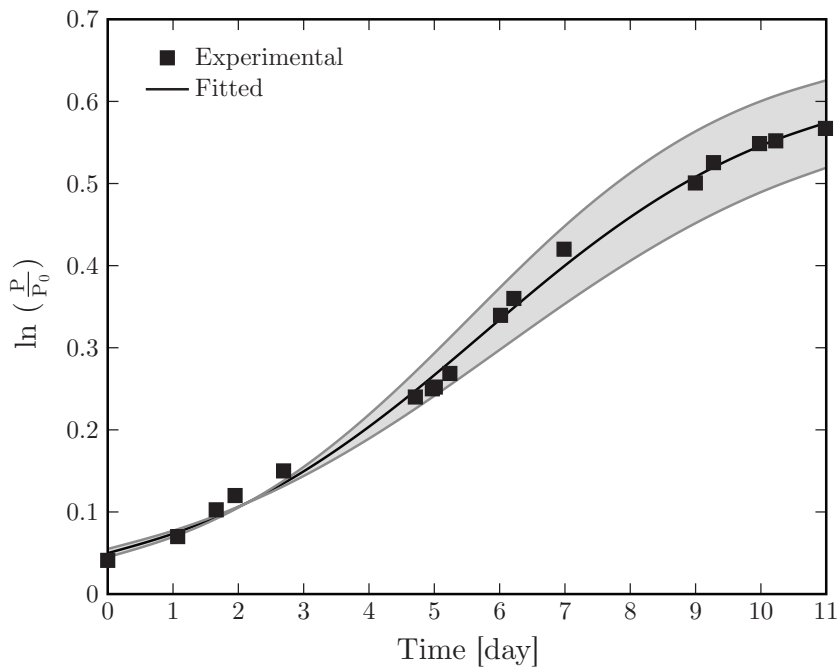

(b)

Figure 5.4: Fitting results of $\ln \left(\frac{\mathrm{P}}{\mathrm{P}_{0}}\right)$ as a function of time to the logistic model for (a) dry membrane and (b) liquid-infused membrane with the feed spacer in the cross flow module. 
these three phases, biological parameters $\lambda, \mu_{m}$ and $A$ can be calculated based on the duration of the lag phase, slope of the exponential phase and average asymptotic value respectively.

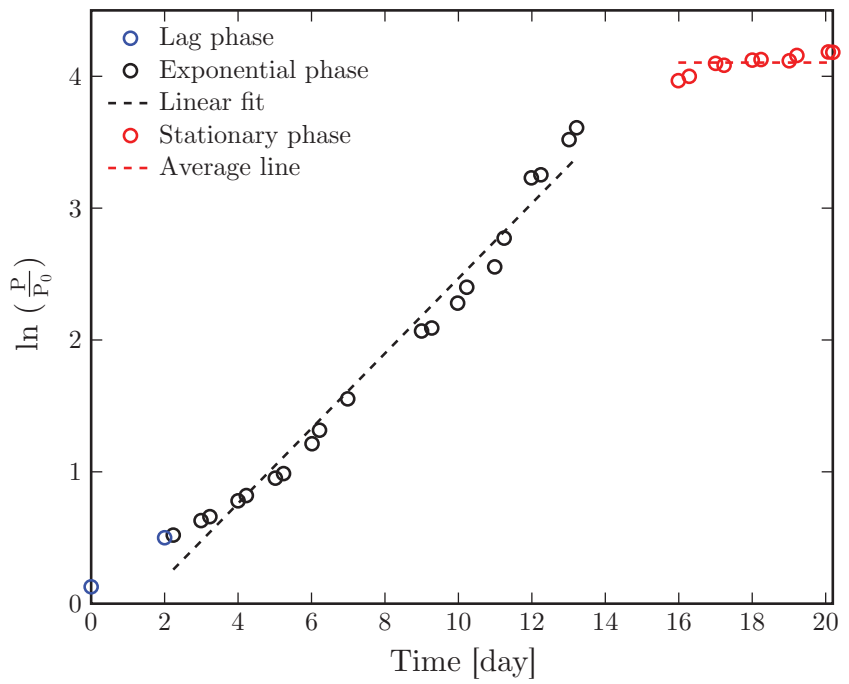

(a)

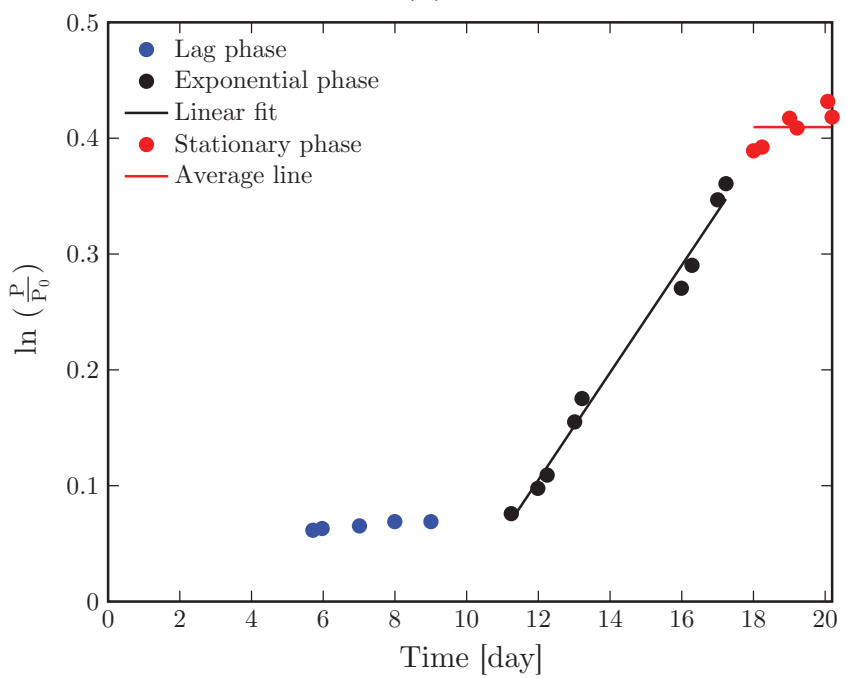

(b)

Figure 5.5: Linear regression results of $\ln \left(\frac{\mathrm{P}}{\mathrm{P}_{0}}\right)$ as a function of time for (a) dry membrane and (b) liquid-infused membrane without the feed spacer in the cross flow module. 


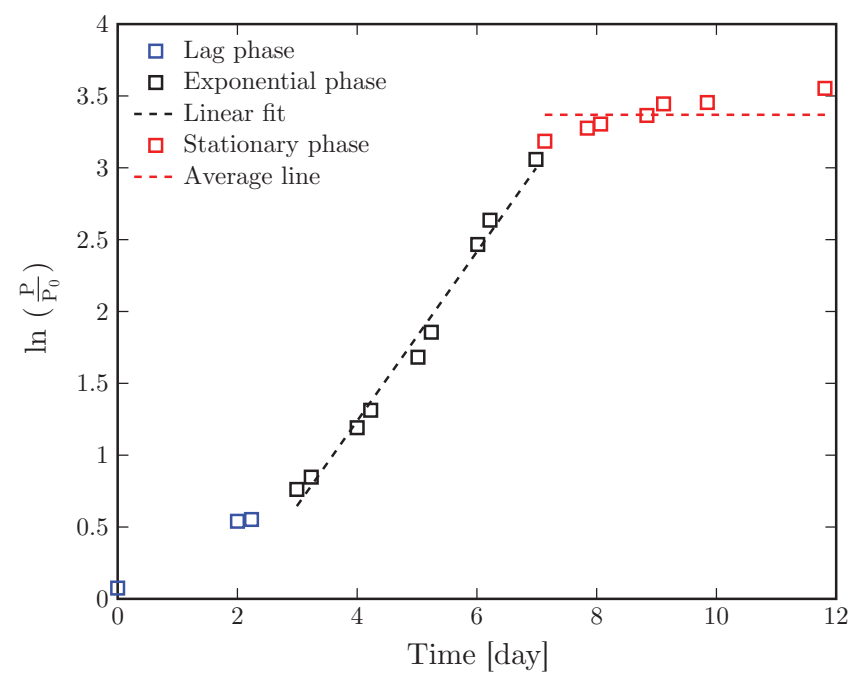

(a)

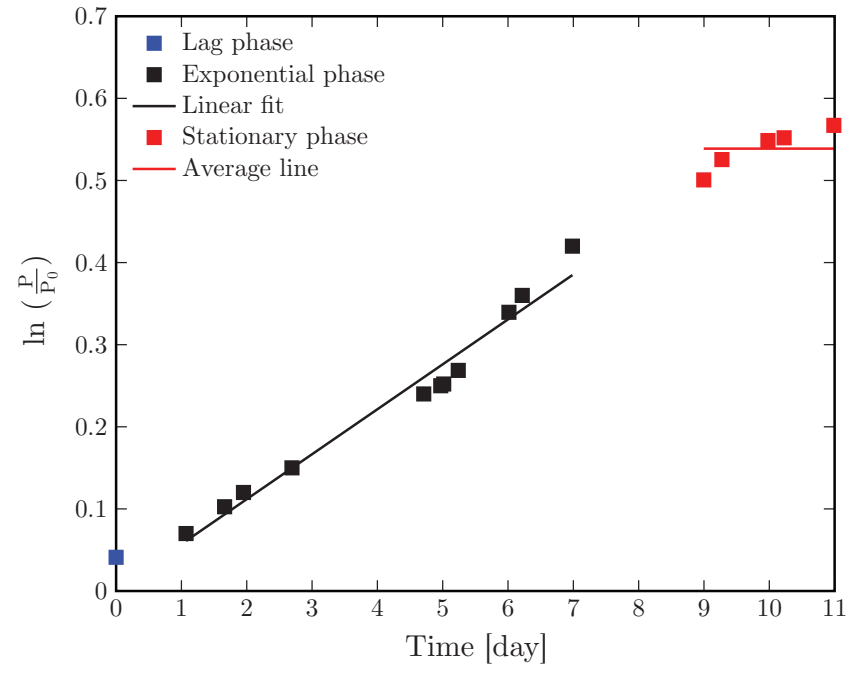

(b)

Figure 5.6: Linear regression results of $\ln \left(\frac{\mathrm{P}}{\mathrm{P}_{0}}\right)$ as a function of time for (a) dry membrane and (b) liquid-infused membrane with the feed spacer in the cross flow module.

The calculated biological values based on linear regression are shown in Table 5.3. It is worth mentioning that $\lambda$ can be also calculated directly from the graph based on the beginning time of the exponential phase. The obtained 
Table 5.3: Biological parameters calculated based on linear regression of the experimental data points of $\ln \left(\frac{\mathrm{P}}{\mathrm{P}_{0}}\right)$ as a function of time (The indicated errors for $\lambda$ and $\mu_{m}$ represent half of the the $95 \%$ confidence interval limits of the linear fit

((Upper CI - Lower CI)/2) and those for $A$ are the standard deviations).

\begin{tabular}{lccc}
\hline \multirow{2}{*}{ Membrane and cell configuration } & \multicolumn{3}{c}{ Biological parameters } \\
\cline { 2 - 4 } & $\lambda($ day $)$ & $\mu_{m}(1 /$ day $)$ & $A(-)$ \\
\hline Dry-without spacer & $1.33 \pm 0.73$ & $0.29 \pm 0.02$ & $4.10 \pm 0.07$ \\
Dry-with spacer & $1.90 \pm 0.74$ & $0.59 \pm 0.06$ & $3.37 \pm 0.13$ \\
LIM-without spacer & $9.74 \pm 2.40$ & $0.05 \pm 4.56 \times 10^{-3}$ & $0.41 \pm 0.02$ \\
LIM-with spacer & $-(0.04 \pm 0.63)$ & $0.06 \pm 7.35 \times 10^{-3}$ & $0.54 \pm 0.03$ \\
\hline
\end{tabular}

values are shown in Table D.5 in Appendix D which are in good agreement within the confidence interval limits of the values shown in Table 5.3. For LIM-with spacer, a negative $\lambda$ is found. This is because there is no lag phase as the biofilm directly starts growing on the feed spacer.

The obtained biological parameters based on the linear regression and logistic models (see Tables 5.2 and 5.3 show a good agreement between these two methods. Based on both methods, larger $\lambda$ and smaller $\mu_{\mathrm{m}}$ values for liquid-infused membranes compared to dry membranes clearly demonstrate the ability of liquid-infused membranes to mitigate biofilm formation and growth respectively. This difference is more pronounced in the cell configuration without the feed spacer. As it has been discussed in Chapters Two and Three, once the liquid-filled pores are opened, a thin layer of the infusion liquid will remain on the pore wall leading to the formation of the so-called liquid-lined pores [28, 29]. The presence of liquid-lining prevents the direct contact between the permeating fluid and solid material of the pore wall [30] (see Chapter Four). The mobility of the liquid molecules on the pore wall can inhibit the permanent interaction with the microorganism in the permeating fluid, thus reducing the biological adhesion [24]. This will subsequently lead to mitigation of biofilm formation and growth in the liquid-infused membranes. The lower water permeability values of LIMs compared to dry membrane in LLD experiments confirmed incomplete removal of the infusion liquid. The analysis showed that around $39 \%$ of the infusion liquid retained in the membrane which was also in the form of liquid-lining on the pore wall of LIMs during filtration (see Appendix D section "LLD analysis" for more detailed information).

Larger $\mu_{m}$ (faster bacterial growth) and smaller $\lambda$ (shorter lag phase) are observed for both dry and liquid-infused membranes in the cell configuration in 
Table 5.4: Flow cytometry results for both dry and liquid-infused membranes.

\begin{tabular}{lcc}
\hline \multirow{2}{*}{ Membrane and cell configuration } & \multicolumn{2}{c}{ Flow cytometry results } \\
\cline { 2 - 3 } & $\begin{array}{c}\text { Bacterial population } \\
\text { density }\left(\text { count } / \mathrm{cm}^{2}\right)\end{array}$ & $\begin{array}{c}\text { Experimental } \\
\text { duration }(\mathrm{hr})\end{array}$ \\
\hline Dry-without spacer & $4.75 \times 10^{8}$ & 503.7 \\
Dry-with spacer & $1.59 \times 10^{9}$ & 282.7 \\
LIM-without spacer & $2.55 \times 10^{8}$ & 503.7 \\
LIM-with spacer & $1.04 \times 10^{9}$ & 282.7 \\
\hline
\end{tabular}

the presence of the feed spacer compared to the configuration without spacer. As the spacer material is conventional and thus not liquid-infused, bacteria will more easily adhere to these and form biofilms that obstruct the flow.

\subsubsection{Membrane autopsy results}

The results of flow cytometry for dry and liquid-infused membranes are shown in Table 5.4. The results reveal smaller population density of bacteria for liquid-infused membranes compared to dry membranes in both configurations. Smaller population density of bacteria is also observed in the absence of the feed spacer in the cross flow cell for both membranes despite the longer experimental duration. These observations further confirm the capability of liquidinfused membranes to mitigate biofilm growth. Additionally, the population density of bacteria on dry membrane without spacer is approximately 2 times larger than that on liquid-infused membrane. This is the same ratio as the one observed between the final TMP increase values of both membranes without the presence of feed spacer (see Figure 5.2). The observed analogous ratios further sheds light on the relation between TMP increase and population of bacteria on the membrane surface.

Confocal laser scanning microscope (CLSM) imaging results demonstrate that the cells deposited on the membrane surface lead to the formation of a layer composed of dead cells. On top of this layer, live bacterial cells are observed (see Appendix D Figure D.6 for snapshots of 3D pictures at different depths of the biofilm structure).

\subsection{Conclusion}

In this work we have reported on the potential of liquid-infused membranes to mitigate biofouling during permeation. The performance of these membranes 
were compared to that of the non-infused counterparts (dry membrane). For the first time, four cross flow membrane filtration experiments with permeate flux were performed using a transparent membrane biofouling monitor (tMBM). In some cases the experiments lasted for more than 20 days. The increase in transmembrane pressure (TMP) was monitored during the experiments as an indirect effect of the presence of a biofilm. The results of the TMP increase as a function of time showed smaller TMP increase for liquid-infused membranes compared to dry membranes. In order to better understand this difference, modelling was performed on the bacterial growth curve, i.e. plot of $\ln \left(\frac{\mathrm{P}}{\mathrm{P}_{0}}\right)$ as a function of time. $\mathrm{P}_{0}$ is the initial TMP value at the start of the experiment. The Sigmoidal bacterial growth curves were fitted to the logistic model. Linear regression was also performed in order to determine three phases, namely the lag phase, the growth phase and the stationary phase. Three corresponding parameters, i.e. lag period $(\lambda)$, specific growth rate $\left(\mu_{\mathrm{m}}\right)$, and asymptotic value of $\ln \left(\frac{\mathrm{P}}{\mathrm{P}_{0}}\right)(A)$ were extracted from both models. The results showed an increase in $\lambda$ from approximately 3 days in dry membranes to 10 days in LIMs. A substantial decrease in the growth rate from 0.351 /day for dry membranes to 0.051 /day for LIMs was also observed confirming the mitigation of biofilm formation and growth in liquid-infused membranes. For both membranes, smaller $\lambda$ (shorter lag period) and larger $\mu_{\mathrm{m}}$ (faster bacterial growth rate) values were observed in the presence of the feed spacer in the membrane module. This shows the role of feed spacers in acceleration of biofilm formation and growth. After the experiments, membrane autopsy and flow cytometry experiments were performed. The results showed smaller population density of bacteria on liquid-infused membranes compared to dry membranes. These results further confirmed the applicability of liquid-infused membranes for mitigation of biofouling. The improved performance of LIMs is attributed to the presence of a thin liquid layer on the pore wall during filtration which prevents direct contact of the foulant with the solid membrane material.

\section{References}

[1] M. Stoller, D. Baiocco, A. Cicci, and M. Bravi, "Description of the biofouling phenomena affecting membranes by the boundary flux concept", Chemical Engineering Transactions 49, 589-594 (2016).

[2] R. Komlenic, "Rethinking the causes of membrane biofouling", Filtration \& Separation 47, 26-28 (2010). 
[3] T. Nguyen, F. A. Roddick, and L. Fan, "Biofouling of water treatment membranes: A review of the underlying causes, monitoring techniques and control measures", Membranes 2, 804 - 840 (2012).

[4] B. Liao, D. Allen, I. Droppo, G. Leppard, and S. Liss, "Surface properties of sludge and their role in bioflocculation and settleability", Water Research 35, 339-350 (2001).

[5] S. N. Liss, I. G. Droppo, D. T. Flannigan, and G. G. Leppard, "Floc architecture in wastewater and natural riverine systems", Environmental Science \& Technology 30, 680-686 (1996).

[6] B. Q. Liao, D. M. Bagley, H. E. Kraemer, G. G. Leppard, and S. N. Liss, "A review of biofouling and its control in membrane separation bioreactors", Water Environment Research 76, 425-436 (2004).

[7] H.-C. Flemming and G. Schaule, "Biofouling on membranes - a microbiological approach", Desalination 70, 95-119 (1988), international Membrane Technology Conference ' 88 .

[8] R. Zhang, Y. Liu, M. He, Y. Su, X. Zhao, M. Elimelech, and Z. Jiang, "Antifouling membranes for sustainable water purification: strategies and mechanisms", Chem. Soc. Rev. 45, 5888-5924 (2016).

[9] J. Mansouri, S. Harrisson, and V. Chen, "Strategies for controlling biofouling in membrane filtration systems: challenges and opportunities", J. Mater. Chem. 20, 4567-4586 (2010).

[10] I. Banerjee, R. C. Pangule, and R. S. Kane, "Antifouling coatings: Recent developments in the design of surfaces that prevent fouling by proteins, bacteria, and marine organisms", Advanced Materials 23, 690-718 (2011).

[11] X. Li, T. Cai, and T.-S. Chung, "Anti-fouling behavior of hyperbranched polyglycerol-grafted poly(ether sulfone) hollow fiber membranes for osmotic power generation", Environmental Science \& Technology 48, 9898-9907 (2014).

[12] L.-J. Zhu, L.-P. Zhu, Y.-F. Zhao, B.-K. Zhu, and Y.-Y. Xu, "Anti-fouling and anti-bacterial polyethersulfone membranes quaternized from the additive of poly(2-dimethylamino ethyl methacrylate) grafted sio2 nanoparticles", J. Mater. Chem. A 2, 15566-15574 (2014). 
[13] M. S. Rahaman, H. Thérien-Aubin, M. Ben-Sasson, C. K. Ober, M. Nielsen, and M. Elimelech, "Control of biofouling on reverse osmosis polyamide membranes modified with biocidal nanoparticles and antifouling polymer brushes", J. Mater. Chem. B 2, 1724-1732 (2014).

[14] H.-Y. Yu, Y. Kang, Y. Liu, and B. Mi, "Grafting polyzwitterions onto polyamide by click chemistry and nucleophilic substitution on nitrogen: A novel approach to enhance membrane fouling resistance", Journal of Membrane Science 449, 50-57 (2014).

[15] V. Kochkodan and N. Hilal, "A comprehensive review on surface modified polymer membranes for biofouling mitigation", Desalination 356, 187-207 (2015), state-of-the-Art Reviews in Desalination.

[16] A. Tiraferri, Y. Kang, E. P. Giannelis, and M. Elimelech, "Superhydrophilic thin-film composite forward osmosis membranes for organic fouling control: Fouling behavior and antifouling mechanisms", Environmental Science \& Technology 46, 11135-11144 (2012).

[17] Q. She, R. Wang, A. G. Fane, and C. Y. Tang, "Membrane fouling in osmotically driven membrane processes: A review", Journal of Membrane Science 499, 201-233 (2016).

[18] M. Ben-Sasson, K. R. Zodrow, Q. Genggeng, Y. Kang, E. P. Giannelis, and M. Elimelech, "Surface functionalization of thin-film composite membranes with copper nanoparticles for antimicrobial surface properties", Environmental Science \& Technology 48, 384-393 (2014).

[19] F. Perreault, H. Jaramillo, M. Xie, M. Ude, L. D. Nghiem, and M. Elimelech, "Biofouling mitigation in forward osmosis using graphene oxide functionalized thin-film composite membranes", Environmental Science \& Technology 50, 5840-5848 (2016).

[20] C. Liu, D. Zhang, Y. He, X. Zhao, and R. Bai, "Modification of membrane surface for anti-biofouling performance: Effect of anti-adhesion and antibacteria approaches", Journal of Membrane Science 346, 121-130 (2010).

[21] L. Qi, Y. Hu, Z. Liu, X. An, and E. Bar-Zeev, "Improved anti-biofouling performance of thin -film composite forward-osmosis membranes containing passive and active moieties", Environmental Science \& Technology 52, 9684-9693 (2018). 
[22] T. A. Johnson, E. A. Rehak, S. P. Sahu, D. A. Ladner, and E. L. Cates, "Bacteria inactivation via $\mathrm{x}$-ray-induced uvc radioluminescence: Toward in situ biofouling prevention in membrane modules", Environmental Science \& Technology 50, 11912-11921 (2016).

[23] T.-S. Wong, S. H. Kang, S. K. Tang, E. J. Smythe, B. D. Hatton, A. Grinthal, and J. Aizenberg, "Bioinspired self-repairing slippery surfaces with pressure-stable omniphobicity", Nature 477, 443-447 (2011).

[24] A. K. Epstein, T.-S. Wong, R. A. Belisle, E. M. Boggs, and J. Aizenberg, "Liquid-infused structured surfaces with exceptional anti-biofouling performance", Proc. Natl. Acad. Sci. U. S. A. 109, 13182-13187 (2012).

[25] P. Kim, T.-S. Wong, J. Alvarenga, M. J. Kreder, W. E. Adorno-Martinez, and J. Aizenberg, "Liquid-infused nanostructured surfaces with extreme anti-ice and anti-frost performance", ACS Nano 6, 6569-6577 (2012).

[26] X. Hou, Y. Hu, A. Grinthal, M. Khan, and J. Aizenberg, "Liquid-based gating mechanism with tunable multiphase selectivity and antifouling behaviour", Nature 519, 70-73 (2015).

[27] I. Okada and S. Shiratori, "High-transparency, self-standable gel-slips fabricated by a facile nanoscale phase separation", ACS Appl. Mater. Interfaces 6, 1502-1508 (2014).

[28] H. Bazyar, S. Javadpour, and R. G. H. Lammertink, "On the gating mechanism of slippery liquid infused porous membranes", Advanced materials Interfaces 3, 1600025 (1-6) (2016), 1600025.

[29] H. Bazyar, P. Lv, J. A. Wood, S. Porada, D. Lohse, and R. G. H. Lammertink, "Liquid-liquid displacement in slippery liquid-infused membranes (SLIMs)", Soft Matter 14, 1780-1788 (2018).

[30] H. Bazyar, N. van de Beek, and R. G. H. Lammertink, "Liquid-infused membranes with oil-in-water emulsions", Langmuir 35, 9513-9520 (2019), 1600025 .

[31] J. C. Overton, A. Weigang, and C. Howell, "Passive flux recovery in protein-fouled liquid-gated membranes", Journal of Membrane Science 539, 257-262 (2017). 
[32] Y. Kovalenko, I. Sotiri, J. V. I. Timonen, J. C. Overton, G. Holmes, J. Aizenberg, and C. Howell, "Bacterial interactions with immobilized liquid layers", Advanced Healthcare Materials 6, 1600948 (1-9) (2017).

[33] N. Keller, J. Bruchmann, T. Sollich, C. Richter, R. Thelen, F. Kotz, T. Schwartz, D. Helmer, and B. E. Rapp, "Study of biofilm growth on slippery liquid-infused porous surfaces made from fluoropor", ACS Applied Materials \& Interfaces 11, 4480-4487 (2019).

[34] C. Dreszer, H.-C. Flemming, A. Wexler, A. Zwijnenburg, J. Kruithof, and J. Vrouwenvelder, "Development and testing of a transparent membrane biofouling monitor", Desalination and Water Treatment 52, 1807-1819 (2014).

[35] J. Vrouwenvelder, C. Picioreanu, J. Kruithof, and M. van Loosdrecht, "Biofouling in spiral wound membrane systems: Three-dimensional cfd model based evaluation of experimental data", Journal of Membrane Science 346, $71-85$ (2010).

[36] M. H. Zwietering, I. Jongenburger, F. M. Rombouts, and K. van't Riet, "Modeling of the bacterial growth curve", Applied and environmental microbiology 56, 1875-1881 (1990).

[37] A. Gaveau, C. Coetsier, C. Roques, P. Bacchin, E. Dague, and C. Causserand, "Bacteria transfer by deformation through microfiltration membrane", Journal of Membrane Science 523, 446 - 455 (2017).

[38] W. E. Ricker, Growth rates and models in: J. R. Brett, W. S. Hoar and D. J. Randall (Eds.), Fish physiology. Vol.8: Bioenergetics and growth (Academic press Inc., New York, London) (1979).

[39] P. F. Verhulst, "Notice sur la loi que la population poursuit dans son accroissement", Corresp. Math. Phys. 10, 113-121 (1838). 


\section{6}

\section{Acoustophoresis of monodisperse oil droplets in water: determining the acoustic energy density ${ }^{\circ}$}

Acoustic manipulation of particles in microchannels has gained a lot of attention recently. Ultrasonic standing wave (USW) separation of oil droplets or particles is an established technology for microscale applications. Designing a microfluidic acoustophoresis chip requires a thorough understanding about the acoustic energy density as an indicator of performance. Due to the energy losses of USWs inside the microchannel, it is found to be a challenge to theoretically predict or experimentally determine the acoustic energy density. Here we investigate the acoustophoretic behavior of monodisperse oil droplets in aqueous surfactant solutions. Two types of oils, i.e. hexadecane and silicone oil with acoustic contrast factors of approximately -1.0 and -0.2 respectively have been studied. Based on the force balance between the primary acoustic radiation force and the drag force on the oil droplet, a relation between acoustic energy density and acoustophoretic velocity is obtained. The acoustic energy density for each oil type is calculated by obtaining corresponding velocity fields around the pressure anti-nodes using particle image velocimetry (PIV). The individual acoustophoretic velocity of oil droplets is measured using particle tracking velocimetry (PTV). A general relationship is then obtained for the acoustic energy density based on the applied electric field by knowing the physical properties of the medium as well as the piezoelectric properties of the transducer.

${ }^{\circ}$ Prepared for submission as: Hanieh Bazyar, Julia Peper, Pengyu Lv, Karin Schroën, and Rob G. H. Lammertink, Acoustophoresis of monodisperse oil droplets in water: determining the acoustic energy density, 2020. 



\subsection{Introduction}

COUSTOPHORESIS is a non-contact and contaminant-free technique used (12. for the manipulation or separation of particles from other particle types or bulk fluid by sound waves in combination with laminar flow fields, typically in microfluidic devices [1, 2. Use of ultrasonic standing wave (USW) for separation applications is highly promising due to the excellent control on particle manipulation and minimal induced mechanical stress [3 5]. It has broad technological implications in areas ranging from food processing [6] 8 , pharmaceutical [9] and biomedical industries [5, 10, 11] to petrochemical [12, 13] and oil recovery from oil-in-water $(\mathrm{O} / \mathrm{W})$ emulsions [13 18]. Ultrasound has also found its application in energy-efficient emulsion fabrication using cavitation intensifying bags [19]. The use of USWs in microfluidics for manipulation of particles or droplets in a fluid, i.e. acoustofluidics, is a mature technique capable of performing tasks such as sorting according to size [20] or acoustic contrast factor [21, affinity specific separation and sample decomplexing [22], continuous flow separation of different particles or cell types [23], continuous flow sonocrystallization or emulsification [24, free flow transport of cell [25], and ultrasonic cavitation [26, 27].

Ultrasound can be either used in continuous or pulsed modes across a broad range of frequencies $(20 \mathrm{kHz}$ up to $1 \mathrm{MHz}$ ) and acoustic pressures depending on the application [27. For acoustic particle handling or streaming, frequencies higher than $1 \mathrm{MHz}$ are required [20, 28]. As will be detailed in section "Oil droplets in acoustic fields", the principle of the acoustic separation technique is that the primary acoustic radiation force (Equation 6.3), resultant from scatterinf of an USW, causes particles or droplets suspended in a fluid to move toward pressure nodes or anti-nodes depending on the material property (see the upper inset of Figure 6.2). The explained phenomena due to acoustic radiation force was first described by Kundt et. al. in $1847[29$ and formulated mathematically by King in 1934 [30. The banding effect under the influence of acoustic radiation force can cause particles to aggregate [1, 4] or droplets to coalesce [14, 31. This will increase the hydrodynamic radius such that buoyancy forces can separate the phases more rapidly due to sedimentation and/or creaming [4].

While research on ultrasound separation technology has been performed extensively, it has not gained widespread adoption in commercial systems partly due to the many parameters influencing the design and operation [1]. One of the important design parameters for microchannel acoustophoresis is the acoustic energy density as it scales with the primary acoustic radiation force. 
It is found to be a challenge to theoretically predict or experimentally determine the energy density in the microchannel 32 .

One technique for measuring the acoustic energy density is by obtaining information on the pressure field (acoustic pressure amplitude) from the movement of tracer microbeads. Single particle tracking was employed to track individual polystyrene microbeads [33. From fitting to the theoretical expression of the trajectory path, acoustic energy density as well as pressure amplitude and acoustophoretic force were obtained. In another method, analysis of acoustophoretic velocity fields measured by micro particle image velocimetry ( $\mu$-PIV) was introduced to obtain the acoustic energy density [34. The $\mu$-PIV analysis was validated further by comparing the estimated values of acoustic energy density obtained by $\mu$-PIV to the values obtained by particle tracking method developed by Barnkob et. al [33]. The comparison was carried out for the same particles, i.e. polystyrene microbeads with diameter of around $5 \mu \mathrm{m}$, at a frequency of $1.968 \mathrm{MHz}$ at $\mathrm{T}=25^{\circ} \mathrm{C}$. Acoustic energy density was obtained as $98.0 \pm 1.1 \mathrm{~J} / \mathrm{m}^{3}$ and $103 \pm 12 \mathrm{~J} / \mathrm{m}^{3}$ based on $\mu$-PIV analysis and particle tracking respectively. The authors discussed that the $\mu$-PIV method in general will lead to better results compared to the particle tracking method.

Full-image $\mu$-PIV has been used previously to investigate acoustic resonances in microfluidic devices [35. It is a powerful tool in combination with images of transient particle motion, for experimental studies of acoustic radiation forces and acoustic streaming in microfluidic chambers. Later on, an acoustic separator (straight microchannel) was investigated through $\mu$-PIV analysis in stop-flow mode [36]. $\mu$-PIV was performed to obtain velocity vectors of particle displacements in zero flow caused by acoustic radiation forces as well as velocity vectors of fluid motion caused by acoustic streaming. In biomedical applications of ultrasound such as transport of cells in microchannels, time-resolved PIV was also used to characterize the fluid motion caused by the ultrasound-mediated transport [25].

As another alternative to particle tracking and particle image velocimetry, light intensity measurements of a suspension of particles were used to quantify acoustophoresis in microchannels [32. In this case, the acoustic energy density was measured by analysing the increase in the light intensity passing through the channel, as suspended particles underwent acoustophoretic focusing [32, 37. The acoustic energy density was found to be a function of the driving voltage squared $\left(V_{\mathrm{pp}}^{2}\right)$ based on fitting of experimental data points [32. Recently, holographic imaging has been reported as a full and accurate characterization of the movement of particles subjected to acoustophoresis in a 
Table 6.1: Comparison of different methods for measurement of acoustic energy density.

\begin{tabular}{ccccc}
\hline Method & $\begin{array}{c}\text { Characterization } \\
\text { of fluid motion }\end{array}$ & $\begin{array}{c}\text { Analysis of } \\
\text { acoustic radiation } \\
\text { force* }\end{array}$ & $\begin{array}{c}\text { Analysis of } \\
\text { acoustic } \\
\text { streaming* }\end{array}$ & $E_{\text {ac }} \propto V_{\mathrm{PP}}^{2}$ \\
\hline Particle tracking & $\checkmark$ & $x$ & $x$ & $\checkmark$ \\
$\mu$-PIV & $\checkmark$ & $\checkmark$ & $x$ & $\checkmark$ \\
Light intensity & $\checkmark$ & $x$ & $x$ & $\checkmark$ \\
Holographic imaging & $\checkmark$ & $x$ & $\checkmark$ & $\checkmark$ \\
\hline
\end{tabular}

${ }^{*}$ In both continuous and stop-flow modes

microfluidic environment 38 . The acoustic energy density and local pressure amplitudes of the ultrasound wave field were retrieved by investigating the dynamics of particle movement along the optical axis. The same voltage-squared dependency was observed for acoustic energy density values according to the fitting results. A comparison between all the mentioned methods are shown in Table 6.1.

Despite all the valuable works on measurements of acoustic energy density, it still cannot be simply measured or calculated theoretically while sophisticated $\mu$-PIV set-up or microscopy techniques such as digital holography are required. In this work we report on a generally accessible method based on PIV, for measurement of acoustic energy density. An expression is obtained for relating the acoustic energy density to the applied electric field based on the acoustic contrast factor of the droplets and piezoelectric properties of the transducer. For a high precision measurement of acoustic energy density, monodisperse oil droplets in aqueous surfactant solutions are used. The movement of oil droplets towards pressure anti-nodes in an applied acoustic field is recorded using normal inverted optical microscope. Particle tracking velocimetry (PTV tool in MATLAB) is then used to obtain the acoustophoretic velocity of individual oil droplets as a function of time and surfactant concentration. The velocity field around each pressure anti-node is obtained by PIV analysis tool in MATLAB and the results are used for the corresponding measurement of the acoustic energy density.

\subsection{Experimental details}




\subsubsection{Materials}

Hexadecane (HD) (reagent plus 99\%), 2-propanol (anhydrous, 99.5\%), silicone oil AR20 (SO), and sodium dodecyl sulfate (SDS) (ACS reagent, $\geq 99.0 \%$ ) were purchased from Sigma-Aldrich, The Netherlands and used without further purification.

\subsubsection{Fabrication of monodisperse $\mathrm{O} / \mathrm{W}$ emulsions}

To avoid the statistical uncertainties that arise from polydispersity of particles in estimation of acoustic energy density [32, monodisperse oil droplets were used for a more precise measurement of acoustic energy density. Monodisperse $\mathrm{O} / \mathrm{W}$ emulsions were prepared using a microfluidic chip based on edge-based droplet generation (EDGE) [39]. The schematic of the set-up is shown in Figure 6.1.

A pressure controller (OB1 Mk3+ from ElveFlow, France) was connected to the nitrogen gas line at 3 bar. Channels 1 and 2 are the low and high pressure channels which can be set to maximum values of 200 and 2000 mbar respectively. Channel 1 was connected to the sodium dodecylsulfate (SDS) surfactant solution bottle and pressurized at 10 or 20 mbar. The oil bottle was connected to the high pressure channel (channel 2) and pressurized at 190-680 mbar depending on the type of the oil and concentration of SDS in the surfactant solution (see Appendix E Table E.1). In order to establish the corresponding pressure on the oil channel, the oil outlet was closed using a two-way valve during emulsion fabrication. The mechanism of droplet formation is explained in details elsewhere [40. The chip is designed in the group of food process engineering at Wageningen University and Research, Wageningen, The Netherlands. It is made out of glass by Micronit Microtechnologies B.V., Enschede, The Netherlands. Anionic SDS was used as the water-soluble surfactant. Four surfactant solutions were prepared by dissolving 10\%, 50\%, $62 \%$ and $100 \%$ of the corresponding critical micelle concentration (CMC) in pure water (Milli-Q grade). From now on, the surfactant solutions are named as SDS 10, SDS 50, SDS 62 and SDS 100 where the number corresponds to the concentration of SDS as percentage of the CMC. The CMC of SDS was experimentally measured as $8.1 \mathrm{mM}$ at $20-25^{\circ} \mathrm{C}$ [41. A period of more than $12 \mathrm{~h}$ was given for the surfactant to completely dissolve in water. Both hexadecane (HD) and silicone oil (SO) were used as the oil phase. In total eight monodisperse $\mathrm{O} / \mathrm{W}$ emulsions were fabricated. The emulsions prepared with SDS 62 were just used for the first preliminary experiments and not used fur- 


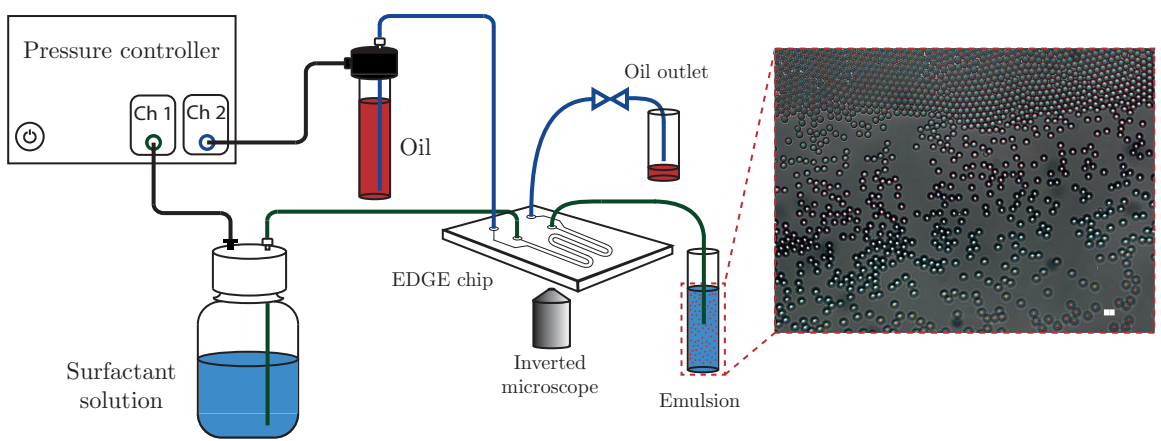

Figure 6.1: Schematic illustration of the monodisperse $\mathrm{O} / \mathrm{W}$ emulsion fabrication using EDGE chip and the optical microscopy picture of the prepared HD droplets in SDS solution with concentration of $62 \%$ CMC (SDS 62) (scale bar is $20 \mu \mathrm{m}$ ).

ther analysis. See Appendix E:Chapter5-SI]Appendix E Figure E.1 and Movie E1 for the picture and video of droplet fabrication. Figure E.2 and Table E.2 show the droplets size distribution and the average droplet size together with the corresponding coefficient of variation $(\mathrm{CV})$ for all the prepared emulsions using SDS 10, SDS 50 and SDS 100.

\subsubsection{Acoustic experiments}

A microfluidic chip with one inlet and three outlets was used to investigate the acoustophoretic behaviour of oil droplets (see Figure 6.2 for the schematic illustration of the chip). The chip is fabricated in silicon using standard photolithography and reactive ion etching (see Appendix E section "Fabrication of the microfluidic chip" for detailed fabrication procedure).

The chip was placed in the chip holder. A ceramic piezoelectric transducer (Disc of Pz26 (NavyI, hard relaxor type PZT with diameter $5 \mathrm{~mm}$ and thickness $0.5 \mathrm{~mm}$ from Meggitt ferroperm, Denmark) was attached on the backside of the chip using a copper tab $(28.5 \times 6 \mathrm{~mm})$ fastened to the chip holder using a screw. The piezoelectric transducer (PZT transducer) was then soldered on top of the copper tab using standard $\mathrm{PbSn}$ solder paste. The connection for the negative polarity was an electronic header pin which was soldered at the end of the tab. The connection for the positive polarity was custom-built by mounting a spring contact probe with a round tip (SS-50-J-2.9-G with receptacle Rss-50-SC from Mouser electronic, The Netherlands) in a nanotight fitting (F-130 from IDEX health and science, The Netherlands) using an appropriate sleeve to clamp the spring contact in place. On the back of the spring contact 


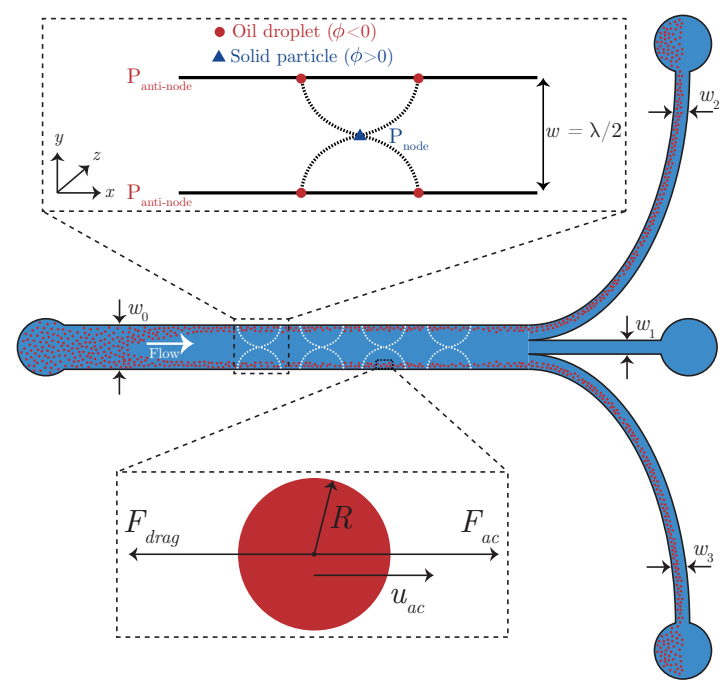

Figure 6.2: Schematic illustration of the microfluidic chip with one inlet and three outlets. $w_{0}$ is $600 \mu \mathrm{m}$ and $w_{1-3}$ is $200 \mu \mathrm{m}$.

probe, a 1-mm plug (SLS1-S from Stäubli Benelux, Belgium) was soldered. The whole connection was then screwed to the top part of the chip holder. Finally, the appropriate socket parts were used for connecting wires to the positive (1-mm plug) and negative (header pin) connections. The spring contact probe was in direct contact with the PZT transducer upon closing off the chip holder. The schematic illustration of the acoustic set-up is shown in Figure 6.3. Since no glue was used for attaching the transducer to the chip, both the chip and the transducer could be easily re-used.

The PZT transducer was actuated at a peak-to-peak voltage $\left(\mathrm{V}_{\mathrm{pp}}\right)$ of 200 $\mathrm{mV}$ using a function generator (Tektronix AFG 2021) and amplified to around $20 \mathrm{~V}$ using a power amplifier (EIN 350L RF power amplifier). An oscilloscope (Tektronix TDS 2022B) was used to monitor the peak-to-peak voltage and the induced sound wave. The electrical signal was sent from the amplifier to the transducer, which converted this signal to an acoustic field creating an acoustophoretic zone perpendicular to the flow direction (see Figure 6.2). All the experiments were performed in a half-wave length microchannel resonator, i. e.

$$
w=\frac{\lambda}{2},
$$

where $w$ is the channel width $(600 \mu \mathrm{m})$ and $\lambda$ is the wave length $(1200 \mu \mathrm{m})$. 


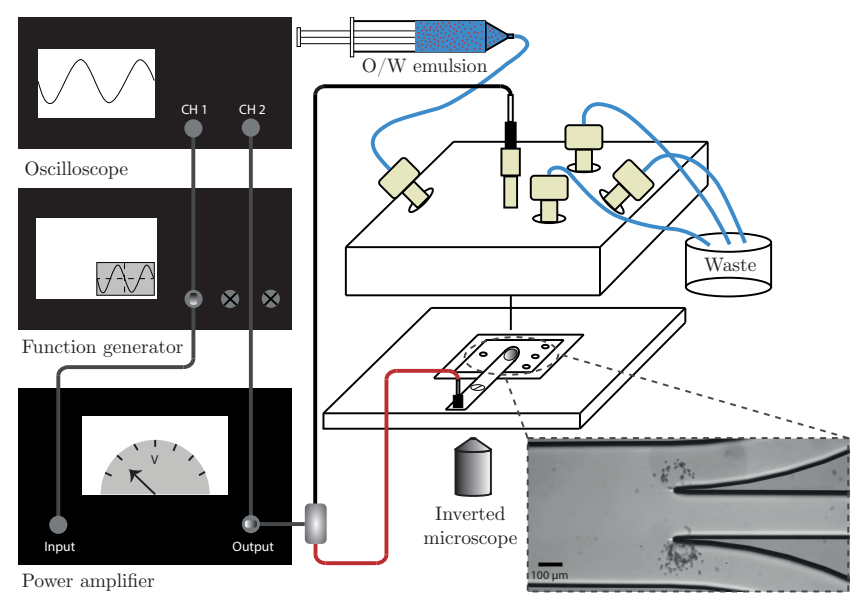

Figure 6.3: Schematic illustration of the acoustic set-up together with the optical microscopy image of the channel outlet showing the vortexes of the SO droplets in SDS solution with concentration of $50 \%$ CMC (SDS 50) due to streaming forces.

The actuation frequency

$$
f=\frac{c}{2 w}
$$

where $c$ is the speed of sound in water $\left(1497 \mathrm{~m} / \mathrm{s}\right.$ at $25^{\circ} \mathrm{C}$ [42], was then calculated as $1.25 \mathrm{MHz}$.

All the observations were performed using an inverted optical microscope (Zeiss Axiovert 40 MAT) and objective with magnification of 10x (Zeiss EC Epiplan 10x/0.25 M27 (free working distance $(\mathrm{FWD})=11.0 \mathrm{~mm}$ )). Вy means of a camera (Hamamatsu orca flash 4.0 c11440) and software (Olympus cellSens Dimensions), the acoustophoretic movement of oil droplets was recorded.

The acoustic experiments were performed on all emulsions ( $\mathrm{SO}$ and HD droplets in SDS 10, SDS 50, SDS 62 and SDS 100) at $\mathrm{V}_{\mathrm{pp}}$ of $20 \mathrm{~V}$ and frequency of $1.25 \mathrm{MHz}$. The acoustophoretic movement of oil droplets was first recorded in time-lapse mode over the whole channel width for $30 \mathrm{~min}$ at 2 frames per minute (FPM). As an example, in Figure 6.4 the first and the $24^{\text {th }}$ time frames of the recorded movie (see Appendix EMovie E2) for concentrated SO droplets in SDS 62 solution are shown. As expected, the oil droplets aggregated at pressure anti-nodes with the spacing distance of $\lambda / 2\left(w_{0}\right)$ [3. The pattern of oil droplets at the anti-nodal planes was observed throughout the whole channel including the outlets. To diminish the particle-particle interaction 


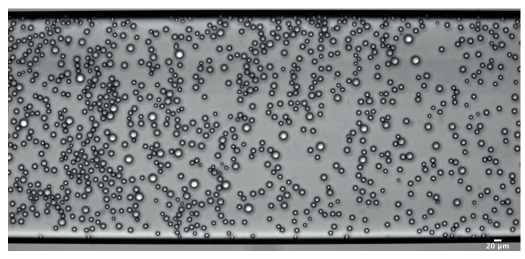

(a)

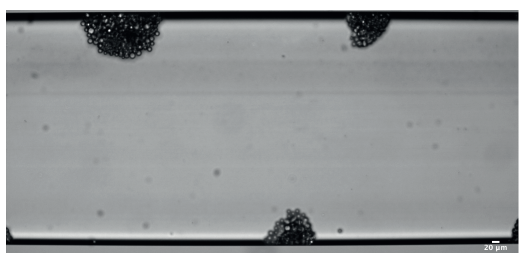

(b)

Figure 6.4: Snapshots of microchannel at (a) first and (b) $24^{\text {th }}$ time frame $\left(12^{\text {th }}\right.$ min) of applying acoustic field at $1.25 \mathrm{MHz}$ and $V_{\mathrm{pp}}=20 \mathrm{~V}$ for 30 minutes on SO droplets dispersed in SDS 62 solution.

and ensuring the validity of single particle tracking theory [34, a more diluted emulsion was used for the rest of the analysis and acoustic experiments of all the other emulsions (see Appendix E Movie E3 for acoustic experiment on SO droplets in SDS 10).

Once the location of the anti-nodes was determined, another series of experiments were performed in detail (zoomed-in) at the anti-node location and recording the time-lapse for 30s at 2 frames per seconds (FPS). Figure E.3 in Appendix Eillustrates the first and the last time frames of the movies for HD and SO droplets in SDS 100. Since the speed of sound in water has a significant dependence on temperature $\left(\frac{\partial c}{\partial T}=4 \mathrm{~m} /(\mathrm{sK})\right)$ [35], impact of heating from piezoelectric transducer on the measurements was prevented by actuating it at a moderate power level and for short intervals $(5 \mathrm{~s}, 10 \mathrm{~s}$, or maximum $30 \mathrm{~s}$ ) during all the detailed recordings.

\subsubsection{Analysis of acoustic experiments}

The acoustophoretic velocity of the oil droplets was measured by tracking the individual oil droplets using particle tracking velocimetry (PTV). The MATLAB tool PTVlab [43. was used for the corresponding PTV analysis to get the average velocity per frame as well as velocity vectors. All original images were binarized to get black background and white droplets using FIJI ImageJ [44] (see Figure 6.5(a) and Movie E4 in Appendix E for the corresponding video combined with the original movie. The similar video for HD droplets in SDS 100 is shown in Movie E5). In order to get the localized velocity field around the region of the pressure anti-node, particle image velocimetry (PIV) was performed using MATLAB tool PIVlab [45. Figure 6.5(b) show the snapshots of the $5^{\text {th }}$ time frame $(2.5 \mathrm{~s})$ of the PIV movie for SO droplets in SDS 100 solution (see Movies E6 and E7 for the combined zoomed-in videos with the PIV 


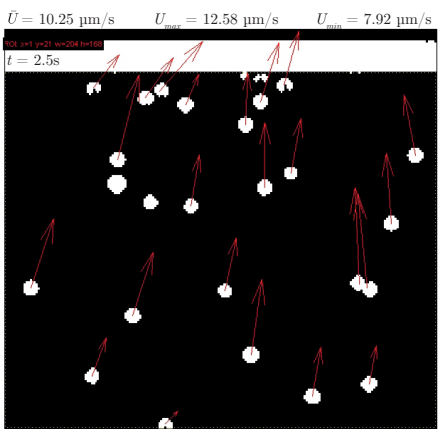

(a)

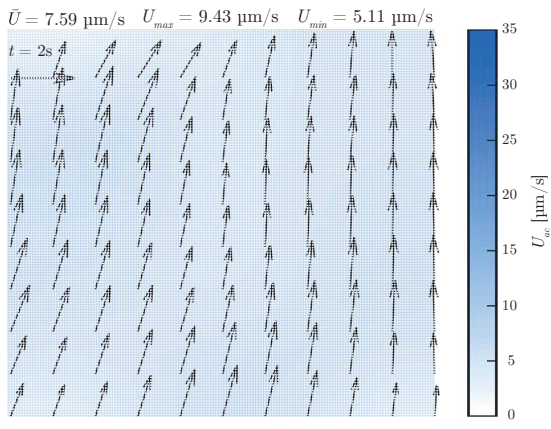

(b)

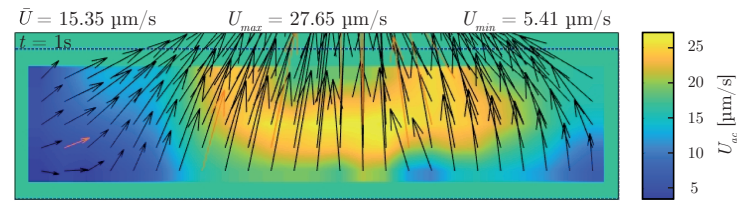

(c)

Figure 6.5: Snapshots of (a) PTV and (b) PIV analysis of the corresponding zoomed-in $5^{\text {th }}$ time frame. (c) PIV analysis over half of the channel width for SO in SDS 100 showing velocity field around the anti-node.

results of SO and HD droplets in SDS 100 respectively). To get a better understanding regarding the velocity field distribution at further distances from the pressure anti-node, PIV analysis was performed over half of the channel width. The snapshot of the second time frame $(1 \mathrm{~s})$ for SO droplets in SDS 100 is shown in Figure 6.5(c). The corresponding video combined with the original movie is shown in Movie E8.

\subsection{Results and discussion}

\subsubsection{Oil droplets in acoustic field}

The superposition between the incident ultrasound, emitted from the piezoelectric transducer, and the reflected wave from the channel walls, leads to the establishment of ultrasonic standing waves (USWs) inside the microchannel [4, 46. Pressure nodes and anti-nodes are formed respectively at regions with destructive and constructive superposition (see the upper inset of Figure 6.2).

When USWs are generated in a medium containing particles or droplets, the waves will be scattered if there is acoustic impedance contrast between 
Table 6.2: Physical properties, compressibility $(\beta)$ and acoustic contrast factor $(\phi)$ of hexadecane, silicone oil AR20 and water (density and viscosity (absolute) were respectively measured at $24^{\circ} \mathrm{C}$ and $20^{\circ} \mathrm{C}$ ).

\begin{tabular}{lccccc}
\hline Liquid & $\begin{array}{c}\text { Density } \\
{\left[\mathrm{g} / \mathrm{cm}^{3}\right]}\end{array}$ & $\begin{array}{c}\text { Viscosity } \\
{[\mathrm{mPa} \mathrm{s}]}\end{array}$ & $\begin{array}{c}\text { Speed of sound } \\
{[\mathrm{m} / \mathrm{s}]}\end{array}$ & $\begin{array}{c}\beta\left(\times 10^{-10}\right) \\
{[1 / \mathrm{Pa}]}\end{array}$ & $\phi[-]$ \\
\hline Hexadecane & $0.727 \pm 0.002$ & $3.2 \pm 0.13$ & $1357[47$ & $7.46 \pm 0.02$ & $-1.006 \pm 0.002$ \\
Silicone oil & $1.003 \pm 0.002$ & $19.6 \pm 0.1$ & $1350[48$ & $5.47 \pm 0.01$ & $-0.223 \pm 0.001$ \\
Water & $1.00 \pm 0.001$ & $1.00 \underline{49}$ & $1497[42$ & $4.462 \pm 0.005$ & - \\
\hline
\end{tabular}

the fluid and the particle/droplet [4]. The scattering of the wave produces a primary acoustic radiation force

$$
F_{\mathrm{ac}}=\frac{4 \pi}{3} R^{3} k E_{\mathrm{ac}} \phi \sin (2 k z)
$$

where $R$ is the droplet radius $(\mathrm{m}), k$ is the wave number $2 \pi / \lambda(1 / \mathrm{m}), \phi$ is the acoustic contrast factor $(-), E_{a c}$ is the acoustic energy density $\left(\mathrm{J} / \mathrm{m}^{3}\right)$ and $z$ is the diagonal distance between each particle/droplet and the pressure nodes/anti-nodes $\left(z=\sqrt{x^{2}+y^{2}}\right)(\mathrm{m})$. This force will move the particles towards the nodes or anti-nodes which depends on the sign of the acoustic contrast factor

$$
\phi=\frac{5 \rho_{\mathrm{p}}-2 \rho_{\mathrm{m}}}{2 \rho_{\mathrm{p}}+\rho_{\mathrm{m}}}-\frac{\beta_{\mathrm{p}}}{\beta_{\mathrm{m}}} .
$$

Where $\rho$ is the density $\left(\mathrm{kg} / \mathrm{m}^{3}\right), \beta$ is the compressibility $\left(\beta=1 / \rho c^{2}\right)(1 / \mathrm{Pa})$ and $c$ is the speed of sound in the corresponding material $(\mathrm{m} / \mathrm{s}) . m$ and $p$ respectively correspond to medium and particle [4,23. Particles with positive $\phi$ (solid particles) and negative $\phi$ (oil droplets) respectively move towards the pressure nodes and anti-nodes (see the upper inset of Figure 6.2). The physical properties of both HD and SO together with the calculated acoustic contrast factor is shown in Table 6.2.

\subsubsection{Acoustophoretic velocity of oil droplets}

The force balance on one single oil droplet is schematically shown in the bottom inset of Figure 6.2. By equating the Stokes' drag force

$$
F_{d r a g}=-6 \pi \eta R u_{a c}
$$




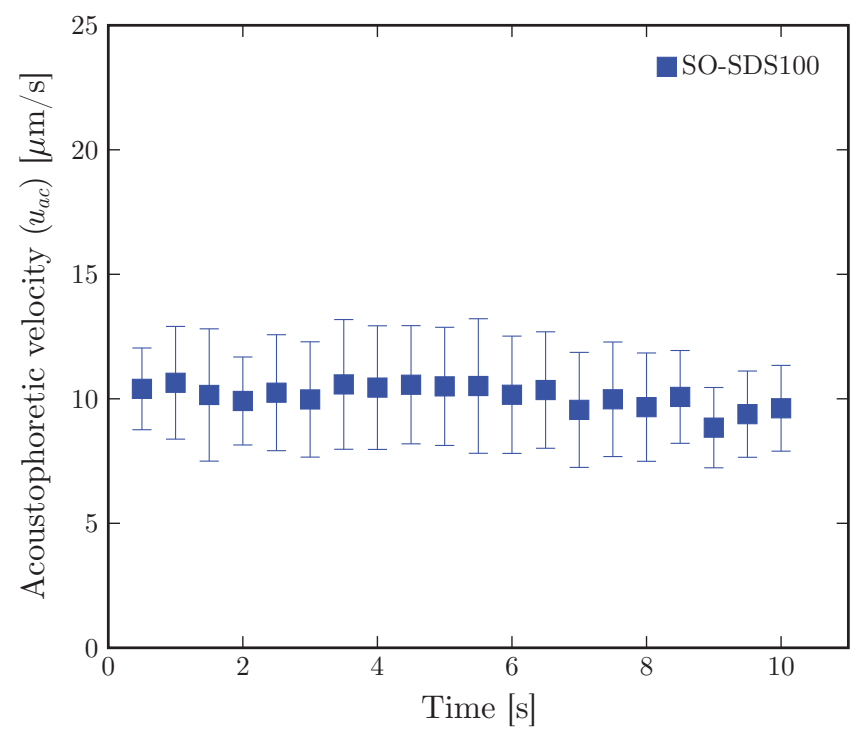

Figure 6.6: Acoustophoretic velocity as a function of time for SO droplets in SDS 100 surfactant solution.

where $\eta$ is the dynamic viscosity of the continuous phase (Pa s), to the primary acoustic radiation force (Equation 6.3), one can define the acoustophoretic velocity as

$$
u_{a c}(z)=\frac{2 \phi k R^{2} E_{a c}}{9 \eta} \sin (2 k z) .
$$

The acoustophoretic velocity is calculated from the horizontal $\left(u_{x}\right)$ and vertical $\left(u_{y}\right)$ vectors of an individual droplet motion, which are both obtained from the corresponding PTV analysis. The total acoustophoretic velocity of oil droplets is then given by

$$
u_{a c}=\sqrt{u_{x}^{2}+u_{y}^{2}} .
$$

Figure 6.6 shows the acoustophoretic velocity of SO oil droplets in SDS 100 surfactant solution as a function of time during the first $10 \mathrm{~s}$. The PTV results of HD droplets in SDS 100 and other HD and SO emulsions are shown in Appendix EFigures E.4 and E.5 respectively. The results show no significant change of velocity as a function of time close to the pressure anti-nodes.

Acoustophoretic velocity as a function of SDS concentration for both HD and SO droplets is shown in Figure 6.7. Within the error margins, no signif- 
icant dependency of the acoustophoretic velocity on the surfactant solution was observed. Average acoustophoretic velocities of $10.5 \pm 2.0$ and $13.1 \pm 3.3$ $\mu \mathrm{m} / \mathrm{s}$ were obtained for $\mathrm{SO}$ and $\mathrm{HD}$ droplets respectively. According to Equation 6.6. the acoustic contrast factor $(\phi)$ and acoustophoretic velocity $\left(u_{a c}\right)$ are proportional. Although the acoustic contrast factor of HD droplets is five times higher than that of SO droplets (see Table 6.2), we did not observe the same ratio between acoustophoretic velocity values. This can be explained based on the contribution of the acoustic energy density $\left(E_{a c}\right)$.

\subsubsection{Acoustic energy density}

By measuring the acoustophoretic velocity, one can calculate the acoustic energy density $\left(E_{a c}\right)$ from Equation 6.6

$$
E_{a c}=\frac{9 \eta u_{a c}}{2 \phi k R^{2}}(\sin (2 k z))^{-1} .
$$

The diagonal distance $z$ was obtained from PIV analysis results by measuring the distance between each droplet (velocity vector) with known $x$ and $y$ coordinates to the anti-node position which possessed the minimum velocity value (see Figure 6.5(c)). It has been shown that the PIV method allows for improved and faster statistics and thus in general leads to better results compared to the PTV method [34. Therefore, the obtained velocity values from PIV analysis were directly used to calculate $E_{a c}$ from Equation 6.8. The acoustic energy density values of both SO and HD droplets in different SDS solutions as a function of time are shown in Figure 6.8.

Similar to the acoustophoretic velocity results (see Figure 6.6 and Appendix E Figures E.4 and E.5 and 6.7), within the error margins, no significant change in $E_{a c}$ as a function of time and SDS concentration was observed. The average values of $0.2 \pm 0.06$ and $1.0 \pm 0.13 \mathrm{~J} / \mathrm{m}^{3}$ were obtained respectively for HD and SO droplets. According to Equation 6.8, the ratio between the measured acoustic energy densities $\left(\left.E_{a c}\right|_{H D} /\left.E_{a c}\right|_{S O}\right)$ is inversely proportional to that between the acoustic contrast factors $\left(\phi_{S O} / \phi_{H D}\right)$ and is equal to 0.2 .

\subsubsection{Relation between acoustic energy density and the input electric field}

The piezoelectric properties of the thin disc transducer is shown in Table 6.3 [50]. The electrochemical coupling factor $\kappa$ is the ratio between the stored mechanical energy and the input electrical energy $\left(\kappa^{2}=\right.$ Stored mechanical 


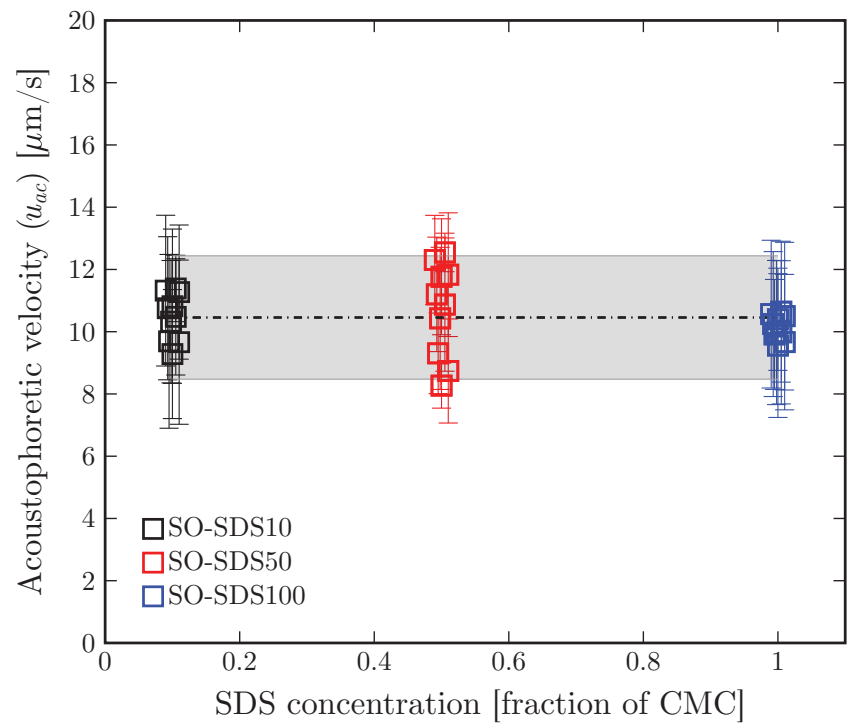

(a)

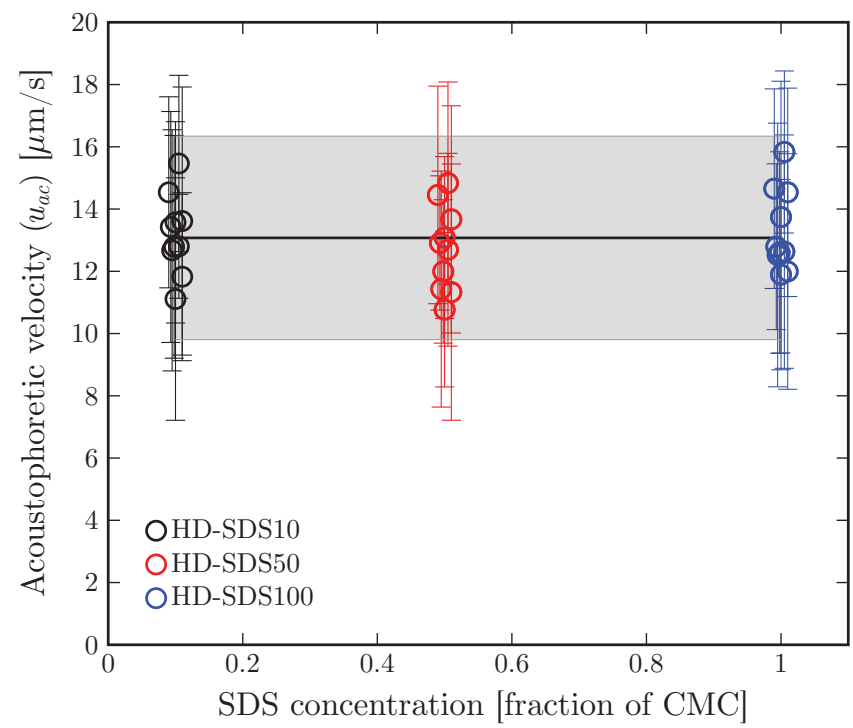

(b)

Figure 6.7: Acoustophoretic velocity as a function of surfactant concentration for (a) SO and (b) HD droplets (Dashed and solid black lines show the average velocity values for $\mathrm{SO}$ and $\mathrm{HD}$ droplets respectively. Shaded areas illustrate the corresponding standard deviation of the average values). 


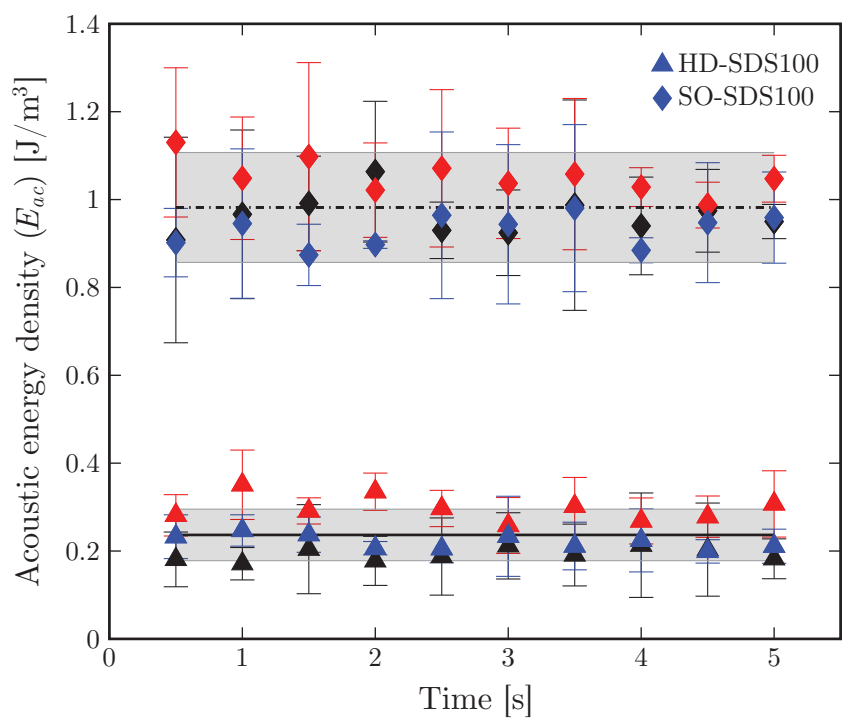

Figure 6.8: Acoustic energy density values obtained from Equation 6.8 for both SO and HD droplets in different surfactant solutions as a function of time (red $(\boldsymbol{\nabla}, \mathbf{\Delta})$ and black $(\boldsymbol{\nabla}, \mathbf{\Delta})$ symbols correspond to droplets in SDS 10 and SDS 50 respectively. The average values for HD and SO droplets are shown with solid and dashed black lines together with the shaded area showing the corresponding standard deviation). 
Table 6.3: Piezoelectric properties of the PZT transducer (Disc of Pz26).

\begin{tabular}{lccc}
\hline \multirow{2}{*}{ PZT transducer } & \multicolumn{3}{c}{ Piezoelectric properties } \\
\cline { 2 - 4 } & $\begin{array}{c}\text { Coupling } \\
\text { factor } \kappa_{t}\end{array}$ & $\begin{array}{c}\text { Coupling } \\
\text { factor } \kappa_{p}\end{array}$ & $\begin{array}{c}\text { Relative dielectric } \\
\text { permittivity } \varepsilon_{33}^{T}\end{array}$ \\
\hline Pz26 & 0.47 & 0.52 & 1300 \\
\hline
\end{tabular}

$t$ : Electric field and vibration are in the same directions

$p$ : Electric field and vibration are in perpendicular directions

$\varepsilon_{33}^{T}$ : At constant stress $(T)$ with electric field and dielectric displacement

both in direction 3

energy/Input electrical energy). $\kappa_{t}$ concerns the coupling factor for the electric field and vibration both in direction 3 (direction $z$ perpendicular to $x-y$ plane). $\quad \kappa_{p}$ is the coupling factor for electric field in direction 3 and radial vibration in directions 1 (direction $x$ ) and 2 (direction $y$ ). The relative dielectric permittivity $\left(\varepsilon_{33}^{T}\right)$ is shown at constant stress $(T)$ with direction of electric field and dielectric displacement both in direction 3 (33) 51.

The total input electrical energy is

$$
E_{\text {elec }}=\frac{1}{2} \varepsilon_{0} \varepsilon_{33}^{T} E^{2},
$$

where $\varepsilon_{0}$ is the permittivity of vacuum $\left(8.85 \times 10^{-12} \mathrm{~F} / \mathrm{m}\right.$ or $\left.\mathrm{J} / \mathrm{V}^{2} \mathrm{~m}\right)$ and $E$ is the applied electric field $(\mathrm{V} / \mathrm{m})$ [51]. The input electrical energy is calculated as $9.2 \mathrm{~J} / \mathrm{m}^{3}$ by considering the potential drop just across the thickness of the piezoelectric transducer $\left(E=4 \times 10^{4} \mathrm{~V} / \mathrm{m}\right)$.

The total stored mechanical energy can be calculated from the coupling factor $\kappa$ and input electric field as

$$
E_{m e c h}=\kappa^{2} E_{\text {elec }}
$$

By using $\kappa_{t}$ as the coupling factor, the stored mechanical energy is calculated as $2.0 \mathrm{~J} / \mathrm{m}^{3}$. The measured acoustic energy densities for silicone oil $\left(1 \mathrm{~J} / \mathrm{m}^{3}\right)$ and hexadecane $\left(0.2 \mathrm{~J} / \mathrm{m}^{3}\right)$ (see section Acoustic energy density and Figure 6.8 are respectively $50 \%$ and $10 \%$ of the total stored mechanical energy in the piezoelectric transducer. The rest of the stored energy is dissipated mainly as the results of secondary acoustic radiation force and streaming effects. Losses due to thermal dissipation in the transducer should also be considered. These losses often vary from experiment to experiment and are thus difficult to estimate 33 . The secondary acoustic radiation force led to the alignment of oil droplets (formation of chains) and circulation of oil droplets at the posi- 
tion of the anti-node (see Appendix E section "Effects of secondary acoustic radiation force" Figure E.6 and Movies E9 and E10). The streaming forces resulted in vortex-like motion of oil droplets (boundary layer streaming) at the conjunction of the outlets in the microchannel due to the sudden decrease in the channel width at this location (see Appendix E section "Effects of streaming force", Figure E.7. Movie E11 and inset of Figure 6.3. . As a consequence, the acoustic energy density $E_{a c}$ is a fraction of the total stored mechanical energy

$$
E_{a c}=f E_{\text {mech }} \text { with } f=\frac{1}{\alpha \phi} .
$$

The pre-factor $\alpha$ is an empirical parameter which is calculated as 10 based on the experimental measured values of $E_{a c}$. Combining Equations 6.9, 6.10 and 6.11 leads to

$$
E_{a c}=\frac{\kappa^{2} \varepsilon_{0} \varepsilon_{33}^{T}}{20 \phi} E^{2}
$$

which relates the acoustic energy density $E_{a c}$ to the applied electric field $E$ by knowing the physical properties of the medium (determined by $\phi$ (see Equation 6.4) and the piezoelectric properties of the transducer (see Table 6.3). This is in line with the voltage square law prediction for acoustic energy density $\left(E_{a c}=\beta V_{p p}^{2}\right)$ with $\beta$ as the fitting parameter depending on the tested system and material $[32,33,38$. The acoustic energy density is particularly important for designing a microfluidic acoustophoresis chip as it scales with the primary acoustic radiation force (Equation 6.3). Equation 6.12 provides a general basis for simple prediction of the acoustic energy density based on the input electric field, piezoelectric properties of the transducer and physical properties of the medium.

\subsection{Conclusion}

We investigated the acoustophoretic behaviour of monodisperse oil droplets (silicone oil and hexadecane) in aqueous surfactant (SDS) solutions with different concentrations (10, 50 and $100 \%$ of the corresponding CMC (8.1 mM)). The monodisperse droplets were prepared using an edge-based droplet generation (EDGE) system. The emulsions were pumped in a microfluidic chip on which the piezoelectric transducer was attached to the back side. The piezoelectric transducer was actuated at a frequency of $1.25 \mathrm{MHz}$ and $\mathrm{V}_{p p}$ of $20 \mathrm{~V}$ 
using a power amplifier. The oil droplets aggregated at the position of the pressure anti-nodes at the channel wall. The acoustophoretic velocity of individual oil droplets was measured using particle tracking velocimetry (PTV) showing no significant dependency on the surfactant concentration. Particle image velocimetry (PIV) was used to obtain the corresponding velocity field around the pressure anti-nodes. The PIV results were further used to measure the diagonal distance between each velocity vector and the anti-nodal position with minimum velocity value. Based on the force balance between primary acoustic radiation force and the hydrodynamic drag force, a relation was obtained between the acoustophoretic velocity and acoustic energy density. The measured acoustic energy densities were relatively constant within the error margins as a function of time and surfactant concentration. The average acoustic energy density values were inversely proportional to the acoustic contrast factor. Finally a general relationship was obtained for the calculation of acoustic energy density as a function of input electrical field based on physical properties of the medium as well as piezoelectric properties of the transducer.

\section{References}

[1] T. Leong, L. Johansson, P. Juliano, S. L. McArthur, and R. Manasseh, "Ultrasonic separation of particulate fluids in small and large scale systems: A review", Industrial \& Engineering Chemistry Research 52, 16555-16576 (2013).

[2] M. Koklu, A. C. Sabuncu, and A. Beskok, "Acoustophoresis in shallow microchannels", Journal of Colloid and Interface Science 351, 407-414 (2010).

[3] I. U. Vakarelski, E. Q. Li, A. I. Abdel-Fattah, and S. T. Thoroddsen, "Acoustic separation of oil droplets, colloidal particles and their mixtures in a microfluidic cell", Colloids and Surfaces A: Physicochemical and Engineering Aspects 506, 138-147 (2016).

[4] F. J. Trujillo, P. Juliano, G. Barbosa-Cánovas, and K. Knoerzer, "Separation of suspensions and emulsions via ultrasonic standing waves - a review", Ultrasonics Sonochemistry 21, 2151-2164 (2014), aOSS 2013.

[5] T. Laurell, F. Petersson, and A. Nilsson, "Chip integrated strategies for acoustic separation and manipulation of cells and particles", Chem. Soc. Rev. 36, 492-506 (2007). 
[6] P. Juliano, S. Temmel, M. Rout, P. Swiergon, R. Mawson, and K. Knoerzer, "Creaming enhancement in a liter scale ultrasonic reactor at selected transducer configurations and frequencies", Ultrasonics Sonochemistry 20, 52-62 (2013).

[7] T. J. Mason, Power ultrasound in food processing - the way forward, in: M.J.W. Povey, T.J. Mason (Eds.), Ultrasound in Food Processing (Blackie Academic \& Professional, London, U. K) (1998).

[8] F. Chemat, Z. e Huma, and M. K. Khan, "Applications of ultrasound in food technology: Processing, preservation and extraction", Ultrasonics Sonochemistry 18, 813-835 (2011), european Society of Sonochemistry (ESS12).

[9] M. Maitz, F. Trampler, M. Gröschl, A. da Câmara Machado, and M. Laimer da Câmara Machado, "Use of an ultrasound cell retention system for the size fractionation of somatic embryos of woody species", Plant Cell Reports 19, 1057-1063 (2000).

[10] F. Petersson, A. Nilsson, C. Holm, H. Jönsson, and T. Laurell, "Separation of lipids from blood utilizing ultrasonic standing waves in microfluidic channels", Analyst 129, 938-943 (2004).

[11] M. Kumar, D. L. Feke, and J. M. Belovich, "Fractionation of cell mixtures using acoustic and laminar flow fields", Biotechnology and Bioengineering 89, 129-137 (2005).

[12] J. P. Dionne, B. McCarthy, B. Ross-Johnsrud, L. Masi, and B. Lipkens, "Large volume flow rate acoustophoretic phase separator for oil water emulsion splitting", The Journal of the Acoustical Society of America 133, 3237-3237 (2013).

[13] E. Alshaafi, A. Prakash, and S. Mercer, "Ultrasonic technique for tracking oil-water emulsion layer in separation vessels", Journal of Petroleum Science and Engineering 184, 106591 (2020).

[14] G. D. Pangu and D. L. Feke, "Acoustically aided separation of oil droplets from aqueous emulsions", Chemical Engineering Science 59, 3183-3193 (2004).

[15] A. Garcia-Lopez and D. N. Sinha, "Enhanced acoustic separation of oilwater emulsion in resonant cavities", The Open Acoustics Journal 1, 66-71 (2008). 
[16] S. Nii, S. Kikumoto, and H. Tokuyama, "Quantitative approach to ultrasonic emulsion separation", Ultrasonics Sonochemistry 16, 145-149 (2009).

[17] X. Luo, J. Cao, H. Yan, H. Gong, H. Yin, and L. He, "Study on separation characteristics of water in oil (w/o) emulsion under ultrasonic standing wave field", Chemical Engineering and Processing - Process Intensification 123, 214-220 (2018).

[18] R. König, E. Benes, M. Gröschl, and J. Hald, "Ultrasonic splitting of oil-in-water emulsions", The Journal of the Acoustical Society of America 105, 1076-1077 (1999).

[19] R. van Zwieten, B. Verhaagen, K. Schroën, and D. F. Rivas, "Emulsification in novel ultrasonic cavitation intensifying bag reactors", Ultrasonics Sonochemistry 36, 446 - 453 (2017).

[20] F. Petersson, L. Åberg, A.-M. Swärd-Nilsson, and T. Laurell, "Free flow acoustophoresis: Microfluidic-based mode of particle and cell separation", Analytical Chemistry 79, 5117-5123 (2007), pMID: 17569501.

[21] A. Fornell, K. Cushing, J. Nilsson, and M. Tenje, "Binary particle separation in droplet microfluidics using acoustophoresis", Applied Physics Letters 112, 063701 (1-4) (2018).

[22] P. Augustsson and T. Laurell, "Acoustofluidics 11: Affinity specific extraction and sample decomplexing using continuous flow acoustophoresis", Lab Chip 12, 1742-1752 (2012).

[23] A. Lenshof, C. Magnusson, and T. Laurell, "Acoustofluidics 8: Applications of acoustophoresis in continuous flow microsystems", Lab Chip 12, 1210-1223 (2012).

[24] D. Rossi, R. Jamshidi, N. Saffari, S. Kuhn, A. Gavriilidis, and L. Mazzei, "Continuous-flow sonocrystallization in droplet-based microfluidics", Crystal Growth \& Design 15, 5519-5529 (2015).

[25] O. Manneberg, B. Vanherberghen, B. Önfelt, and M. Wiklund, "Flow-free transport of cells in microchannels by frequency-modulated ultrasound", Lab Chip 9, 833-837 (2009).

[26] Y. Iida, K. Yasui, T. Tuziuti, M. Sivakumar, and Y. Endo, "Ultrasonic cavitation in microspace", Chem. Commun. 2280-2281 (2004). 
[27] D. Fernandez Rivas and S. Kuhn, "Synergy of microfluidics and ultrasound", Topics in Current Chemistry 374, 70 (2016).

[28] A. Bernassau, P. Glynne-Jones, F. Gesellchen, M. Riehle, M. Hill, and D. Cumming, "Controlling acoustic streaming in an ultrasonic heptagonal tweezers with application to cell manipulation", Ultrasonics 54, 268-274 (2014).

[29] A. Kundt and O. Lehmann, "Ueber longitudinale schwingungen und klangfiguren in cylindrischen flüssigkeitssäulen", Annalen der Physik 229, $1-12(1874)$.

[30] L. V. King, "On the acoustic radiation pressure on spheres", Proceedings of the Royal Society of London. Series A, Mathematical and Physical Sciences 147, 212-240 (1934).

[31] G. Pangu and D. Feke, "Kinetics of ultrasonically induced coalescence within oil/water emulsions: Modeling and experimental studies", Chemical Engineering Science 64, 1445-1454 (2009).

[32] R. Barnkob, I. Iranmanesh, M. Wiklund, and H. Bruus, "Measuring acoustic energy density in microchannel acoustophoresis using a simple and rapid light-intensity method", Lab Chip 12, 2337-2344 (2012).

[33] R. Barnkob, P. Augustsson, T. Laurell, and H. Bruus, "Measuring the local pressure amplitude in microchannel acoustophoresis", Lab Chip 10, 563-570 (2010).

[34] P. Augustsson, R. Barnkob, S. T. Wereley, H. Bruus, and T. Laurell, "Automated and temperature-controlled micro-piv measurements enabling long-term-stable microchannel acoustophoresis characterization", Lab Chip 11, 4152-4164 (2011).

[35] S. M. Hagsäter, T. G. Jensen, H. Bruus, and J. P. Kutter, "Acoustic resonances in microfluidic chips: full-image micro-piv experiments and numerical simulations", Lab Chip 7, 1336-1344 (2007).

[36] S. M. Hagsäter, A. Lenshof, P. Skafte-Pedersen, J. P. Kutter, T. Laurell, and H. Bruus, "Acoustic resonances in straight micro channels: Beyond the 1d-approximation", Lab Chip 8, 1178-1184 (2008). 
[37] M. Ohlin, I. Iranmanesh, A. E. Christakou, and M. Wiklund, "Temperature-controlled mpa-pressure ultrasonic cell manipulation in a microfluidic chip", Lab Chip 15, 3341-3349 (2015).

[38] T. Cacace, V. Bianco, M. Paturzo, P. Memmolo, M. Vassalli, M. Fraldi, G. Mensitieri, and P. Ferraro, "Retrieving acoustic energy densities and local pressure amplitudes in microfluidics by holographic time-lapse imaging", Lab Chip 18, 1921-1927 (2018).

[39] K. C. van Dijke, G. Veldhuis, K. Schroën, and R. M. Boom, "Simultaneous formation of many droplets in a single microfluidic droplet formation unit", AIChE Journal 56, 833-836 (2010).

[40] K. van Dijke, R. de Ruiter, K. Schroën, and R. Boom, "The mechanism of droplet formation in microfluidic edge systems", Soft Matter 6, 321-330 (2010).

[41] H. Bazyar, N. van de Beek, and R. G. H. Lammertink, "Liquid-infused membranes with oil-in-water emulsions", Langmuir 35, 9513-9520 (2019), pMID: 31241957.

[42] A. Kumar, P. Pathak, and N. Dass, "A study of speed of sound in water", IOSR Journal of Applied Physics 8, 21-23 (2016).

[43] W. Brevis, Y. Niño, and G. H. Jirka, "Integrating cross-correlation and relaxation algorithms for particle tracking velocimetry", Experiments in Fluids 50, 135-147 (2011).

[44] J. Schindelin, I. Arganda-Carreras, E. Frise, V. Kaynig, M. Longair, T. Pietzsch, S. Preibisch, C. Rueden, S. Saalfeld, B. Schmid, J.-Y. Tinevez, D. J. White, V. Hartenstein, K. Eliceiri, P. Tomancak, and A. Cardona, "Fiji: an open-source platform for biological-image analysis", Nature Methods 9, 676-682 (2012).

[45] W. Thielicke and E. J. Stamhuis, "Pivlab towards user-friendly, affordable and accurate digital particle image velocimetry in matlab", Journal of Open Research Software 2, e30 (1-10) (2014).

[46] M. Hill and N. R. Harris, Microfluidic technologies for miniaturized analysis systems (MEMS reference shelf) (Springer-Verlag, New York Inc.) (2007). 
[47] S. Outcalt, A. Laesecke, and T. J. Fortin, "Density and speed of sound measurements of hexadecane", The Journal of Chemical Thermodynamics 42, 700-706 (2010).

[48] P. Flow, "Speed of sound in common liquids", http://www. precisionflow.co.uk/speed_of__sound.htm.

[49] E. EDGE, "Physical properties of water", https://www.engineersedge. com/physics/water__density_viscosity_specific_weight_13146. htm.

[50] F. Piezoelectric, "Data sheet for piezoelectric properties of pz26 (navy i) hard relaxor type pzt", https://www.meggittferroperm.com/ wp-content/uploads/2017/10/MSSDK_PZ26_Datasheet-201809.pdf.

[51] K. Uchino, Advanced Piezoelectric materials: science and technology (Woodhead Publishing series in electronic and optical materials) (2010). 


\section{7 \\ On the permeability prediction of porous media}

Predicting permeability, as one of the important characteristics of a porous medium, is desirable for many applications. Numerical finite element results suggested a unique, scaling power-law relationship between the normalized permeability $\left(\kappa / d^{2}\right)$ and the averaged second nearest neighbor fiber distances [1]. Here, this universal relation is validated experimentally using microfluidic chips mimicking random arrays of fibers with various porosity values. To generate random, non-overlapping fiber arrays, a Monte Carlo (MC) algorithm by considering a minimum distance between fibers, is used. Based on these, microfluidic chips with different porosity values, i.e. $0.55,0.6,0.7$ and 0.85 , are fabricated in silicon wafer by etching these arrays of cylindrical pillars. The experiments are performed by permeating water or oil (hexadecane) through these designed pillar array media. The pressure of the liquid is increased step-wise and the corresponding flux values are measured. The experimental conditions are chosen such that the creeping flow regime $(\operatorname{Re} \ll 1)$ is established and Darcy's law can be used to calculate permeability. The same normalized permeability values $\left(\kappa / d^{2}\right)$ are obtained for both water and hexadecane which are ranging from 0.007 to 0.1 for the different microfluidic chips. The analogous scaling power-law relation is observed between normalized permeability and the second nearest fiber distance showing good agreement with the numerical results.

'Prepared for submission as: Hanieh Bazyar, Thejas Hulikal Chakrapani, Wouter den Otter, Stefan Luding and Rob G. H. Lammertink, On the permeability prediction of porous media, 2020. 



\subsection{Introduction}

LOW and transport phenomena involving porous media are encountered in numerous fields of science ranging from agriculture, biomedical, construction, ceramic, chemical and petroleum engineering, to food and soil sciences and powder technology [2. In all these applications, macroscopic transport properties, such as permeability, are of prime interest. It is understood that these characteristics are strongly dependent on not only the porosity value, but also the pore structure [3. The fact that a link exists between intrinsic microstructural parameters of a porous media, such as tortuosity, fiber arrangement, shape and orientation and macroscopic parameters, has motivated the development of a more general relationship between these two parameters 4.

Porous media can be composed of particulate or two-dimensional (2D) long cylinders/fiber-like particles which forms a specific category known as fibrous porous media [5. Common examples of fibrous media include natural substances such as biological tissues (e. g. wood, cork and bones) and man-made materials such as composite materials and industrial filters [1, 6]. As an example, in composite manufacturing processes, a fabric reinforcement (e. g. an assembly of fiber filaments or of stitched fiber strands) is infiltrated with uncured resin by an assigned pressure gradient [7. Thus, the accurate prediction of permeability is of significant importance in such processes.

Experimental techniques for measurement of permeability often yield consistent results [8]. However, they have no predictive capability since new sets of experiments must be performed on a case-by-case basis [9]. As a consequence, the analytical or numerical prediction of permeability has been the goal of many researchers in the field of porous media flow. Analytical predictions such as those developed by Gebart [10. or Bruschke et. al. [11] are based on theoretical assumptions which are capable of predicting permeability of fiber arrays in both longitudinal and transversal directions. Requirement of experimental or numerical validations as well as applicability in a certain range of fiber volume fraction or idealized regularly aligned fibers, further curtail widespread application of analytical predictive models [1, 7]. For more general or rather complex microstructures, one needs to rely on numerical simulations.

There have been a large number of computational and numerical approaches in modeling flow in fibrous microstructures to predict the permeability. These works include regular/ordered fibrous media [5, 12 14] as well as random/disordered fibrous media [1, 15, 17]. Katz and Thompson were one of the first to 
find that the relation between the macroscopic permeability and microstructural descriptor, namely, the critical pore diameter, concerns a power law [18]. Later on, Gebart presented an expression for transverse permeability of square or hexagonally ordered arrays showing a power law relation between permeability and fiber volume fraction [10]. As a more extensive work, Yazdchi et. al. investigated the effect of microstructural parameters such as fiber arrangement, on the permeability of ordered or disordered fibrous media using finite element method (FEM) simulations [1, 5. As will be detailed in section Permeability prediction model, a scaling power-law relation for predicting the transverse permeability of ordered/disordered fiber arrangements was observed in terms of the microstructural average channel width $\gamma_{2}$ [1]. This relation is valid for a wide range of porosities as well as all values of inter-fiber distance $\Delta_{\min }$.

Here, we aim to experimentally validate the universal power-law relation for predicting permeability of a porous media. For this purpose a microfluidic chip mimicking the fibrous microstructure with random arrays of round pillars, representing the fibers, is used. Microfluidic model porous media, known as micromodels, are devices with a transparent connected porous network enabling the direct visualization of flow, transport and phase behaviour in porous media [19, 20. Since the development of the first micromodel by Chatenever and Calhoun in 1952 [21, a wide variety of micromodels resembling a porous medium with regular as well as irregular shapes, anisotropy and pore sizes have been established. Different materials can be used to fabricate pore network patterns, among which silicon $[22,26$, glass $[27-29]$ and polymers such as polydimethyl siloxane (PDMS) [30 34] are the most well-known. For more detailed information on materials, fabrication methods and applications of micromodels, the reader is referred to the recent review by Anbari et. al. [19].

Due to the tremendous flexibility in in-situ observation as well as pressureflux measurements in micromodels, they have also found their applications in permeability measurements. Joseph et. al. estimated the absolute permeability of different pore network designs fabricated in silicon with varying number of pores and throats [35. They measured pressure drop across the pore network and permeability was estimated by applying Darcy's law (see section Permeability calculation of fibrous microstructures). Later on, the same approach has been used by Yun et. al. for permeability measurement of silicon micromodels with complex geometries [36]. The absolute permeability of carbonate-derived pore structure with dual-porosity and dual-depth was calculated using Darcy's law by measuring several steady-state pressure drops 
across the micromodel at different flow rates. Another technique, namely particle tracking velocimetry, has also been used for permeability measurements of micromodels [37]. Suspended finite-sized colloidal particles were used and the results showed no dependency of the calculated permeability to the particle size.

In this work, the fibrous microstrcuture, with non-overlapping random fiber arrays, is first generated using Monte Carlo (MC) algorithm. The generated microstructures with different porosity values, namely $0.55,0.6,0.7$ and 0.85 , are then used to design the corresponding micromodels. The micromodels consist of random arrays of pillars which are fabricated in silicon using deep reactive ion etching (DRIE). The permeability of fabricated micromodels is measured based on Darcy's law by permeating water or hexadecane liquids through. The pressure is increased step-wise and the corresponding flow values are measured. The same permeability values are obtained for both liquids.

\subsection{Materials and method}

\subsubsection{Permeability prediction model}

Based on numerical finite element (FE) methods, Yazdchi et. al. developed a microstructural model based on lubrication effects of the narrow/effective channels [1. The universal lubrication relation is valid for a wide range of porosity values and accounts for ordered or disordered fibrous media. The numerical FE results suggested a unique, scaling power law relationship between the permeability $(\kappa)\left(\mathrm{m}^{2}\right)$, obtained from fluid flow simulations, and the average second nearest neighbor fiber distance $\left(\gamma_{2}\right)$ as

$$
\frac{\kappa}{d^{2}}=C \gamma_{2}^{2.5},
$$

in which $d$ is the fiber diameter $(\mathrm{m})$ and $C$ is the geometric factor $\left(\frac{\kappa}{d^{2}}\right.$ is known as the normalized permeability).

The $2^{\text {nd }}$ nearest neighbor distance $\gamma_{2}$ is identical to the mean value of the shortest Delaunay triangulation (DT) edges constructed using the centers of the fibers. A DT is the set of lines joining a set of points such that each point is joined to its nearest neighbor [38. It satisfies a so-called "empty circle" property in which the circumcircle of each triangle (formed by three points) does not contain any of the other points. The concept of DT is suitable for characterization of the fiber arrangements with many other applications such as finding the nearest neighbor, mesh generation and surface reconstruction 
[39. The reader is referred to Yazdchi et. al. [1] sections 4.1.3, 4.1.4 and Figure 7 for more detailed information on DT. In the following subsections, permeability calculation based on Yazdchi et. al. [1] and definition of $\gamma_{2}$ are explained in more detail.

\subsubsection{Numerical calculation of permeability}

According to Darcy's law, for unidirectional flow through a porous medium in the creeping flow regime $(\operatorname{Re} \ll 1)$ [40, the superficial fluid velocity $(U)$ is proportional to the pressure gradient as

$$
U=-\frac{\kappa}{\mu} \nabla p .
$$

The proportionality constant $\kappa$ is called the permeability of the medium, which strongly depends on microstructure properties such as fiber arrangement and porosity. The FEM software ANSYS ${ }^{\circledR}$ was used to calculate the fluid velocity from discretization of continuity and Navier-Stokes equations into linear triangular elements. The superficial velocity and permeability of the fibrous medium are obtained using Equation 7.2 [1].

\subsubsection{Definition of $2^{\text {nd }}$ nearest neighbor distance $\left(\gamma_{2}\right)$}

For an arrangement of cylindrical pillars (see for example Figure $7.3(\mathrm{a})],\left\langle\gamma_{2}\right\rangle$ is defined as

$$
\left\langle\gamma_{2}\right\rangle=\frac{\left\langle D_{2}\right\rangle}{d}-1
$$

where $d$ is the fiber diameter and $\left\langle D_{2}\right\rangle$ is the mean second nearest neighbour distance from a pillar. Since every pillar has a second nearest neighbour in a random pillar configuration, $D_{2}$ and $\gamma_{2}$ can be expressed as probability distribution functions (PDFs) (see Figure 7.6). The corresponding algorithm for evaluation of $\left\langle D_{2}\right\rangle$ is shown in Appendix $\mathrm{F}$ section "Algorithm for calculation of $2^{\text {nd }}$ nearest neighbor $\left(\gamma_{2}\right)$ "

\subsubsection{Generation of fibrous microstructure}

A 2D representation of the fibrous microstructure is considered such that the fibers are randomly distributed in a square domain and confined by walls with normal in $z$ direction. This is equivalent to realistic porous media which are finite and confined with walls [1]. Here we use a Monte Carlo (MC) procedure 
to generate random, non-overlapping fiber arrays. In this method, we consider a minimum dimensionless inter-fiber distance, i.e.

$$
\Delta_{\min }=\frac{\delta_{\min }}{d}
$$

in which $\delta_{\min }$ is the distance between fibers and $d$ is the fiber diameter, to avoid fiber overlap. The MC procedure perturbs fiber center locations in randomly chosen directions and magnitudes, given an initial fiber configuration on a triangular lattice 41. The perturbation is rejected if it leads to an overlap with a neighboring fiber. Note that, to ensure the gap between fibers $\left(\Delta_{\min }\right)$, a virtual diameter, i. e. $d^{*}=d\left(1+\Delta_{\min }\right)$ is assigned to each fiber leading to the virtual porosity $\varepsilon^{*}=1-\left((1-\varepsilon)\left(1+\Delta_{\min }\right)^{2}\right)$ [1]. In order to get a short range-correlated random position field, $10^{7}$ steps are used for each random configuration with different porosity values.

\subsubsection{Chosen porosity and $\Delta_{\min }$ values}

From the calculation of $2^{\text {nd }}$ nearest neighbor $\gamma_{2}$ and the corresponding PDF plot, one can observe that this parameter is a function of the porosity value. Yazdchi et. al. showed that the variation between these two parameters also depends on the value of $\Delta_{\min }$ (Figure 9 of Ref [1]). All the results together with the best fit to Equations 7.3 show that at high porosity, all the curved collapse and $\Delta_{\min }$ has less effect on $\gamma_{2}$. Therefore, we have selected porosity values of $0.55,0.6,0.7$ and 0.85 with the highest value of $\Delta_{\min }$, i.e. 0.2 . Due to the fabrication limits in the minimum distance between fibers $\left(\delta_{\min }\right)$, highest value of $\Delta_{\min }$ has been selected (see Tables 7.1 and 7.2 for $\delta_{\min }$ values).

In our MC simulation using MATLAB, for each porosity, 800 fibers are generated in a square domain of $20 \times 20$ (non-dimensionalized), i.e. simulation unit cell. By knowing the total area of the unit cell $\left(A_{\mathrm{T}}=20 \times 20\right)$ and the fibers $\left(N \pi r_{0}^{2}\right)$, one can calculate the fiber radius $r_{0}$ for each porosity value using

$$
r_{0}=\sqrt{\frac{(1-\varepsilon) A_{\mathrm{T}}}{N \pi}}
$$

where $N$ is the total number of fibers in the simulation unit cell (800).

\subsubsection{Statistical analysis of the fibrous microstructure}

In order to characterize and classify microstructures based on the spatial arrangement of heterogeneities, there are various statistical descriptions [42]. 
Among these methods, the radial (pair) distribution function $g(r)$ is the most popular. It is defined as the probability of finding the center of a fiber inside an annulus of internal radius $r$ and thickness $d r$ with center at a randomly selected fiber (see inset of Figure 7.2 [1]. The mathematical description of $g(r)$ is

$$
g(r)=\frac{1}{2 \pi r} \frac{d K(r)}{d r}, \quad \text { with } \quad K(r)=\frac{A}{N^{2}} \sum_{k=1}^{N} I_{k}(r),
$$

where $K(r)$ is a second-order intensity function, also known as Ripley's function [41, $I_{k}(r)$ is the number of centers of fibers that lie within a circle of radius $r$ about an arbitrary chosen fiber and $N$ is the number of fibers in the observation area $A$. As the distance $r$ increases, $g(r)$ tends to 1 in a statistically valid fiber distribution without long-range order.

\subsubsection{Fabrication of fibrous microstructure}

The generated fibrous microstructures with different porosity values, are used to design the masks of the corresponding microfluidic chips. For this purpose, the layout editor software CleWin 5 (developed by WieWeb software, The Netherlands) is used. A square of $500 \times 500 \mu \mathrm{m}$ with 800 fibers is considered as the corresponding unit cell in the mask design. The scaling factor $a=25 \mu \mathrm{m}$ can be defined as the ratio between the unit cell of the chip $(500 \mu \mathrm{m})$ and that of the MC simulation (20). Each microfluidic chip consists of random arrays of cylindrical pillars, representing the corresponding fibrous microstructure, which is fabricated in silicon using standard photolithography and reactive ion etching (see SI for detailed fabrication procedure). The total area of the porous medium in the chip is $5 \times 2.5 \mathrm{~mm}$ which is designed in the mask by repeating the chip unit cell in both length and width directions. Thus, the total number of unit cells is 50 which leads to 40,000 pillars $(50 \times 800)$ in each microstrcuture. In order to consider the pillar microstrcutures as $2 \mathrm{D}$, the pillars are fabricated with the height of $h=20 \mu \mathrm{m}$ leading to relatively small but near unity aspect ratio values $\left(h / d_{\text {act }}\right)$ (see Table 7.2).

The fabricated pillar microstructures in the chips with different porosity values are observed using an inverted optical microscope (Zeiss Axiovert 40 MAT) and an objective of 5x magnification (Zeiss EC Epiplan 5x/0.13 (working distance $(\mathrm{WD})=19.8 \mathrm{~mm})$ ). The side view of the pillars as well as the top view and the pillar surface roughness are observed using scanning electron microscopy (SEM) (JEOL JSM 5610). 
The actual pillar diameter of each microstructure $\left(d_{\text {act }}\right)$ is obtained by measuring the pillar diameter of at least 35 pillars using image analysis tool in the imaging software (HoKaWo 3.00) of the inverted microscope. By knowing the pillar diameter, one can calculate the actual porosity as

$$
\varepsilon_{\mathrm{act}}=1-\frac{A_{\mathrm{pT}}}{A_{\mathrm{T}}},
$$

based on the total projected area of the pillars $\left(A_{\mathrm{pT}}=N \times \pi d^{2} / 4\right.$ where $N$ is total number of pillars, i.e. 40,000) and that of the microstructured area $\left(A_{T}=5 \times 2.5 \mathrm{~mm}^{2}\right)$.

\subsubsection{Permeability measurements}

The measurement of the permeability is performed by pushing water with absolute viscosity $1 \mathrm{mPa}$ s (Milli-Q grade) or oil (hexadecane (reagent plus 99\% from Sigma Aldrich, The Netherlands)) with higher viscosity (3.2 mPa s) (see Appendix C, Table C.1) through the microfluidic chips. All the chips are hydrophilic, since they are used as received from clean room with no further cleaning or treatment.

The experiments are performed by increasing the pressure step-wise from 100 mbar to 1000 mbar with steps of 100 mbar using a pressure controller (OB1 Mk3+ from ElveFlow, France). The corresponding flow values are measured simultaneously using a flow meter (Bronkhorst mini Cori flow M12 with working range of $0.1-200 \mathrm{~g} / \mathrm{h}$ with accuracy value of $2 \%$. At each step, pressure is kept constant for $20 \mathrm{~s}$ and flow is measured every $10^{\text {th }}$ of a second. The average values of flow and pressure at each step, excluding the first five data points, are used to obtain the corresponding flow and pressure values of that step. For reproducibility purposes, each experiment is performed four times and consistent results are obtained. To ensure disappearance of any possible air bubble, the results of the third or fourth run are used for further analysis. It is worth mentioning that in the first run, the first pressure step (100 mbar) is kept for $1 \mathrm{~min}$ to give enough time to the permeating liquid to fill the chip and connection tubing. The schematic of the set-up is shown in Figure 7.1

\subsection{Results and discussion}




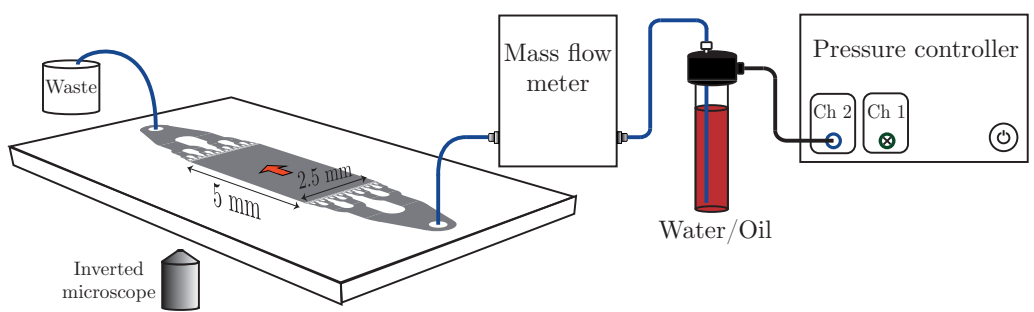

Figure 7.1: Schematic illustration of the experimental set-up used for permeability measurements of random fibrous microstructures fabricated in the microfluidic chip.

\subsubsection{Analysis of radial distribution function $(g(r))$}

The comparison of $g(r)$ for microstructures with different porosity values are shown in Figure 7.2. As $r$ increases, we observe a number of oscillations after which $g(r)$ approaches unity. This indicates that the numerically generated microstructures are statistically random for larger $r$. The first maximum results from the excluded area of the pillars with the virtual diameter $d^{*}$. It is important to notice the large number of oscillations at the porosity values of 0.55 and 0.6 which indicates a strong structuring, akin to a crystal. However, at porosity values of 0.7 and 0.85 the dilute nature of the system ensures a weak structuring. It is worth mentioning that to avoid boundary edge effects on the statistics, we consider periodic boundary condition in our MC simulations for generation of fibrous microstructures.

\subsubsection{Comparison between the designed and fabricated fibrous microstructures}

The pictures of the designed cells and corresponding SEM images of the fabricated unit cells for the microstructures with porosity 0.55 and 0.7 are shown in Figure 7.3 (The corresponding pictures for porosity 0.6 and 0.85 are shown in Appendix F Figure F.1p. It is worth mentioning that the shown SEM images concern the same region as the corresponding unit cells. The original SEM images for porosity 0.55 and 0.7 are taken at magnification of $110 \mathrm{x}$ and $90 \mathrm{x}$ respectively. To better observe the pillars from the top view, the zoomed-in SEM images and digital designs of all the microfluidic chips with different porosity values are shown in Appendix F Figures F.2 and F.3. The SEM images of the side view of all the fabricated microfluidic chips are shown in Figure 7.4. It can be observed that the pillar walls are not smooth and posses a corrugated structure. This is because of the deep reactive ion etching (DRIE) 


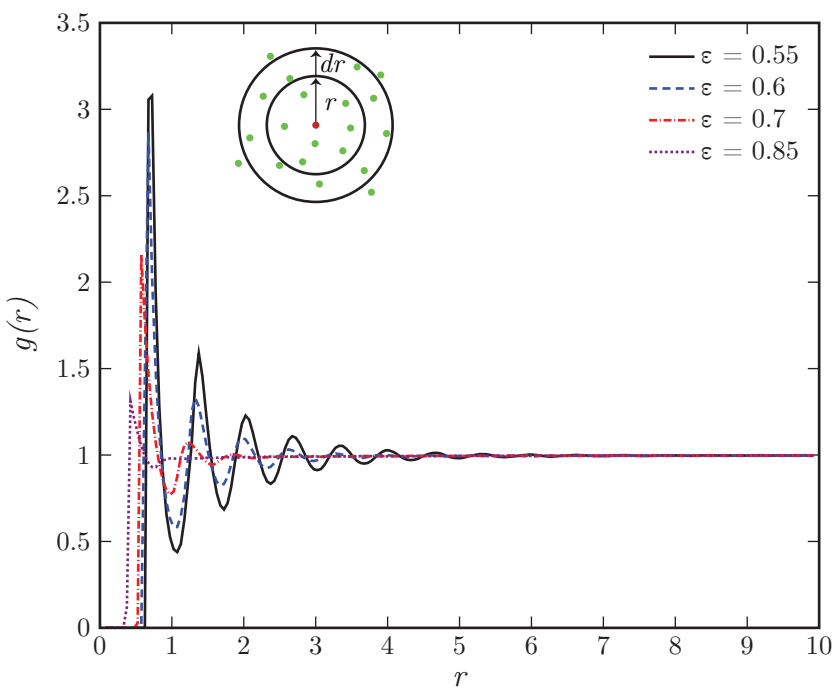

Figure 7.2: Plot of $g(r)$ for 800 fibers generated with MC procedure with $\Delta_{\text {min }}=0.2$ at different porosity values.

procedure used for etching of the pillars (see Appendix F section "Fabrication procedure of the microfluidic chip"). The side view SEM images showing the inlet/outlet of the chips are shown in Appendix F Figure F.4. The zoomed-in side view SEM images of the pillars in all the microfluidic chips are shown in Appendix F Figure F.5 depicting corrugated pillar wall structures.

The designed pillar diameter and porosity together with the corresponding virtual parameters are shown in Table 7.1. The corresponding actual pillar diameter, porosity and aspect ratio are shown in Table 7.2 (including the corresponding standard deviation). A good agreement is obtained between the simulated and fabricated fibrous microstructures with different porosity values. Due to the etching process in the fabrication of the pillars in the microfluidic chip (see Figure 7.4 and Appendix F Figure F.5), the actual pillar diameters are slightly smaller than the designed ones leading to larger actual porosity.

\subsubsection{Permeability calculation of fibrous microstructures}

The permeability of all pillar microstructures with different porosity values is obtained based on simplified Darcy's law 


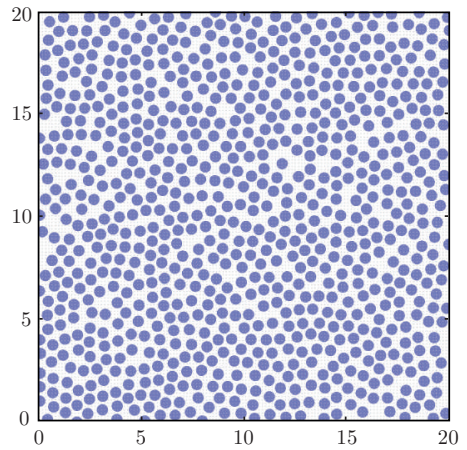

(a)

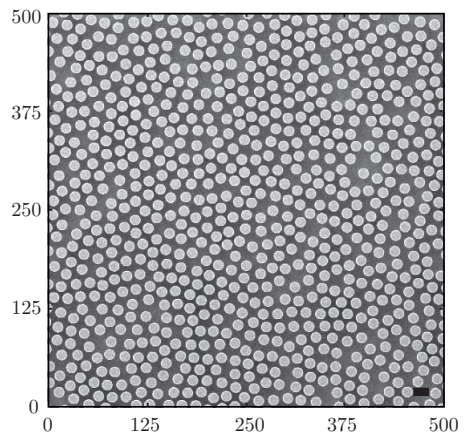

(c)

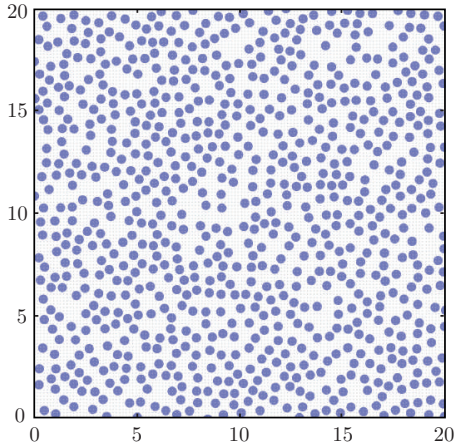

(b)

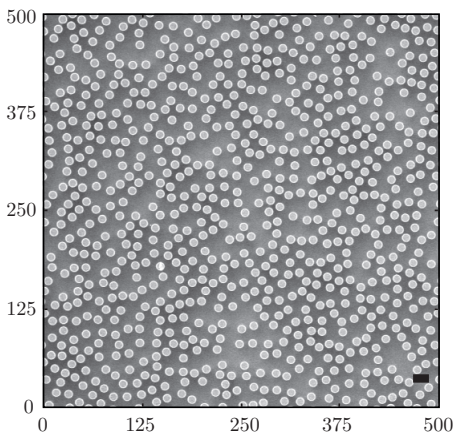

(d)

Figure 7.3: Pictures of simulated unit cell of the microstructure with porosity (a) 0.55 and (b) 0.7 using MC algorithm. The corresponding SEM images of the fabricated unit cells in the microfluidic chip are shown respectively in (c) and (d) (both axis are in $\mu \mathrm{m}$ and scale bar is $20 \mu \mathrm{m})$.

Table 7.1: The designed values of porosity $\left(\varepsilon_{\mathrm{sim}}\right)$, pillar diameter $\left(d_{\text {sim }}=2 r_{0} \times a\right)$ (obtained from Equation 7.5 and minimum distance between fibers

$\left(\delta_{\min (\operatorname{sim})}\right)$ (obtained from Equation 7.4 together with virtual values of porosity $\left(\varepsilon^{*}\right)$ and pillar diameter $\left(d^{*}\right)$ obtained from $\mathrm{MC}$ simulation results for $\Delta_{\min }=0.2$.

\begin{tabular}{lcccc}
\hline$\varepsilon_{\operatorname{sim}}$ & $d_{\operatorname{sim}}[\mu \mathrm{m}]$ & $\delta_{\min (\operatorname{sim})}[\mu \mathrm{m}]$ & $d^{*}[\mu \mathrm{m}]$ & $\varepsilon^{*}$ \\
\hline 0.55 & 13.38 & 2.68 & 16.06 & 0.35 \\
0.6 & 12.62 & 2.52 & 15.14 & 0.42 \\
0.7 & 10.93 & 2.19 & 13.11 & 0.57 \\
0.85 & 7.73 & 1.55 & 9.27 & 0.78 \\
\hline
\end{tabular}




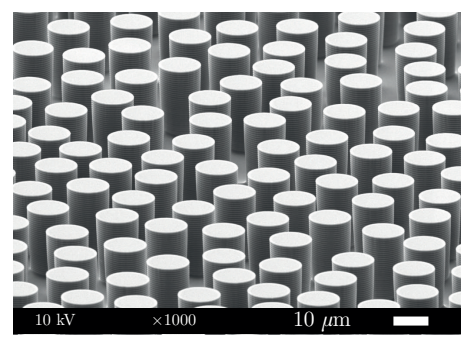

(a)

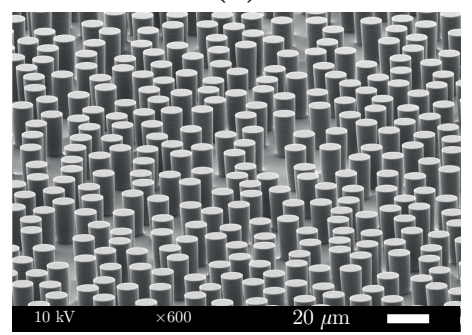

(c)

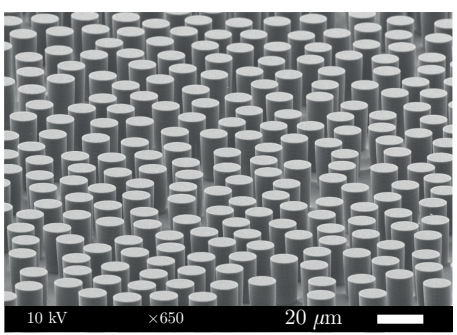

(b)

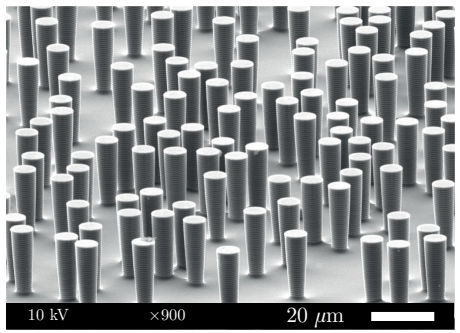

(d)

Figure 7.4: SEM images of the tilted side view of the fabricated microfluidic chips with porosity (a) 0.55 , (b) 0.6 , (c) 0.7 and (d) 0.85 .

Table 7.2: Calculated actual values of porosity $\left(\varepsilon_{\text {act }}\right)$ (obtained from Equation 7.7), pillar diameter $\left(d_{\text {act }}\right)$, minimum distance between fibers $\left(\delta_{\min (\text { act })}\right)$ and aspect ratio (pillar height $h / d_{\text {act }}$ based on the pictures of the fabricated microfluidic chips.

\begin{tabular}{lcccc}
\hline$\varepsilon_{\text {sim }}$ & $d_{\text {act }}[\mu \mathrm{m}]$ & $\delta_{\min (\mathrm{act})}[\mu \mathrm{m}]$ & $\frac{h}{d_{\text {act }}}$ & $\varepsilon_{\text {act }}$ \\
\hline 0.55 & $12.93 \pm 0.30$ & $2.59 \pm 0.06$ & $1.55 \pm 0.037$ & $0.58 \pm 0.020$ \\
0.6 & $11.84 \pm 0.26$ & $2.37 \pm 0.05$ & $1.69 \pm 0.037$ & $0.65 \pm 0.016$ \\
0.7 & $10.40 \pm 0.27$ & $2.08 \pm 0.05$ & $1.92 \pm 0.049$ & $0.73 \pm 0.039$ \\
0.85 & $7.16 \pm 0.26$ & $1.43 \pm 0.05$ & $2.79 \pm 0.101$ & $0.87 \pm 0.009$ \\
\hline
\end{tabular}


Table 7.3: The values of permeability $(\kappa)$, normalized permeability $\left(\kappa / d^{2}\right)$ and second nearest neighbor distance $\left(\gamma_{2}\right)$ of water and hexadecane through pillar microstructures with different porosity values (the values after \pm for normalized permeability show (lower values-upper values)/2).

\begin{tabular}{lcccc}
\hline Porosity & Liquid & $\kappa \times 10^{-12}\left[\mathrm{~m}^{2}\right]$ & $\kappa / d^{2} \times 10^{-3}[-]$ & $\gamma_{2}[-]$ \\
\hline \multirow{2}{*}{0.55} & Water & 1.23 & $7.380 \pm 0.349$ & \multirow{2}{*}{$0.288 \pm 0.026$} \\
& Hexadecane & 1.19 & $7.141 \pm 0.337$ & \\
\multirow{2}{*}{0.6} & Water & 1.70 & $12.144 \pm 0.538$ & \multirow{2}{*}{$0.333 \pm 0.027$} \\
& Hexadecane & 1.59 & $11.323 \pm 0.502$ & \\
\multirow{2}{*}{0.7} & Water & 2.67 & $24.729 \pm 1.267$ & \multirow{2}{*}{$0.470 \pm 0.034$} \\
& Hexadecane & 2.64 & $24.442 \pm 1.252$ & \\
\multirow{2}{*}{0.85} & Water & 5.06 & $98.662 \pm 7.181$ & \multirow{2}{*}{$0.939 \pm 0.070$} \\
& Hexadecane & 5.09 & $99.201 \pm 7.221$ & \\
\hline
\end{tabular}

$$
Q=-\frac{\kappa A}{\mu} \frac{d p}{d x},
$$

where $Q$ is the volumetric flow rate of the permeating liquid (water or hexadecane) $\left(\mathrm{m}^{3} / \mathrm{s}\right), \kappa$ is the permeability $\left(\mathrm{m}^{2}\right), A$ is the total permeating area (here channel width $(w=2.5 \mathrm{~mm}) \times$ channel height $(h=50 \mu \mathrm{m})\left(\mathrm{m}^{2}\right), \mu$ is the absolute viscosity of the permeating liquid $(\mathrm{Pa} \mathrm{s})$, and $\frac{d p}{d x}$ is the pressure gradient across the channel which is considered as $\Delta p /$ channel length $(l=5$ $\mathrm{mm})(\mathrm{Pa} / \mathrm{m})$. By plotting the flux of the permeating liquid $\left(\mathrm{m}^{3} / \mathrm{m}^{2} \mathrm{~s}\right)$ multiplied by the viscosity of the permeating liquid as a function of the applied pressure gradient, one can obtain the permeability from the slope.

Figure 7.5 shows the flux $\times$ viscosity vs. pressure gradient plots for both water and hexadecane through pillar microstructures with different porosity values. A linear relation between flux $\times$ viscosity and pressure gradient is observed for both liquids at different porosity values indicating that the fluid content remains constant [43. It is worth mentioning that the lines depict linear fitting to the obtained results using MATLAB. The corresponding movies of water and hexadecane filling the chips are shown in Appendix F (Movies F1-F4).

The permeability values of both water and hexadecane through microstructures with different porosity values are shown in Table 7.3. No considerable difference is observed between the obtained values confirming no dependency of permeability on the type of liquid. 


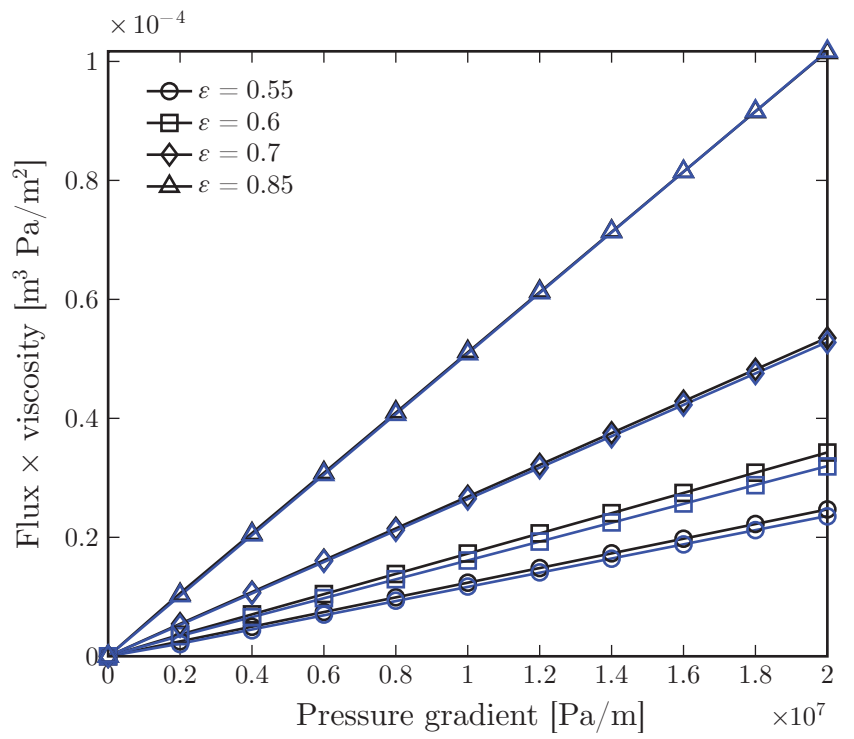

Figure 7.5: Plot of flux $\times$ viscosity as a function of pressure gradient for both water and hexadecane through microstructures with different porosity values (symbols are data points and lines are the corresponding linear fit with black and blue colors for water and hexadecane respectively). 


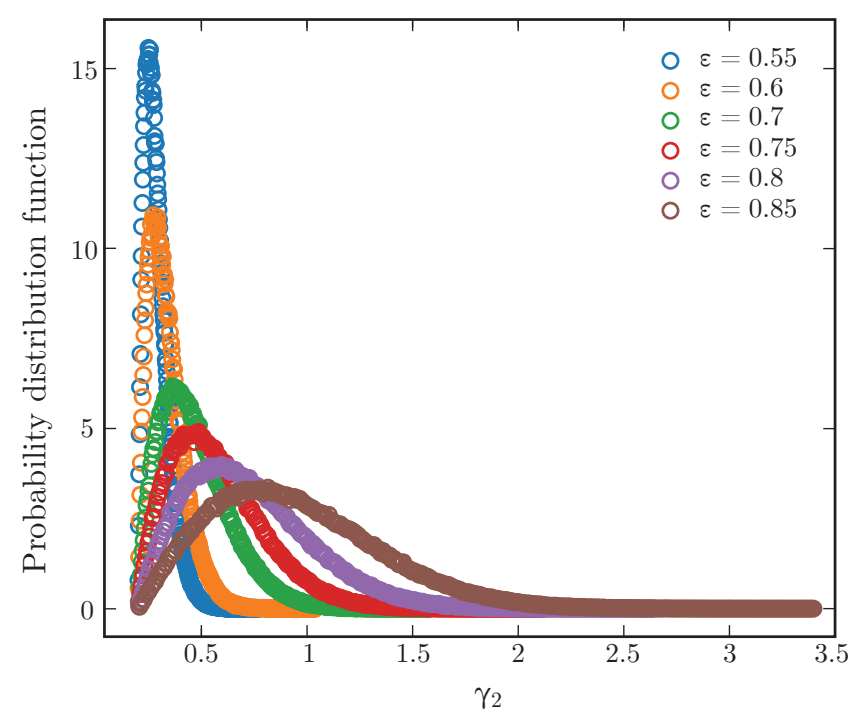

Figure 7.6: The probability distribution function (PDF) of $\gamma_{2}$ at different porosity values $(\varepsilon)$. Porosity 0.75 and 0.8 are shown for a better comparison.

\subsubsection{Calculated values of $2^{\text {nd }}$ nearest neighbor distance $\left(\gamma_{2}\right)$}

The corresponding PDF plots for calculated $\gamma_{2}$ at different porosity values are shown in Figure 7.6. A broader distribution is observed at higher porosity values. This will be discussed further in section "Experimental validation of permeability model". The mean values of $\gamma_{2}$ together with the corresponding standard deviation are given in Table 7.3 . It is worth mentioning that the presented standard deviation is the combined one stemming from both calculation of $\gamma_{2}$ and fabrication of the pillars which lead to a variation in pillar diameter $d$ (see Table 7.2). The corresponding error analysis is explained in Appendix F section "Error analysis in calculation of $\gamma_{2}$ ".

\subsubsection{Modification of the numerical model}

The scaling power-law model proposed by Yazdchi et. al. [1, is a completely $2 \mathrm{D}$ model. However, the aspect ratio of the pillars in the fabricated micromodels is relatively close to unity (see Table 7.1) suggesting that the effects of the third dimension cannot be neglected. The numerical model is thus modified to account for the effects of the top and bottom walls on the fluid flow.

Poiseuille law for flow between two flat plates is considered as 44 


$$
q=-\frac{h^{3}}{12 \mu} \frac{d p}{d x}
$$

where $h$ is the height between two flat plates (here equal to pillar height) (m), $\mu$ is the absolute viscosity of the fluid ( $\mathrm{Pa} \mathrm{s}$ ) and $\frac{d p}{d x}$ is the pressure gradient across the channel. $q$ corresponds to the flow per unit length parallel to the flow direction. As a relevant dimension, the width $w$ has been chosen as the unit length. Thus, the volumetric flow rate $Q$ is defined as $Q=q \times w$. The cross sectional area of the flat plates is $A=w \times h$, where $w$ is the corresponding width $(\mathrm{m})$. Fluid flux can be then determined as

$$
\frac{Q}{A}=-\frac{h^{2}}{12 \mu} \frac{d p}{d x}
$$

By considering $\frac{Q}{A} \times \mu$ as a function of pressure gradient, the corresponding permeability for flow through two parallel plates is $\kappa_{\mathrm{F}}=\frac{h^{2}}{12}$. The resistance to the flow stemming from the top and bottom walls is then the inverse of the permeability and is equal to $R_{\mathrm{F}}=\frac{12}{h^{2}}$.

The total effective resistance in the micromodel consisting of the pillars and the top and bottom walls can be defined by adding the flow resistances

$$
R_{\mathrm{eff}}=\frac{12}{h^{2}}+\frac{1}{\kappa_{2 \mathrm{D}}}
$$

where $R_{\mathrm{F}}$ is the resistance from the walls and $R_{2 \mathrm{D}}$ is that of the $2 \mathrm{D}$ microstructure which is the inverse of the permeability in the $2 \mathrm{D}$ model $\left(\kappa_{2} \mathrm{D}\right)$.

The inverse of the effective resistance $\left(R_{\text {eff }}\right)$ leads to the effective permeability $\left(\kappa_{\text {eff }}\right)$

$$
\kappa_{\text {eff }}=\frac{h^{2} \kappa_{2 \mathrm{D}}}{12 \kappa_{2 \mathrm{D}}+h^{2}} .
$$

The normalized effective permeability can be then calculated by dividing $\kappa_{\text {eff }}$ by $d^{2}$ as

$$
\frac{\kappa_{\text {eff }}}{d^{2}}=\frac{h^{2} / d^{2}}{12+h^{2} / \kappa_{2 \mathrm{D}}} .
$$

$\kappa_{2 \mathrm{D}}$ can be calculated from the $2 \mathrm{D}$ model (Equation 7.1) considering the simulation values for pillar diameter $d$ and calculated $\gamma_{2}$ values (see Tables 7.1 and 7.3). The pre-factor $C$ and power are those obtained from the numerical model (see section "Experimental validation of permeability model"). 


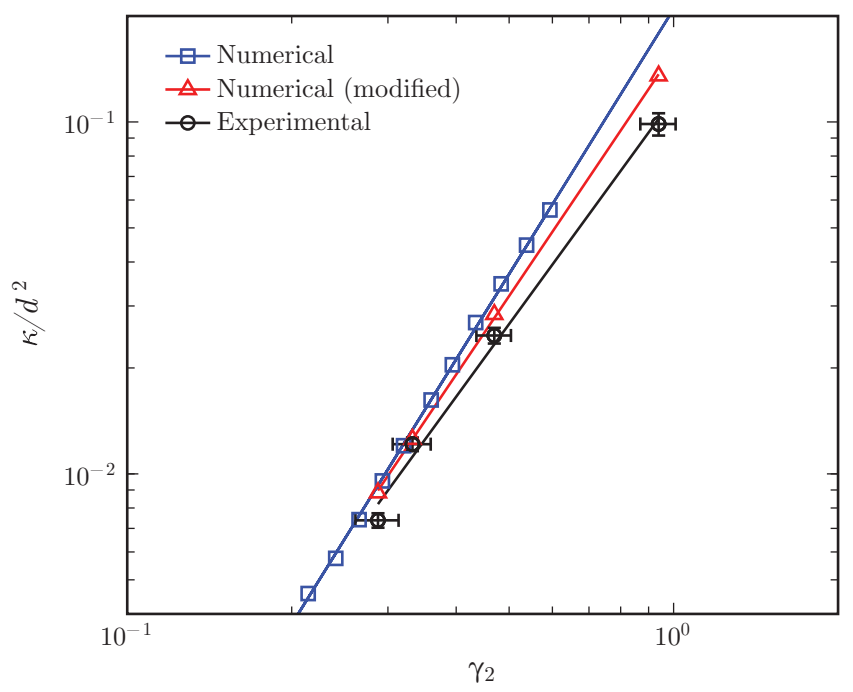

Figure 7.7: Experimental and numerical values of normalized permeability $\left(\kappa / d^{2}\right)$ as a function of second nearest neighbor distance $\gamma_{2}$. Symbols are showing data points and lines are the linear fit. The horizontal error bars show the total standard deviation in measurement of $\gamma_{2}$ (see section "Calculated values of $2^{\text {nd }}$ nearest neighbor distance $\left(\gamma_{2}\right)$ "' and the vertical error bars show the standard deviation in measurement of normalized permeability stemming from variations in actual pillar diameter (see Table 7.2 .

\subsubsection{Experimental validation of permeability model}

In order to compare the experimental results to the numerical ones, the normalized permeability is calculated as $\frac{\kappa}{d^{2}}$ where $d$ is the pillar diameter. The values of normalized permeability for both water and hexadecane are shown in Table 7.3. The corresponding $2^{\text {nd }}$ nearest neighbor distance $\gamma_{2}$ for each porosity is the one calculated from Equation 7.3 (see Table 7.3 and section "Definition of $2^{\text {nd }}$ nearest neighbor distance $\left(\gamma_{2}\right)$ ").

To validate the permeability prediction model, which is the scaling power law relation between normalized permeability and $\gamma_{2}$ (Equation 7.1), the experimental normalized permeability is plotted as a function of $\gamma_{2}$. The numerical values are obtained from Figure 11 of Yazdchi et. al. [1] for $\Delta_{\min }=0.2$ and range of calculated $\gamma_{2}$. Both results together with the results of the modified model (Equation 7.13) are shown in Figure 7.7. The linear fitting is used to obtain the corresponding power and the pre-factor $C$ which are given in Table 7.4 . 
Table 7.4: The power and pre-factor $C$ of Equation 7.1 obtained from linear fitting to the experimental and numerical results of normalized permeability as a function of $\gamma_{2}$ (Figure 7.7).

\begin{tabular}{lccc}
\hline Data type & Liquid & Power & Pre-factor $(C)$ \\
\hline \multirow{2}{*}{ Experimental } & Water & $2.132 \pm 0.046$ & $0.117 \pm 9.3 \times 10^{-3}$ \\
& Hexadecane & $2.180 \pm 0.046$ & $0.118 \pm 9.8 \times 10^{-3}$ \\
\hline Numerical & Water & 2.501 & 0.209 \\
\hline Numerical (modified) & Water & 2.303 & 0.158 \\
\hline
\end{tabular}

Overall, the experimental results show lower normalized permeability values compared to the numerical model. This can be explained based on the effects of the top and bottom walls on the results whereas the model is purely $2 \mathrm{D}$. A simplified model has been considered to account for this effect (see section "Modification of the numerical model") on the numerical results showing closer values to the experimental results. However, a full $3 \mathrm{D}$ simulation is needed to completely address the effect of the walls on the normalized permeability values. Another possible explanation for deviation between experimental and numerical results can be attributed to the fabrication procedure. As it is shown in Figure 7.4, the fabricated pillars possess a corrugated and rough structure. The obtained values of pillar diameter are also smaller than the simulated ones (see Tables 7.1 and 7.2 leading to slightly different porosity value than those used in simulations. At low porosity values (0.55 and 0.6$)$, within error margins, a good agreement is observed between experimental and numerical results. At higher porosity values $(0.7$ and 0.85$)$, the experimental results are closer to the modified model suggesting an enhanced influence of the walls in more open structures. At the highest porosity value more deviation from the numerical and modified models is observed. This can be attributed to the broader probability distribution function at higher porosity values (see Figure 7.6). This can highly affect the calculated mean values of $\gamma_{2}$.

\subsection{Conclusion}

This work showed the experimental support for predicting permeability in a microstructure with random arrays of fibers. The model predicted a scaling power-law relation between the normalized permeability $\left(\kappa / d^{2}\right)$ and the second nearest neighbor fiber distance $\left(\gamma_{2}\right)$. The microstructures were designed using a Monte Carlo algorithm in MATLAB with different porosity values namely, $0.55,0.6,0.7$ and 0.85 . The designed microstructures were further used as 
the mask for fabrication of the microfluidic chip consisted of random arrays of cylindrical pillars in silicon. The experiments were conducted by permeating water or oil (hexadecane) through the microfluidic chips at varying pressure values and simultaneously measuring the corresponding flow rate. The permeability was calculated as the slope of line plotted with the flux $\times$ viscosity as a function of pressure gradient. The $\gamma_{2}$ values for each porosity were calculated by measuring the mean second nearest neighbor distance from a pillar $\left(\left\langle D_{2}\right\rangle\right)$. A similar scaling power-law relationship (with slightly different power and prefactor) is observed between experimental normalized permeability values and $\gamma_{2}$ showing good agreement with the numerical results. The slight deviation of the experimental results from the numerical model was attributed to two reasons. (1) The effects from the top and bottom walls in the microfluidic chip led to 3D experimental conditions whereas the numerical modelling was purely 2D. (2) High dependence of $\gamma_{2}$ to the porosity confirmed by the probability distribution functions. The work demonstrates the predictive power of structure characteristics for permeability of a porous medium.

\section{References}

[1] K. Yazdchi, S. Srivastava, and S. Luding, "Micro-macro relations for flow through random arrays of cylinders", Composites Part A: Applied Science and Manufacturing 43, 2007-2020 (2012).

[2] M. Sahimi, chapter 1, 1-10, first edition (Wiley-VCH Verlag GmbH and Co. KGaA, Weinheim, Germany) (2011).

[3] E. Plougonven, "Link between the microstructure of porous materials and their permeability", PhD dissertation, Université Sciences et Technologies - Bordeaux I, Bordeaux, France (2009).

[4] K. Yazdchi, S. Srivastava, and S. Luding, "Multi-scale permeability of particulate and porous media", in World Congress Particle Technology 6, edited by N. M. GmbH, 1-4, 6th World Congress on Particle Technology, WCPT 2010 (Nürnberg Messe GmbH, Nuremberg, Germany) (2010).

[5] K. Yazdchi, S. Srivastava, and S. Luding, "Microstructural effects on the permeability of periodic fibrous porous media", International Journal of Multiphase Flow 37, 956-966 (2011).

[6] D. D. Ganji and S. H. H. Kachapi, "Chapter 7 - nanofluid flow in porous medium", in Application of Nonlinear Systems in Nanomechanics and 
Nanofluids, edited by D. D. Ganji and S. H. H. Kachapi, Micro and Nano Technologies, 271 - 316 (William Andrew Publishing, Oxford) (2015).

[7] H. L. Liu and W. R. Hwang, "Permeability prediction of fibrous porous media with complex 3d architectures", Composites Part A: Applied Science and Manufacturing 43, 2030-2038 (2012).

[8] J. F.R. Phelan, Y. Leung, and R. Parnas, "Modeling of microscale flow in unidirectional fibrous porous media", Journal of Thermoplastic Composite Materials 7, 208-218 (1994).

[9] N. Ngo and K. Tamma, "Microscale permeability predictions of porous fibrous media", International Journal of Heat and Mass Transfer 44, 3135-3145 (2001).

[10] B. Gebart, "Permeability of unidirectional reinforcements for rtm", Journal of Composite Materials 26, 1100-1133 (1992).

[11] M. V. Bruschke and S. G. Advani, "Flow of generalized newtonian fluids across a periodic array of cylinders", Journal of Rheology 37, 479-498 (1993).

[12] T. Papathanasiou, "A structure-oriented micromechanical model for viscous flow through square arrays of fibre clusters", Composites Science and Technology 56, 1055-1069 (1996).

[13] W. R. Hwang and S. G. Advani, "Numerical simulations of stokes-brinkman equations for permeability prediction of dual scale fibrous porous media", Physics of Fluids 22, 113101(1-14) (2010).

[14] A. Kudaikulov, C. Josserand, and A. Kaltayev, "Theoretical and numerical prediction of the permeability of fibrous porous media", in Mathematical Modeling of Technological Processes, edited by N. Danaev, Y. Shokin, and A.-Z. Darkhan, 85-93 (Springer International Publishing, Cham) (2015).

[15] X. Chen and T. D. Papathanasiou, "On the variability of the kozeny constant for saturated flow across unidirectional disordered fiber arrays", Composites Part A: Applied Science and Manufacturing 37, 836 - 846 (2006). 
[16] X. Chen and T. Papathanasiou, "Micro-scale modeling of axial flow through unidirectional disordered fiber arrays", Composites Science and Technology 67, 1286-1293 (2007).

[17] J. F. Wang and W. R. Hwang, "Permeability prediction of fibrous porous media in a bi-periodic domain", Journal of Composite Materials 42, 909-929 (2008).

[18] A. J. Katz and A. H. Thompson, "Quantitative prediction of permeability in porous rock", Phys. Rev. B 34, 8179-8181 (1986).

[19] A. Anbari, H.-T. Chien, S. S. Datta, W. Deng, D. A. Weitz, and J. Fan, "Microfluidic model porous media: Fabrication and applications", Small 14, 1703575(1-15) (2018).

[20] J. T. Ok, K. B. Neeves, W. Xu, and X. Yin, Microfluidic and Nanofluidic Porous Media Analogs for Oil and Gas Applications, chapter Chapter 8, 135-146.

[21] A. Chatenever and J. Calhoun, John C., "Visual examinations of fluid behavior in porous media - part i", Journal of Petroleum Technology 4, 149-156 (1952).

[22] C. Chomsurin and C. J. Werth, "Analysis of pore-scale nonaqueous phase liquid dissolution in etched silicon pore networks", Water Resources Research 39, 1265(1-11) (2003).

[23] C. Zhang, M. Oostrom, T. W. Wietsma, J. W. Grate, and M. G. Warner, "Influence of viscous and capillary forces on immiscible fluid displacement: Pore-scale experimental study in a water-wet micromodel demonstrating viscous and capillary fingering", Energ \& Fuel 25, 3493-3505 (2011).

[24] N. S. Kumar Gunda, B. Bera, N. K. Karadimitriou, S. K. Mitra, and S. M. Hassanizadeh, "Reservoir-on-a-chip (roc): A new paradigm in reservoir engineering", Lab Chip 11, 3785-3792 (2011).

[25] J. W. Grate, R. T. Kelly, J. Suter, and N. C. Anheier, "Silicon-onglass pore network micromodels with oxygen-sensing fluorophore films for chemical imaging and defined spatial structure", Lab Chip 12, 4796-4801 (2012). 
[26] H. Bazyar, P. Lv, J. A. Wood, S. Porada, D. Lohse, and R. G. H. Lammertink, "Liquid-liquid displacement in slippery liquid-infused membranes (slims)", Soft Matter 14, 1780-1788 (2018).

[27] M. Ferer, C. Ji, G. S. Bromhal, J. Cook, G. Ahmadi, and D. H. Smith, "Crossover from capillary fingering to viscous fingering for immiscible unstable flow: Experiment and modeling", Phys. Rev. E 70, 016303 (1-7) (2004).

[28] C. V. Chrysikopoulos, C. C. Plega, and V. E. Katzourakis, "Non-invasive in situ concentration determination of fluorescent or color tracers and pollutants in a glass pore network model", Journal of Hazardous Materials 198, 299 - 306 (2011).

[29] N. K. Karadimitriou, V. Joekar-Niasar, S. M. Hassanizadeh, P. J. Kleingeld, and L. J. Pyrak-Nolte, "A novel deep reactive ion etched (drie) glass micro-model for two-phase flow experiments", Lab Chip 12, 3413-3418 (2012).

[30] M. Auset and A. A. Keller, "Pore-scale processes that control dispersion of colloids in saturated porous media", Water Resources Research 40, W03503 (1-11) (2004).

[31] V. Berejnov, N. Djilali, and D. Sinton, "Lab-on-chip methodologies for the study of transport in porous media: energy applications", Lab Chip 8, 689-693 (2008).

[32] C. Cottin, H. Bodiguel, and A. Colin, "Drainage in two-dimensional porous media: From capillary fingering to viscous flow", Phys. Rev. E 82, 046315 (1-10) (2010).

[33] C. Cottin, H. Bodiguel, and A. Colin, "Influence of wetting conditions on drainage in porous media: A microfluidic study", Phys. Rev. E 84, $026311(1-8)(2011)$.

[34] N. K. Karadimitriou, M. Musterd, P. J. Kleingeld, M. T. Kreutzer, S. M. Hassanizadeh, and V. Joekar-Niasar, "On the fabrication of pdms micromodels by rapid prototyping, and their use in two-phase flow studies", Water Resources Research 49, 2056-2067 (2013).

[35] J. Joseph, N. S. K. Gunda, and S. K. Mitra, "On-chip porous media: Porosity and permeability measurements", Chemical Engineering Science 99, $274-283$ (2013). 
[36] W. Yun, C. M. Ross, S. Roman, and A. R. Kovscek, "Creation of a dualporosity and dual-depth micromodel for the study of multiphase flow in complex porous media", Lab Chip 17, 1462-1474 (2017).

[37] C. Scholz, F. Wirner, Y. Li, and C. Bechinger, "Measurement of permeability of microfluidic porous media with finite-sized colloidal tracers", Experiments in Fluids 53, 1327-1333 (2012).

[38] A. Okabe, B. Boots, K. Sugihara, and S. N. Chiu, Spatial tessellations: concepts and applications of Voronoi diagrams, 2 edition (John Wiley \& Sons Ltd., Chichester) (2000).

[39] O. Durán, N. Kruyt, and S. Luding, "Analysis of three-dimensional micromechanical strain formulations for granular materials: Evaluation of accuracy", International Journal of Solids and Structures 47, 251-260 (2010).

[40] H. Darcy, Les Fontaines Publiques de la Ville de Dijon (Victor Dalmont, Paris) (1856).

[41] X. Chen and T. D. Papathanasiou, "The transverse permeability of disordered fiber arrays: a statistical correlation in terms of the mean nearest interfiber spacing", Transport in Porous Media 71, 233-251 (2008).

[42] I. Schenker, F. T. Filser, L. J. Gauckler, T. Aste, and H. J. Herrmann, "Quantification of the heterogeneity of particle packings", Phys. Rev. E 80, 021302(1-9) (2009).

[43] M. Mietton-Peuchot, C. Condat, and T. Courtois, "Use of gas-liquid porometry measurements for selection of microfiltration membranes", J. Membr. Sci. 133, 73-82 (1997).

[44] W. M. Lai, D. Rubin, and E. Krempl, "Chapter 6 - newtonian viscous fluid", in Introduction to Continuum Mechanics (Fourth Edition), edited by W. M. Lai, D. Rubin, and E. Krempl, fourth edition edition, $353-$ 410 (Butterworth-Heinemann, Boston) (2010). 


\section{8}

Reflections and perspectives 

HIS thesis describes fundamental as well as applied research on a novel type of membrane called slippery liquid-infused membrane (SLIM). This membrane belongs to the category of recently introduced functional surfaces known as slippery liquid-infused porous surfaces (SLIPS). Inspired by carnivorous pitcher plant in nature, these surfaces possess micro/nanostructures which are used to lock-in an intermediary liquid. The liquid spontaneously infiltrates through the structures due to capillary wicking and forms a smooth, slippery layer on the surface, provided that the solid substrate is preferentially wetted by this liquid. In SLIM, a porous polymeric membrane which is made from low surface tension polymer material, i.e. high-fluorine content polymer, is used as the substrate. Employment of a fluorinated oil as the infusion liquid further satisfies the chemical compatibility with the solid substrate.

We have investigated the underlying working mechanisms and transport behaviour down to the pore scale. Liquid-infused pores act like a gate which can be opened and closed in response to an immiscible permeating fluid pressure. In the open state, the pore wall remains covered by the infusion liquid leading to the formation of liquid-lined pores. Once pressurizing and permeation are stopped, the closed state of the pore is recovered due to liquid re-infusion. The so-called gating mechanism is deeply explored in Chapter Two by using gas as the immiscible permeating fluid. The remaining liquid film thickness on the pore wall is estimated experimentally and theoretically. The liquid film thickness increases with the viscosity of the infusion liquid which directly affects the re-infusion dynamics. The thicker the liquid film thickness, the faster the re-infusion.

The core function of any membrane is separation, while gating is a very powerful phenomenon to achieve this function. This further requires a thorough understanding of the displacement mechanism as well as the stability of the infusion liquid. In Chapter Three, the retention of the infusion liquid and immiscible displacement mechanism under high flux values of the permeating fluid (water) are investigated. The underlying mechanism corresponds to capillary fingering which is observed in drainage in porous media flow. Preferential flow pathways of water are observed using a micromodel mimicking our porous membrane which consists of square pillars. Around $43 \%$ of infusion liquid remains after water permeation, in the form of pools, bridges and thin films around pillars confirming the presence of liquid lining.

The presence of liquid-lining in SLIM prevents direct contact between permeating fluid and solid material of the membrane. We show in Chapter 
Four that liquid-lining offers another interesting characteristic for SLIM in separation applications. The goal is to separate oil from water in oil-in-water $(\mathrm{O} / \mathrm{W})$ emulsions as a representative of oily wastewater. Unlike the conventional membrane filtration in which the continuous water phase is permeating, here the dispersed oil phase is aimed to be permeated. To achieve this goal, oil droplets must come in contact with the membrane surface which is obtained here based on gravity-assisted creaming. Compared to non-infused (dry) membranes, SLIM shows improved performance in successful permeation of oil and retention of water. This is attributed to the presence of liquid-lining which provides an additional interface between infusion liquid and permeating oil. According to interfacial energy arguments, this leads to higher combined interfacial energy values with the water phase giving rise to higher required entry pressure values.

Absence of direct contact between permeating fluid and membrane material due to liquid-lining provides anti-fouling properties as well. In Chapter Five, the anti-biofouling performance of SLIM is investigated under long-term cross flow filtration using tap water and nutrient solutions as the permeating fluid. The increase in transmembrane pressure (TMP) is used as an indication of biofilm layer formation. TMP values are further employed for obtaining bacterial growth curves. Modeling of bacterial growth curves obtained from liquid-infused and dry membranes, elucidates the role of liquid-lining in significantly increasing the formation period (lag phase) of biofilms as well as decreasing the growth rate. Liquid layers on the pore wall inhibit the permanent interaction between foulant and solid membrane material leading to anti-fouling behaviour.

Permeation of the minor phase, i.e. oil from an $\mathrm{O} / \mathrm{W}$ emulsion is an interesting alternative in oily wastewater treatment based on membrane filtration. The movement of oil droplets towards the membrane surface is the main requisite which can be accelerated upon application of an external field. In Chapter Six, an acoustic field is investigated as the applied external field. Further design and fabrication of acoustic separation systems requires proper estimation of the acoustic energy density (AED). The acoustophoretic behaviour of monodisperse oil droplets in surfactant solutions are studied in a microfluidic chip. The acoustophoretic velocity neither depends on surfactant concentration nor time. This provides more room for general calculation of the AED based on experimental results. Finally, a generally-accessible equation is presented for theoretical prediction of AED showing a square dependency to the applied electric field. Based on this equation, the AED can be estimated by 
knowing the available physical and piezoelectric properties of the medium and transducer respectively.

Predicting permeability of porous media is essential since it can further prevent conducting time-consuming and expensive experiments on a case-by-case basis. In Chapter Seven, a numerical model for predicting porous media permeability is presented which is further validated experimentally. In this case the porous media was considered as random arrays of non-overlapping fibers. The model demonstrates a universal scaling power-law between normalized permeability and the second nearest neighbor distance between fibers. Micromodels consisting of random arrays of cylindrical pillars with different porosity values were fabricated. The obtained permeability values of water and oil as the permeating fluid were used for further validation of the model. A good agreement was achieved showing the general applicability of the model.

\subsection{Reflections}

\subsubsection{Crossflow filtration for oil permeation}

As it has been previously explained in Chapter Four, a more cost-effective approach to treat oily wastewater is permeation of the minor phase (oil) rather than the major phase (water). The proof of concept has been discussed extensively in Chapter Four in which permeation was performed based on gravityassisted creaming in a dead-end filtration mode using relatively high oil concentration in $\mathrm{O} / \mathrm{W}$ emulsions. Dead-end filtration mode is usually used for lab experiments, whereas in contrast, cross-flow mode is employed for continuous operations in industrial applications [1]. Thus, the applicability of the idea of oil permeation has to be investigated in cross-flow filtration mode as well as low oil concentrations [2]. To address these issues, a cross-flow cell has been designed such that oil droplets move towards the membrane surface by the help of gravity (see Figure 8.1(a)). The emulsions were prepared by dispersing 5 wt.\% hexadecane in SDS aqueous surfactant solutions with both high and low SDS concentration, i.e. $50 \%$ and $10 \%$ of the corresponding CMC (SDS50 and SDS10 respectively). The gravity-assisted cross flow filtration was conducted for around $4 \mathrm{~h}$ using a commercial cross-flow set-up (Osmo Inspector 2 from Convergence B.V. The Netherlands), with both dry and liquid-infused membranes (K101-infused commercial PVDF membrane HVHP00010 from Merck Millipore) To check the efficiency of oil permeation during filtration, the concentration of oil in the feed was measured every hour using UV spectrophotometer (UV-1800). A UV-sensitive dye, namely Oil Red 


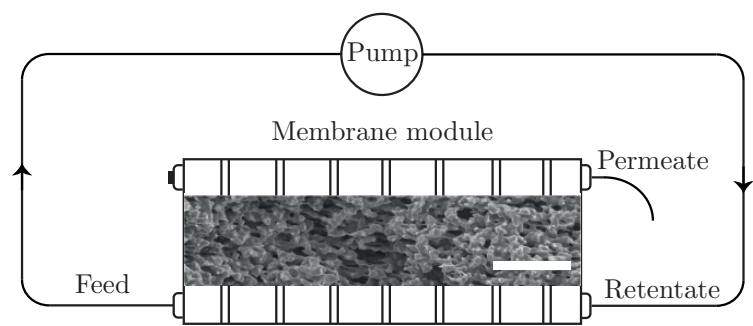

(a)

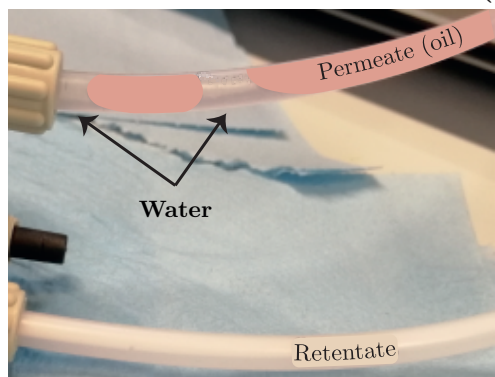

(b)

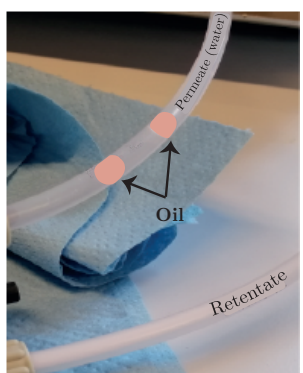

(c)

Figure 8.1: (a) Schematic illustration of the gravity-assisted cross-flow filtration set-up and SEM image of the commercial PVDF membrane from Merck Millipore (HVHP00010) (scale bar is $10 \mu \mathrm{m}$ ). Permeate pictures of $5 \mathrm{wt} \%$ hexadecane in SDS50 surfactant solution through (b) K101-infused and (c) dry membrane during cross-flow filtration (for illustration purposes the oil area is schematically shown).

from Sigma-Aldrich, was added to the oil before emulsion preparation.

In both cases, the same results as the experiments in Chapter Four (deadend filtration mode), were obtained. At low surfactant concentrations (SDS10) no water was observed in the permeate through both dry and liquid-infused membranes and the feed oil concentration was decreased to around $1 \mathrm{wt} . \%$ in both cases (see Figure 8.2). At high surfactant concentration (SDS50) water also permeated through both membranes. For the liquid-infused membrane, the permeate was mainly oil with small amount of water (see Figure 8.1(b)) The dry membrane failed to permeate oil while water permeated excessively (see Figure 8.1(c) . As extensively explained in Chapter Four, due to the presence of liquid-lining in liquid-infused membranes and the formation of three-phase interfaces, the amount of permeated water in this case was lower than that through dry membranes.

The feasibility of gravity-assisted oil permeation in cross-flow filtration mode was also investigated at lower concentrations of oil. Emulsions were prepared 
by dispersing 0.5 and 0.01 wt.\% hexadecane in SDS10 surfactant solution. The cross-flow filtration experiments were performed using both dry and liquidinfused membranes for $4 \mathrm{~h}$. The feed oil concentration decreased to around 0.1 wt.\% (see Figure 8.2(b) . Since both membranes showed the same behaviour, the liquid-infused membrane was only tested for cross-flow filtration with 0.01 wt.\% (100 ppm) hexadecane for $2 \mathrm{~h}$. The feed oil concentration in this case, was decreased to around $0.006 \mathrm{wt} \%$ (60 ppm) (see Figure $8.2(\mathrm{c})$ confirming the applicability of the method even at very low oil concentration in the $\mathrm{O} / \mathrm{W}$ emulsion.

\subsubsection{Electrophoresis of oil droplets}

The gravity-assisted oil permeation technique is not suitable when there is no or little density difference between the oil and water phase. External fields such as an electric field, can be applied to enable the transport of oil droplets. Further development of this idea requires a thorough understanding of electrophoretic behaviour of oil droplets. To exclude the size effects and gravityassisted creaming, the electrophoresis experiments were performed using the same monodisperse $\mathrm{O} / \mathrm{W}$ emulsions as prepared for the acoustic experiments (Chapter Six [2] (silicone oil in SDS10, SDS50 and SDS100). The experiments were performed in a cell consists of two gold-plated copper electrodes (see Figure 8.3(a) . Between the electrodes, a dedicated place for the membrane was also considered in the cell design to mimic the experimental conditions in cross-flow electro-filtration (see section "Cross-flow electro-filtration for oil permeation"). A constant potential of $2.2 \mathrm{~V}$ was applied for $60 \mathrm{~s}$ during electrophoresis experiments. To minimize the electrode polarization influence, the polarity of the electric potential was reversed to $-2.2 \mathrm{~V}$ for $60 \mathrm{~s}$ after each measurement. The electrophoretic movement of oil droplets was recorded using a microscope at 1 FPS. After the required image analysis (binarization), the electrophoretic movement of droplets were tracked and analyzed using particle tacking velocimetry (PTV) as explained in Chapter Six Figure 8.3(b) shows a snapshot of the first frame of the recorded movie (Movie 1) for the silicone oil droplets in SDS10 when there is no membrane placed in the cell.

The electrophoretic velocity of oil droplets was measured as a function of surfactant concentration when no membrane placed in the cell. The electrophoretic mobility $\left(\mu_{e p}\left(\mathrm{~m}^{2} / \mathrm{V} \mathrm{s}\right)\right)$ of oil droplets was obtained using

$$
\mu_{e p}=\frac{u_{e p}}{E},
$$




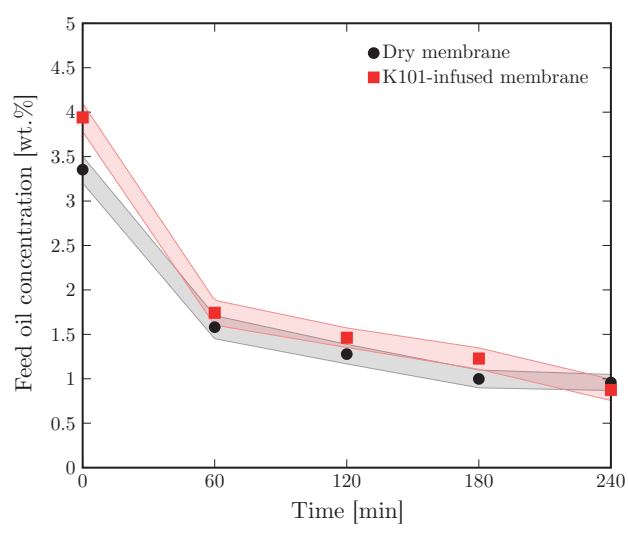

(a)

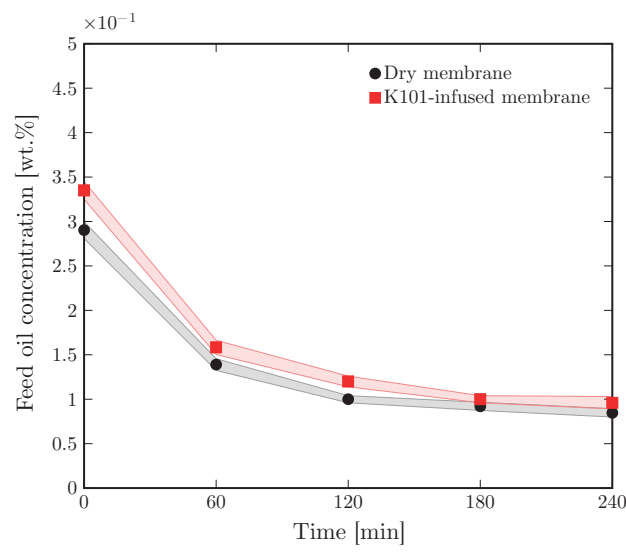

(b)

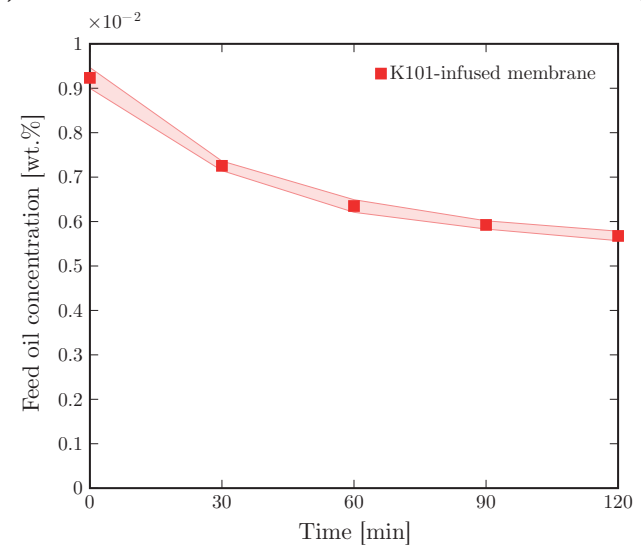

(c)

Figure 8.2: Oil concentration in the feed as a function of time during gravity-assisted cross-flow filtration of emulsions made by dispersing (a) 5 wt.\%, (b) 0.5 wt.\% and (c) 0.01 wt.\% (100 ppm) hexadecane in SDS10 surfactant solution using dry and K101infused membranes (the shaded area bounds the corresponding standard deviation stems from measuring the oil content using UV-spectrometer). 


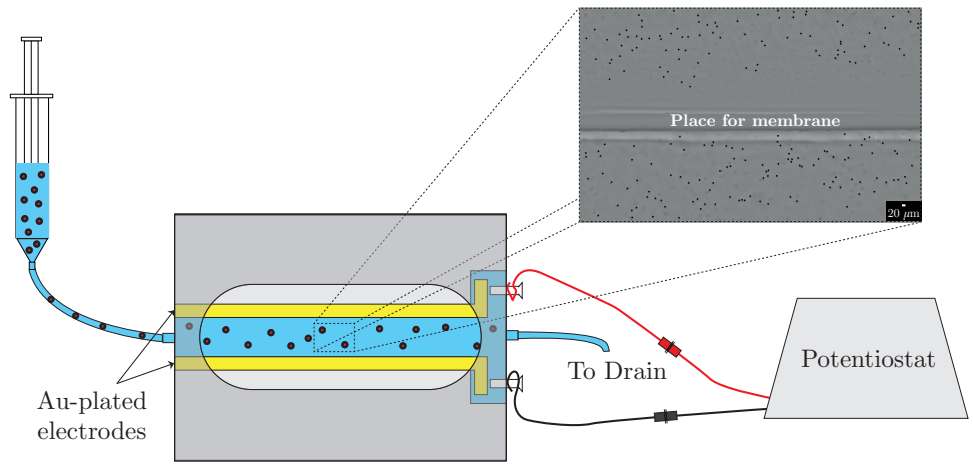

(a)

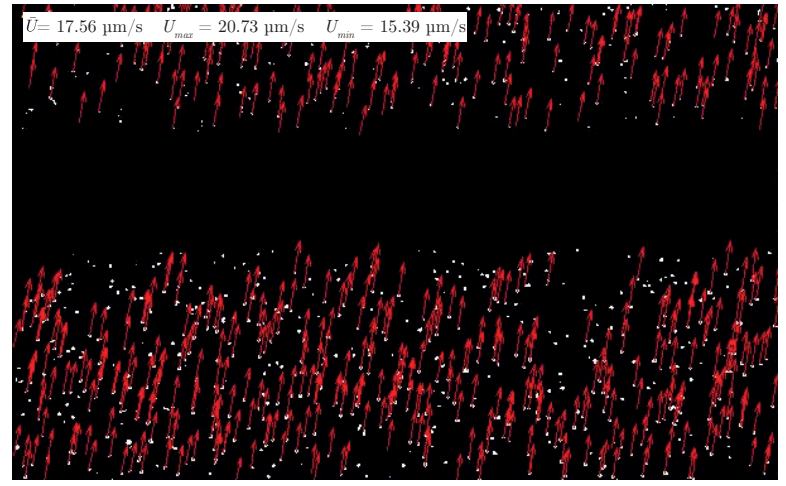

(b)

Figure 8.3: (a) Schematic of electrophoretic set-up together with a snapshot of the experiment showing the movement of silicone oil droplets in SDS10 (for visualization purposes the oil droplets are shown schematically). (b) Snapshot of the particle tracking velocimetry analysis (first frame) for silicone oil droplets in SDS10 when there is no membrane placed in the cell. 
where $u_{e p}$ is the electrophoretic velocity $(\mathrm{m} / \mathrm{s})$ and $E$ is the applied electric field $(\mathrm{V} / \mathrm{m})$. The corresponding zeta potential $(\zeta(\mathrm{V}))$ was calculated from Smoluchowski equation 3 ]

$$
\mu_{e p}=\frac{2 \varepsilon_{r} \varepsilon_{0}}{3 \eta} \zeta
$$

where $\varepsilon_{r}$ is the relative permittivity of the oil phase $(-), \varepsilon_{0}$ is permittivity of vacuum $\left(8.85 \times 10^{-12} \mathrm{~F} / \mathrm{m}\right)$ and $\eta$ is the viscosity of the water phase $(\mathrm{Pa} \mathrm{s})$. This equation is the simplified version of Henry formula [4] $\left(\mu=\frac{\varepsilon_{r} \varepsilon_{0}}{\eta} \zeta f(\kappa a)\right)$ and applicable when $\kappa a$ (where $\kappa$ is the inverse Debye screening length and $a$ is the droplet radius) is sufficiently larger than unity [5]. The calculated zeta potential of silicone oil droplets as a function of SDS concentration is shown in Figure $8.4(\mathrm{a})$, The experimental data points are fitted to Grahame equation considering SDS as a 1:1 salt (ion valence $Z=1$ ) [6]

$$
\zeta=\frac{2 k_{B} T}{Z e} \sinh ^{-1}\left(\sigma \cdot \sqrt{\frac{1}{8 \varepsilon_{r} \varepsilon_{0} k_{B} T I}}\right),
$$

which relates the zeta potential to ionic strength $I$ (SDS concentration $\left.\left(\mathrm{mol} / \mathrm{m}^{3}\right)\right)$ considering a constant surface charge density $\sigma\left(\mathrm{C} / \mathrm{m}^{2}\right)$ as the fitting parameter. $T$ is temperature $(\mathrm{K}), e$ is elementary charge $\left(1.6 \times 10^{-19} \mathrm{C}\right)$ and $k_{B}$ is Boltzman constant $\left(1.38 \times 10^{-23} \mathrm{~J} / \mathrm{K}\right)$. The inverse relationship between zeta potential and ionic strength explains the observed decrease in zeta potential as a function of surfactant concentration which is mainly attributed to the shrinkage of the electric double layer (increased $\kappa$ ) by the increase in ionic strength [7, 8].

To investigate the effect of electric filed on oil droplet movement during CFEF, a series of electrophoresis experiments was performed in which one of the electrodes was completely covered by the membrane. This was conducted to mimic the experimental situation of CFEF experiments in which two electrodes are placed in two compartments and completely separated from each other by the membrane. The results for silicone oil droplets are shown in Figure 8.4(b), As it is explained in details in Chapter Four, when a dry membrane is used for oil permeation, it will be infused by the permeating oil during filtration. Thus, the membrane which was covering the electrode, was infused with silicone oil as the permeating oil phase prior to the experiment. A significant decrease in the electrophoretic velocity is observed upon covering the electrode with the liquid-infused membrane. The obtained electrophoretic velocity in this case is very low showing no enhancement of oil droplet velocity. 


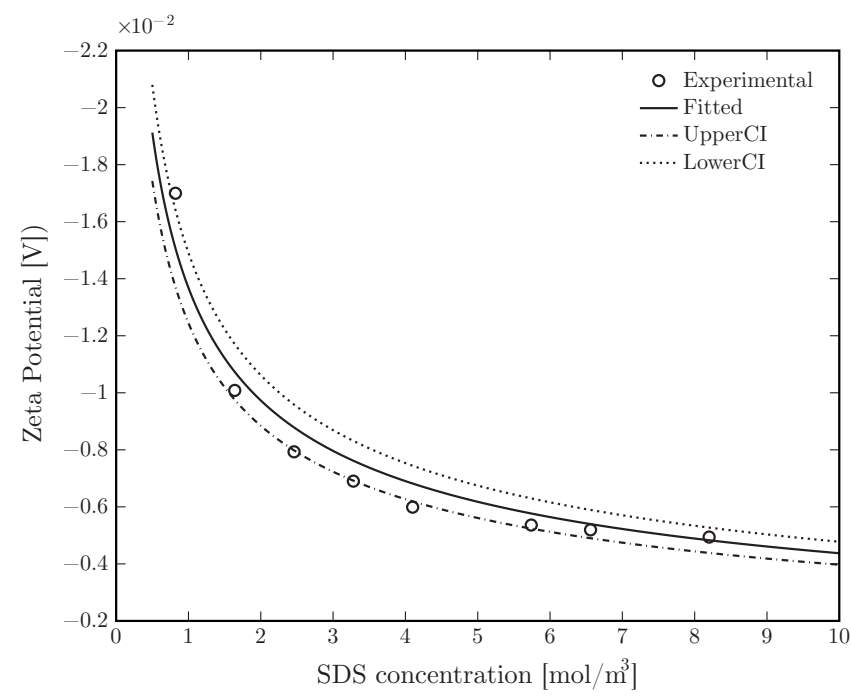

(a)

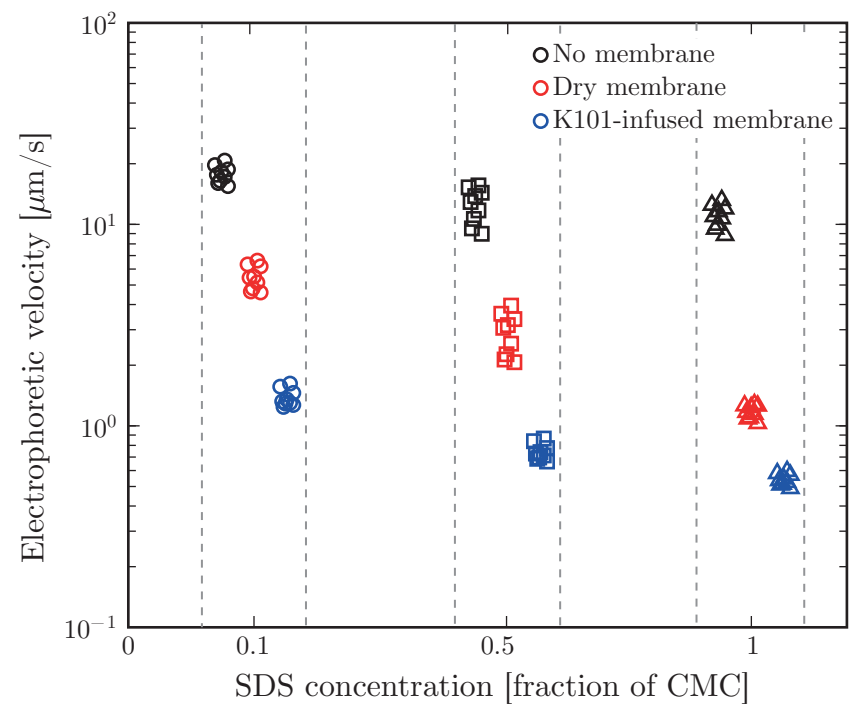

(b)

Figure 8.4: (a) Zeta potential of silicone oil droplets as a function of SDS concentration together with the fit to Grahame equation (Equation 8.3). (b) Electrophoretic velocity as a function of SDS concentration for silicone oil droplets without a membrane in the cell (black symbols), and when one of the electrodes was covered with a dry membrane (red symbols) and a K101-infused membrane (blue symbols). 


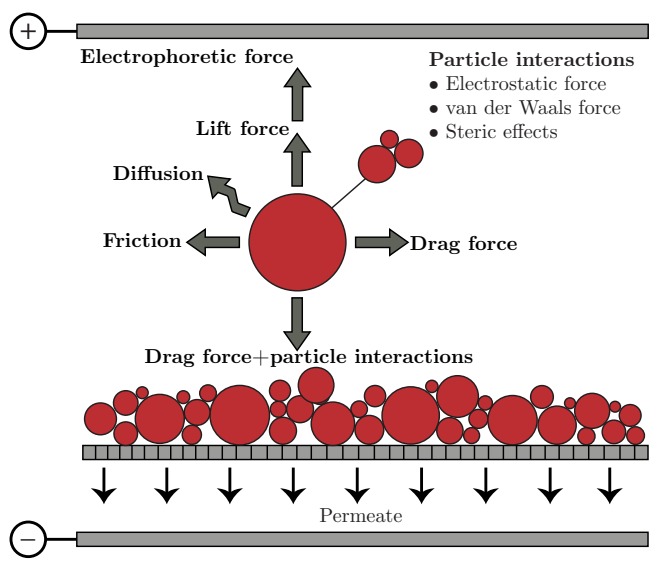

Figure 8.5: Force balance on a particle during the electro-filtration process (adapted with modification from Ref [10]. Copyright@1999, Elsevier B.V.).

This is mainly attributed to the high electrical resistance of the liquid-infused membrane. This observation together with a decrease in zeta potential with an increase in surfactant concentration will be discussed further in section "Perspectives"

\subsubsection{Cross-flow electro-filtration for oil permeation}

Application of an electric field during cross-flow filtration leads to the socalled cross-flow electro-filtration ( $\mathrm{CFEF}$ ) which was originally developed to assist cross-flow filtration in minimizing concentration polarization [9]. Since most particles acquire a surface charge, they can be taken away from the membrane surface based on their electrophoretic motion and hence, reducing concentration polarization and fouling [10, 11]. The deposition characteristics of particles may be described by the force balance on the particle in the vicinity of the membrane or cake layer [12] (Figure 8.5). When the drag force of the permeate $\left(\mathrm{F}_{\text {perm }}\right)$ exceeds the oppositely directed lift force $\left(\mathrm{F}_{\text {lift }}\right)$, deposition of the particle will occur [10. Upon application of an electric field, the imposed electrophoretic force enhances the lift force on the particles leading to their removal from the membrane surface. Electroosmosis is another electrokinetic effect in electrofiltration which may occur within the cake layer and filter medium, allowing for more fluid to flow across the membrane [13 15].

Here, the concept of CFEF is used for oil permeation from density matched $\mathrm{O} / \mathrm{W}$ emulsions (silicone oil AR20). In order to check if this technique can 


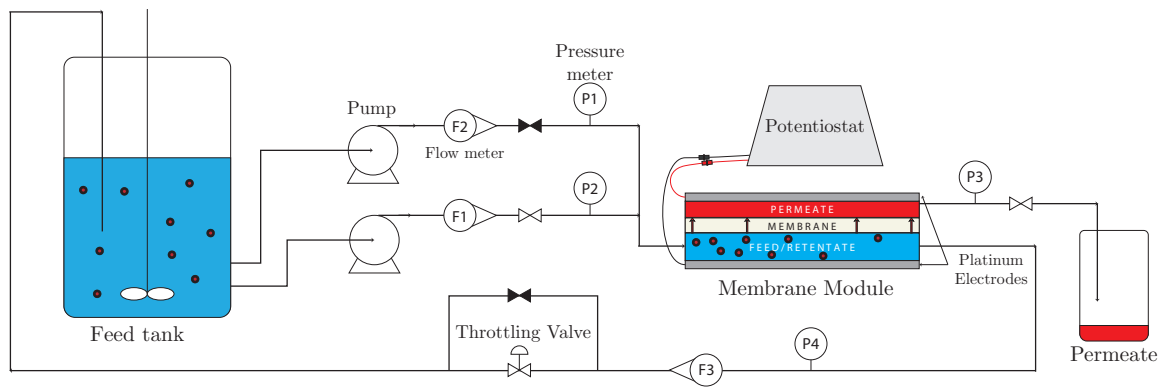

Figure 8.6: Schematic illustration of cross-flow electro-filtration set-up for permeation of oil from $\mathrm{O} / \mathrm{W}$ emulsions.

further enhance the permeation efficiency of gravity-assisted oil permeation in cross-flow filtration, emulsions containing hexadecane as the oil phase were also tested. Two Titanium electrodes coated with Platinum were incorporated in the cross flow membrane module (see Figure 8.1(a) and used for CFEF experiments using the same set-up as cross-flow filtration (see Figure 8.6). Since the oil phase is intended to permeate during filtration, the permeate side has been already filled with the oil prior to the experiment. The same potential as during the electrophoresis experiments, i.e. $2.2 \mathrm{~V}$ was applied. A K101infused membrane was used for CFEF, because a dry membrane will be infused with permeating oil during permeation leading to even lower electrophoretic velocity than K101-infused membrane (see Figure 8.4(b)].

The results of feed oil concentration as a function of filtration time for emulsions containing 0.5 wt.\% hexadecane and silicone oil in SDS10 surfactant solutions are shown in Figure 8.7. Comparison of cross-flow filtration with CFEF for permeation of hexadecane through K101-infused membrane (Figure 8.7(a), shows no significant enhancement mainly due to the high electrical resistance of the membrane as observed in electrophoresis experiments. In the case of silicone oil (Figure 8.7(b)), neither cross-flow nor CFEF can be used for oil permeation due to the similar density of the oil with the water phase and high resistance of the membrane respectively.

\subsection{Perspectives}

In the last century the global population quadrupled, while the world water demand increased sevenfold [16]. This global water challenge will become greater as the population and economies of developing countries expand. In 


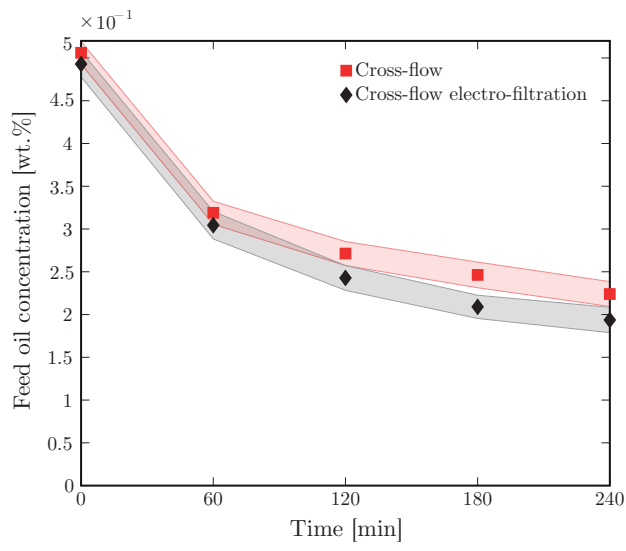

(a)

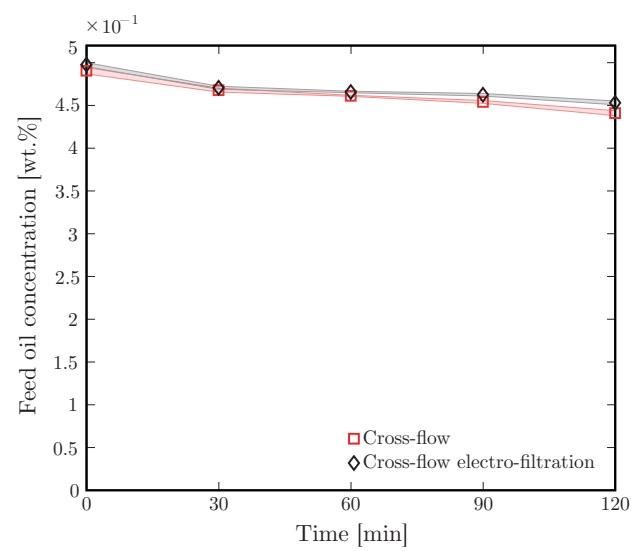

(b)

Figure 8.7: Comparison between cross-flow and cross-flow electro-filtration for permeation of 0.5 wt.\% (a) hexadecane and (b) silicone oil through K101-infused membrane (the shaded area bounds the corresponding standard deviation stems from measuring the oil content using UV-spectrometer).

the next forty years, the global population is expected to grow nearly $40 \%$, and hence, domestic, agriculture, industry, and energy demands on water resources will continue to grow [17. In response to the increasing problem of water shortage, treated urban wastewater is currently widely reused and considered to be a reliable alternative water source [18. Regions inhabited by more than $40 \%$ of the world's population already are in a situation where water demand exceeds supply. The shortage of water and the increasing need for food due to the expanding world population and for irrigation water, both in respect to sufficient quality and quantity, render reuse an indispensable practice. Nowadays, closing the urban water cycles is of high priority on the policy agendas of many countries around the world [18].

Direct discharge of oil-contaminated wastewater, as one of the largest wastewater streams, can cause tremendous threats not only to the environment but also to the human health [19, 20]. Atmospheric pollution, affecting crop production, destructing the natural landscape and endangering aquatic resources mainly due to the oil spills are among other potential threats [21, 22]. Consequently, oily wastewater treatment is urgently needed in today's field of environmental engineering problems. Efficient, cost-effective processes for oil/water separation, also in the presence of surfactants, are greatly desired 23. Surfactant-stabilized mixtures of oil and water are classified in terms of 
the diameter $(d)$ of the dispersed phase as free oil $(d>150 \mu \mathrm{m})$, dispersion $(20 \mu \mathrm{m} \leqslant d \leqslant 150 \mu \mathrm{m})$ or an emulsion $(d<20 \mu \mathrm{m})$ [24]. In most cases the oil/water mixtures exist in the form of an emulsion which is more difficult to separate using conventional gravity separators and skimming technologies [25]. Thus, the environmental and economic demands highlight the urgent need for functional materials and processes that can achieve efficient oil/water separation [26. An effective strategy considers novel materials with special wettability since oil/water separation is an interfacial phenomenon [27-31]. Membrane-based technologies are attractive for oil/water separation because of energy efficiency, cost-effectiveness and applicability across a wide range of industrial effluents [25].

In this thesis the combined approach has been presented on the use of membranes with special wettability (non-wetting properties) for oil/water separation. A novel idea has been introduced in which dispersed oil droplets permeate through the membrane while the continuous water phase is being retained. The advantages of such an approach are two-fold: (1) a significant decrease in membrane fouling as the "Achilles' heels" of membrane processes and (2) an economically affordable approach as large volumes of continuous phase do not permeate through the membrane. For this idea to be successful, movement of oil droplets towards the membrane and coalescence on the surface are key challenges. Gravity, as one of the universe's fundamental forces, has been shown to be successful in bringing small oil droplets towards the membrane surface (Chapter Four, albeit slowly. As it has been shown in sections "Electrophoresis of oil droplets" and "Cross-flow electro-filtration for oil permeation"] electric fields provide challenges attributed to the high resistance of the oil immersed membranes. The high dependence of electrophoretic mobility of oil droplets to the surfactant concentration (see Figure 8.4(a) further curtails the application of electric field for oil permeation application. However, as one of the widely-used external fields, application of electric fields can be considered by employment of new membrane materials or re-designing the separation system.

One of the new materials which can be used for fabrication of responsive membranes, for this application, are electro-conductive polymers. These polymers are among the category of stimuli-responsive polymers which can be added during or after membrane formation in order to add responsiveness to a membrane 32 (see Chapter One for detailed information on these kinds of membranes and fabrication procedure). Electro-responsive polymer membranes, i.e., polymer membranes able to respond to an electric potential, 
can be obtained by membrane functionalization with custom-designed electrically conductive polymers [33. Polymers such as polyaniline [34, polypyrrole [35, 36] and carbon nanotubes [37] are the most used electro-conductive materials which can be employed for this purpose.

In re-designing of the separation system, two approaches can be taken into account. One is by employing the membrane as one the electrodes. The idea of cathode membranes, which are mainly used in EMBR applications (electric field-assisted membrane bioreactor) for suppressing membrane fouling [38 40], is a useful inspiration for oil permeation applications. Another approach considers introducing the third electrode as well as separating electrode chamber in order to incorporate a an electrode solution different from the aqueous surfactant solution. With this approach, a monotonous increase in electrophoretic mobility with surfactant concentration (even above CMC) has been found [41. This is mainly because of a weakening influence of electro-osmotic flow at the channel wall by the increase in the ionic strength in aqueous phase.

As it has been shown in Chapter Six, acoustophoresis with no dependency on surfactant concentration, can be another alternative as the external field for oil permeation applications. Combining acoustic fields with membrane crossflow filtration can introduce an innovative technique for oil/water separation using membrane technology. This idea can make more room for fundamental studies in understanding the acoustic behaviour of membranes as well as oil droplets and solid contaminants.

\section{References}

[1] B. Chakrabarty, A. Ghoshal, and M. Purkait, "Cross-flow ultrafiltration of stable oil-in-water emulsion using polysulfone membranes", Chemical Engineering Journal 165, 447-456 (2010).

[2] J. Velandres, "Slippery liquid-infused membranes (slims) for oil permeation from oil-in-water $(\mathrm{o} / \mathrm{w})$ emulsions using crossflow electro-filtration technique", (2019).

[3] M. V. von Smoluchowski, "Elektrische endosmose und strömungsströme", in Handbuch der Elektrizität und des Magnetismus, edited by F. Auerbach and L. Graetz, 366 (J. A. Barth) (1921).

[4] D. C. Henry and A. Lapworth, "The cataphoresis of suspended particles. part I;the equation of cataphoresis", Proceedings of the Royal Society 
of London. Series A, Containing Papers of a Mathematical and Physical Character 133, 106-129 (1931).

[5] S. M. Agnihotri, H. Ohshima, H. Terada, K. Tomoda, and K. Makino, "Electrophoretic mobility of colloidal gold particles in electrolyte solutions", Langmuir 25, 4804-4807 (2009).

[6] J. N. Israelachvili, "Chapter 14 - electrostatic forces between surfaces in liquids", in Intermolecular and Surface Forces (Third Edition), edited by J. N. Israelachvili (Academic Press).

[7] F. Yang, W. Wu, S. Chen, and W. Gan, "The ionic strength dependent zeta potential at the surface of hexadecane droplets in water and the corresponding interfacial adsorption of surfactants", Soft Matter 13, 638-646 (2017).

[8] K. G. Marinova, R. G. Alargova, N. D. Denkov, O. D. Velev, D. N. Petsev, I. B. Ivanov, and R. P. Borwankar, "Charging of oil-water interfaces due to spontaneous adsorption of hydroxyl ions", Langmuir 12, 2045-2051 (1996).

[9] C.-J. Chuang, C.-Y. Wu, and C.-C. Wu, "Combination of crossflow and electric field for microfiltration of protein/microbial cell suspensions", Desalination 233, 295-302 (2008), the Fourth Conference of Aseanian Membrane Society: Part 1.

[10] T. Weigert, J. Altmann, and S. Ripperger, "Crossflow electrofiltration in pilot scale", Journal of Membrane Science 159, 253-262 (1999).

[11] H.-H. Lee, Y.-H. Weng, and K.-C. Li, "Electro-ultrafiltration study on aldrich humic substances with different molecular weights", Separation and Purification Technology 63, 23-29 (2008).

[12] J. Altmann and S. Ripperger, "Particle deposition and layer formation at the crossflow microfiltration", Journal of Membrane Science 124, 119-128 (1997).

[13] G. Akay and R. Wakeman, "Electric field enhanced crossflow microfiltration of hydrophobically modified water soluble polymers", Journal of Membrane Science 131, 229-236 (1997). 
[14] C. Visvanathan and R. B. Aim, "Application of an electric field for the reduction of particle and colloidal membrane fouling in crossflow microfiltration", Separation Science and Technology 24, 383-398 (1989).

[15] J. D. Henry Jr., L. F. Lawler, and C. H. A. Kuo, "A solid/liquid separation process based on cross flow and electrofiltration", AIChE Journal 23, 851-859 (1977).

[16] U. N. D. Program, Human Development Report 2006, 131-171 (Palgrave Macmillan UK) (2006).

[17] Food and A. O. (FAO), "Coping with water scarcity. challenge of the $21^{\text {st }}$ century", Working papers id:11330, eSocialSciences (2016).

[18] K. Kümmerer, D. D. Dionysiou, and D. Fatta-Kassinos, Scope of the Book Wastewater Reuse and Current Challenges, 1-5 (Springer International Publishing, Cham) (2016).

[19] C. H. Peterson, S. D. Rice, J. W. Short, D. Esler, J. L. Bodkin, B. E. Ballachey, and D. B. Irons, "Long-term ecosystem response to the exxon valdez oil spill", Science 302, 2082-2086 (2003).

[20] T. Oki and S. Kanae, "Global hydrological cycles and world water resources", Science 313, 1068-1072 (2006).

[21] L. Yu, M. Han, and F. He, "A review of treating oily wastewater", Arabian Journal of Chemistry 10, S1913-S1922 (2017).

[22] M. Schrope, "Oil spill: Deep wounds", Nature News 472, 152-154 (2011).

[23] E. Kintisch, "An audacious decision in crisis gets cautious praise", Science 329, 735-736 (2010).

[24] A. K. Kota, G. Kwon, W. Choi, J. M. Mabry, and A. Tuteja, "Hygroresponsive membranes for effective oil-water separation", Nature Communications 3, 1025 (1-8) (2012).

[25] M. Cheryan and N. Rajagopalan, "Membrane processing of oily streams. wastewater treatment and waste reduction", Journal of Membrane Science 151, 13-28 (1998).

[26] X. Gao, L.-P. Xu, Z. Xue, L. Feng, J. Peng, Y. Wen, S. Wang, and $\mathrm{X}$. Zhang, "Dual-scaled porous nitrocellulose membranes with underwater 
superoleophobicity for highly efficient oil/water separation", Advanced Materials 26, 1771-1775 (2014).

[27] M. Liu, Y. Zheng, J. Zhai, and L. Jiang, "Bioinspired super-antiwetting interfaces with special liquid-solid adhesion", Accounts of Chemical Research 43, 368-377 (2010).

[28] X. Yao, Y. Song, and L. Jiang, "Applications of bio-inspired special wettable surfaces", Advanced Materials 23, 719-734 (2011).

[29] L.-P. Xu, J. Peng, Y. Liu, Y. Wen, X. Zhang, L. Jiang, and S. Wang, "Nacre-inspired design of mechanical stable coating with underwater superoleophobicity", ACS Nano 7, 5077-5083 (2013).

[30] L. Heng, T. Guo, B. Wang, Y. Zhang, and L. Jiang, "Polymer porous interfaces with controllable oil adhesion underwater", RSC Adv. 5, 102378-102383 (2015).

[31] X. Meng, M. Wang, L. Heng, and L. Jiang, "Underwater mechanically robust oil-repellent materials: Combining conflicting properties using a heterostructure", Advanced Materials 30, 1706634 (1-8) (2018).

[32] P. Kaner, P. Bengani-Lutz, I. Sadeghi, and A. Asatekin, "Responsive filtration membranes by polymer self-assembly", Technology 4, 217-228 (2016).

[33] P. Formoso, E. Pantuso, G. De Filpo, and F. P. Nicoletta, "Electroconductive membranes for permeation enhancement and fouling mitigation: A short review", Membranes 7, 39 (1-24) (2017).

[34] H. Bai and G. Shi, "Gas sensors based on conducting polymers", Sensors 7, 267-307 (2007).

[35] L.-X. Wang, X.-G. Li, and Y.-L. Yang, "Preparation, properties and applications of polypyrroles", Reactive and Functional Polymers 47, 125-139 (2001).

[36] Y.-T. Tsai, C.-H. Choi, N. Gao, and E.-H. Yang, "Tunable wetting mechanism of polypyrrole surfaces and low-voltage droplet manipulation via redox", Langmuir 27, 4249-4256 (2011). 
[37] M. Curcio, U. G. Spizzirri, G. Cirillo, O. Vittorio, N. Picci, F. P. Nicoletta, F. Iemma, and S. Hampel, "On demand delivery of ionic drugs from electro-responsive cnt hybrid films", RSC Adv. 5, 44902-44911 (2015).

[38] J. Liu, L. Liu, B. Gao, and F. Yang, "Integration of bio-electrochemical cell in membrane bioreactor for membrane cathode fouling reduction through electricity generation", Journal of Membrane Science 430, 196-202 (2013).

[39] L. Liu, J. Liu, G. Bo, F. Yang, J. Crittenden, and Y. Chen, "Conductive and hydrophilic polypyrrole modified membrane cathodes and fouling reduction in MBR", Journal of Membrane Science 429, 252-258 (2013).

[40] L. Liu, F. Zhao, J. Liu, and F. Yang, "Preparation of highly conductive cathodic membrane with graphene (oxide)/ppy and the membrane antifouling property in filtrating yeast suspensions in EMBR", Journal of Membrane Science 437, 99-107 (2013).

[41] J. Tuček, Z. Slouka, and M. Přibyl, "Electric field assisted transport of dielectric droplets dispersed in aqueous solutions of ionic surfactants", Electrophoresis 39, 2997-3005 (2018). 


\section{Appendix A}

\section{A.1 Physical properties of the infusion liquids}

The physical properties of the infusion liquids used for making the liquid infiltrated membranes is shown in Table A.1.

\section{A.2 Impregnation experiment and porometry re- sults}

In Figure A.1 the results of impregnation experiment are shown for Krytox 101 and FC-43-infused membranes. The Experimental and predicted values of the Washburn coefficient are presented in Table A.2.

The gas-liquid porometry measurements of other liquid-infused membranes are shown in Figure A.2.

\section{A.3 Theoretical calculation of liquid film thickness}

Before calculation of the remaining liquid film thickness on the pore wall, the type of the flow regime should be defined. Since the pore diameter is in the range of micrometer and the volumetric flow rate of the liquid is negligible compared to that of the gas, the flow regime according to the Griffith and Wallis diagram would be the annular flow [1].

Most of the models for predicting the liquid film thickness in annular two phase flow are based on the liquid flow rates or velocity [2 4]. Hence, it is necessary to know the liquid characteristics such as velocity, flow rate and flux. Since in our experiments it was not possible to measure these liquid 


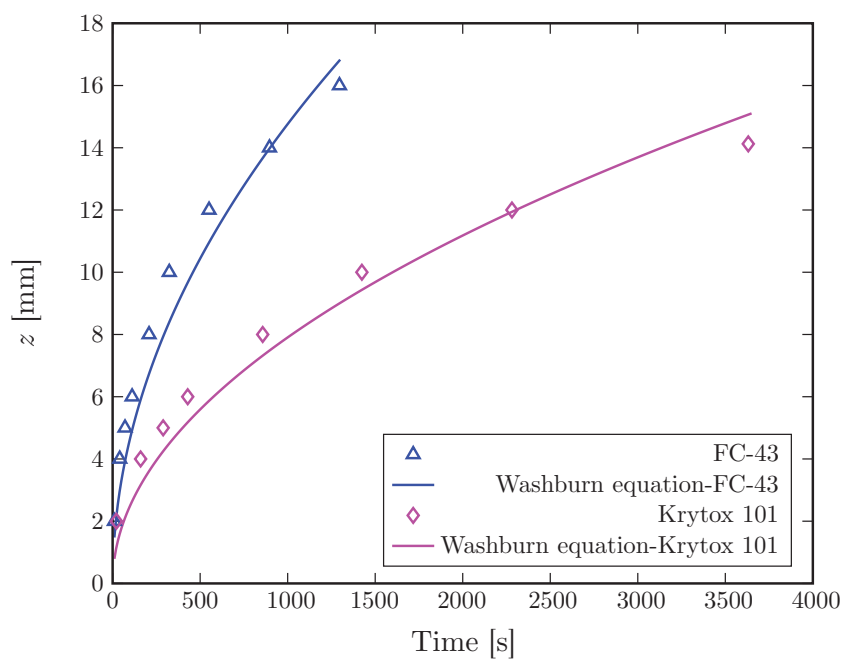

Figure A.1: Results of impregnation experiments on Krytox 101 and FC-43-infused membranes.

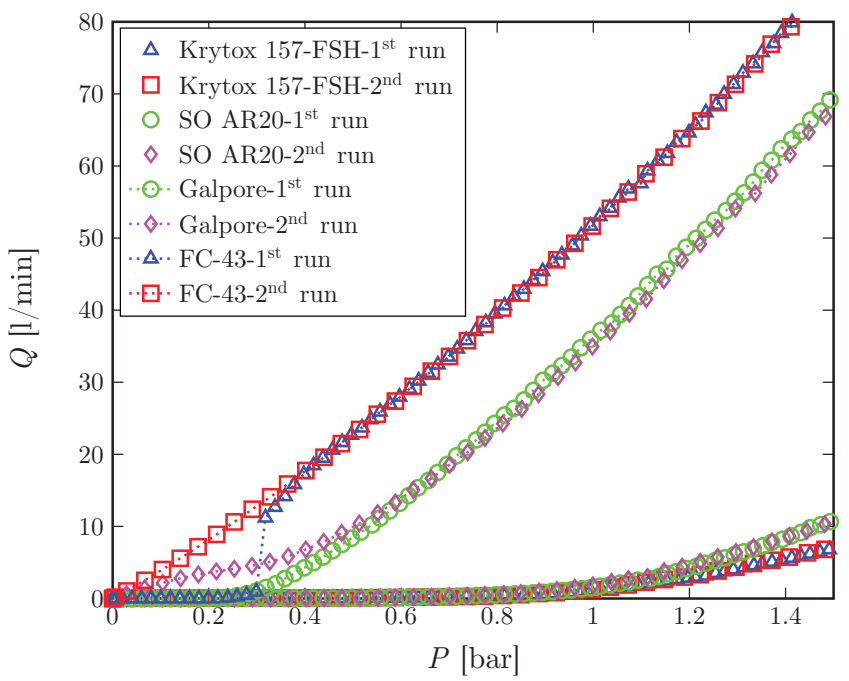

Figure A.2: Comparison of the porometry results of FC-43 and other liquid-infused PVDF membranes. 
Table A.1: Physical properties of different infusion liquids.

\begin{tabular}{|c|c|c|c|c|}
\hline Infusion liquid & Chemical structure & $\begin{array}{l}\text { Surface tension } \\
\quad\left[\mathrm{mN} \mathrm{m}^{-1}\right]\end{array}$ & $\begin{array}{l}\text { Absolute viscosity } \\
\text { at } 20^{\circ} \mathrm{C}[\mathrm{mPa} \mathrm{s}]\end{array}$ & $\begin{array}{c}\text { Density at } \\
20^{\circ}{\mathrm{C}\left[\mathrm{g} \mathrm{cm}^{-3}\right]}\end{array}$ \\
\hline Fluorinert FC-43 & $\begin{array}{l}\text { Perfluorocarbon } \\
\text { (PFC) }\end{array}$ & 16 & 4.7 & 1.86 \\
\hline Galpore & $\begin{array}{c}\text { Perfluoropolyether } \\
\text { (PFPE) }\end{array}$ & 15.9 & 4.4 & $1.7-1.9$ \\
\hline Krtytox GPL oil 101 & $\begin{array}{c}\text { Perfluoropolyether } \\
\text { (PFPE) }\end{array}$ & 17 & 17.4 & 1.85 \\
\hline Krytox 157 FSH & $\begin{array}{l}\text { Poly (hexafluoro- } \\
\text { propylene } \\
\text { oxide) }\end{array}$ & 17 & 800 & 1.9 \\
\hline Silicone oil AR20 & $\begin{array}{l}\text { Polyphenylmethyl- } \\
\text { siloxane }\end{array}$ & 20.6 & 20 & 1.01 \\
\hline
\end{tabular}

Table A.2: Proportional coefficients for infusion liquids based on impregnation experiments.

\begin{tabular}{lcc}
\hline Infusion liquid & $\begin{array}{c}\text { Experimental } \\
\text { coefficient }\end{array}$ & $\begin{array}{c}\text { Washburn } \\
\text { coefficient }\end{array}$ \\
\hline Krytox 101 & 0.29 & 0.25 \\
SO AR20 & 0.41 & 0.35 \\
Krytox 157 & 0.075 & 0.068 \\
Galpore & 0.43 & 0.37 \\
FC-43 & 0.55 & 0.46 \\
\hline
\end{tabular}

parameters directly, they are calculated based on the experimental values of the liquid film thickness and pressure as follows.

According to the annular two phase flow with circumferentially uniform film flow rate and film thickness and with a smooth gas-liquid interface, an interrelationship (triangular relationship) between film thickness $\left(r_{0}-r_{\mathrm{i}}\right)$, pressure gradient $(d p / d z)$ and liquid mass flow rate $\left(W_{\mathrm{LF}}\right)$ exists. By neglecting the gravitational and acceleration effects in the gas phase and due to the negligibility of the liquid volumetric weight compared to the pressure drop, the following simplified equation can be derived [1

$$
W_{\mathrm{LF}}=\int_{r_{\mathrm{i}}}^{r_{0}} 2 \pi \rho_{\mathrm{L}} r u d r \approx \frac{-\pi \rho_{\mathrm{L}}}{8 \mu_{\mathrm{L}}}\left[\frac{d p}{d z}\left(r_{0}^{2}-r_{\mathrm{i}}^{2}\right)^{2}\right] .
$$

Where $\rho_{\mathrm{L}}$ and $\mu_{\mathrm{L}}$ are the density $\left(\mathrm{kg} / \mathrm{m}^{3}\right)$ and viscosity of the liquid $(\mathrm{Pa} \mathrm{s})$ respectively, $r_{\mathrm{i}}$ is the effective and $r_{0}(\mathrm{~m})$ is the initial pore radius, and $d p / d z$ 
$(\mathrm{Pa} / \mathrm{m})$ is the pressure gradient across the pore.

Consequently by calculation of the liquid mass flow rate, $W_{\mathrm{LF}}(\mathrm{kg} / \mathrm{s})$, the other parameters such as liquid velocity, liquid volumetric flow rate and liquid flux can be obtained easily based on the physical properties of the liquid and the liquid film thickness.

\section{A.3.1 Modification of the Lockhart-Martinelli method}

In two phase flow, the Lockhart-Martinelli correlation is widely used to predict the pressure drop. As a correlation scheme their approach represents an asymptotic normalization of two phase flow data which can finally plotted in the curve of two phase flow multiplier for liquid $\left(\phi_{\mathrm{L}}\right)$ as a function of the Martinelli parameter $(X)$ 5. Lockhart-Martinelli approach failed to produce suitable equations for predicting the two phase pressure gradient, consequently, there are a number of related methodologies such as the Turner-Wallis method also known as the separate cylinders model [6] and the Chisholm model [7] which were introduced as extensions of the Lockhart-Martinelli approach.

\section{A.3.1.1 Modified Chisholm model}

Chisholm proposed the now widely adopted equations for calculation of the two phase flow multiplier in gas phase [7]

$$
\phi_{\mathrm{G}}^{2}=1+C X+X^{2},
$$

where $X$ is the Martinelli parameter and defined as the ratio between pressure drops $\Delta P_{\mathrm{L}}$ and $\Delta P_{\mathrm{G}}$

$$
X=\sqrt{\Delta P_{\mathrm{L}} / \Delta P_{\mathrm{G}}} .
$$

In the original Chisholm model, $C$ was chosen to be equal to $C_{11}=5$ for laminar-laminar flow and other values, for other combinations of the flow regimes to provide agreement with the curves, presented graphically in Lockhart and Martinelli's original paper [7. It should also be pointed out that the Chisholm constants have remained unchanged when Equation A.2 is reported in the literature [8].

A lot of researchers try to propose relations for calculation of $C$ to fit any one data set with greater accuracy 9 11. In the case of mini- and microchannels, because of the large effect of surface tension and gap size, $C$ is dependent on the Laplace number [12] 


$$
L a=\frac{\sqrt{\sigma / g\left(\rho_{\mathrm{L}}-\left(\rho_{\mathrm{G}}\right)\right.}}{2 r_{0}},
$$

where $\sigma$ is the surface tension of the liquid $(\mathrm{N} / \mathrm{m}),\left(\rho_{\mathrm{G}}\right.$ is the density of the gas phase $\left(\mathrm{kg} / \mathrm{m}^{3}\right)$ and $r_{0}$ is the radius of the mini- or microchannel $(\mathrm{m})$.

In the laminar flow region, $C$ is strongly affected not only by $L a$ but also by the Reynolds number in the liquid phase $\left(\mathrm{Re}_{\mathrm{L}}\right)$. As a result, the following expression can be obtained for $C$ in the laminar flow region [13]

$$
C=26\left(1+\frac{R e_{\mathrm{L}}}{1000}\right)\left[1-\exp \left(-\frac{0.513}{0.27 L a+0.8}\right)\right] .
$$

The other important parameters which should be defined are pressure drops assuming liquid or gas alone is flowing inside the tube, i.e., $\Delta P_{\mathrm{L}}$ and $\Delta P_{\mathrm{G}}$ respectively. These parameters can be calculated as [2]

$$
\Delta P_{\mathrm{L}}=\left(\frac{L}{r_{0}}\right) f_{\mathrm{L}} \frac{G^{2}(1-x)^{2}}{\rho_{\mathrm{L}}}
$$

and

$$
\Delta P_{\mathrm{G}}=\left(\frac{L}{r_{0}}\right) f_{\mathrm{G}} \frac{G^{2} x^{2}}{\rho_{\mathrm{G}}} .
$$

In Equations A.6 and A.7, $f$ is the Fanning friction factor which is expressed for laminar flow regime as [2]

$$
f=16 / R e \quad(\text { Laminar, } R e<2300) .
$$

$x$ is the flow quality and defined as the ratio between gas mass flow rate $\dot{m}_{\mathrm{G}}$ to the total mass flow rate

$$
x=\frac{\dot{m}_{\mathrm{G}}}{\dot{m}_{\mathrm{G}}+\dot{m}_{\mathrm{L}}},
$$

and $G$ is the total mass flux $\left(\mathrm{kg} / \mathrm{m}^{2} \mathrm{~s}\right)$ calculated from the mass fluxes of liquid and gas flows as [2]

$$
G=\frac{\dot{m}_{\mathrm{G}}+\dot{m}_{\mathrm{L}}}{A}
$$

In the current study, the gas velocity becomes large compared to that of liquid and the inlet pressure also increases up to several bars. Therefore, 
pressure drop of gas phase should be calculated with taking compressibility in to account [2]

$$
\left(\frac{d p}{d z}\right)_{\mathrm{G}}=\frac{2 f_{\mathrm{G}}}{r_{0}} \cdot \frac{(G \cdot x)^{2}}{\bar{\rho}_{\mathrm{G}}},
$$

where $\bar{\rho}_{\mathrm{G}}$ is the density of the compressed gas. Assuming an ideal gas, gas density can be written as

$$
\bar{\rho}_{\mathrm{G}}=\rho_{\mathrm{G}}\left(\frac{P_{\mathrm{in}}+P_{\mathrm{out}}}{2 P_{\mathrm{out}}}\right),
$$

where $\rho_{\mathrm{G}}$ is the gas density at atmospheric pressure $(\mathrm{kg} / \mathrm{m} 3), P_{\text {in }}$ is the inlet pressure and $P_{\text {out }}$ is the outlet pressure which is the atmospheric pressure in the present study. Therefore, pressure drop assuming the gas alone is flowing inside the tube, $\Delta P_{\mathrm{G}}$ (Equation A.7) can be modified to

$$
\Delta P_{\mathrm{G}}=\left(\frac{L}{r_{0}}\right) f_{\mathrm{G}} \frac{G^{2} x^{2}}{\rho_{\mathrm{G}}}\left(\frac{P_{\mathrm{in}}+P_{\mathrm{out}}}{2 P_{\mathrm{out}}}\right) .
$$

The experimental conditions of the present study (for two phase flow i.e., gas and Krytox GPL 101, through one cylindrical pore) are shown in Table A.3 Based on the Reynolds number values, both phases are in the laminar flow regime.

Now by defining all the required parameters, the Martinelli parameter $X$ and two phase flow multiplier in the gas phase $\phi_{\mathrm{G}}$ can be calculated. These parameters are required for calculation of the liquid film thickness which will be explained later.

\section{A.3.1.2 Modified Turner-Wallis model}

Turner-Wallis method which is also referred to as the "separate cylinder" models, leads to an implicit expression for the two mixed flow regimes [6]. Consequently some modifications have been done to this model by Awad and Muzychka with a different physical approach [14. Additionally, instead of using simple friction models, they proposed using Churchill's model [15] for the friction factor in smooth and rough pipes for all values of the Reynolds number. The resulting model when written as a two phase flow gas multiplier takes the form 14

$$
\phi_{\mathrm{G}}^{2}=\left[1+\left(X^{2}\right)^{q}\right]^{\frac{1}{q}} .
$$


Table A.3: Experimental conditions in the present study for two phase flow i.e., gas and Krytox GPL 101, through one cylindrical pore with radius $1 \mu \mathrm{m}$ at the corresponding pressure values in section III of the gas-liquid porometry results starting from 1.2 bar.

\begin{tabular}{lccccc}
\hline Pressure $[\mathrm{bar}]$ & $G\left[\mathrm{~kg} / \mathrm{m}^{3}\right]$ & $u_{\mathrm{G}}[\mathrm{m} / \mathrm{s}]$ & $\begin{array}{c}u_{\mathrm{L}}\left(\times 10^{-3}\right) \\
{[\mathrm{m} / \mathrm{s}]}\end{array}$ & $R e_{\mathrm{G}}$ & $\begin{array}{c}R e_{\mathrm{L}} \\
\left(\times 10^{-5}\right)\end{array}$ \\
\hline 1.23 & 4.92 & 4.90 & 1.12 & 0.58 & 3.87 \\
1.25 & 5.10 & 5.05 & 1.13 & 0.60 & 3.76 \\
1.27 & 5.22 & 5.17 & 1.15 & 0.61 & 3.80 \\
1.29 & 5.30 & 5.26 & 1.17 & 0.62 & 3.88 \\
1.31 & 5.46 & 5.41 & 1.18 & 0.64 & 3.86 \\
1.33 & 5.60 & 5.54 & 1.19 & 0.66 & 3.84 \\
1.35 & 5.74 & 5.67 & 1.21 & 0.68 & 3.86 \\
1.37 & 5.87 & 5.79 & 1.22 & 0.69 & 3.85 \\
1.39 & 6.00 & 5.91 & 1.24 & 0.71 & 3.87 \\
1.41 & 6.13 & 6.04 & 1.25 & 0.72 & 3.88 \\
1.43 & 6.26 & 6.15 & 1.27 & 0.74 & 3.91 \\
1.45 & 6.39 & 6.28 & 1.28 & 0.75 & 3.92 \\
1.48 & 6.48 & 6.37 & 1.31 & 0.77 & 4.00 \\
1.50 & 6.63 & 6.51 & 1.32 & 0.78 & 4.00 \\
\hline
\end{tabular}

The value of $q$ is 0.307 for large tubes and 0.5 for micrchannels, minichannels and capillaries [16]. Awad and Butt showed that the method works well for flow through porous and fractured media [17.

Friction factor can be calculated based on Churchill's model as 15

$$
f=2\left[\left(\frac{8}{R e_{\mathrm{D}}}\right)^{12}+\left(\frac{1}{\left(A_{1}+A_{2}\right)^{3 / 2}}\right)\right]^{1 / 12},
$$

where

$$
\begin{gathered}
A_{1}=\left(2.457 \ln \left[\frac{1}{\left(7 / R e_{\mathrm{D}}\right)^{0.9}+(0.27 k / D)}\right]\right)^{16} \\
A_{2}=\left(\frac{37530}{r e_{\mathrm{D}}}\right)^{16},
\end{gathered}
$$

and $R e_{\mathrm{D}}$ is the Reynolds number in the gas or liquid phase and $k / D$ is the relative roughness. 
In the current study, due to small values of the Reynolds number in the gas and liquid phases, the second term in the denominator of Equation A.16 can be neglected and same values as the Fanning friction factor (Equation A.8 will be obtained. Furthermore, as stated before, both phases are in the laminar flow regime and in this case roughness does not have significant effect [18.

\section{A.3.2 Fourar and Lenormand model}

Fourar and Lenormand presented a new model for describing the two phase flow in porous media and fractures. Their model was based on the generalization of the single phase Forchheimer's Equation by introducing a function $F$ as a multiplier factor of the superficial velocity during the two phase flow. They presented their model based on the relative permeability and Martinelli parameter. For the viscous flow regimes $(R e \ll 1)$ function $F$ for the gas phase can be calculated according to the relative permeability in the same phase $\left(\kappa_{\mathrm{rG}}\right)$ as [19]

$$
F_{\mathrm{G}}=\frac{1}{\kappa_{\mathrm{rG}}} .
$$

The two phase flow multiplier in the gas phase for the viscous flow regimes $(R e \ll 1)$ can be obtained from 19

$$
\phi_{\mathrm{G}}=\sqrt{F_{\mathrm{G}}} .
$$

In the present study, the measured permeability for section III of all infused membranes except FC-43-infused one can be considered as the effective permeability for the gas phase. The absolute permeability of the single gas phase in the membrane is the measured permeability for the same section of the FC-43-infused membrane. Because as evidenced, the membrane is completely emptied in this region and consequently single gas phase is flowing throughout the membrane. The ratio of these two values is therefore the relative permeability of the membrane to the gas phase.

\section{A.3.3 Calculation of liquid film thickness}

By considering a laminar liquid flow model, liquid film thickness $\delta$ can be determined easily from the interfacial shear stress $\tau_{\mathrm{i}}$. In this case the relationship between the shear stress and liquid film velocity $u$ is 


$$
\tau=\mu_{\mathrm{L}} \frac{d u}{d r}
$$

As liquid film velocity for laminar flow is linearly proportional along the direction $r$, shear stress at liquid-gas interface is

$$
\tau_{\mathrm{i}}=\mu_{\mathrm{L}} \frac{u_{\mathrm{i}}}{\delta}
$$

Then, the liquid film velocity $u$ can be derived as

$$
u=\frac{u_{\mathrm{i}}}{\delta} r=\frac{\tau_{\mathrm{i}}}{\mu_{\mathrm{L}}} r
$$

The mass flow rate of the liquid film is

$$
\dot{m}_{\mathrm{L}}=G A(1-x)=\int_{0}^{\delta} \rho u 2 \pi\left(r_{0}-r\right) d r .
$$

By substituting Equation A.22 in to Equation A.23 and by considering smaller values of liquid film thickness $\delta$ compared to that of initial pore radius $r_{0}$, liquid mass flow rate can be derived as

$$
\dot{m}_{\mathrm{L}}=\frac{2 \pi \rho_{\mathrm{L}} \tau_{\mathrm{i}}}{\mu_{\mathrm{L}}} \int_{0}^{\delta}\left(r_{0}-r\right) d r \approx \frac{\pi r_{0} \rho_{\mathrm{L}} \tau_{\mathrm{i}}}{\mu_{\mathrm{L}}} \delta^{2} .
$$

Finally, the liquid film thickness can be calculated as

$$
\delta^{2}=\frac{G(1-x) r_{0} \mu_{\mathrm{L}}}{\rho_{\mathrm{L}} \tau_{\mathrm{i}}},
$$

where $r_{0}$ is the pore radius (m), $x$ and $G$ are calculated according to Equations A.9 and A.10 respectively. $\tau_{\mathrm{i}}$ is calculated according to the properties of the gas phase as

$$
\tau_{\mathrm{i}}=\left(\frac{d p}{d z}\right)_{\mathrm{G}} \phi_{\mathrm{G}}^{2} \frac{r_{0}}{2}=\frac{\Delta P_{\mathrm{G}}}{L} \phi_{\mathrm{G}}^{2} \frac{r_{0}}{2},
$$

where $\Delta P_{\mathrm{G}}$ is calculated using Equation A.13. $\phi_{\mathrm{G}}$ can be determined according to the modified Chisholm model (Equation A.2), or modified Turner-Wallis model (Equation A.14), or Fourar and Lenormand model (Equation A.19). According to the calculated $\phi_{\mathrm{G}}$ based on each model, different theoretical values for liquid film thickness can be obtained. 
Table A.4: The standard deviation (SD) of the predicted to the experimental values and the mean relative error for calculation of the film thickness based on different models in liquid-infused membranes.

\begin{tabular}{lccccc} 
Model & SD and error [\%] & Krytox 101 & Krytox 157 & SO AR20 & Galpore \\
\hline \multirow{2}{*}{ Modified Chisholm } & SD & 6 & 4 & 7 & 2 \\
& Error & -9 & -19 & -9 & -22 \\
\hline \multirow{2}{*}{ Modified Turner-Wallis } & SD & 6 & 6 & 7 & 5 \\
& Error & 19 & 6 & 19 & -1 \\
\hline \multirow{2}{*}{ Fourar-Lenormand } & SD & 8 & 4 & 9 & 4 \\
& Error & 11 & 29 & 11 & -9 \\
\hline
\end{tabular}

Table A.5: The exponent of pressure with respect to the experimental and predicted values of flow $\left(\Delta P^{n} \sim Q\right)$ for Krytox 101-infused membrane.

\begin{tabular}{lr}
\hline K101-infused membrane & Exponent of pressure \\
\hline Experimental & 2.21 \\
Modified Chisholm & 1.60 \\
Modified Turner-Wallis & 1.40 \\
Fourar-Lenormand & 1.26 \\
\hline
\end{tabular}

\section{A.3.4 Precision of the liquid film thickness calculation}

In Table A.4 the standard deviation (SD) percent of the predicted to the experimental values and mean relative error for calculation of the film thickness for the mentioned infused membranes based on different models are presented.

\section{A.4 Calculation of the gas flow rate}

A comparison between the calculated and experimental values of gas flow rate for Krytox 101-infused membrane is shown in Figure A.3. The exponent of pressure with respect to the experimental and predicted values of flow are represented in Table A.5. According to the slight decrease in the film thickness with pressure based on the mentioned models, an almost linear relation between the predicted gas flow and pressure can be observed.

\section{References}

[1] H. G. F. and H.-T. N. S., Annular two phase flow (Pergamon, New York, USA) (1970). 


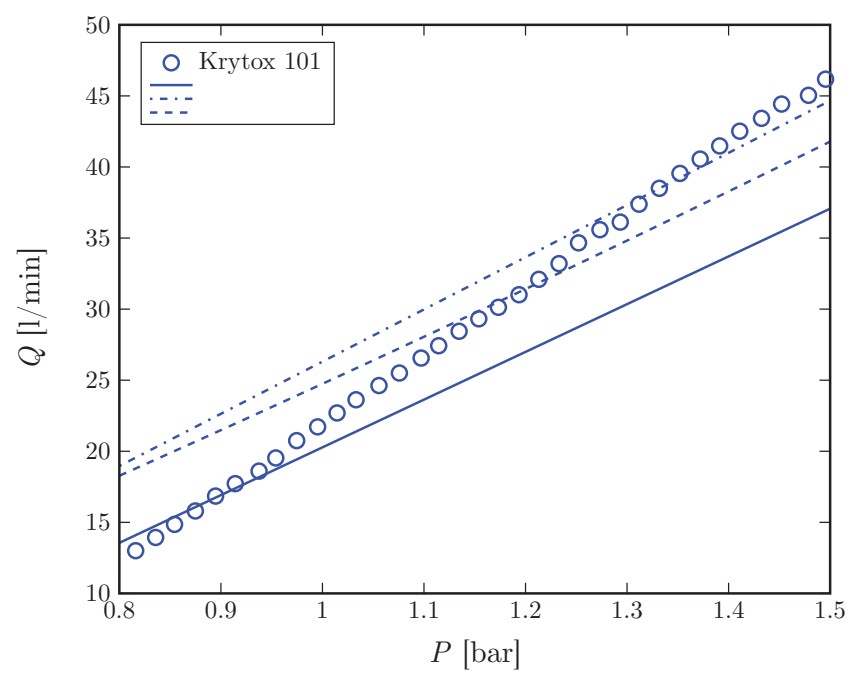

Figure A.3: Comparison between calculated and experimental values of gas flow rate in section III for Krytox 101-infused membrane (Solid, dash dotted and dashed lines respectively correspond to the modified Chisholm, Turner-Wallis, and Fourar and Lenormand models).

[2] Y. Han, H. Kanno, Y.-J. Ahn, and N. Shikazono, "Measurement of liquid film thickness in micro tube annular flow", International Journal of Multiphase Flow 73, $264-274$ (2015).

[3] C. Shearer and R. Nedderman, "Pressure gradient and liquid film thickness in co-current upwards flow of gas/liquid mixtures: Application to film-cooler design", Chemical Engineering Science 20, 671 - 683 (1965).

[4] R. Srivastava, "Liquid film thickness in annular flow", Chemical Engineering Science 28, 819 - 824 (1973).

[5] R. Lockhart and R. Martinelli, "Proposed correlation of data for isothermal two phase flow, two component flow in pipes", Chemical engineering progress 45, 39-48 (1949).

[6] G. B. Wallis, One dimensional two phase flow (McGraw-Huill, New York, USA) (1969).

[7] D. Chisholm, "A theoretical basis for the lockhart-martinelli correlation for two-phase flow", International Journal of Heat and Mass Transfer 10, $1767-1778$ (1967). 
[8] Y. S. Muzychka and M. M. Awad, "Asymptotic Generalizations of the Lockhart-Martinelli Method for Two Phase Flows", Journal of Fluids Engineering 132, 031302(1-12) (2010).

[9] W. P. B., Two-phase flow and heat transfer (Oxford University press, New York, USA) (1996).

[10] K. Mishima and T. Hibiki, "Some characteristics of air-water two-phase flow in small diameter vertical tubes", International Journal of Multiphase Flow 22, $703-712$ (1996).

[11] N. J. English and S. G. Kandlikar, "An experimental investigation into the effect of surfactants on air-water two-phase flow in minichannels", Heat Transfer Engineering 27, 99-109 (2006).

[12] W. Zhang, "Study on constitutive equations for flow boiling in minichannels", Ph.D. thesis, Kyoto University, Japan (2005).

[13] L. Sun and K. Mishima, "Evaluation analysis of prediction methods for two-phase flow pressure drop in mini-channels", International Journal of Multiphase Flow 35, 47 - 54 (2009).

[14] A Simple Asymptotic Compact Model for Two-Phase Frictional Pressure Gradient in Horizontal Pipes, volume Fluids Engineering of ASME International Mechanical Engineering Congress and Exposition (2004).

[15] C. S. W., "Friction-factor equation spans all fluid-flow regimes", Chemical Engineering Journal 84, 99-92 (1977).

[16] M. M. Awad, "Two-phase flow modeling in pipes", Ph.D. thesis, Memorial University of Newfoundland, Canada (2005).

[17] M. M. Awad and S. D. Butt, "A robust asymptotically based modeling approach for two-phase flow in porous media", Journal of Heat Transfer 131, 101014(1-12) (2009).

[18] M. L. F., "Friction factors for pipe flow", Transactions of American Society Mechanical Engineers 66, 671-684 (1944).

[19] M. Fourar and R. Lenormand, "A new model for two-phase flows at high velocities through porous media and fractures", Journal of Petroleum Science and Engineering 30, 121 - 127 (2001). 


\section{Appendix B}

\section{B.1 SLIM fabrication and characterization}

The SLIMs are fabricated by infusing Polyvinylidene fluoride (PVDF) membranes with different types of infusion liquids (hydrocarbon as well as fluorinated). Table 3.1 in Chapter Two shows the physical properties of the used liquids. The pendant drop method is used to measure surface tension values using a contact angle Goniometer (Dataphysics OCA20). A modular compact Rheometer (Anton Paar MCR502) is used for measuring absolute viscosity values of the liquids, using a cone plate geometry (CP25-2). The density is measured using gas pycnometer (AccuPyc II 1340 Pycnometer) at $24^{\circ} \mathrm{C}$. (In all tables the standard deviation is reported for 6 measurements except for density which is reported for 30 measurements). The membrane is further characterized using a scanning electron microscopy (SEM) (JEOL $5600 \mathrm{LV}$ ), capillary flow porometer (Porolux-1000), and contact angle Goniometer (Dataphysics OCA 20).

The SEM images of top, bottom and cross section of the PVDF membrane are shown in Figure B.1. The pore size distribution of the membrane is obtained from capillary flow porometry. In this measurement, nitrogen gas is pushing through the infused membrane with a low surface tension liquid, i.e. FC-43 (Table 3.1 in Chapter Two) at different pressures, the gas flow rate is measured correspondingly. The capillary flow porometry result for the PVDF membrane is shown in Figure B.2. This measurement is conducted in two runs: in the first run, the so called wet curve, a sudden increase in gas flow rate is observed which corresponds to the pressure where the biggest pores are opened (first bubble point (FBP)). In the second run as the liquid has been already push out, a linear behaviour between flow and pressure is obtained 
(dry curve). The point where wet and dry curves meet corresponds to the smallest pore sizes. Simultaneously half-dry curve is also plotted where the flow values are half of the flow values of the dry curve. The crossing point of this curve and wet curve determines the mean flow pore sizes (MFP). The Young-Laplace equation (Equation 3.3 in Chapter Two by considering total wetting is used to relate pressure to the pore size. Based on the results of this measurement, the pore size distribution of the membrane can be obtained which is shown in Figure B.3. As can be seen from Figures B.2 and B.3, the PVDF membrane has a narrow and homogeneous pore size distribution with average pore radius of $1.65 \mu \mathrm{m}$ and size distribution of $0.11 \mu \mathrm{m}$ (full width at half $\max / 2$ ).

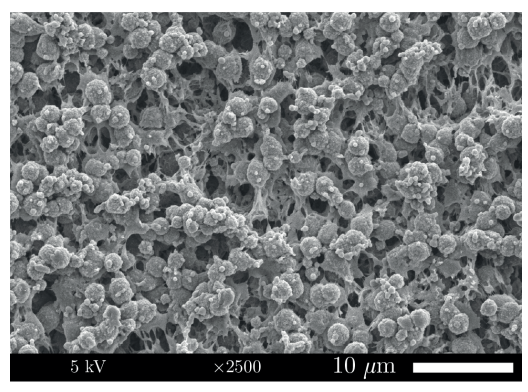

(a)

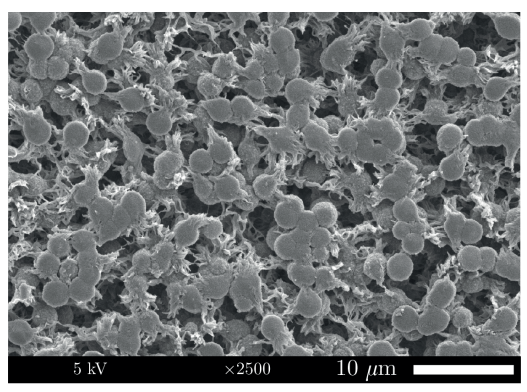

(b)

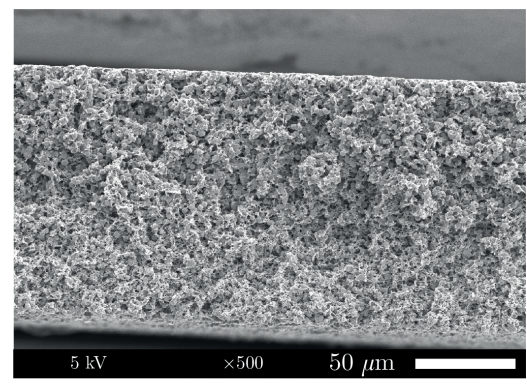

(c)

Figure B.1: Scanning electron microscopy (SEM) images of PVDF membrane. (a) Top surface, (b) bottom surface and (c) cross section. 


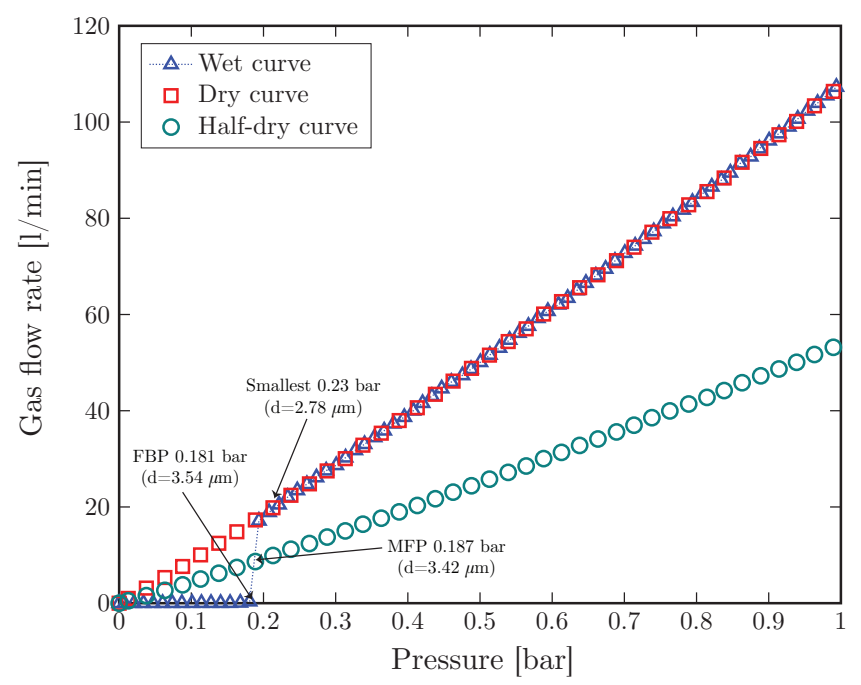

Figure B.2: Capillary flow porometry results of PVDF membrane showing flow rate of nitrogen gas as a function of pressure. The corresponding pressure values for the biggest pore sizes (first bubble point (FBP)), mean flow pore sizes (MFP) and smallest pore sizes are indicated with arrows.

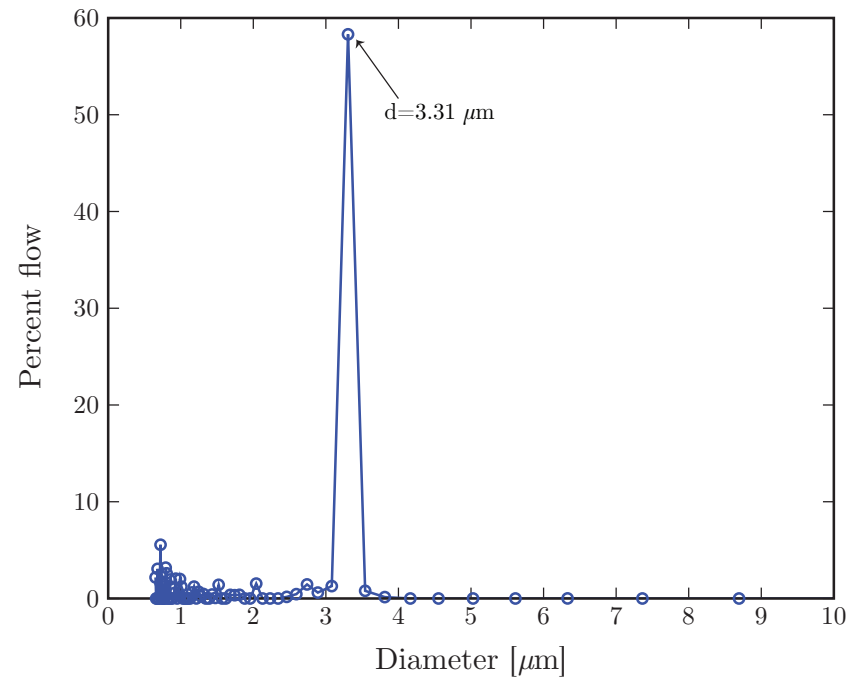

Figure B.3: Pore size distribution of the PVDF membrane. 
Table B.1: Water contact angle measurements (CA) on dry, liquid-infused and dense PVDF (K101 and SO are abbreviated forms of Krytox 101 and SO AR20 respectively).

\begin{tabular}{lcccc}
\hline Infusion liquid & $\begin{array}{c}\text { Advancing } \\
\mathrm{CA}\left(\theta_{\text {adv }}\right)\left[^{\circ}\right]\end{array}$ & $\begin{array}{c}\text { Receding } \\
\mathrm{CA}\left(\theta_{\text {rec }}\right)\left[^{\circ}\right]\end{array}$ & $\begin{array}{c}\text { Hysteresis } \\
{\left[{ }^{\circ}\right]}\end{array}$ & $\begin{array}{c}\text { Mean static } \\
\mathrm{CA}\left[^{\circ}\right]\end{array}$ \\
\hline None (porous PVDF) & $142 \pm 0.3$ & $117 \pm 1.2$ & $25 \pm 1$ & $136 \pm 0.3$ \\
None (dense PVDF) & $122 \pm 0.9$ & $90 \pm 0.4$ & $32 \pm 0.3$ & $120 \pm 0.8$ \\
Dense PVDF immersed in K101 & $175 \pm 0.5$ & $154 \pm 0.6$ & $20 \pm 0.2$ & $170 \pm 0.5$ \\
Dense PVDF immersed in SO & $161 \pm 0.4$ & $158 \pm 0.3$ & $2 \pm 0.4$ & $159 \pm 0.6$ \\
Krytox 101 & $119 \pm 0.1$ & $114 \pm 0.3$ & $5.1 \pm 0.3$ & $117 \pm 0.1$ \\
FC-43 & $118 \pm 0$ & $113 \pm 0.3$ & $4.7 \pm 0.3$ & $116 \pm 0.3$ \\
Galpore & $120 \pm 0.2$ & $114 \pm 0.5$ & $6.2 \pm 0.7$ & $117 \pm 0.5$ \\
SO AR20 & $94 \pm 0.1$ & $90 \pm 0.2$ & $4.1 \pm 0.2$ & $93 \pm 0.3$ \\
\hline
\end{tabular}

\section{B.2 Contact angle measurements}

The water contact angle measurement results on dry and liquid-infused PVDF membranes as well as dense PVDF are shown in Table B.1. The static contact angle on surfaces was measured by using drops having a volume of 2 $\mu \mathrm{l}$. Advancing and receding contact angles were determined by placing the needle in the drop (sessile drop needle-in mode) and continuously supplying or withdrawing water up to $6 \mu \mathrm{l}$ at $0.5 \mu \mathrm{l} / \mathrm{min}$ within six cycles. The delay time between each advancing and receding measurement was set to be $2 \mathrm{~s}$. A high contact angle and low contact angle hysteresis are obtained for liquid infused membranes. This is the key design parameter for droplet mobility and slippery behavior of these membranes [1, 2].

\section{B.3 Interfacial tension measurements}

The surface tension of water and the interfacial tension between water and the infusion liquids are measured using a contact angle Goniometer (Dataphysics OCA 20). The pendant drop method is used for this measurement. The results are shown in Table B.2. Table B.3 shows the surface tension values of water and SO AR20 labeled with Rhodamine $6 \mathrm{G}$ and Perylene fluorescent dyes respectively. It is worth mentioning that the interfacial tension between water and silicone oil AR20 (SO AR20) could not be measured by this method, because of the very similar densities for these two liquids. Therefore, the interfacial tension between water and SO AR20 is calculated using Van der Waals components of silicone oil surface tension (which is about $18.8 \mathrm{mN} / \mathrm{m}$ ) 
[3].

Table B.2: Interfacial tension values between water and different fluids

\begin{tabular}{lr}
\hline Fluids & Interfacial tension $[\mathrm{mN} / \mathrm{m}]$ \\
\hline Air & $72.2 \pm 0.07$ \\
K101 & $54.7 \pm 0.16$ \\
FC-43 & $53.6 \pm 0.10$ \\
Galpore & $53.2 \pm 0.15$ \\
SO AR20 & 18 \\
\hline
\end{tabular}

Table B.3: Surface tension values of water and SO AR20 labeled with $17.7 \mu \mathrm{M}$ and $8.7 \mathrm{mM}$ Rhodamine $6 \mathrm{G}$ and Perylene fluoresent dyes respectively.

\begin{tabular}{lr}
\hline Fluids & Surface tension $[\mathrm{mN} / \mathrm{m}]$ \\
\hline Water+Rhodamine 6G & $71.9 \pm 0.12$ \\
SO AR20+Perylene & $21.5 \pm 0.04$ \\
\hline
\end{tabular}

\section{B.4 Liquid-liquid displacement porometry (LLDP) experiments}

The LLDP results of infused PVDF membranes with other infusion liquids, i.e. FC-43, Galpore and SO AR20, are shown in Figure B.4. Unlike other liquid infused membranes, a non-linear relation between pressure and flux is observed for SO AR20-infused membrane in the $2^{\text {nd }}$ run of all cycles (Figure B.4(c). The reason can be attributed to the higher kinematic viscosity of silicone oil compared to the other liquids (Table 3.1 in Chapter Two), resulting in slower fluid movement and thicker liquid lining on the pore wall. This will subsequently give rise to the change of pore radius with pressure [1. Additionally, the lower pressure values for SO AR20-infused membrane compared to those of other liquid-infused membranes is a direct result of the lower interfacial tension value between water and silicone oil compared to the other liquid pairs (see Table B.2.

\section{B.5 Fitting results}

The corresponding range of 95\% confidence interval (CI) for all the fitting parameters, i.e., total number of pores per unit area $N$, geometric mean radius 


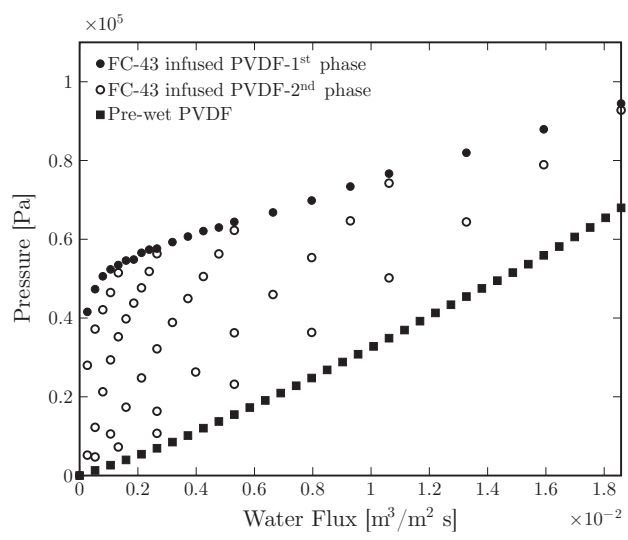

(a)

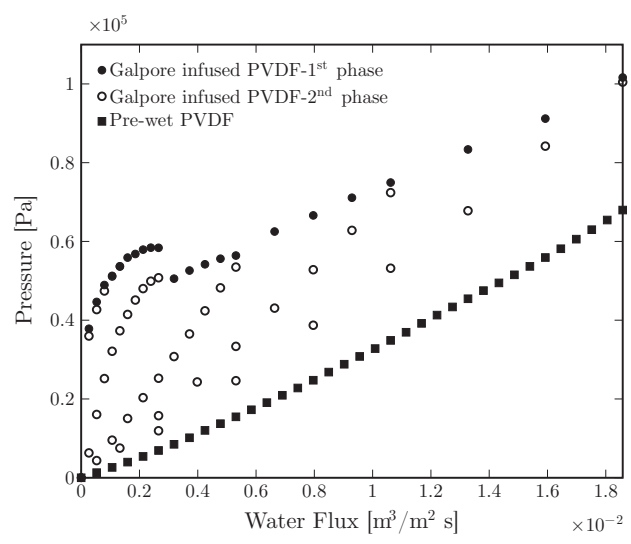

(b)

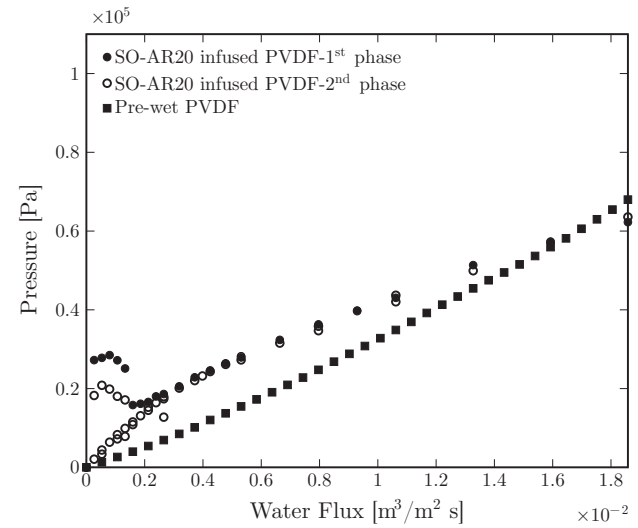

(c)

Figure B.4: Liquid-liquid displacement porometry experiments of infused PVDF membrane with (a) FC-43, (b) Galpore, and (c) SO AR20. 
Table B.4: Range of $95 \%$ confidence interval for all fitting parameters.

\begin{tabular}{lccc}
\hline Membranes & $\log N$ & $\log R$ & $S$ \\
\hline Dry & $12.09 \pm 0.86$ & $-6.39 \pm 0.23$ & $1.53 \pm 0.14$ \\
K101-infused & $10.55 \pm 0.09$ & $-6.07 \pm 0.03$ & $1.37 \pm 0.03$ \\
SO AR20-infused & $13.57 \pm 1.76$ & $-7.59 \pm 0.78$ & $2.82 \pm 0.55$ \\
\hline
\end{tabular}

$R$, and geometric standard deviation $S$ is shown in Table B.4. The fitting parameters for dry and K101-infused membranes fall on the same parameter space, however, a deviation can be observed for SO AR20-infused membrane. The reason can be related to the adsorption phenomena of some unknown additives in silicone oil. LLDP experiment of SO AR20-infused membrane also shows a different behaviour compared to the other liquid-infused membranes (see Figure B.4.

\section{B.6 Relation between permeability and porosity (tube model)}

Flow through a straight circular tube can be obtained from the HagenPoiseuille equation [4, 5]

$$
Q=\frac{\pi r^{4}}{8 \mu} \frac{\Delta P}{L},
$$

where $Q$ is the volumetric flow rate $\left(\mathrm{m}^{3} / \mathrm{s}\right), r$ is the radius of the tube $(\mathrm{m}), \mu$ is the viscosity of the permeating fluid ( $\mathrm{Pa} \mathrm{s}), \Delta P$ is the pressure drop $(\mathrm{Pa})$ over the length of tube $L(\mathrm{~m})$. By assuming a collection of such tubes passing through a cubical piece of porous medium of length $L$, a simple model for permeability of the porous medium can be derived. If we have $n$ tubes of length $L$ and radius $r$, passing directly through the sample at right angles to one pair of faces, then the porosity $\phi$ will be given by

$$
\phi=\frac{n \pi r^{2}}{L^{2}} .
$$

The total volumetric flow through the medium is given by $Q_{\text {total }}=n Q$

$$
Q_{\text {total }}=\frac{\phi L^{2} r^{2}}{8 \mu} \frac{\Delta P}{L},
$$

where $Q$ and $n$ are obtained from Equations B.1 and B.2 respectively. 
Comparison of Equation B.3 with Darcy's law [6]

$$
Q=\frac{\kappa A}{\mu} \frac{\Delta P}{L},
$$

gives us

$$
\kappa=\frac{\phi r^{2}}{8},
$$

for the permeability $(\kappa)$ of this simple one-dimensional model.

A pseudo three-dimensional tube model can be obtained by arranging the $n$ capillaries in such a way that $n / 3$ capillaries are parallel to the z-axis. In this model, the permeability for the same porosity $\phi$ is one-third of the permeability of the one-dimensional model (Equation B.5). Therefore, the threedimensional tube model will be derived as

$$
\kappa=\frac{\phi r^{2}}{24} .
$$

\section{B.7 Fabrication of the microfluidic chip}

The microfluidic chip was fabricated using standard photolithography and deep reactive ion etching (DRIE) techniques at MESA ${ }^{+}$Nanolab/clean room at the University of Twente. The process can be divided in to three steps, namely etching of the pore network into the silicon $(\mathrm{Si})$ wafer, etching the access holes through the Si wafer and finally bonding the finished $\mathrm{Si}$ wafer to a Pyrex wafer. The photolithography was done twice using two masks to make the pore network (pillars) and the access holes respectively. Before starting the photolithography, the Si wafers were thermally oxidized to get a $\mathrm{SiO}_{2}$ layer of $1 \mu \mathrm{m}$, i.e. hard mask. This was done by wet oxidation of $\mathrm{Si}$ wafer at temperature of $1150^{\circ} \mathrm{C}$ for 2 hours and 20 minutes. After coating the $\mathrm{Si}$ wafer with a photoresist layer, the first mask was aligned with the wafer and the pillar pattern is transferred to the layer by exposure to UV light and resist development. The developed resist layer is then annealed at temperature of $120^{\circ} \mathrm{C}$ for 10 minutes using a hot plate. The next step is to etch the protection $\mathrm{SiO}_{2}$ layer and then the pillar pattern into the $\mathrm{Si}$ wafer (to a depth of $50 \mu \mathrm{m}$ ) using DRIE technique (Bosch process recipe was used). Then the photoresist layer was stripped using oxygen plasma and a protection foil (Dupont MX 5020 foil) was applied to the top side. By the same procedure, a positive photo resist layer was developed using the second mask on the 
backside of Si wafer. The access holes are etched and the photoresist and foil were stripped away. The remaining $\mathrm{SiO}_{2}$ layer was removed by dipping the wafer in buffered HF solution (BHF (1:7)) for 20 minutes. Finally, the wafer was cleaned using piranha $\left(\mathrm{H}_{2} \mathrm{SO}_{4}: \mathrm{H}_{2} \mathrm{O}_{2}(3: 1)\right.$ vol.\%) and dried. The finished $\mathrm{Si}$ wafer was anodically bonded to the Pyrex wafer.

\section{B.8 Liquid-liquid displacement in microfluidic chip}

The remaining infusion liquid in the chip after displacing with water can be in the form of pools, bridges and thin films around pillars (Movie B1 and still image (Figure 3.7(a) in Chapter Two). The plot of specific interfacial length between water and remaining infusion liquid (including all liquid structures) is shown in Figure B.5. The specific interfacial length $\left(\mathrm{a}_{\mathrm{it}}\right)\left(\mathrm{mm}^{-1}\right)$ is calculated as interfacial length $(\mathrm{mm})$ divided by the pore area $\left(\mathrm{mm}^{2}\right)$ which is defined as the porosity times the total chip area. These lengths include interfaces between wetting and non-wetting fluids as well as thin films around pillars. In Figure B.5(b) the specific interfacial length for fluid-fluid interfaces is shown. The total specific interfacial length including thin films around pillars is shown in Figure B.5(a),

The observation of thin films around pillars further confirms the presence of the liquid-lined pores in the membranes. This is crucial for anti-fouling characteristics of liquid infused surfaces. A three-dimensional image of the chip is taken using a laser scanning confocal microscope (LSCM) to show the presence of this thin films along the pillars (Figure B.6. The optical sectioning resolution of $5.76 \mu \mathrm{m}$ for z-stack imaging is used in LSCM. Due to the distortion induced by mismatch of the refractive index between water, glass and air the height of the pillar is observed less than $50 \mu \mathrm{m}$. In order to correct for that, the cross sectional images (Figure B.6(b)) are re-scaled. The observed conical shape is because of defocusing which was inevitable.

\section{B.9 Local saturation of the non-wetting phase}

In order to better quantify the formation and evolution of the fingers, local saturation of non-wetting phase $\left(\mathrm{S}_{\mathrm{nw}}\right)$ is plotted as a function of time $(t)$ and location $(x)$. For measuring the local saturation, each time frame of the displacement movie is divided vertically into 33 slices and $S_{n w}$ is calculated for each slice. The result is shown in Figure B.7, where the first four time frames 


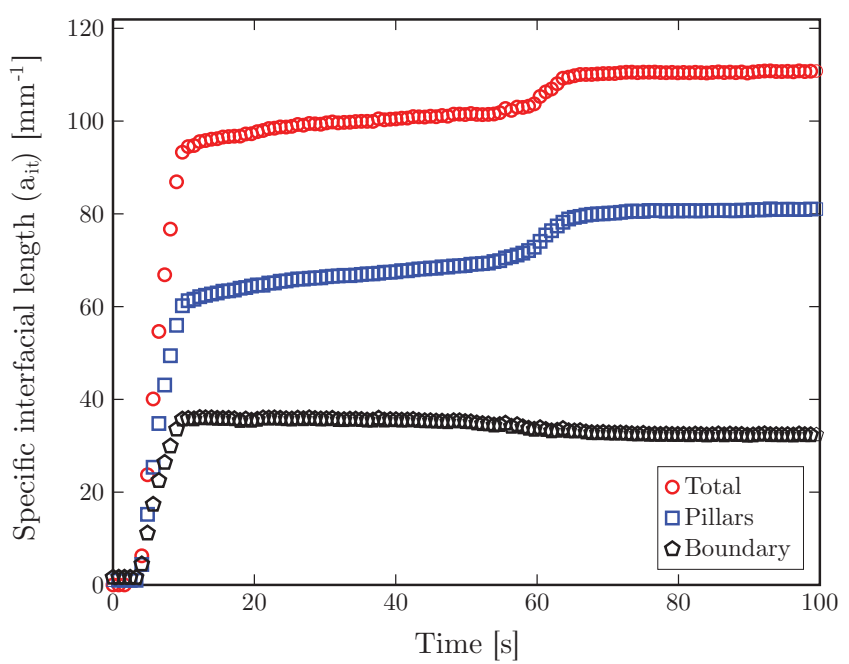

(a)

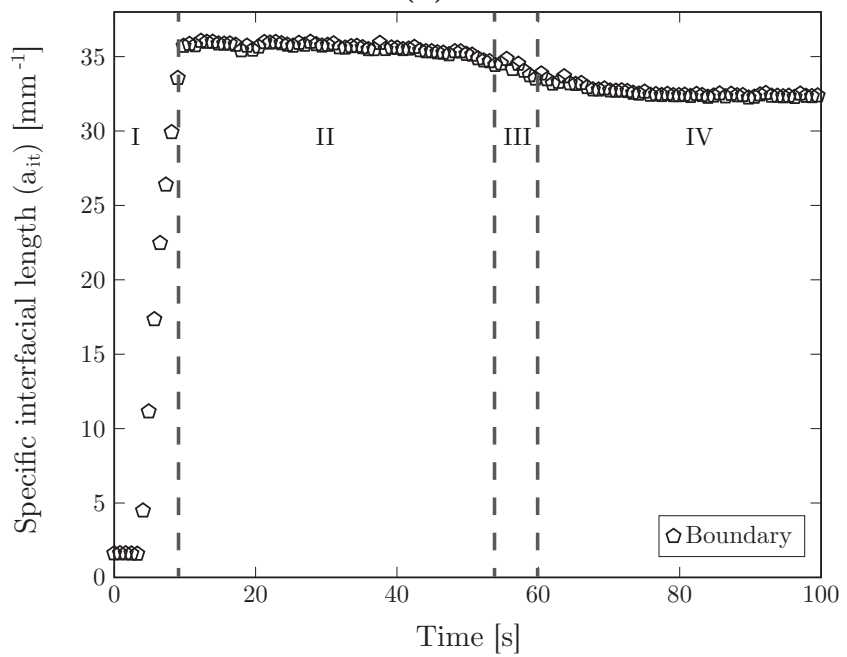

(b)

Figure B.5: (a) Specific interfacial length between water and remaining infusion liquid in the chip as a function of time. $a_{i t}$ between water and thin films around pillars is shown as squares (Pillars). $\mathrm{a}_{\mathrm{it}}$ between water and other structures of the remaining infusion liquid (pools and bridges) is shown as pentagons (Boundary). The summation of these two specific interfacial lengths is shown as circles (Total). (b) Specific interfacial length $\left(\mathrm{a}_{\mathrm{it}}\right)$ as a function of time for the boundary between water and oil phases. 


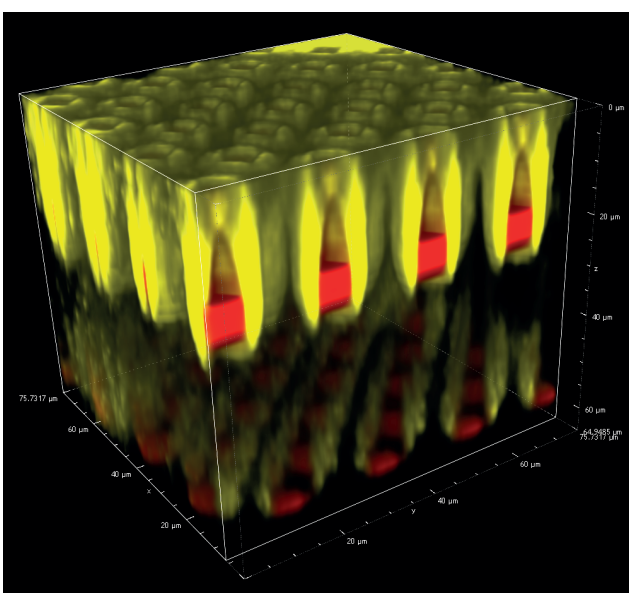

(a)

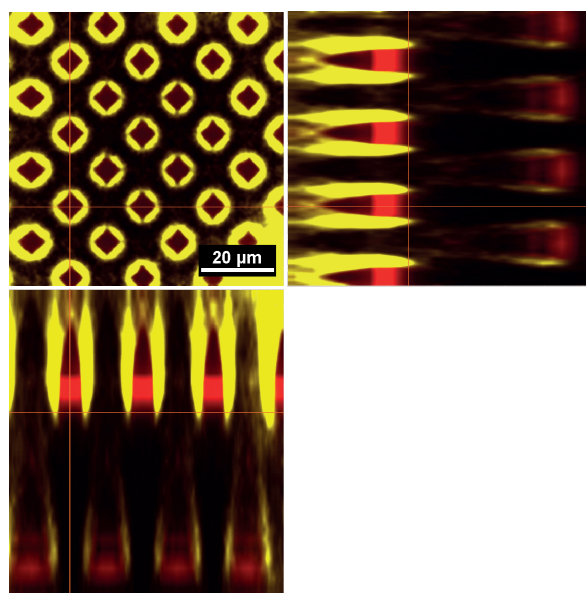

(b)

Figure B.6: (a) Three-dimensional image of the chip after displacing the infusion liquid with water (b) cross section of the three-dimensional image showing the presence of thin liquid film along the pillars (red colors are indicating pillars and yellow color shows the remaining infusion liquid (SO AR20)).

show the initial formation of the fingers. This corresponds to the movement of a shock front towards the outlet.

\section{B.10 Box counting algorithm}

Hausdorff MATLAB code (Hausdorff (Box-Counting) fractal dimension code) is used for fractal dimension analysis using a box counting algorithm. In the algorithm, each image is first transformed to a binary image. In this image nonzero pixels belong to an object and zero pixels constitute the background. The image is then covered by a grid and the number of grid boxes which contain at least one object pixel are counted. The same procedure will be repeated but with a finer grid with smaller boxes. $D$ is then the slope of the line when $\log B$ (number of boxes) is plotted against $\log a$ (inverse of the box size) (see Equation 3.7 in Chapter Two).

\section{B.11 Buckley-Leverett analysis}

To derive Buckley-Leverett equation, one should start with Darcy's law (or relative permeability equations) and continuity equations for each phase (wet- 


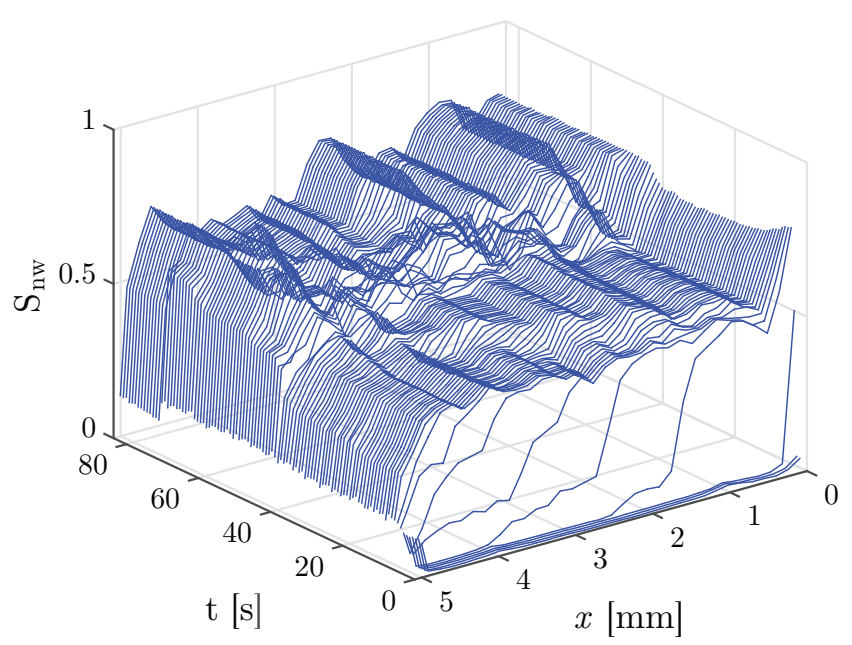

Figure B.7: Local Saturation of the non-wetting phase $\left(S_{\mathrm{nw}}\right)$ as a function of location $x$ and time index $t$ for the corresponding displacement movie (Movie B1).

ting and non-wetting). By considering the law relating capillary pressure to saturation and concept of fractional flow (the ratio of each phase velocity to total velocity), equation B.7 will be obtained for one-dimensional immiscible displacement. (For the detailed and full derivation reader is referred to reference [7]).

$$
\frac{u}{\phi}\left(\frac{d \varphi_{\mathrm{nw}}}{d S_{\mathrm{nw}}} \frac{\partial S_{\mathrm{nw}}}{\partial x}+\frac{\partial}{\partial x}\left(\psi_{\mathrm{nw}} \frac{\partial S_{\mathrm{nw}}}{\partial x}\right)\right)+\frac{\partial S_{\mathrm{nw}}}{\partial t}=0
$$

where $\varphi_{\mathrm{nw}}$ and $\psi_{\mathrm{nw}}$ are defined as

$$
\varphi_{\mathrm{nw}}=\frac{\frac{\mu_{\mathrm{w}}}{\kappa_{\mathrm{w}_{\mathrm{w}}}}+\frac{\kappa\left(\rho_{\mathrm{w}}-\rho_{\mathrm{nw}}\right) g}{u}}{\frac{\mu_{\mathrm{w}}}{\kappa_{r_{\mathrm{w}}}}+\frac{\mu_{\mathrm{nw}}}{\kappa_{r_{\mathrm{nw}}}}},
$$

and

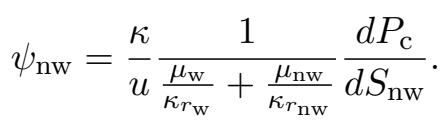

In these equations, $u$ is the total fluid velocity $(\mathrm{m} / \mathrm{s}), \phi$ is porosity, $S_{\mathrm{nw}}$ is the saturation of non-wetting phase, $P_{\mathrm{c}}$ is the capillary pressure defined as difference between pressure of wetting and non-wetting phases, $\mu$ is absolute viscosity $(\mathrm{Pa} \mathrm{s}), \rho$ is density $\left(\mathrm{kg} / \mathrm{m}^{3}\right), \kappa$ is absolute permeability, and $\kappa_{\mathrm{r}}$ is 
relative permeability of the porous medium. The subscripts $\mathrm{w}$ and nw stand for wetting and non-wetting phases respectively.

Equation B.7 is a parabolic partial differential equation (PDE) of unknown function $S_{\text {nw }}$ and its partial derivatives up to the second order. If this equation can be integrated, the problem is completely solved. There are stationary solutions for this equation, but some problems of the displacement of one fluid by another having practical importance can not be solved by a stationary solution. However, since a non-stationary solution is somewhat complicated, Buckley and Leverett have considered replacing equation B.7 with a simpler one by neglecting the term representing the action of capillary forces [8]. This assumption is valid when the gradient of capillary pressure $\left(\frac{\partial P_{\mathrm{c}}}{\partial x}\right)$ vanishes which is the case if the flow rate or fluid velocity is large and the density difference $\left(\rho_{\mathrm{w}}-\rho_{\text {nw }}\right)$ is small or gravity is not important. Finally, the BuckleyLeverett equation will be obtained as

$$
\frac{\phi}{u} \frac{\partial S_{\mathrm{nw}}}{\partial t}+\frac{d f_{\mathrm{nw}}}{d S_{\mathrm{nw}}} \frac{\partial S_{\mathrm{nw}}}{\partial x}=0,
$$

where $f_{\text {nw }}$ is the fractional flow for the non-wetting phase defined as

$$
f_{\mathrm{nw}}=\varphi_{\mathrm{nw}}+\psi_{\mathrm{nw}} \frac{\partial S_{\mathrm{nw}}}{\partial x} .
$$

Based on the assumption of Buckley-Leverett, $P_{\mathrm{c}}$ is virtually zero or independent of $S_{\mathrm{nw}}$ and saturation is a function of $x$ which varies very slowly. In this case, $\psi_{\mathrm{nw}} \frac{\partial S_{\mathrm{nw}}}{\partial x}$ is small compared to $\varphi_{\mathrm{nw}}$ and $f_{\mathrm{nw}}=\varphi_{\mathrm{nw}}$.

Neglecting the action of capillary forces lowers the order of Equation B.7 by one unit giving the Buckley-Leverett equation (Equation B.10) as a first order PDE for the unknown function $S_{\mathrm{nw}}$. To solve Equation B.10, the MATLAB reservoir simulation tool box (MRST) is used [9. The solution imposes the requirement that there must be a shock front at which there is discontinuity in the function of $S_{\text {nw }}$.

To solve the Buckley-Leverett equation, a model is required to relate relative permeability to saturation values. We used a pure power-law relationship, i.e. the Corey model

$$
\kappa_{r_{\mathrm{w}}}=\left(\widehat{S}_{\mathrm{nw}}\right)^{n_{\mathrm{w}}} k_{\mathrm{w}}^{0}, \quad \kappa_{r_{\mathrm{nw}}}=\left(1-\widehat{S}_{\mathrm{nw}}\right)^{n_{\mathrm{nw}}} k_{\mathrm{nw}}^{0},
$$

where the exponents $n_{\mathrm{w}}>1$ and $n_{\mathrm{nw}}>1$ and the constants $k_{\alpha}^{0}$, used for endpoint scaling, are fitting parameters. 
$\widehat{S}_{\text {nw }}$ is the normalized non-wetting saturation defined as

$$
\widehat{S}_{\mathrm{nw}}=\frac{S_{\mathrm{nw}}-S_{\mathrm{nwr}}}{1-S_{\mathrm{nwr}}} .
$$

The exponents $n_{\mathrm{w}}$ and $n_{\mathrm{nw}}$ are estimated using the Purcell model. In this model the exponents are equal to $\frac{2+\lambda}{\lambda}$ where $\lambda$ is a parameter related to pore size distribution of the sample [10].

Here, we use a simplified version of the Corey model in which the residual saturations $S_{\mathrm{nwr}}$ and $S_{\mathrm{wr}}$ are assumed to be zero and the end points are scaled to unity, so that $\kappa_{r_{\mathrm{w}}}=\left(S_{\mathrm{nw}}\right)^{n_{\mathrm{w}}}$ and $\kappa_{r_{\mathrm{nw}}}=\left(1-S_{\mathrm{nw}}\right)^{n_{\mathrm{nw}}}$. In our model, $\lambda$ is estimated as one and therefore the exponents $n_{\mathrm{w}}$ and $n_{\mathrm{nw}}$ are equal to three.

One more parameter which should be defined in order to solve the BuckleyLeverett equation, is the absolute permeability $(\kappa)$ of the porous medium. Kozeny-Carman equation [11.

$$
\kappa=\frac{\phi^{3}}{6 S^{2}}
$$

is used to calculate this parameter for our porous micromodel.

Equation B.14 is a generalization of the tube model (B.6) assuming that the resistance to flow arises from viscous drag along the pore walls. In this equation, $S$ is the specific surface defined as the internal surface area per unit bulk volume

$$
S=\frac{A_{\text {pore }}}{V_{\text {bulk }}},
$$

where $A_{\text {pore }}$ consists of two parts, i.e. $A_{\text {pore }_{(1)}}$ and $A_{\text {pore }_{(2)}} \cdot A_{\text {pore }_{(1)}}$ is calculated from the porosity of the micromodel $\left(\phi \times A_{\text {chip }}\right)$, where $A_{\text {chip }}$ is the area of the microfluidic chip. $A_{\text {pore }_{(2)}}$ is the total circumferential area of the pillars $(4 a h \times n)$ where $a$ and $h$ are the side length and height of the square pillars respectively and $n$ is the number of pillars in the microfluidic chip (62500).

\section{References}

[1] H. Bazyar, S. Javadpour, and R. G. H. Lammertink, "On the gating mechanism of slippery liquid infused porous membranes", Adv. Mater. Interfaces 3, 1600025 (1-6) (2016). 
[2] C. Semprebon, G. McHale, and H. Kusumaatmaja, "Apparent contact angle and contact angle hysteresis on liquid infused surfaces", Soft Matter 13, 101-110 (2017).

[3] M. Kobayashi, Y. Terayama, H. Yamaguchi, M. Terada, D. Murakami, K. Ishihara, and A. Takahara, "Wettability and antifouling behavior on the surfaces of superhydrophilic polymer brushes", Langmuir 28, $7212-7222$ (2012).

[4] G. Hagen, "Über die bewegung des wassers in engen zylindrischen rohren", Annalen der Physik und Chemie 46, 423-442 (1839).

[5] J. L. Poiseuille, "Recherches expérimentales sur le mouvement des liquides dans les tubes de très-petits diamètres", Comptes rendus de l'Académie des sciences 11, 961-967, 1041-1048 (1840).

[6] H. Darcy, Les Fontaines Publiques de la Ville de Dijon (Victor Dalmont, Paris, Paris) (1856).

[7] C. Marle, Multiphase Flow in Porous Media (Gulf Publishing Company, Houston, Texas) (1981).

[8] S. E. Buckley and M. C. Leverett, "Mechanism of fluid displacement in sands", Trans. AIME 146, 107-116 (1942).

[9] K.-A. Lie, An introduction to reservoir simulation using MATLAB: User guide for the Matlab Reservoir Simulation Toolbox (MRST) (SINTEF ICT, December 2016, http://www.sintef.no/Projectweb/MRST/Publications, SINTEF ICT, Department of applied mathematics, Oslo, Norway) (2016).

[10] M. Sahimi, Flow and Transport in Porous Media and Fractured Rock, 519-573 (Wiley-VCH Verlag GmbH and Co. KGaA, Weinheim, Germany) (2011).

[11] P. C. Carman, Flow of gases through porous media, 1-18 (Academic Press, Cambridge, Massachusetts) (1956). 


\section{Appendix C}

\section{C.1 Membrane characterization}

The PVDF membrane is characterized using scanning electron microscopy (SEM) (JEOL $5600 \mathrm{LV}$ ) and capillary flow porometer (Porolux-1000). The SEM images of top, bottom and cross section of the membrane are shown in Figure C.1.

Capillary flow porometry measurement on PVDF membrane is done by pushing nitrogen gas through the membrane infused with a low surface tension liquid, i.e. Fluorinert FC-43, at different pressure values. The corresponding gas flow rate is measured simultaneously. Figure C.2(a) shows the nitrogen gas flow rate as a function of pressure for the PVDF membrane. This measurement is conducted in two runs: in the first run, the so called wet curve, a sudden increase in gas flow rate is observed which corresponds to the pressure where the biggest pores are opened (first bubble point (FBP)). In the second run as the liquid has been already pushed out, a linear behaviour between flow and pressure is obtained (dry curve). The point where wet and dry curves meet corresponds to the smallest pore size. The half-dry curve is also plotted where the flow values are half of the flow values of the dry curve. The crossing point of this curve and wet curve determines the mean flow pore size (MFP). The Young-Laplace equation (equation 1 in the paper) by considering total wetting $\left(\theta_{\mathrm{E}}=180^{\circ}\right)$ is used to relate pressure to the pore size. Based on the results of this measurement, the pore size distribution of the membrane can be obtained which is shown in Figure C.2(b). As can be seen in Figure C.2, the PVDF membrane has a narrow pore size distribution with an average pore radius of $1.78 \mu \mathrm{m}$ and size distribution of $0.14 \mu \mathrm{m}$ (full width at half $\max / 2$ ). 


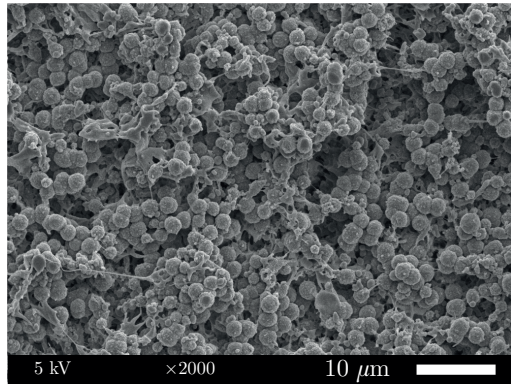

(a)

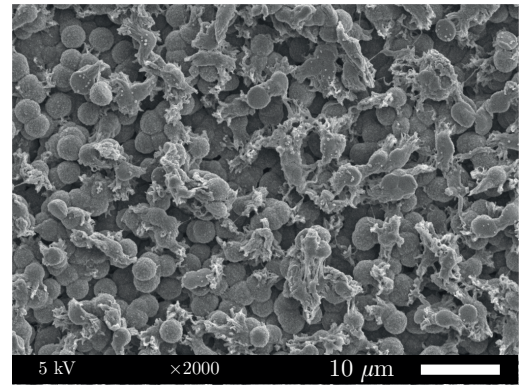

(b)

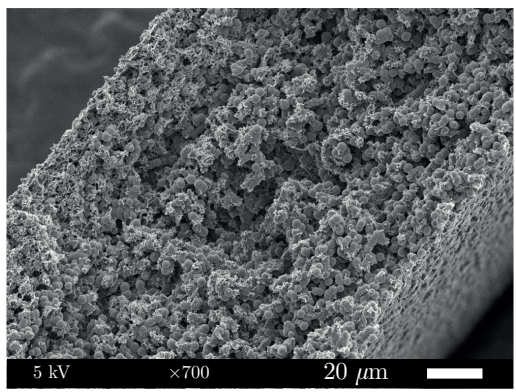

(c)

Figure C.1: Scanning electron microscopy (SEM) images of the PVDF membrane. (a) Top surface, (b) bottom surface, (c) cross section. 


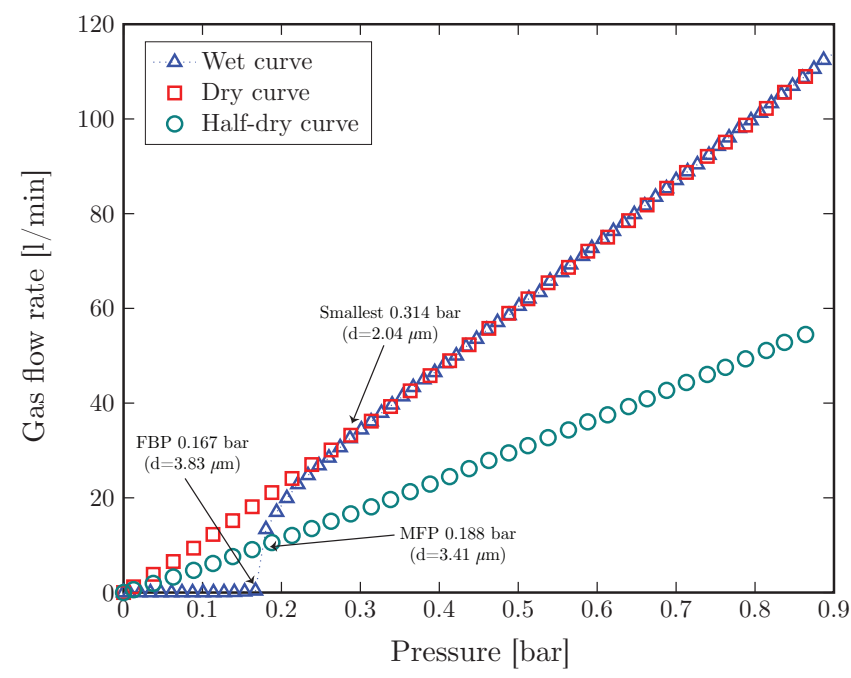

(a)

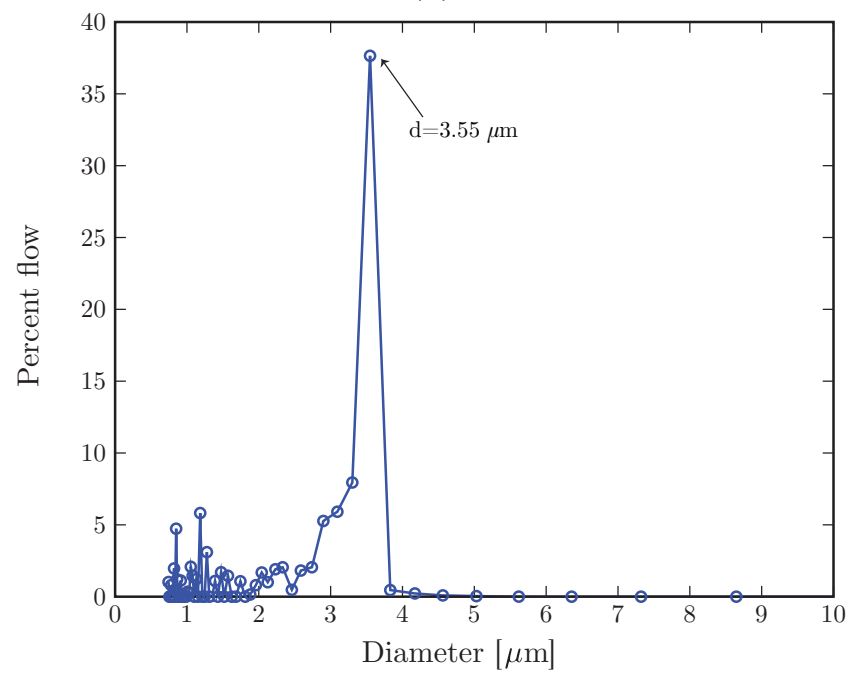

(b)

Figure C.2: Capillary flow porometry results of the PVDF membrane. (a) Flow rate of nitrogen gas as a function of pressure. The corresponding pressure values for the biggest pore size (first bubble point (FBP)), mean flow pore size (MFP), and smallest pore size are indiciated with arows. (b) Pore size distribution of the membrane. 
Table C.1: Physical properties of the oils (the values after \pm show the standard deviation). Absolute and Kinematic viscosity are measured at $20^{\circ} \mathrm{C}$ and density is measured at $24^{\circ} \mathrm{C}$. The interfacial tension value shows the one between two oils.

\begin{tabular}{lccccc}
\hline Oil & $\begin{array}{c}\text { Surface } \\
\text { tension } \\
{[\mathrm{mN} / \mathrm{m}]}\end{array}$ & $\begin{array}{c}\text { Interfacial } \\
\text { tension } \\
{[\mathrm{mN} / \mathrm{m}]}\end{array}$ & $\begin{array}{c}\text { Absolute } \\
\text { viscosity } \\
{[\mathrm{mPa} \mathrm{s}]}\end{array}$ & $\begin{array}{c}\text { Kinematic } \\
\text { viscosity } \\
{\left[\mathrm{mm}^{2} / \mathrm{s}\right]}\end{array}$ & $\begin{array}{c}\text { Density } \\
{\left[\mathrm{g} / \mathrm{cm}^{3}\right]}\end{array}$ \\
\hline Krytox 101 & $16.3 \pm 0.13$ & $8.7 \pm 0.08$ & $25 \pm 0.1$ & 13.5 & $1.85 \pm 0.01$ \\
Hexadecane & $25.5 \pm 0.34$ & $8.7 \pm 0.08$ & $3.2 \pm 0.13$ & 4.4 & $0.727 \pm 0.0021$ \\
\hline
\end{tabular}

Table C.2: Physical properties of water and the surfactant solutions (the values after \pm show the standard deviation and density is measured at $24^{\circ} \mathrm{C}$ ).

\begin{tabular}{ccccc}
\hline $\begin{array}{c}\text { Aqueous } \\
\text { solutions }\end{array}$ & $\begin{array}{c}\text { Surface tension } \\
{[\mathrm{mN} / \mathrm{m}]}\end{array}$ & $\begin{array}{c}\text { Interfacial tension } \\
\text { with K101 }[\mathrm{mN} / \mathrm{m}]\end{array}$ & $\begin{array}{c}\text { Interfacial tension } \\
\text { with hexa }[\mathrm{mN} / \mathrm{m}]\end{array}$ & $\begin{array}{c}\text { Density } \\
{\left[\mathrm{g} / \mathrm{cm}^{3}\right]}\end{array}$ \\
\hline MQ water & $72.7 \pm 0.67$ & $54.7 \pm 0.16$ & $28.6 \pm 0.27$ & $0.997 \pm 0.0012$ \\
CTAB 10 & $70.3 \pm 0.17$ & $47.7 \pm 0.67$ & $12.2 \pm 0.08$ & $0.955 \pm 0.0009$ \\
CTAB 50 & $49.9 \pm 0.33$ & $29.8 \pm 0.14$ & $3.3 \pm 0.06$ & $0.997 \pm 0.0009$ \\
SDS 10 & $68.8 \pm 0.22$ & $47.6 \pm 0.67$ & $25.5 \pm 0.15$ & $0.941 \pm 0.0015$ \\
SDS 50 & $50.6 \pm 0.30$ & $31.8 \pm 0.25$ & $12.8 \pm 0.13$ & $0.867 \pm 0.0022$ \\
\hline
\end{tabular}

\section{C.2 Physical properties of surfactant solutions and oils}

The physical properties of the used oils, i.e., Krytox 101 and hexadecane as well as the surfactant solutions are shown in Tables C.1 and C.2 respectively. The density values are measured using a gas pycnometer (AccuPyc II 1340 Pycnometer) at $24{ }^{\circ} \mathrm{C}$. The pendant drop method is used to measure surface tension and interfacial tension values using a contact angle Goniometer (Dataphysics OCA20). Drop shape analysis was used for this measurement using the software of Dataphysics OCA20. A modular compact Rheometer (Anton Paar MCR502) is used for measuring absolute viscosity values of the oils using a cone plate geometry (CP25-2). In all tables the standard deviation is reported for at least 6 measurements except for density which is reported for 30 measurements.

\section{C.3 Pictures of the fabricated emulsions}

To better distinguish between oil and water in permeation experiments, hexadecane was dyed red using Sudan IV before emulsion fabrication. The pic- 
ture of the corresponding prepared emulsion is shown in Figure C.3(a). In order to observe the fabricated emulsions under laser scanning confocal microscope (LSCM), hexadecane was dyed using a fluorescent dye (Perylene) (Figure C.3(b) $)$. The three-dimensional image of the emulsion obtained using LSCM is shown in Figure C.3(c). Pictures of the prepared emulsions, filtration set-up and all the permeates are taken with mobile phone (Huawei Mate 10 Lite).

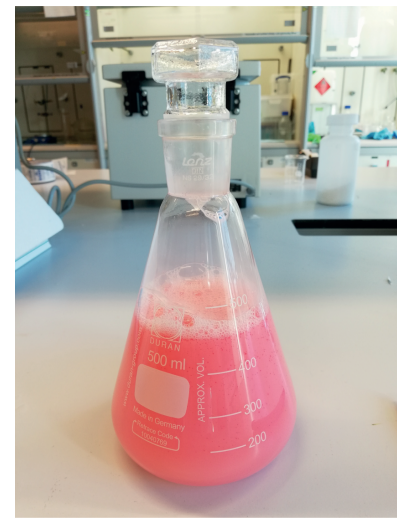

(a)

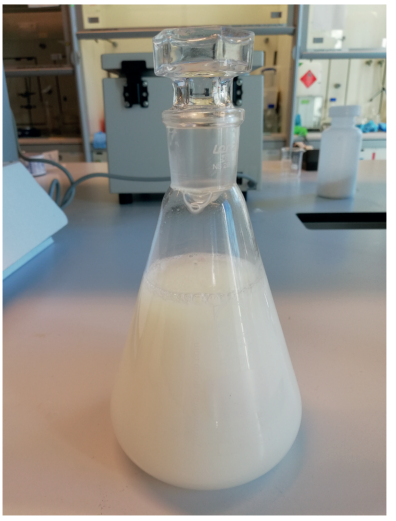

(b)

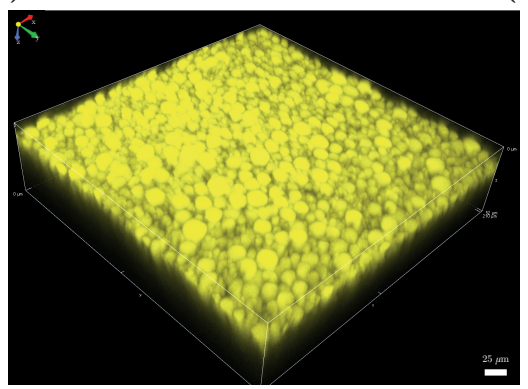

(c)

Figure C.3: Pictures of the prepared emulsions made by dispersing 5 wt.\% hexadecane in SDS solution with concentration of 10\% CMC (SDS 10) using (a) Sudan IV as the dye and (b) fluorescent Perylene as the dye in hexadecane. (c) Three-dimensional image of the emulsion shown in (b) using LSCM. 


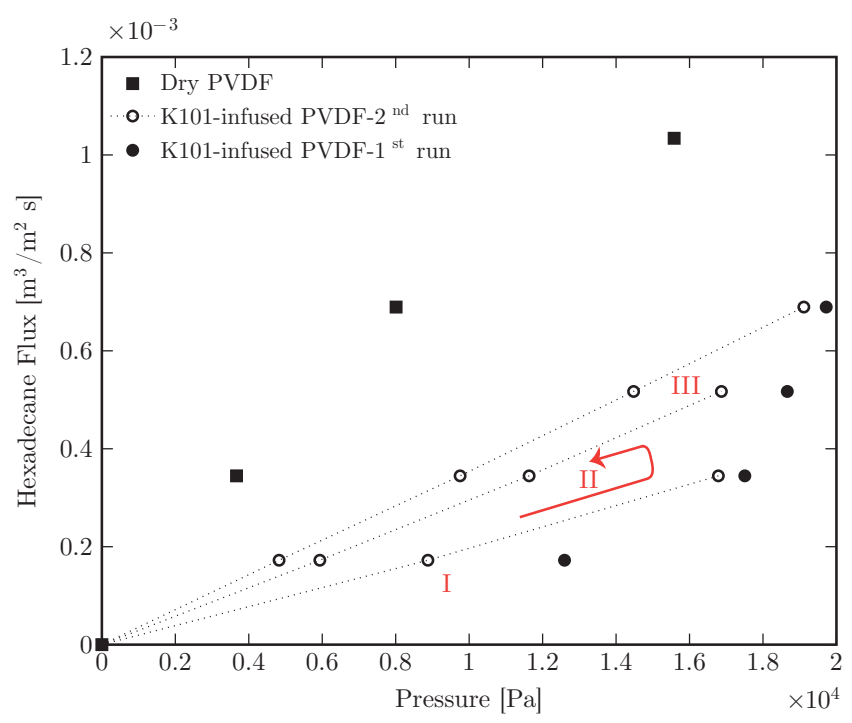

Figure C.4: Successive liquid-liquid displacement (LLD) experiment in a flux controlled mode on Krytox 101-infused PVDF membrane using hexadecane. LLD is done in three different cycles (I-III) and each cycle consists of a $1^{\text {st }}$ (filled symbols) and a $2^{\text {nd }}$ run (open symbols). In each run flux is increased step-wise from zero up to a certain maximum value and pressure is measured correspondingly. A typical sequence of the measurement is shown for cycle II.

\section{C.4 Liquid-liquid displacement (LLD) analysis of hexadecane through liquid-infused membrane}

In order to better understand the retention of the infusion liquid in the liquidinfused membrane after hexadecane is pushed through the membrane, liquidliquid displacement (LLD) experiment was done. The LLD experiment is performed in three different cycles. Each cycle is carried out in a flux-increasing mode, which is done twice starting from zero up to a certain flux value. In each run, the flux is increased step-wise. At each step, flux is kept constant for $100 \mathrm{~s}$ and the pressure is reported for the last $40 \mathrm{~s}$ of each step (see Chapter Three 1]. The result is shown in Figure C.4.

In order to check for the presence of the infusion liquid in the membrane after the experiment, the obtained results are compared with the results of the dry membrane (see Figure C.4). The permeability of dry as well as liquidinfused membranes is calculated using Darcy's law 2 . 
Table C.3: Comparison of permeability and fraction of active pores for three different cycles of liquid infused membrane and for the dry case.

\begin{tabular}{ccc}
\hline Membrane & $\begin{array}{r}\text { Permeability }(\kappa) \\
\left(\text { Darcy }^{*}\right)\end{array}$ & $\begin{array}{c}\text { Estimated fraction } \\
\text { of active pores }\end{array}$ \\
\cline { 2 - 3 } SLIM-cycle 1 & $8.91 \times 10^{-3}$ & 0.31 \\
SLIM-cycle 2 & $1.33 \times 10^{-2}$ & 0.47 \\
SLIM-cycle 3 & $1.56 \times 10^{-2}$ & 0.55 \\
Dry & $2.85 \times 10^{-2}$ & 1 \\
\cline { 2 - 3 } & \\
& \\
& \\
& \\
& \\
&
\end{tabular}

Here and in the following, $Q$ is the volumetric flow of the permeating fluid (in this case hexadecane) $\left(\mathrm{m}^{3} / \mathrm{s}\right), \kappa$ is the permeability $\left(\mathrm{m}^{2}\right), A$ is the total area of the membrane $\left(\mathrm{m}^{2}\right), \mu$ is the viscosity of the displacing fluid ( $\left.\mathrm{Pa} \mathrm{s}\right)$, $\frac{d p}{d x}$ is the pressure gradient across the membrane thickness $(\mathrm{Pa} / \mathrm{m}), r$ is the mean pore radius $(\mathrm{m})$, and $\phi$ is porosity. A simple model is then used to relate permeability to porosity $\phi$, namely Appendix B [1]

$$
\kappa=\frac{\phi r^{2}}{24} .
$$

The calculated porosity is a measure of opened and active pores for hexadecane transport in the membrane. The results of the calculated permeability and the estimated fraction of the active pores are shown in Table C.3 (membrane thickness and water viscosity are considered as $134 \mu \mathrm{m}$ and $1 \mathrm{mPa}$ s respectively). This fraction is the ratio between the calculated porosity for the liquid-infused membrane in each cycle and that of the dry membrane. The permeability of the liquid-infused membrane increases in each cycle, revealing that new pores are opened for hexadecane transport. The lower permeability values of liquid-infused membrane in comparison with dry membrane suggests incomplete removal of the infusion liquid with around $45 \%$ retained infusion liquid in the membrane. For more information on this kind of analysis, we refer the reader to our previous work [1] (Chapter Three. 


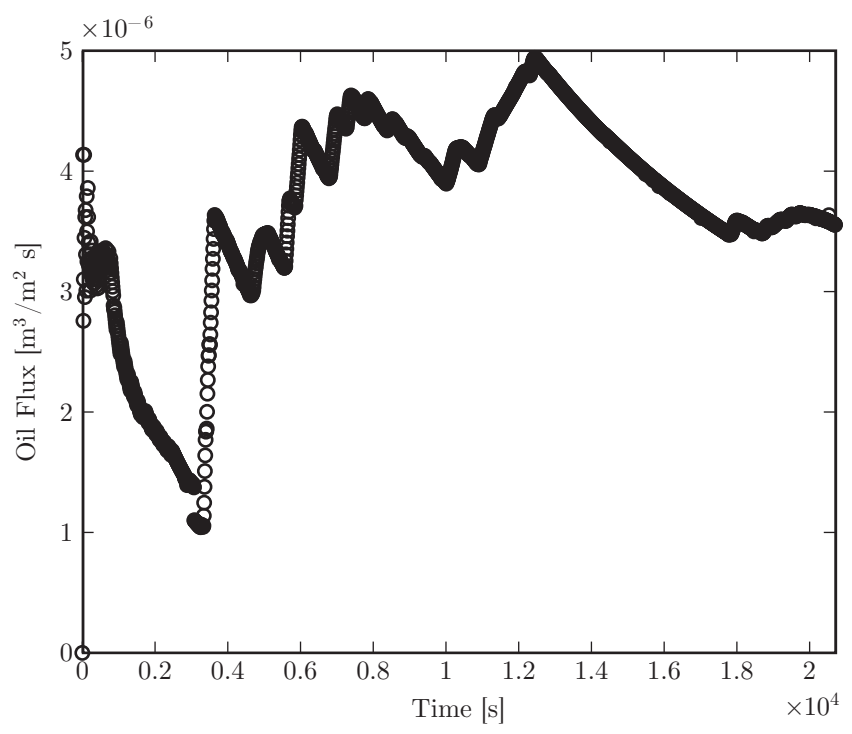

Figure C.5: Flux of the discontinuous permeated oil as a function of time during dead-end filtration for oil permeation from $\mathrm{O} / \mathrm{W}$ emulsion ( $5 \mathrm{wt} . \%$ hexadecane in SDS 10) through K101-infused membrane.

\section{C.5 Measurement of permeated oil during filtration experiments}

The flux of permeated oil through K101-infused membrane was measured for the emulsion made with SDS 10 (Figure C.5). The points where there are an increase in flux correspond to refreshing of the feed chamber. Flux decrease in this case is caused by a decrease in oil droplet concentration. The observed oil flux strongly depends on the frequency of refreshing the feed chamber as well as the oil concentration. By considering an average flux of $0.4 \times 10^{-5} \mathrm{~m}^{3} / \mathrm{m}^{2} \mathrm{~s}$, a TMP of 0.1 bar, an oil viscosity of $3.2 \mathrm{mPa}$ s and membrane thickness of around $134 \mu \mathrm{m}$, the oil permeability can be calculated as $1.74 \times 10^{-4}$ Darcy based on Darcy's law (Equation C.1). This value is lower than the permeability which was measured in LLD analysis in the first cycle (see Table C.3). This can be explained based on the fewer active (opened) pores in the emulsion separation experiments compared to that in the first cycle of LLD experiments. 


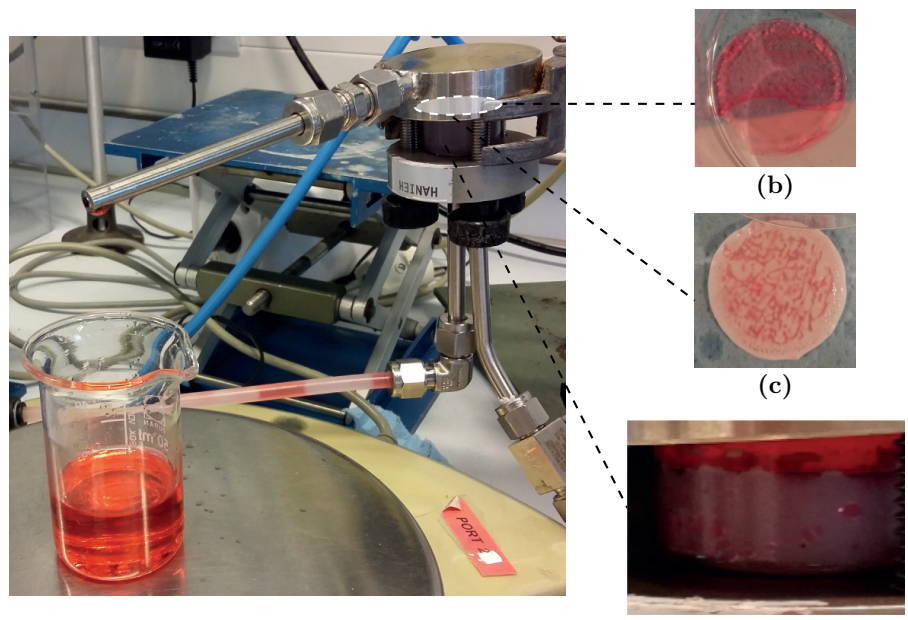

(a)

(d)

Figure C.6: Pictures of (a) Filtration set-up used up side down for oil permeation from $\mathrm{O} / \mathrm{W}$ emulsions, (b) dry membrane, (c) liquid-infused membrane after oil permeation experiments and (d) coalescence of oil droplets on the membrane surface and formation of an oil layer.

\section{C.6 Pictures of filtration set-up and membranes af- ter oil permeation}

The picture of the filtration set-up while permeating the oil phase is shown in Figure C.6. The insets (b) and (c) are respectively showing the dry and liquid-infused membranes after oil permeation experiment. As explained in Chapter Three dry membrane is completely infused with hexadecane after oil permeation. However, due to the presence of retained Krytox 101 oil in the liquid-infused membrane after hexadecane permeation (45\%) (see section Liquid-liquid displacement (LLD) analysis), only some traces of hexadecane are observed in the membrane afterwards.

\section{C.7 Permeate pictures of different $\mathrm{O} / \mathrm{W}$ emulsions from dry and liquid-infused membranes}

The permeate pictures of the emulsion made by dispersing 5 wt. $\%$ hexadecane in low concentration of CTAB surfactant solution (10\% CMC) from dry and liquid-infused membranes are shown in Figure C.7. As it is evident, no water 
droplets are observed showing selective oil permeation and retention of water by both membranes.

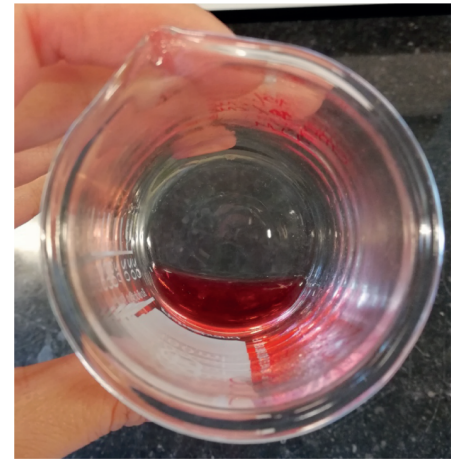

(a)

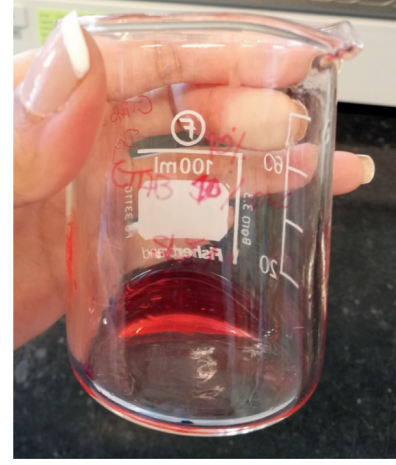

(b)

Figure C.7: Permeate pictures of the emulsion made by dispersing 5 wt.\% hexadecane in low concentration of CTAB surfactant solution (10\% CMC) from (a) dry membrane and (b) liquid-infused membrane.

The permeate pictures of the emulsion made with high concentration of CTAB surfactant solution $(50 \%$ CMC) from both membranes are depicted in Figure C.8. Unwanted permeated water can be clearly observed. The amount of permeated water from liquid-infused membrane is approximately half of that from dry membrane.

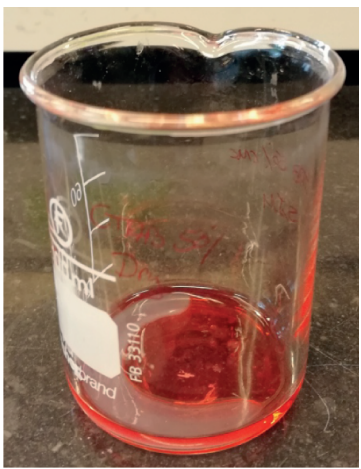

(a)

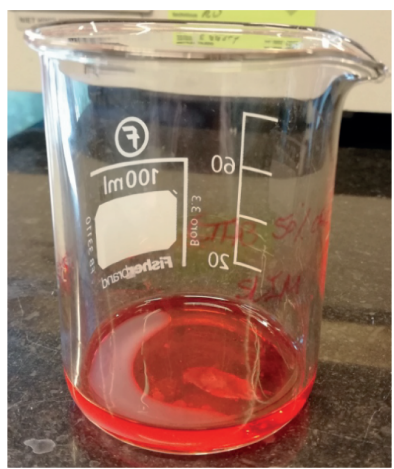

(b)

Figure C.8: Permeate pictures of the emulsion made by dispersing 5 wt. $\%$ hexadecane in high concentration of CTAB surfactant solution (50\% CMC) from (a) dry membrane and (b) liquid-infused membrane. 
The permeate pictures of the emulsions containing $10 \%$ and $50 \%$ of SDS solutions from dry and liquid-infused membranes are illustrated in Figure C.9. As expected, no water droplets are observed in permeates of emulsion with low concentration of SDS from both membranes. At high concentration of SDS solution, small amount of water is permeated from liquid-infused membrane. However, the amount of permeated water from dry membrane is approximately 4 times higher showing improved performance of liquid-infused membrane in the same experimental conditions.

\section{C.8 Droplet size distribution of prepared emulsions}

Dynamic light scattering was used to measure the oil droplet size distribution of all the prepared emulsions using a Malvern Mastersizer 2000 particle size analyzer. The number and volume-averaged droplet size distribution of the emulsions made with low and high concentration CTAB surfactant solutions are shown in Figures C.10(a) and C.10(b). The number and volume-averaged droplet size distribution of the emulsion made with high concentration SDS solution (50\% CMC) is shown in Figure C.10(d).

\section{C.9 Surfactant adsorption on the liquid-lined pores in hexadecane-infused membranes}

As surfactant solution is pushed through the membrane pore, the concentration of the surfactant in the pore is lowered by the surfactant adsorption on the liquid-lined pore. The equilibrium between surfactant concentration in the pore $\left(C_{P}\right)$ and that of the bulk $\left(C_{0}\right)$ can be written as

$$
C_{0} \times V=C_{P} \times V+\Gamma \times A .
$$

Here, $\Gamma$ is the surfactant adsorption on the pore wall $\left(\mathrm{mol} / \mathrm{m}^{2}\right), V$ is the volume $\left(\pi r^{2} L\right)\left(\mathrm{m}^{3}\right)$ and $A$ is the surface area $(2 \pi r L)\left(\mathrm{m}^{2}\right)$ of the pore. For simplicity, the pore is considered to be cylindrical with pore radius $r(\mathrm{~m})$ and pore length $L(\mathrm{~m})$, and $C_{P}$ is taken as the average concentration inside the pore. Therefore, Equation C.3 can be simplified as

$$
C_{0}=C_{P}+\left(\frac{2}{r}\right) \Gamma .
$$

In order to have a better understanding regarding the relation between $C_{0}$ and $C_{P}$, surfactant adsorption on the liquid-lined pore, i.e., $\Gamma$, should be 


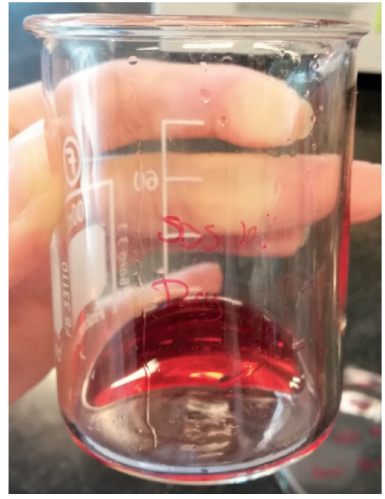

(a)

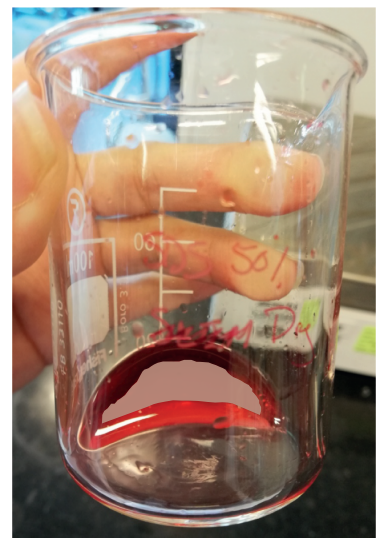

(c)

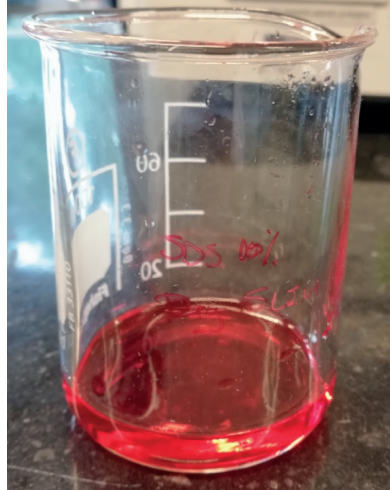

(b)

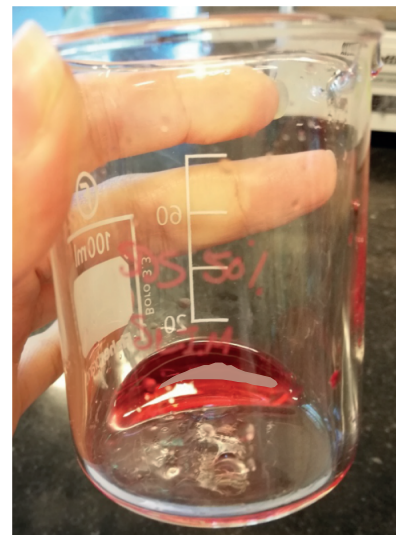

(d)

Figure C.9: Permeate pictures of the emulsion made by dispersing 5 wt.\% hexadecane in low concentration of SDS surfactant solution (10\% CMC) from (a) dry membrane and (b) liquid-infused membrane. Permeate pictures of the emulsion made with high concentration of SDS surfactant solution (50\% CMC) from (c) dry membrane and (d) liquid-infused membrane (for visualization purposes, the water area is schematically demonstrated). 


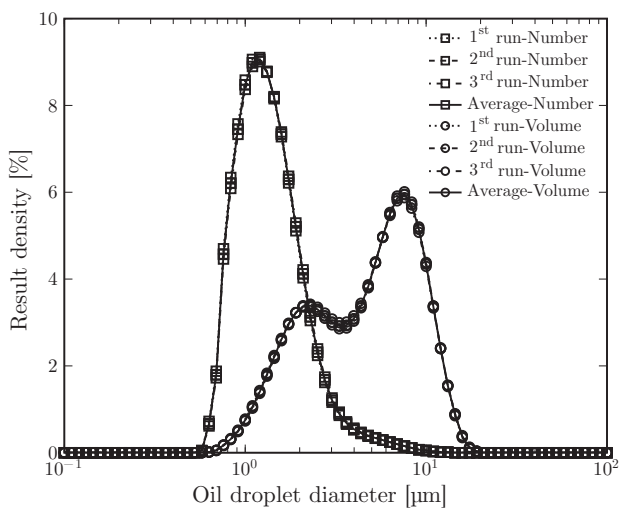

(a)

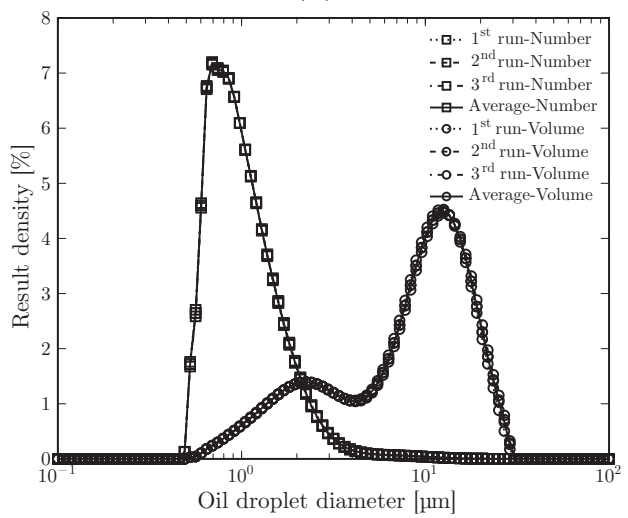

(c)

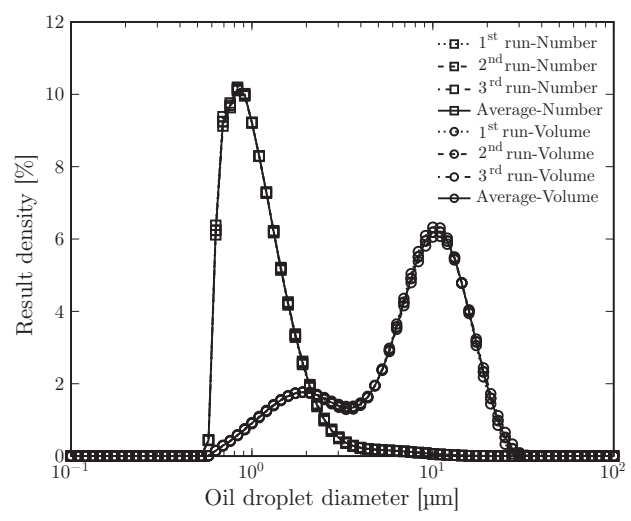

(b)

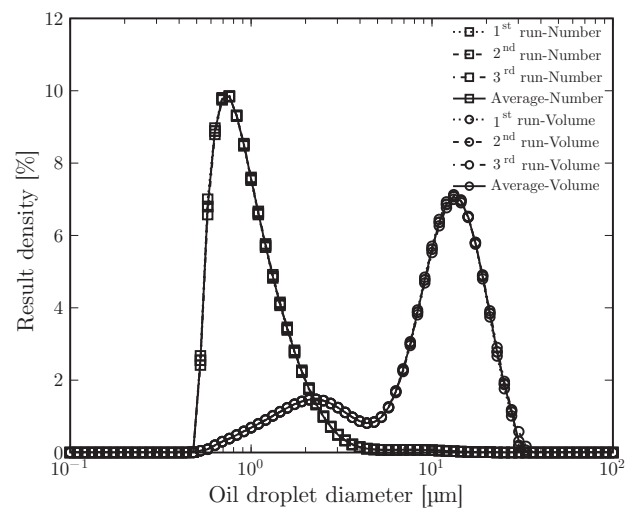

(d)

Figure C.10: Number and volume-averaged droplet size distribution of the emulsions made with (a) $10 \% \mathrm{CMC}$ of CTAB, (b) $50 \%$ CMC of CTAB, (c) $10 \%$ CMC of SDS and (d) $50 \%$ CMC of SDS surfactant solutions. 
determined as a function of the concentration. Surfactant adsorption can be calculated from the change in surface tension by changing the surfactant concentration. This relation is based on the Gibbs equation

$$
\Gamma=-\frac{1}{R T} \frac{d \gamma}{d \ln (C)}=-\frac{C}{R T} \frac{d \gamma}{d C},
$$

where $\gamma$ is the surface tension $(\mathrm{mN} / \mathrm{m}), C$ is the surfactant concentration $\left(\mathrm{mol} / \mathrm{m}^{3}\right), R$ is the universal gas constant $(\mathrm{J} / \mathrm{mol} \mathrm{K})$, and $T$ is the absolute temperature $(\mathrm{K})[3]$.

The adsorption was calculated for surfactant solutions pushing through hexadecane-infused membranes by measuring the interfacial tension (IFT) values between hexadecane and series of surfactant solutions with different concentrations using pendant drop method. The surfactant concentration was ranging from 0 to $12.15 \mathrm{~mol} / \mathrm{m}^{3}$ with $0.81 \mathrm{~mol} / \mathrm{m}^{3}$ steps for SDS. Series of CTAB surfactant solutions were prepared with different concentrations from 0 to $0.92 \mathrm{~mol} / \mathrm{m}^{3}$ with steps of $0.092 \mathrm{~mol} / \mathrm{m}^{3}$. Figures C.11(a) and C.11(c) show the corresponding IFT values as a function concentration for SDS and CTAB solutions respectively. By plotting IFT as a function of log of concentration (Figures C.11(b) and C.11(d) , one can find the critical micelle concentration (CMC) for SDS and CTAB respectively. CMC corresponds to the point where there is no change in the surfactant adsorption (slope of the line is zero). The CMC value is $0.74 \mathrm{~mol} / \mathrm{m}^{3}$ for CTAB which is in the range reported in the literature $\left(0.7-0.94 \mathrm{~mol} / \mathrm{m}^{3}\right)$ [4] and $8.1 \mathrm{~mol} / \mathrm{m}^{3}$ for SDS which is in good agreement with what has been reported in the literature [7, 8.

The IFT results before CMC value were fitted to Szyszkowski equation where the relation between IFT and surfactant concentration is defined (Equation 4.2 in Chapter Three. The fitting results for SDS and CTAB surfactant solutions are respectively shown in Figures C.12(a) and C.12(b). The corresponding values of the fitting parameters $a$ and $b$ are shown in Table 4.2 in Chapter Three.

Differentiation of Szyszkowski equation and substitution in the Gibbs equation (Equation C.5) gives the Szyszkowski-Langmuir adsorption isotherm which defines the relation between adsorption and surfactant concentration [9]

$$
\Gamma=\frac{\Gamma_{0} \alpha C}{1+\alpha C} .
$$

Here, $\Gamma_{0}=b \gamma^{*} / R T$ and $\alpha=1 / a$ where $R$ is the universal gas constant (8.314 $\mathrm{J} / \mathrm{mol} \mathrm{K}$ ) and $T$ is the absolute temperature $(293 \mathrm{~K})$. 


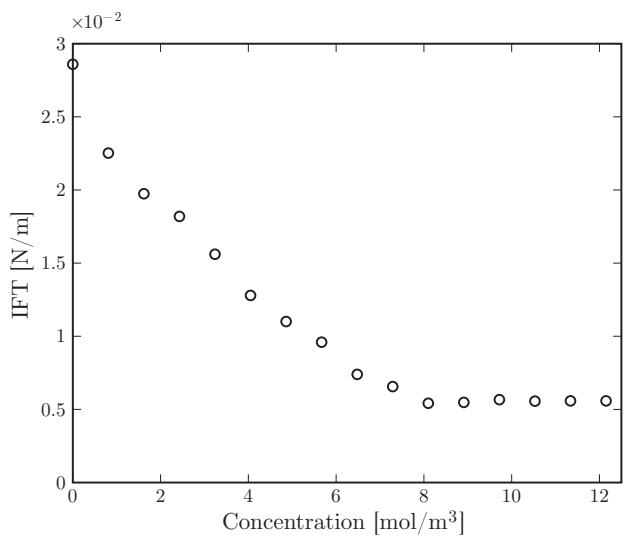

(a)

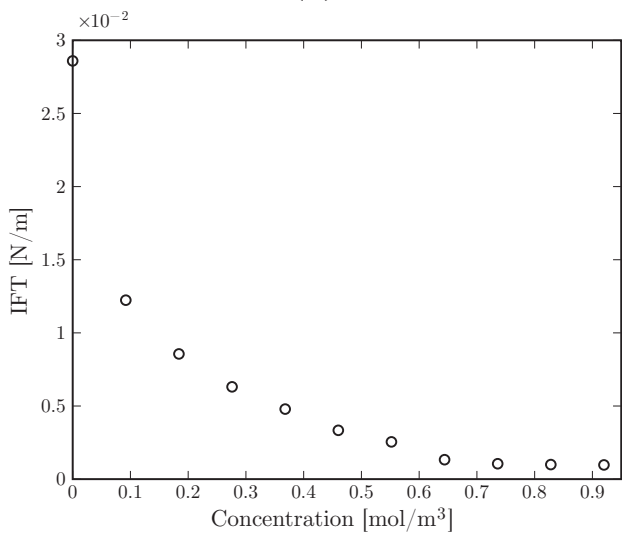

(c)

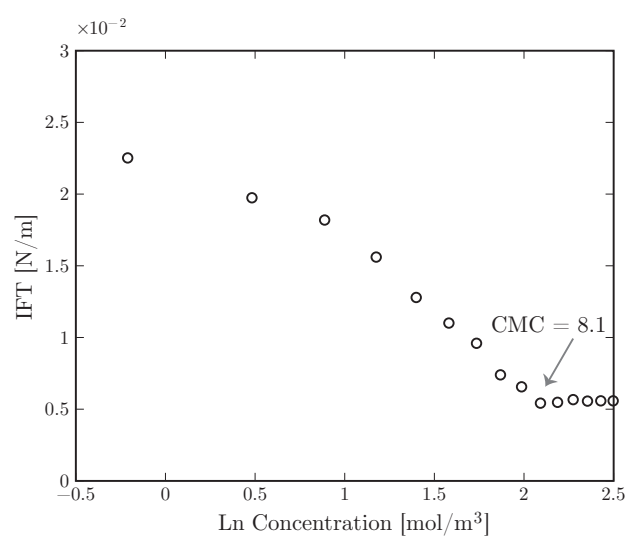

(b)

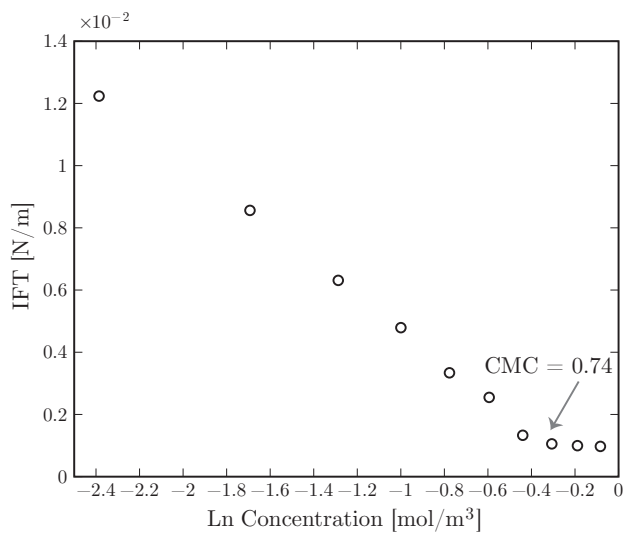

(d)

Figure C.11: (a) Interfacial tension (IFT) between pure hexadecane and SDS solutions with different concentrations. (b) IFT as a function of logarithm of SDS concentration showing the CMC of the surfactant in $\mathrm{mol} / \mathrm{m}^{3}$. (c) The same plot as (a) and (d) the same plot as (b) for CTAB surfactant solutions. 


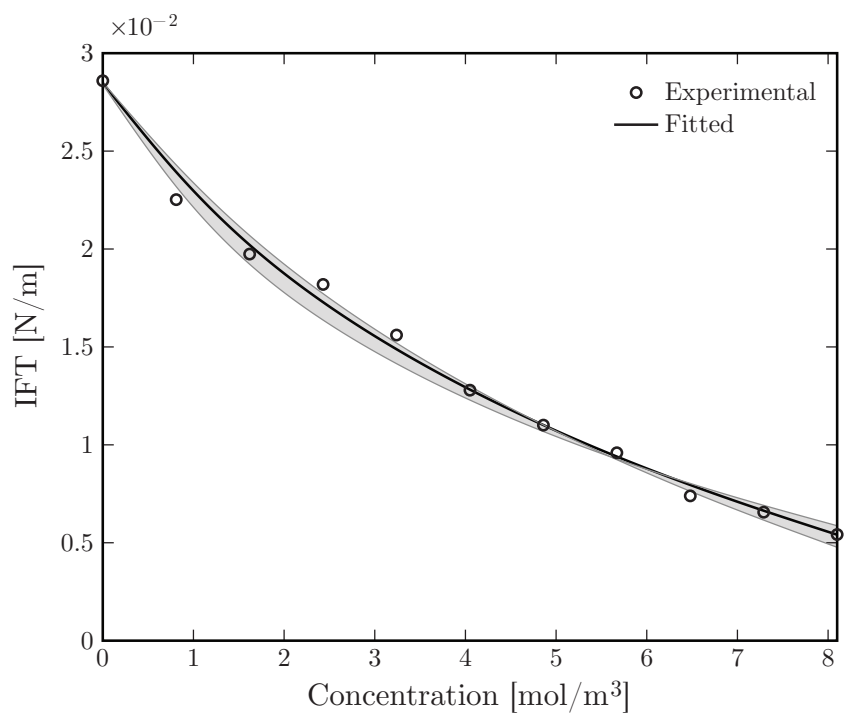

(a)

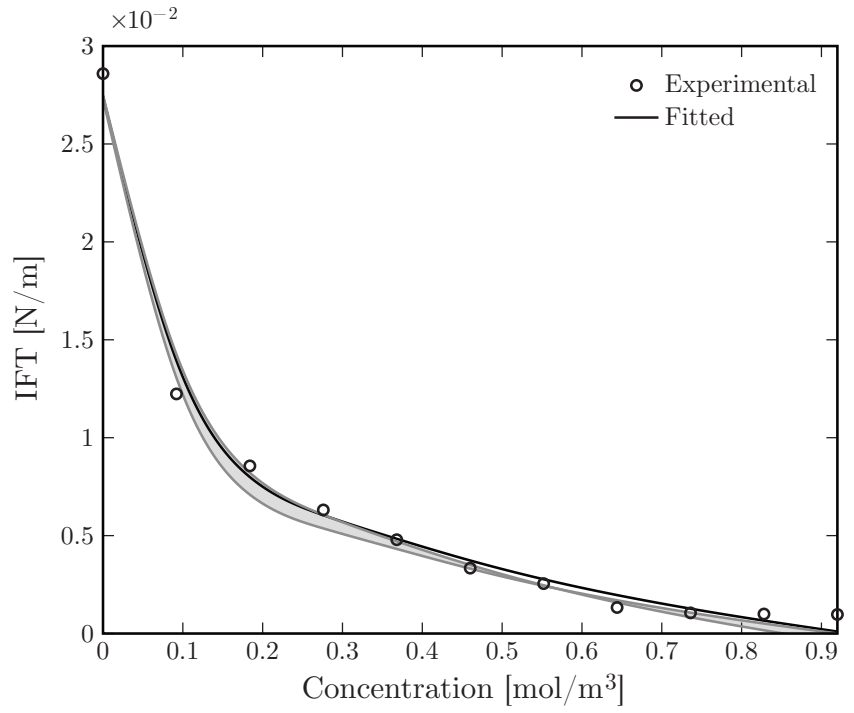

(b)

Figure C.12: Fitting of IFT results between hexadecane and surfactant solutions based on Szyszkowski equation (Equation 4.2 in Chapter Three for (a) SDS soluion and (b) CTAB solution (the shaded area bounds the upper and lower confidence interval limits of the corresponding fitting). 
By considering surfactant concentration in the pore $\left(C_{P}\right)$ in SzyszkowskiLangmuir isotherm (Equation C.6) and substituting in to Equation C.4 the relation between $C_{0}$ and $C_{P}$ can be defined as

$$
C_{0}=C_{P}+\frac{2 \Gamma_{0}}{\left(\frac{1}{C_{P} \alpha}+1\right) r}
$$

Solving Equation C.7 for $C_{P}$ gives

$$
\alpha C_{P}^{2}+\left(1+\frac{2 \Gamma_{0} \alpha}{r}-\alpha C_{0}\right) C_{P}-C_{0}=0
$$

By knowing $\alpha$ and $\Gamma_{0}$, the equation which relates surfactant concentration in the bulk $\left(C_{0}\right)$ to surfactant concentration in the pore $\left(C_{P}\right)$ can be solved (Equation C.8). Figures C.13(a) and C.13(b) show the relation between $C_{0}$ and $C_{P}$ for SDS and CTAB surfactant solutions and different values of pore radius respectively.

The relation between $C_{0}$ and $C_{P}$ highly depends on the pore radius. For a small pore radius $(0.1 \mu \mathrm{m})$, significant amount of surfactant adsorbs on the liquid-lined pore, i.e., liquid-liquid interface between surfactant solution and hexadecane, leads to a very low surfactant concentration in the pore $\left(C_{P}\right)$. This effect for larger pore radii is less pronounced. The average pore radius of the membrane used in this work is approximately $2 \mu \mathrm{m}$ (see Figure C.2(b) resulting in some decrease in surfactant concentration inside the pores. Decrease in surfactant concentration leads to an increase in interfacial tension which can correspondingly increase the LEP. The change in LEP though highly depends on the pore curvature radius as well (see Equation 4.3 in Chapter Three which relates LEP to surfactant concentration and pore radius). The corresponding curvature radii $r$ were found by considering the solution of $C_{P}$ in to Equation 4.3 as the surfactant concentration

$\Delta P=\frac{2 \gamma^{*}}{r}\left[1-(b) \times \ln \left(1-\frac{1}{2}\left(\left(1+\frac{2 \Gamma_{0}-C_{0} r}{a r}\right)-\sqrt{\left(1+\frac{2 \Gamma_{0}-C_{0} r}{a r}\right)^{2}+\frac{4 C_{0}}{r}}\right)\right)\right]$

and fitting to the experimental LEP values using least square method in MATLAB.

The fitted results of LEP using both Equations (Equation 4.3 in Chapter Three and Equation C.9 for SDS solution through hexadecane-infused membrane are shown in Figure C.14. By including $C_{P}$ in Equation 4.3 (Equation C.9 , it is considered that the adsorption/desorption of the surfactant 


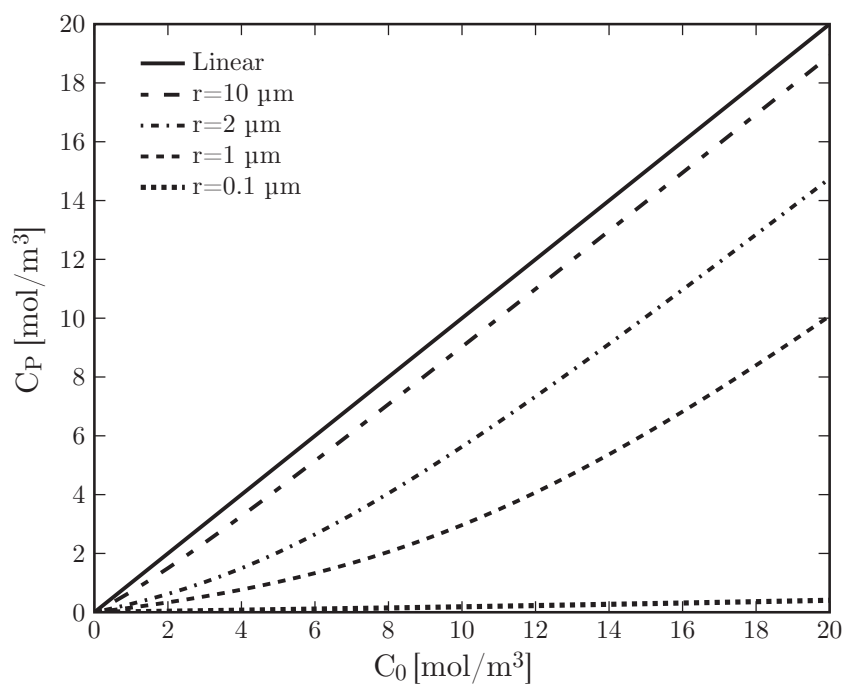

(a)

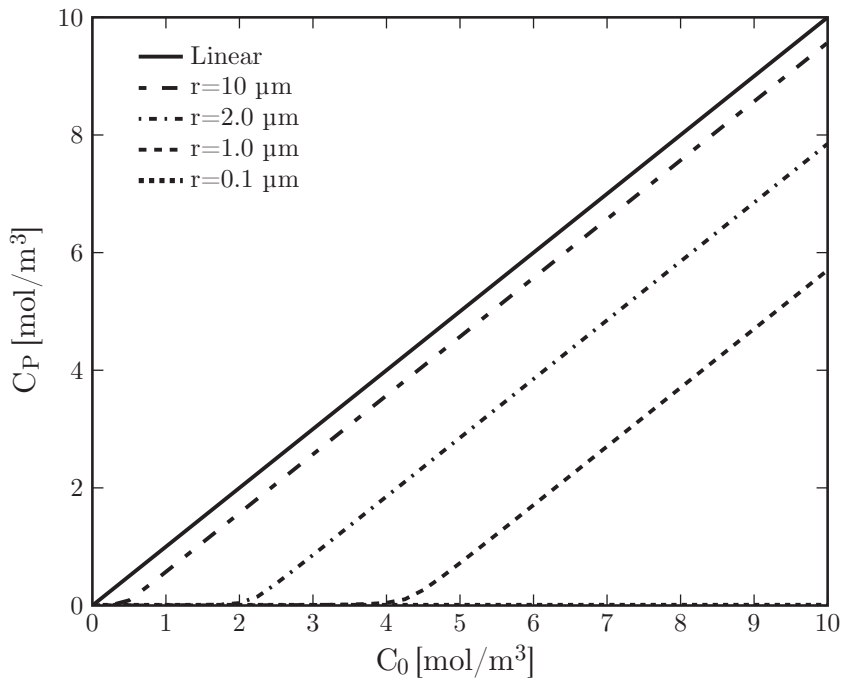

(b)

Figure C.13: Concentration of the surfactant in the pore $\left(C_{P}\right)$ as a function of surfactant concentration in the bulk $\left(C_{0}\right)$ based on Equation C.8 for (a) SDS and (b) CTAB solutions pushing through hexadecane-infused membrane. 


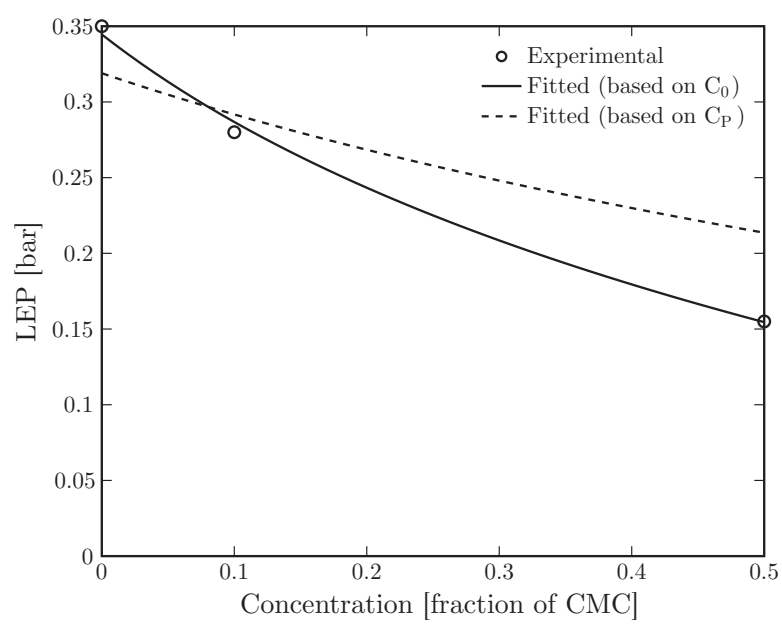

Figure C.14: LEP values of SDS solution through hexadecane-infused membrane. Solid and dashed lines are respectively showing the fitting results using Equation 4.3 in Chapter Three and Equation C.9

on the liquid-lined pore is fast enough to establish a continuous equilibrium. For SDS through hexadecane-infused membrane, fitted $r$ using Equation 4.3 is $1.66 \pm 9.25 \times 10^{-2} \mu \mathrm{m}$ and using Equation C.9 is $1.80 \pm 0.71 \mu \mathrm{m}$ (values after \pm show the confidence interval limits ((Upper CI-Lower CI)/2)). As it is evident in Figure C.14. Equation 4.3 can better predict the experimental LEP results confirming that surfactant adsorption on the liquid-lined pore is in a way that it is always in equilibrium with $C_{0}$. The same results were obtained for other surfactant solutions through hexadecane or K101-infused membranes.

\section{C.10 Surfactant adsorption on the liquid-lined pores in Krytox101-infused membranes}

The same analysis as before has been done to investigate surfactant adsorption on the liquid-lined pore for Krytox101-infused membranes. Figure C.15 shows the IFT between Krytox 101 and both surfactant solutions. The CMC is measured as $8.1 \mathrm{~mol} / \mathrm{m}^{3}$ and $0.92 \mathrm{~mol} / \mathrm{m}^{3}$ for SDS and CTAB surfactants respectively which is in good agreement with literature [4 8 .

The experimental results of IFT as a function of surfactant concentration are fitted to Szyszkowski equation (Equation 4.2 in Chapter Three) (Figure C.16). The obtained fitting parameter $a$ and $b$ are shown in Table 4.2 in 


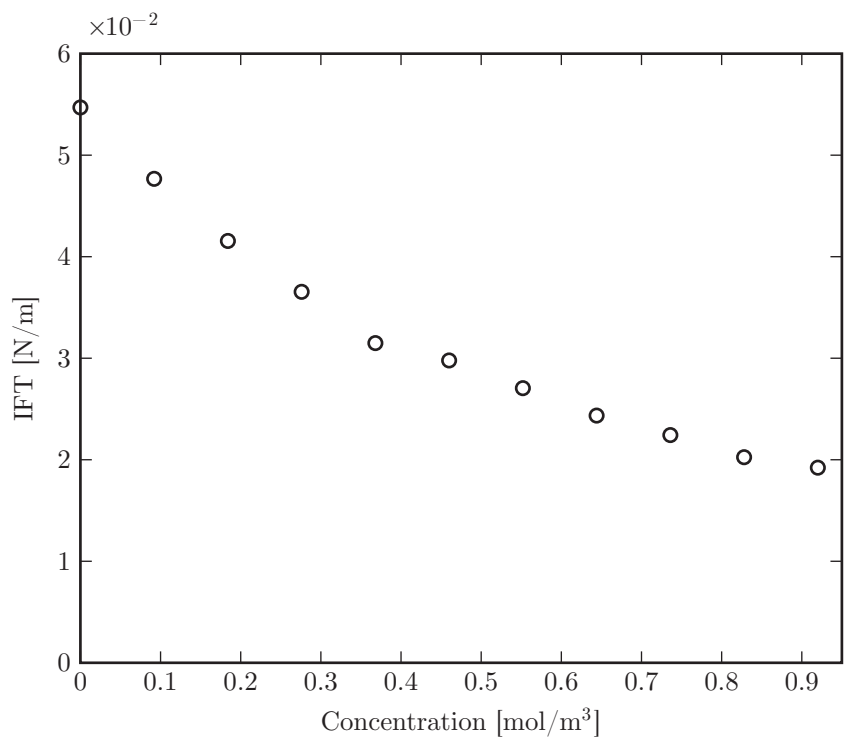

(a)

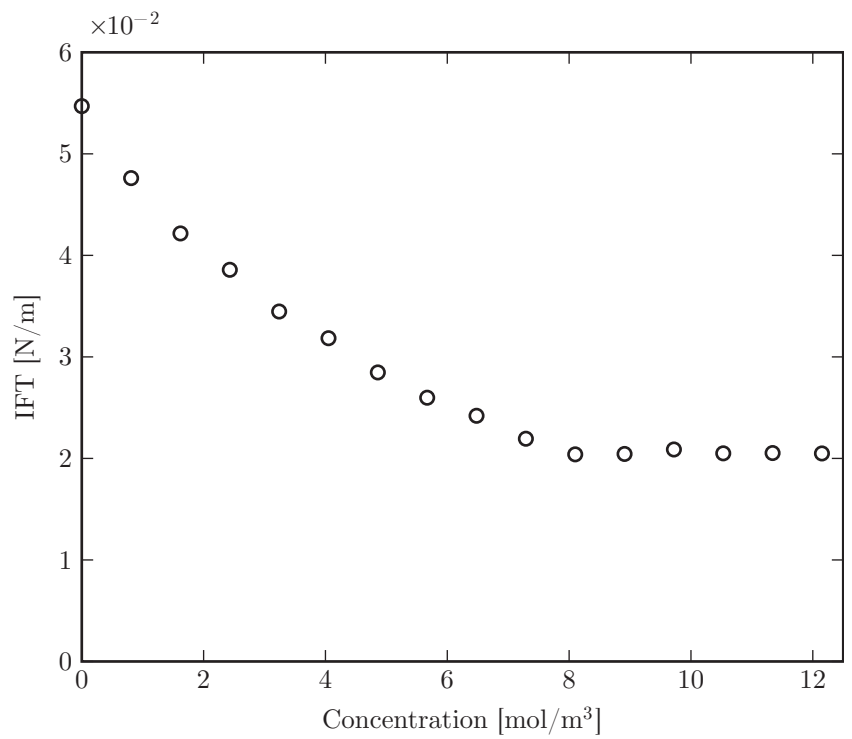

(b)

Figure C.15: Interfacial tension (IFT) between pure Krytox 101 and (a) CTAB solutions, (b) SDS solutions with different concentrations. 
the paper for both surfactant solutions. By knowing the fitting parameter, Equation C.8 can be solved. Figure C.17 shows the relation between $\left(C_{0}\right)$ and $\left(C_{P}\right)$ for CTAB and SDS solutions.

Comparison between the concentration of the surfactant solution in the pore $\left(C_{P}\right)$ and that of the bulk $\left(C_{0}\right)$ for both surfactants and liquid-infused membranes, i.e., hexadecane and $\mathrm{K} 101$, with pore radius of $2 \mu \mathrm{m}$ is shown in Figure C.18. As it is evident, at the same bulk concentration of the surfactant $\left(C_{0}\right)$, surfactant concentration in the pore $\left(C_{P}\right)$ is lower for K101-infused pore compared to that for hexadecane-infused one. The difference between $C_{P}$ values is more significant for CTAB surfactant solution (Figure C.18(a)).

It can be concluded that due to the surfactant adsorption on K101-infused pores compared to hexadecane-infused pores, the surfactant concentration is lower in the pore of the former due to enhanced adsorption. The lower surfactant concentration will lead to the higher interfacial tension which subsequently increases the corresponding LEP value. At the same operating pressure, less surfactant solution is expected to permeate through the K101-infused membrane compared to the hexadecane-infused membrane.

\section{References}

[1] H. Bazyar, P. Lv, J. A. Wood, S. Porada, D. Lohse, and R. G. H. Lammertink, "Liquid-liquid displacement in slippery liquid-infused membranes (slims)", Soft Matter 14, 1780-1788 (2018).

[2] H. Darcy, Les Fontaines Publiques de la Ville de Dijon (Victor Dalmont, Paris, Paris) (1856).

[3] G. T. Barnes and I. R. Gentle, Interfacial science: An introduction, 1 edition (Oxford university press, University of Oxford, United Kingdom) (2005).

[4] S. P. Moulik, M. E. Haque, P. K. Jana, and A. R. Das, "Micellar properties of cationic surfactants in pure and mixed states", The Journal of Physical Chemistry 100, 701-708 (1996).

[5] B. Barry, J. Morrison, and G. Russell, "Prediction of the critical micelle concentration of mixtures of alkyltrimethylammonium salts", Journal of Colloid and Interface Science 33, 554-561 (1970). 


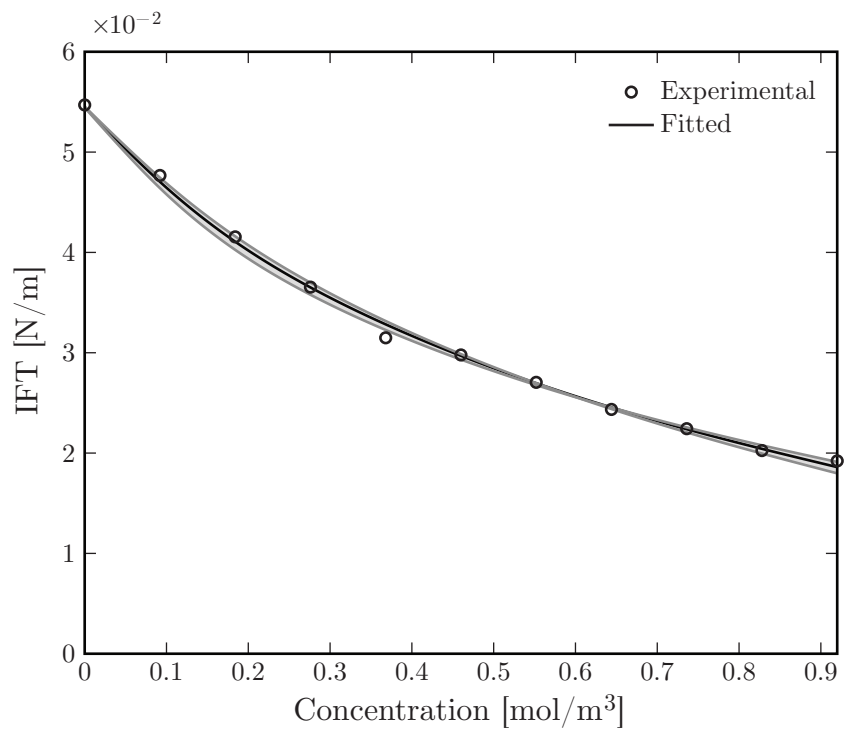

(a)

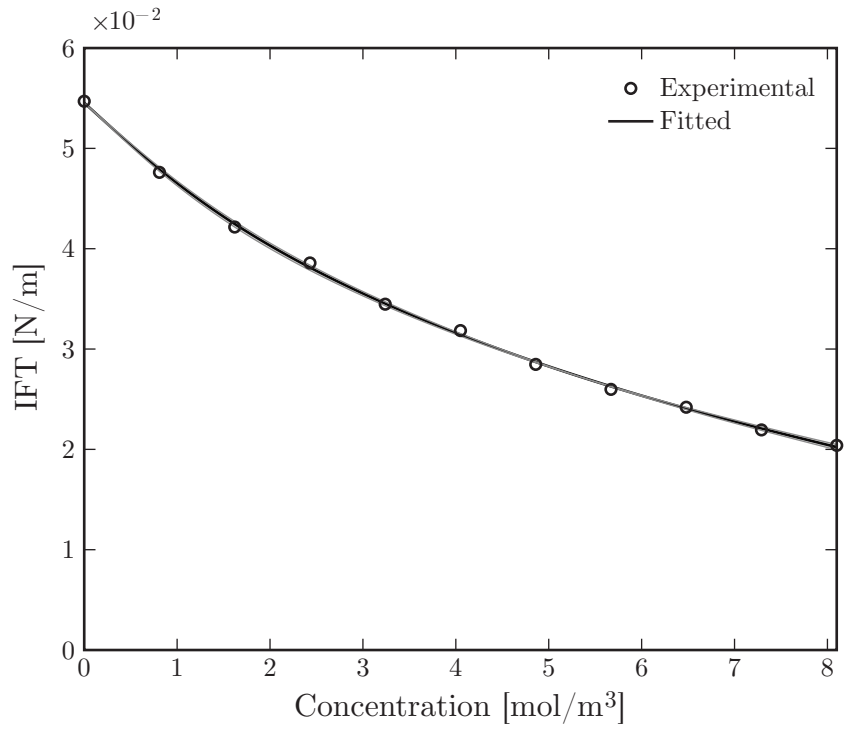

(b)

Figure C.16: Fitting of IFT results between Krytox 101 and surfactant solutions based on Szyszkowski equation (Equation 4.2 in Chapter Three for (a) CTAB soluion and (b) SDS solution (the shaded area bounds the upper and lower confidence interval limits of the corresponding fitting). 


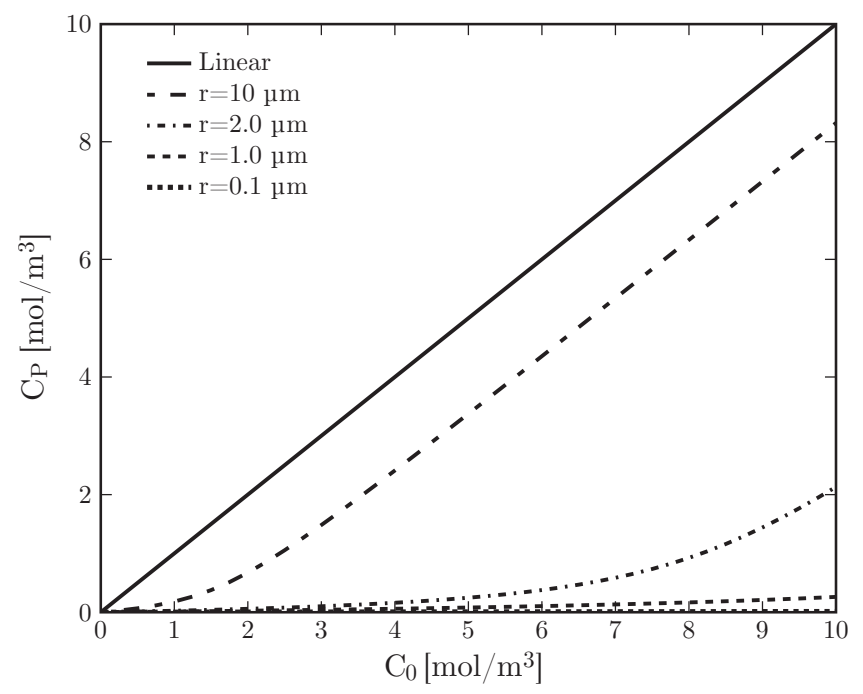

(a)

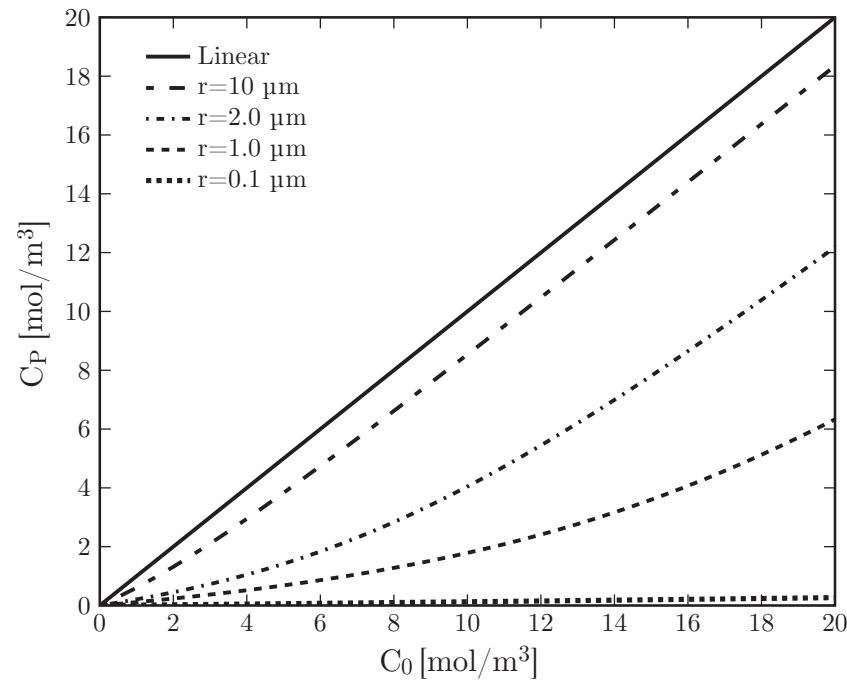

(b)

Figure C.17: Concentration of the surfactant in the pore $\left(C_{P}\right)$ as a function of surfactant concentration in the bulk $\left(C_{0}\right)$ based on Equation C.8 for (a) CTAB and (b) SDS surfactant solutions pushing through K101-infused membranes. 


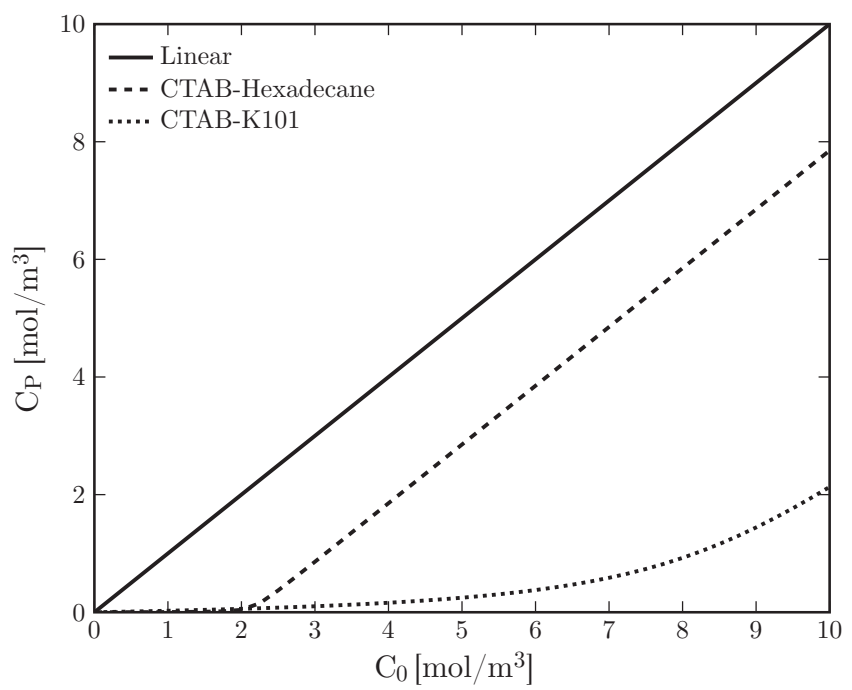

(a)

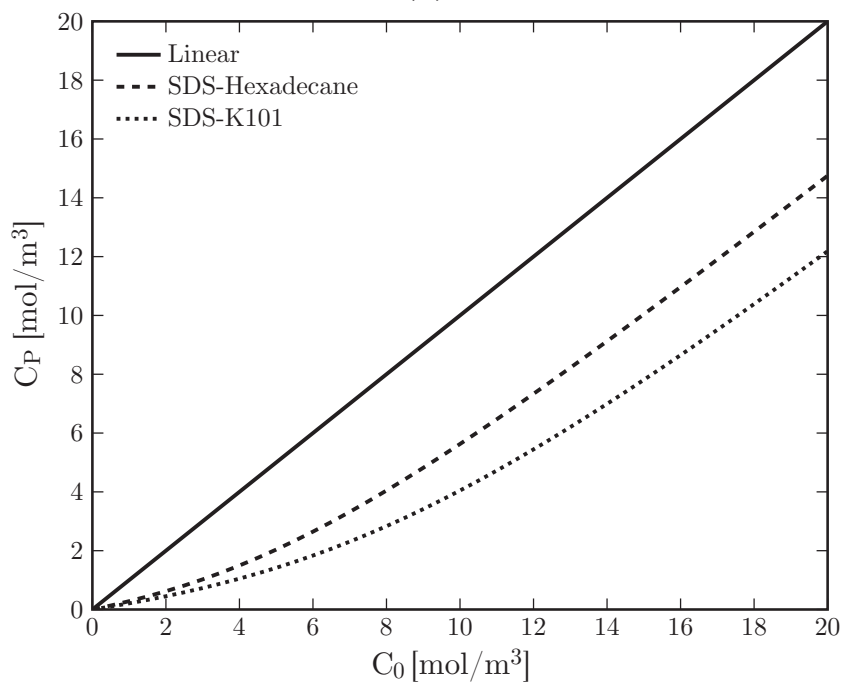

(b)

Figure C.18: Concentration of the surfactant in the pore $\left(C_{P}\right)$ as a function of surfactant concentration in the bulk $\left(C_{0}\right)$ for (a) CTAB and (b) SDS surfactant solutions pushing through both liquid-infused membranes with pore radius of $2 \mu \mathrm{m}$. 
[6] H. Singh, S. Singh, and D. Mahalwar, "Electrolytic conductivities of anionic and cationic surfactants in 1-propanol-water mixtures", Journal of Colloid and Interface Science 59, 386-389 (1977).

[7] J. Baxter-Hammond, C. R. Powley, K. D. Cook, and T. A. Nieman, "Determination of critical micelle concentrations by bipolar pulse conductance", Journal of Colloid and Interface Science 76, 434-438 (1980).

[8] G. Stalidis, A. Avranas, and D. Jannakoudakis, "Interfacial properties and stability of oil-in-water emulsions stabilized with binary mixtures of surfactants", Journal of Colloid and Interface Science 135, 313-324 (1990).

[9] I. Langmuir, "Oil lenses on water and the nature of monomolecular expanded films", The Journal of Chemical Physics 1, 756-776 (1933). 


\section{Appendix D}

\section{D.1 Membrane characterization}

The commercial PVDF membrane (HVHP00010) is characterized using scanning electron microscopy (SEM) (JEOL $5600 \mathrm{LV}$ ) and capillary flow porometer (Porolux-1000). The SEM images of top, bottom and cross section of the membrane are shown in Figure D.1.

Capillary flow porometry measurement on the commercial PVDF membrane is done by pushing nitrogen gas through the membrane infused with a low surface tension liquid, i.e. Fluorinert FC-43, at different pressure values. The corresponding gas flow rate is measured simultaneously. Figure D.2(a) shows the nitrogen gas flow rate as a function of pressure for the PVDF membrane. This measurement is conducted in two runs: in the first run, the so called wet curve, a sudden increase in gas flow rate is observed which corresponds to the pressure where the biggest pores are opened (first bubble point (FBP)). In the second run as the liquid has been already pushed out, a linear behaviour between flow and pressure is obtained (dry curve). The point where wet and dry curves meet corresponds to the smallest pore size. The half-dry curve is also plotted where the flow values are half of the flow values of the dry curve. The crossing point of this curve and wet curve determines the mean flow pore size (MFP). The Young-Laplace equation

$$
\Delta P=\frac{2 \gamma\left|\cos \theta_{\mathrm{E}}\right|}{r},
$$

by considering total wetting $\left(\theta_{\mathrm{E}}=180^{\circ}\right)$ is used to relate pressure to the pore size. In Equation (D.1), $r$ is the pore radius $(\mathrm{m}), \gamma$ is the interfacial tension $(\mathrm{N} / \mathrm{m})$ between permeating fluid and liquid, and $\theta_{\mathrm{E}}$ is the advancing contact 


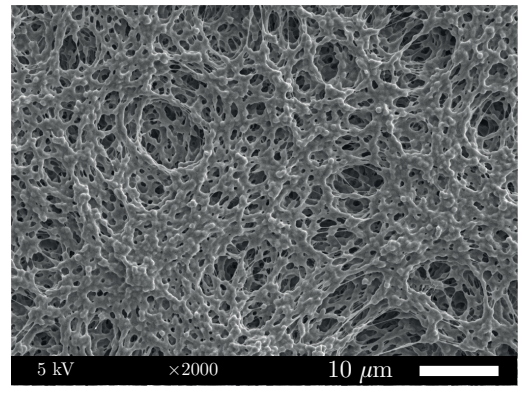

(a)

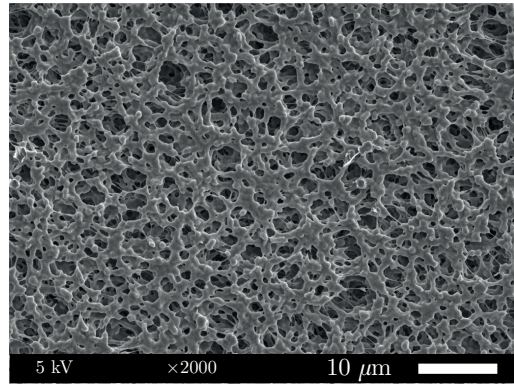

(b)

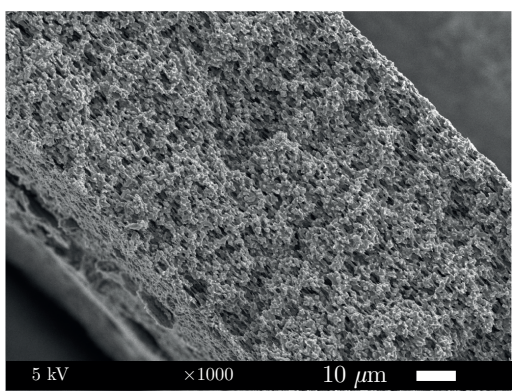

(c)

Figure D.1: Scanning electron microscopy (SEM) images of the commercial PVDF membrane from Merck (HVHP00010). (a) Top surface, (b) bottom surface, (c) cross section. 
Table D.1: Static and ARCA measurements on dry and K101-infused commercial PVDF membranes (values after \pm are the corresponding standard deviation).

\begin{tabular}{lcccc}
\hline \multirow{2}{*}{ Sample } & \multicolumn{4}{c}{ Contact angle $\left(^{\circ}\right)$} \\
\cline { 2 - 5 } & Mean Static & Advancing $\left(\theta_{\text {Adv }}\right)$ & Receding $\left(\theta_{\text {Rec }}\right)$ & Hysteresis \\
\hline Dry membrane & $121.90 \pm 0.49$ & $124.38 \pm 0.53$ & $97.86 \pm 2.99$ & $26.53 \pm 2.64$ \\
K101-infused & $104.24 \pm 1.18$ & $106.12 \pm 1.35$ & $87.54 \pm 1.71$ & $18.58 \pm 1.38$ \\
\hline
\end{tabular}

angle (larger than $90^{\circ}$ ) of the permeating fluid with respect to the pore wall.

Based on the results of this measurement, the pore size distribution of the membrane can be obtained which is shown in Figure D.2(b) As can be seen in Figure D.2, the commercial PVDF membrane has a narrow pore size distribution with an average pore radius of $0.51 \mu \mathrm{m}$ and size distribution of 0.043 $\mu \mathrm{m}$ (full width at half $\max / 2$ ).

The contact angle measurement on dry and liquid-infused membrane (K101infused) is performed using contact angle Goniometer (Dataphysics OCA20). Static contact angle measurement is performed by dispensing a $2 \mu \mathrm{l}$ water drop on the membrane surface. At least 6 independent static measurements are performed on different spots of the membrane surface. Dynamic measurements (advancing-receding contact angle (ARCA)) are performed within six cycles by placing the needle in the $2 \mu \mathrm{l}$-drop (sessile drop needle-in mode) and continuously supplying or withdrawing water up to $6 \mu \mathrm{l}$ at the rate of $0.5 \mu \mathrm{l} / \mathrm{min}$. The delay time between each cycle (advancing and receding measurement) is $2 \mathrm{~s}$. The average results of all the measurements results are shown in Table D.1. A lower contact angle hysteresis and subsequently higher droplet mobility are observed for liquid-infused membrane compared to dry membrane. However, contact angle hysteresis of liquid-infused membrane is not $<5^{\circ}$ which implies "slipperiness" [1. This is possibly due to the presence of hydrophilic impurities in the PVDF membrane reported by the manufacturer.

\section{D.2 Liquid-liquid displacement (LLD) analysis}

In order to better understand the retention of the infusion liquid in the liquidinfused membrane after water is pushed through the membrane, liquid-liquid displacement (LLD) experiment is done. The schematic of the set-up is shown in Figure D.3(a) A Bronkhorst mass flow controller (mini CORI-FLOW M14) and pressure meter (IN-PRESS P-502CI) which are connected using a control valve (COMBI-FLOW Mass flow C5I) are used. The LLD experiment is performed in four different cycles. Each cycle is carried out in a flux-increasing 


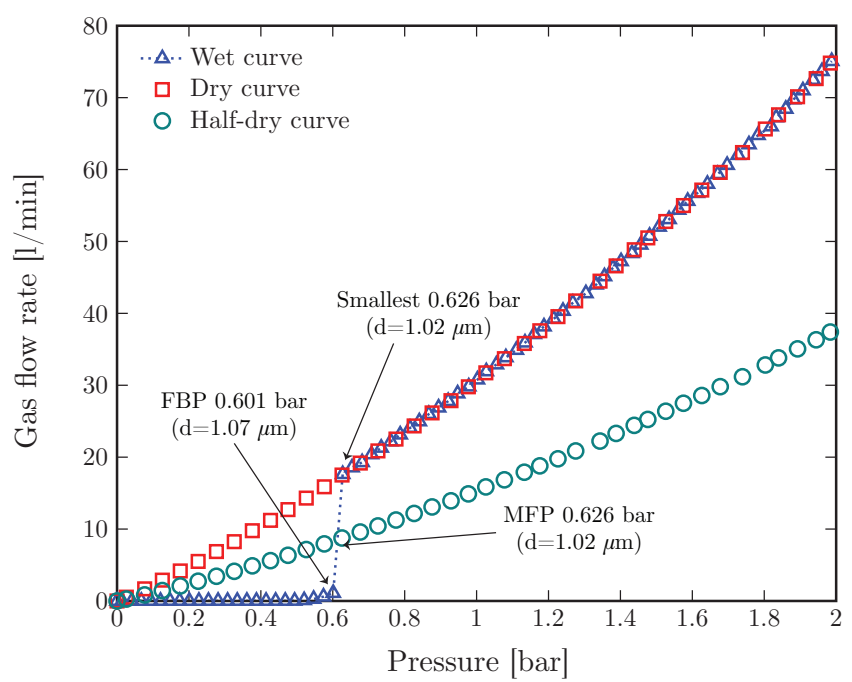

(a)

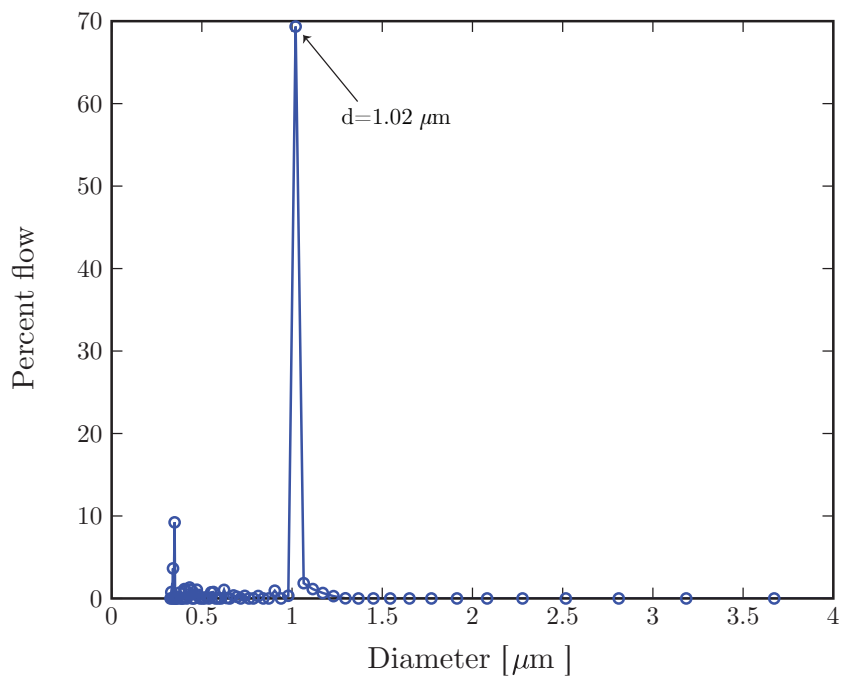

(b)

Figure D.2: Capillary flow porometry results of the commercial PVDF membrane. (a) Flow rate of nitrogen gas as a function of pressure. The corresponding pressure values for the biggest pore size (first bubble point (FBP)), mean flow pore size (MFP), and smallest pore size are indicated with arows. (b) Pore size distribution of the membrane. 
mode, which is done twice starting from zero up to a certain flux value. In each run, the flux is increased step-wise. At each step, flux is kept constant for $100 \mathrm{~s}$ and the pressure is reported for the last $40 \mathrm{~s}$ of each step [1]. The result is shown in Figure D.3(b).

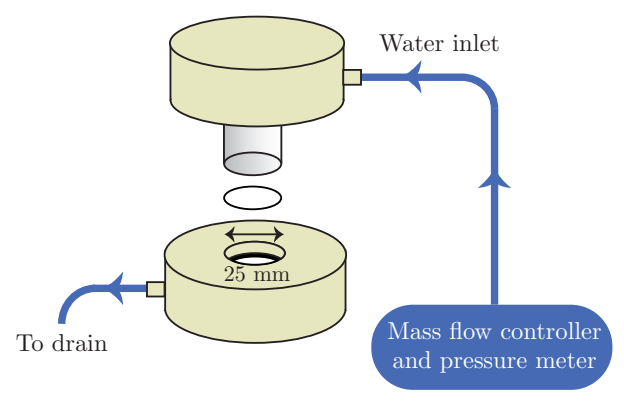

(a)

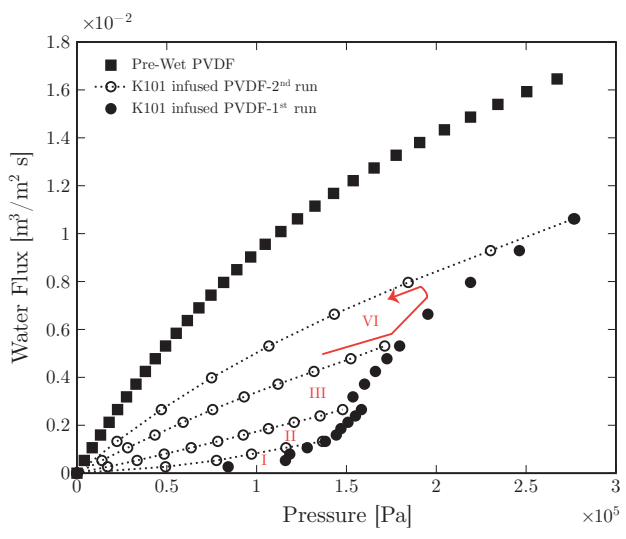

(b)

Figure D.3: (a) The set-up used for liquid-liquid displacement (LLD) experiment. (b) Successive LLD experiment in a flux controlled mode on Krytox 101-infused PVDF membrane using hexadecane. LLD is done in four different cycles (I-IV) and each cycle consists of a $1^{\text {st }}$ (filled symbols) and a $2^{\text {nd }}$ run (open symbols). In each run flux is increased step-wise from zero up to a certain maximum value and pressure is measured correspondingly. A typical sequence of the measurement is shown for cycle IV.

In order to check for the presence of the infusion liquid in the membrane after the experiment, the obtained results are compared with the results of the pre-wet membrane (see Figure D.3). To make the pre-wet membrane first the membrane was infused with $15.5 \mu \mathrm{l} \mathrm{cm}^{-2}$ ethanol. Then the ethanol-infused membrane was kept in a beaker with $200 \mathrm{ml}$ of MQ water overnight. This is done to make sure that the ethanol in the membrane pores are replaced with water. The permeability of pre-wet as well as liquid-infused membranes is calculated using Darcy's law [2]

$$
Q=\frac{\kappa a}{\mu} \frac{d p}{d x} .
$$

Here and in the following, $Q$ is the volumetric flow of the permeating fluid (in this case water) $\left(\mathrm{m}^{3} / \mathrm{s}\right), \kappa$ is the permeability $\left(\mathrm{m}^{2}\right), a$ is the total area of the membrane $\left(\mathrm{m}^{2}\right), \mu$ is the viscosity of the displacing fluid $(\mathrm{Pa} \mathrm{s}), \frac{d p}{d x}$ is 
Table D.2: Comparison of permeability and fraction of active pores for three different cycles of liquid-infused membrane and for the dry case.

\begin{tabular}{|c|c|c|}
\hline Membrane & $\begin{array}{l}\text { Permeability }(\kappa) \\
\left(\text { Darcy }^{*}\right)\end{array}$ & $\begin{array}{c}\text { Estimated fraction } \\
\text { of active pores }\end{array}$ \\
\hline LIM-cycle 1 & $7.99 \times 10^{-4}$ & 0.16 \\
\hline LIM-cycle 2 & $1.46 \times 10^{-3}$ & 0.29 \\
\hline LIM-cycle 3 & $2.49 \times 10^{-3}$ & 0.49 \\
\hline LIM-cycle 4 & $3.06 \times 10^{-3}$ & 0.61 \\
\hline Pre-wet & $5.03 \times 10^{-3}$ & 1 \\
\hline
\end{tabular}

the pressure gradient across the membrane thickness $(\mathrm{Pa} / \mathrm{m}), r$ is the mean pore radius $(\mathrm{m})$, and $\phi$ is porosity. A simple model is then used to relate permeability to porosity $\phi$, namely 1$]$

$$
\kappa=\frac{\phi r^{2}}{24} .
$$

The calculated porosity is a measure of opened and active pores for water transport in the membrane. The results of the calculated permeability and the estimated fraction of the active pores are shown in Table D.2 (membrane thickness and water viscosity are considered as $80 \mu \mathrm{m}$ and $1 \mathrm{mPa}$ s respectively). This fraction is the ratio between the calculated porosity for the liquid-infused membrane in each cycle and that of the pre-wet membrane. The permeability of the liquid-infused membrane increases in each cycle, revealing that new pores are opened for water transport. The lower permeability values of liquid-infused membrane (LIM) in comparison with pre-wet membrane suggests incomplete removal of the infusion liquid with around $39 \%$ retained infusion liquid in the membrane. For more information on this kind of analysis, we refer the reader to Chapter Three [1].

\section{D.3 Results of feed pressure increase}

The feed pressure increase during the bio-fouling experiment was also monitored. The results for both dry and liquid-infused membranes with the presence of the feed spacer in the membrane module is shown in Figure D.4. Lower feed pressure increase at a certain time is observable for liquid-infused membrane compared to dry membrane. This further shows that less bio-film is formed on the surface of the liquid-infused membrane compared to that of the 


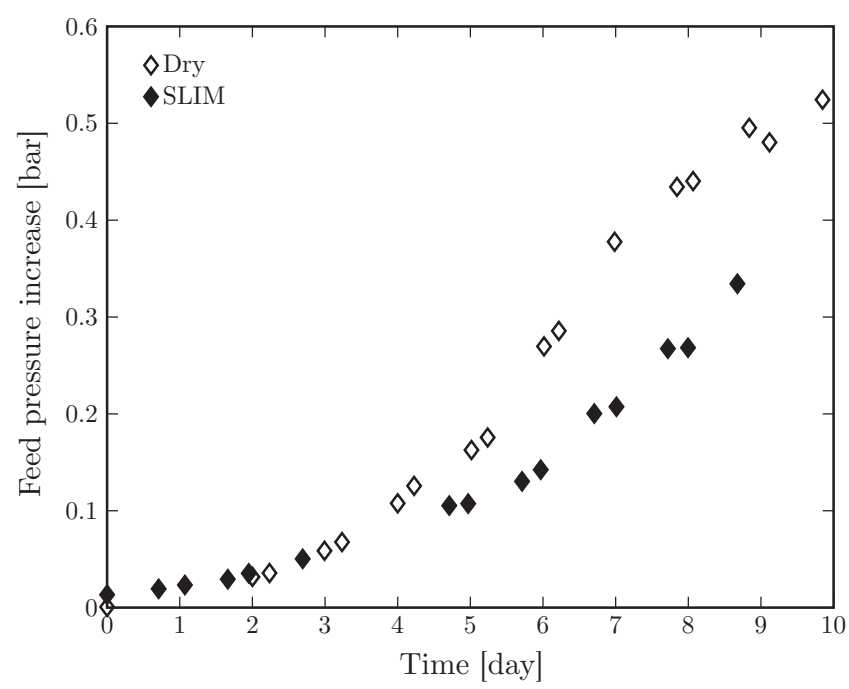

Figure D.4: Feed pressure increase as a function of time during biofouling experiments for both dry and liquid-infused membranes with presence of the feed spacer in the cell configuration.

dry membrane due to the presence of the infusion liquid.

\section{D.4 Effect of nutrient concentration}

The effect of nutrient concentration on bacterial growth is investigated by increasing the nutrient concentration to $7.2 \mathrm{~g} \mathrm{CH}_{3} \mathrm{COONa}, 1.1 \mathrm{~g}$ $\mathrm{NaH}_{2} \mathrm{PO}_{4} \cdot 2 \mathrm{H}_{2} \mathrm{O}$, and $2.6 \mathrm{~g} \mathrm{NaNo}$. The results of TMP and feed pressure increase are shown in Figure D.5. The lower increase in both TMP and feed pressure for liquid-infused membrane compared to dry membrane confirm improved performance of liquid-infused membranes in mitigation of bio-fouling. The increase in both TMP and feed pressure of liquid-infused membrane in the presence of the feed spacer in the membrane monitor can be attributed to the effect of spacer in acceleration of biofilm formation and growth. This is explained more in details in Chapter Four. 


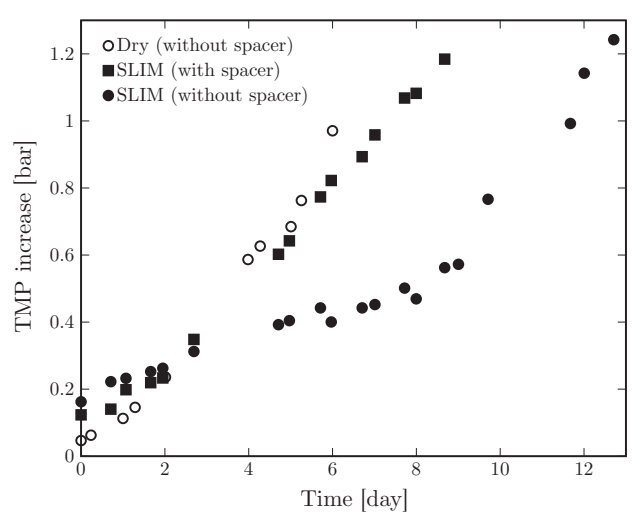

(a)

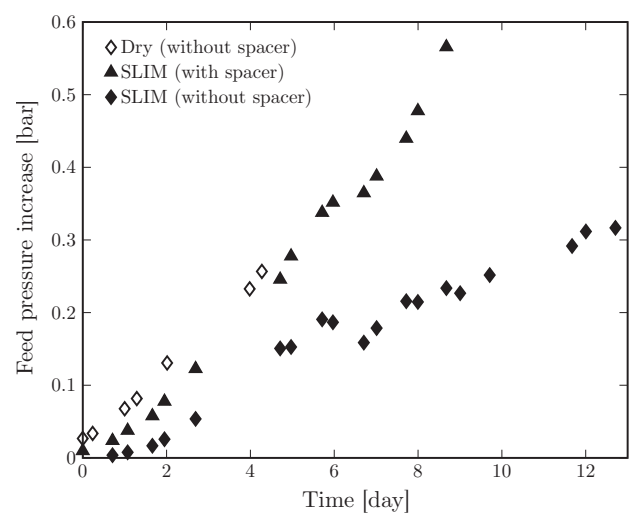

(b)

Figure D.5: (a) TMP increase and (b) feed pressure increase for both dry and liquidinfused membranes in biofouling experiments performed with higher concentration of nutrients.

\section{D.5 Confocal laser scanning microscope (CLSM) images}

Figure D.6 shows images obtained from z-stack of CLSM at different depths. Figures D.6(a) and D.6(b) demonstrate closest plane to the biofilm surface (feed water solution side). The closest plane to the membrane area is shown in Figures D.6(c) and D.6(d).

\section{D.6 Modification of logistic model}

The fitting parameters $(a, b$, and $c)$ for both membranes with different cell configurations are shown in Table D.3. Based on definition of biological parameters (see Chapter Four, section "Modeling of bacterial growth curve"), one can determine the modified logistic model accordingly.

The sigmoidal logistic model (Equation 5.1 in Chapter Four) can be rewritten as

$$
y=a \cdot[1+\exp (b-c t)]^{-1} .
$$

The first and second derivatives of Equation D.4 are respectively

$$
\frac{d y}{d t}=a c \exp (b-c t) \cdot[1+\exp (b-c t)]^{-2}
$$




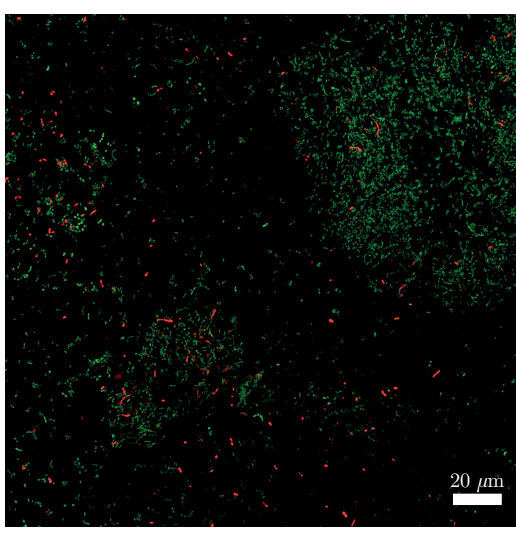

(a)

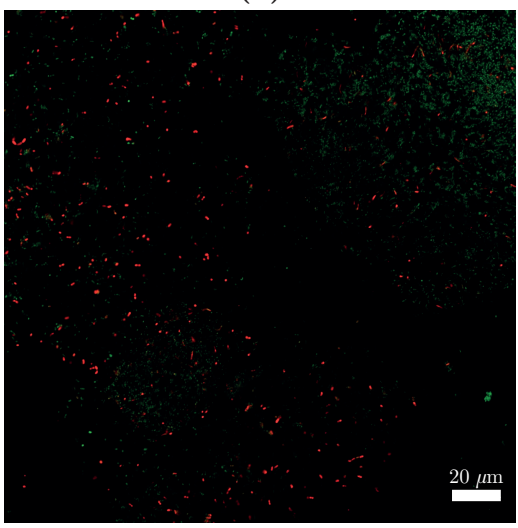

(c)

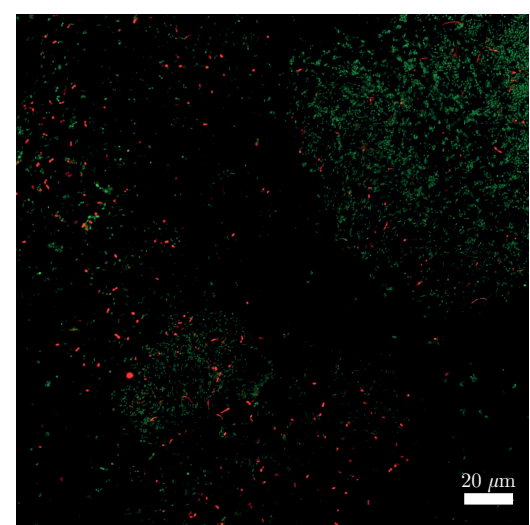

(b)

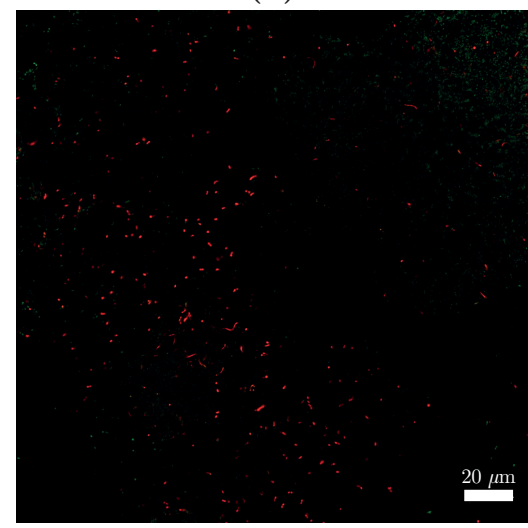

(d)

Figure D.6: CLSM images of the biofilm (green and red respectively show live and dead cells) from the surface of LIM-without spacer at different depths of (a) $1.33 \mu \mathrm{m}$ (side facing the feed water channel), (b) $3.56 \mu \mathrm{m}$, (c) $5.78 \mu \mathrm{m}$, and (d) $8.01 \mu \mathrm{m}$ (side facing the membrane surface).

Table D.3: Fitting parameters of fitted experimental data points of $\ln \left(\frac{\mathrm{P}}{\mathrm{P}_{0}}\right)$ as a function of time to logistic model (Equation D.4) (all the values after \pm are half of the the $95 \%$ confidence interval limits ((Upper CI - Lower CI)/2)).

\begin{tabular}{lccc}
\hline \multirow{2}{*}{ Membrane and cell configuration } & \multicolumn{3}{c}{ Fitting parameters } \\
\cline { 2 - 4 } & $a(-)$ & $b(-)$ & $c(-)$ \\
\hline Dry-without spacer & $4.41 \pm 0.12$ & $2.82 \pm 0.16$ & $0.31 \pm 0.02$ \\
Dry-with spacer & $3.64 \pm 0.13$ & $3.56 \pm 0.34$ & $0.72 \pm 0.08$ \\
LIM-without spacer & $0.48 \pm 0.04$ & $6.48 \pm 0.91$ & $0.44 \pm 0.07$ \\
LIM-with spacer & $0.64 \pm 0.04$ & $2.46 \pm 0.17$ & $0.43 \pm 0.05$ \\
\hline
\end{tabular}


and

$$
\frac{d^{2} y}{d t^{2}}=a c^{2} \exp (b-c t) \cdot[1+\exp (b-c t)]^{-3} \cdot[\exp (b-c t)-1] .
$$

The inflection point is where the second derivative is zero, i.e. $\exp (b-c t)-$ $1=0$. Therefore $t_{\mathrm{i}}=\frac{b}{c}$ and the corresponding $y$ value at the inflection point using Equation D.4 is equal to $\frac{a}{2}$. The specific growth rate $\left(\mu_{\mathrm{m}}\right)$ is then the first derivative (Equation D.5) at the inflection point, i.e.

$$
\left.\frac{d y}{d t}\right|_{t=t_{\mathrm{i}}}=\mu_{\mathrm{m}}=\frac{a c}{4} .
$$

By knowing one point $\left(\frac{b}{c}, \frac{a}{2}\right)$ and the slope of the tangent line $\left(\frac{a c}{4}\right)$, one can describe the tangent line as

$$
y=\frac{a c}{4} t-\frac{a(b-2)}{4} .
$$

Lag period $\lambda$ is defined as the t-axis intercept of the tangent line (Equation D.8 $=0$ ). Therefore $\lambda$ is calculated as

$$
\lambda=\frac{b-2}{c} .
$$

Asymptotic value $A$ is reached when $\mathrm{t} \rightarrow \infty$ in Equation D.4. By considering that,

$$
t \rightarrow \infty \Rightarrow y=a \Rightarrow A=a .
$$

The mathematical parameters $a, b$, and $c$ can be calculated based on biological parameters, $\lambda, \mu_{\mathrm{m}}$, and $A$ using Equations D.10, D.9, and D.7 respectively. By substituting these mathematical parameters in logistic model (Equation D.4 one can define the modified logistic model (Equation 5.2 in Chapter Four.

\section{D.7 Linear regression}

The $\mathrm{R}^{2}$ values of the linear fit to the exponential phase together with the root mean square error (RMSE) and summation of square error (SSE) are shown in Table D.4 for different cell configurations. As it is evident a relatively good fit was obtained for all the results. The obtained duration of the lag phase, i.e. $\lambda$ directly from the graph of $\ln \left(\frac{\mathrm{P}}{\mathrm{P}_{0}}\right)$ as a function of time for different cell configurations is shown in Table D.5. 
Table D.4: Accuracy of the linear regression of the experimental data points of $\ln \left(\frac{\mathrm{P}}{\mathrm{P}_{0}}\right)$ as a function of time.

\begin{tabular}{lccc}
\hline \multirow{2}{*}{ Membrane and cell configuration } & \multicolumn{3}{c}{ Goodness of linear fit to exponential phase } \\
\cline { 2 - 4 } & $\mathrm{R}^{2}$ & $\mathrm{RMSE}$ & $\mathrm{SSE}$ \\
\hline Dry-without spacer & 0.979 & 0.156 & 0.438 \\
Dry-with spacer & 0.986 & 0.102 & 0.073 \\
LIM-without spacer & 0.988 & 0.013 & 0.001 \\
LIM-with spacer & 0.969 & 0.021 & 0.004 \\
\hline
\end{tabular}

Table D.5: The values of the lag phase $\lambda$ obtained directly from the graph of $\ln \left(\frac{\mathrm{P}}{\mathrm{P}_{0}}\right)$ as a function of time.

\begin{tabular}{lc}
\hline Membrane and cell configuration & $\lambda$ \\
\hline Dry-without spacer & 2.001 \\
Dry-with spacer & 2.235 \\
LIM-without spacer & 9.004 \\
LIM-with spacer & 0.000 \\
\hline
\end{tabular}

\section{References}

[1] H. Bazyar, P. Lv, J. A. Wood, S. Porada, D. Lohse, and R. G. H. Lammertink, "Liquid-liquid displacement in slippery liquid-infused membranes (slims)", Soft Matter 14, 1780-1788 (2018).

[2] H. Darcy, Les Fontaines Publiques de la Ville de Dijon (Victor Dalmont, Paris, Paris) (1856). 


\section{Appendix E}

\section{E.1 Monodisperse emulsion fabrication using EDGE set-up}

All the emulsions were prepared using edge-based droplet generation (EDGE) microfluidic chip by dispersing silicone oil (SO) or hexadecane (HD) in SDS surfactant solution with different concentrations (10, 50 and $100 \%$ of the corresponding CMC $(8.1 \mathrm{mM}))$. Pressure of the continuous surfactant solution channel was set at 10 or 20 mbar. The pressure of the dispersed oil channel depends on the type of oil and concentration of the surfactant, i.e. interfacial tension between oil and surfactant solution. Table E.1 shows the maximum values of the applied pressure for dispersed and continuous phase channels. It is worth mentioning that by setting the pressure at the maximum value of the oil channel, highly concentrated emulsion was obtained. These emulsions were diluted approximately 10 times for acoustic experiments.

Table E.1: Applied pressure values on dispersed oil and continuous surfactant solution channels in EDGE chip for monodisperse emulsion fabrication.

\begin{tabular}{lcc}
\hline Emuslion & $\begin{array}{c}\left.\mathrm{P}\right|_{\text {Oil channel }} \\
(\mathrm{mbar})\end{array}$ & $\begin{array}{c}\left.\mathrm{P}\right|_{\text {SDS channel }} \\
(\mathrm{mbar})\end{array}$ \\
\hline HD-SDS10 & 680 & 10 \\
HD-SDS50 & 445 & 20 \\
HD-SDS100 & 200 & 10 \\
SO-SDS10 & 510 & 10 \\
SO-SDS50 & 340 & 10 \\
SO-SDS100 & 190 & 10 \\
\hline
\end{tabular}


Figure E.1 shows the fabricated SO droplets in SDS surfactant solution with concentration of 100\% CMC (SDS100). Movie E1 shows the corresponding video for fabrication of SO droplets in SDS 100 using EDGE chip recorded at 240 frames per second (FPS).

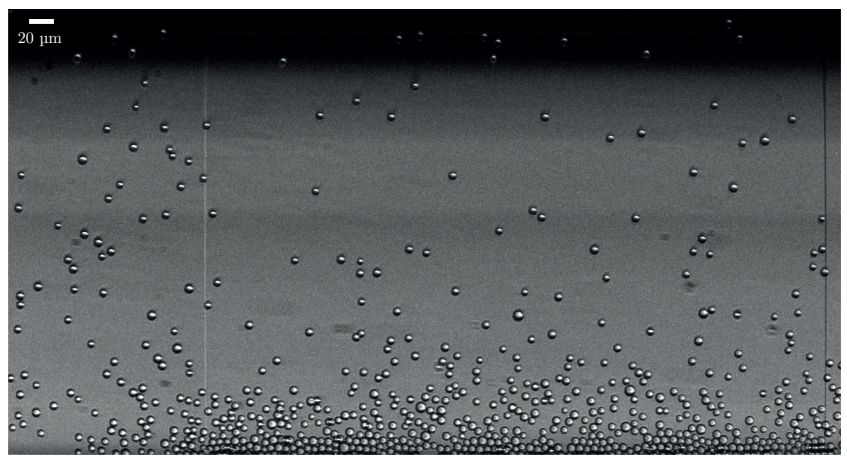

Figure E.1: Picture of the fabricated SO droplets in SDS 100 using EDGE chip.

The droplets size distribution of all emulsions was obtained by measuring the droplet diameter of at least 30 droplets using image analysis tool in the imaging software (HoKaWo 3.00). Figure E.2 shows the obtained droplet size distributions for both SO and HD droplets. The average values of droplet diameter together with the corresponding standard deviation (SD) and coefficient of variation $(\mathrm{CV})$ is shown in Table E.2. CV is

$$
\mathrm{CV}=\frac{\text { Standard deviation }}{\text { Average diameter }} \times 100,
$$

which is often used to characterize the droplet size distribution. Monodisperse emulsions have a CV below $25 \%$ whereas emulsions with $\mathrm{CV}$ above $25 \%$ are regarded as polydisperse [1. CV of all fabricated emulsions are below $25 \%$ showing monodispersity of the droplet sizes.

\section{E.2 Acoustic experimental results}

Acoustic experiments were performed on all fabricated emulsions at frequency of $1.25 \mathrm{MHz}$ and $\mathrm{V}_{\mathrm{pp}}$ of $200 \mathrm{mV}$ which was amplified to around $20 \mathrm{~V}$ using a power amplifier. As an example, Movie E2 shows the recorded time lapse over the whole channel width for concentrated SO droplets in $1.44 \mathrm{~g} / 1$ SDS surfactant solution (SDS62). Movie E3 shows an example of acoustic experiment in a more diluted emulsion (SO in SDS10). It is worth mentioning that 


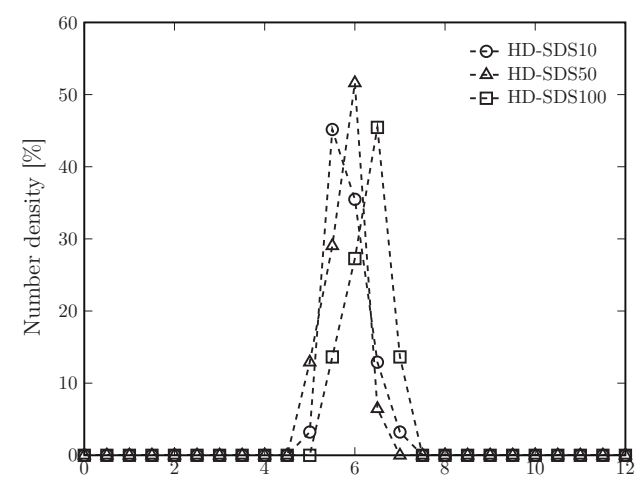

Droplet diameter $[\mu \mathrm{m}]$

(a)

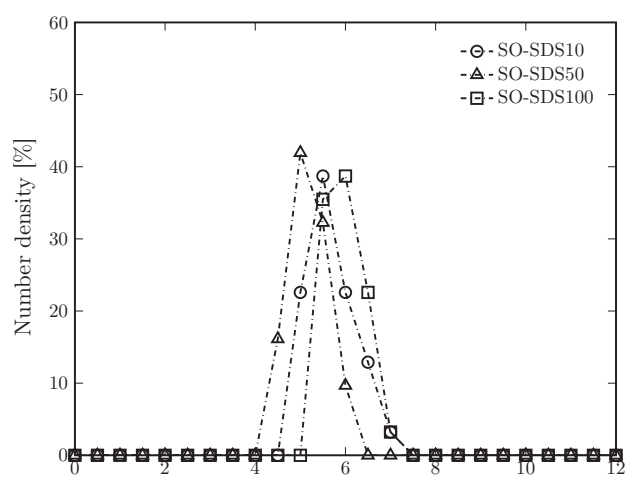

Droplet diameter $[\mu \mathrm{m}]$

(b)

Figure E.2: Droplet size distribution of (a) HD droplets and (b) SO droplets in different SDS surfactant concentrations.

Table E.2: Average values of at least 30 droplet diameters obtained from image analysis together with the corresponding SD and CV.

\begin{tabular}{lccc}
\hline Emuslion & $\begin{array}{c}\text { Average droplet } \\
\text { diameter }(\mu \mathrm{m})\end{array}$ & $\mathrm{SD}(\mu \mathrm{m})$ & $\mathrm{CV}^{*}(\%)$ \\
\hline HD-SDS10 & 5.81 & 0.45 & 7.78 \\
HD-SDS50 & 5.76 & 0.37 & 6.50 \\
HD-SDS100 & 6.32 & 0.38 & 6.03 \\
SO-SDS10 & 5.66 & 0.52 & 9.12 \\
SO-SDS50 & 5.22 & 0.45 & 8.66 \\
SO-SDS100 & 5.97 & 0.48 & 8.06 \\
\hline
\end{tabular}

${ }^{*} \mathrm{CV}$ is $\mathrm{SD}$ divided by average droplet diameter 


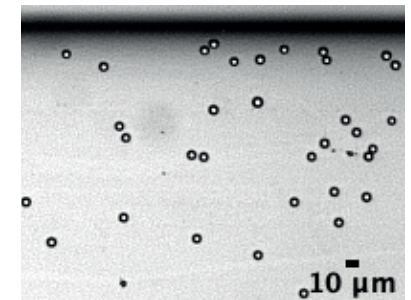

(a)

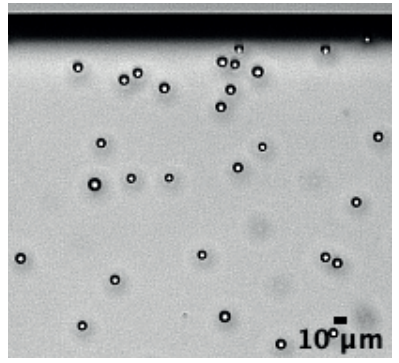

(c)

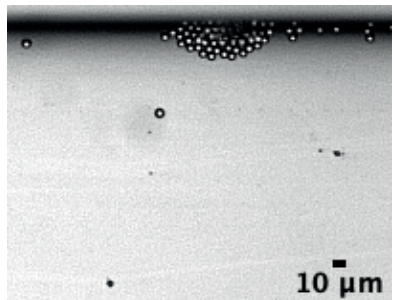

(b)

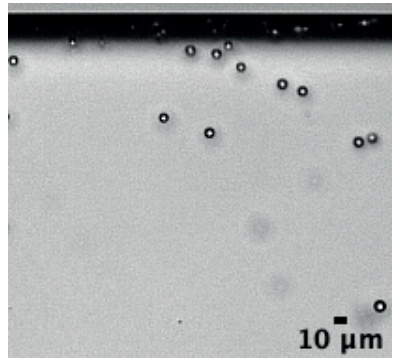

(d)

Figure E.3: Snapshots of microchannel zoomed-in at the location of the anti-node for HD droplets in SDS 100 at (a) first and (b) last time frame $\left(30^{\text {th }} \mathrm{s}\right)$ of applying acoustic field at $1.25 \mathrm{MHz}$ and $\mathrm{V}_{\mathrm{pp}}=20 \mathrm{~V}$. (c) and (d) show the same time frames for SO droplets in SDS 100.

all the original time lapse were recorded at 2 frames per minute (FPM), but the movies here are shown 60 times faster at 2 FPS. In order to track the acoustophoretic movement of oil droplets towards the anti-nodal positions, a series of time lapse were recorded close to the position of the anti-nodes in detailed experiments (zoomed-in mode) at 2 FPS for 30s. Figure E.3 illustrates the first and the last time frames of the recorded time lapse for SO and HD droplets in SDS100 surfactant solution.

\section{E.3 Particle tracking velocimetry (PTV) results}

To track the oil droplets individually while applying acoustic field, PTV in MATLAB was used in order to obtain the velocity of droplets as a function of time. Before PTV analysis all the time frames of the zoomed-in movies at the position of the anti-nodes, were binarized in FIJI ImageJ to obtain a good contrast between oil droplets and the background. Figure 6.5(a) in Chapter Five shows an example of the binarized $5^{\text {th }}$ time frame $(2.5 \mathrm{~s})$ and the velocity 


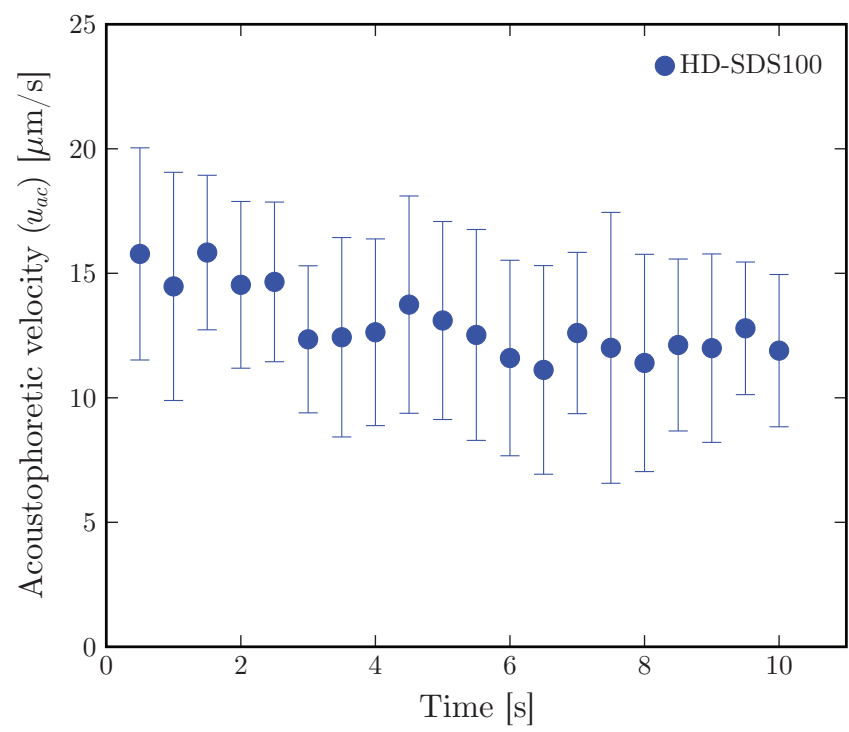

Figure E.4: Acoustophoretic velocity as a function of time for HD droplets in SDS100 surfactant solution.

vectors of the SO droplets in SDS100. Movie E4 and Movie E5 illustrate the combined original and PTV videos of SO and HD droplets in SDS100 respectively which were recorded at 2 FPS for 30s. The obtained velocity values as a function of time for the corresponding movies are shown in Figures 6.6 in Chapter Five and E.4 Figure E.5 shows the velocity values of SO and $\mathrm{HD}$ droplets as a function of time for all the tested SDS concentrations.

\section{E.4 Particle image velocimetry (PIV) results}

In order to obtain the velocity field around the anti-node, PIV was performed on all zoomed-in movies. Figure 6.5(b) in Chapter Five shows an example of the obtained result for SO droplets in SDS 100 at the $5^{\text {th }}$ time frame $(2.5 \mathrm{~s})$. The corresponding PIV video combined with the original zoomed-in time lapse at 2 FPS for 10s is shown in Movie E6, Movie E7 shows the combined PIV and original videos for HD droplets in SDS100 at 2 FPS. The velocity field distribution at further distances was obtained by doing PIV over half of the channel width. Figure 6.5(c) in Chapter Five demonstrates the PIV result of SO droplets in SDS 100 for the $2^{\text {nd }}$ time frame (1s) of the corresponding video (Movie E8). The velocity field distribution over half of the channel width 


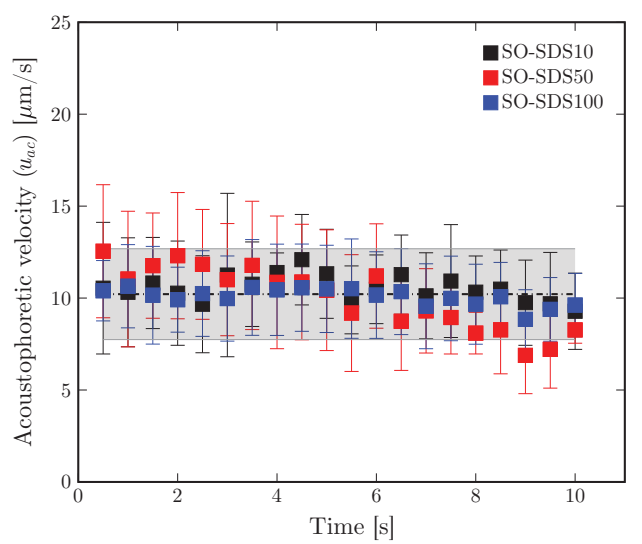

(a)

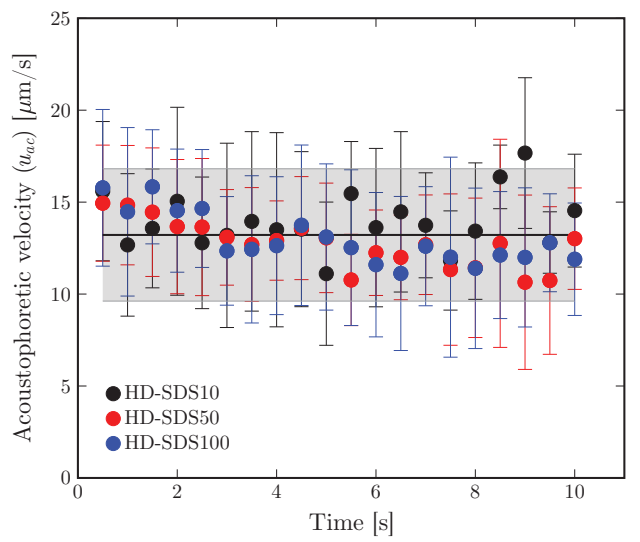

(b)

Figure E.5: Acoustophoretic velocity as a function of time for (a) SO and (b) HD droplets in different SDS surfactant solutions.

shows the maximum velocity at further distances around the anti-nodal point (yellow ring in Figure 6.5(c) with the minimum velocity at the position of the anti-node. By knowing the position of the anti-node, one can determine the diagonal distance $(z)$ between each velocity vector (with known $x$ and $y$ coordinates) and the anti-nodal point.

\section{E.5 Effects of secondary acoustic radiation force}

Particles in an acoustic field are moving either towards pressure nodes or antinodes as a result of primary acoustic radiation force (Equation 6.3 in Chapter Five. The scattering of sound wave by neighboring particles leads to the secondary acoustic radiation forces or Bjerknes forces [2]. For particles with negative acoustic contrast factor $\phi$, this force is repulsive between particles in the direction along the wave front propagation and it is attractive in the perpendicular direction [3, 4]. For positive $\phi$ the situation is vice versa. Secondary acoustic radiation force can be described by

$$
F_{\text {sec }}=4 \pi R_{p_{1}}^{3} R_{p_{2}}^{3}\left(\frac{\left(3 \cos ^{2} \theta_{r}-1\right)\left(\rho_{p}-\rho_{m}\right)^{2} v^{2}}{6 \rho_{m} d^{4}}-\frac{\left(\beta_{p}-\beta_{m}\right)^{2} \rho_{m} \omega^{2} P^{2}}{9 d^{2}}\right)
$$

where $d$ is the center-center distance between the particles, $\omega$ is the angular frequency of the oscillation, $v$ is the velocity in a one-dimensional acoustic 


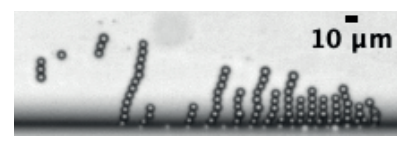

(a)

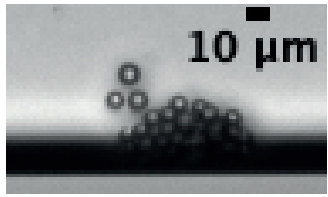

(c)

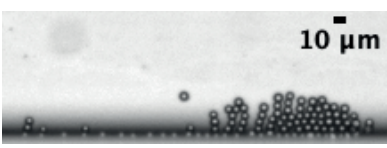

(b)

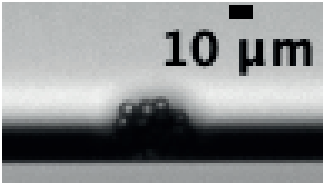

(d)

Figure E.6: Snapshots of formation of chains for HD droplets in SDS 100 solution at (a) $20^{\text {th }}$ and (b) $40^{\text {th }}$ times frames. Snapshots of the circulation of SO droplets in SDS 50 at the position of anti-node at (c) $16^{\text {th }}$ and (d) $40^{\text {th }}$ times frames.

plane wave, $P$ is the pressure, and $R_{p_{1}}$ and $R_{p_{2}}$ are the radii of the interacting particles. A negative sign of the secondary force can be interpreted as an attractive force, and vice versa. The forces are proportional with the particle volumes and the angular frequency, and inversely proportional with the distance separating the particles. The forces are therefore only effective when the particles are large, the frequency is high and the inter-particle distance is sufficiently small [3]. The effects of secondary acoustic radiation forces were observed as formation of chains in vertical direction $(y)$ and movement of chains towards each other in horizontal direction $(x)$ for HD droplets in SDS100. The secondary acoustic radiation force is attractive in both $x$ and $y$ directions since propagation of sound wave from the piezoelectric transducer is towards the plane of the paper. Figures E.6(a) and E.6(b) show snapshots of the corresponding video recorded at $1 \mathrm{FPM}$ (here 120 times faster at $2 \mathrm{FPS}$ ) (Movie E9) depicting formation and movement of the HD oil chains in SDS100 solution. Another indication of the secondary acoustic radiation force effects was circulation of the oil droplets at the position of the anti-nodes. Figures E.6(c) and E.6(d) illustrate snapshots of the video recorded at 2 FPM (here 60 times faster at 2 FPS) (Movie E10) showing circulation of SO droplets at the anti-nodal point in the surfactant solution of SDS50.

\section{E.6 Effects of streaming force}

Another effect was the vortex-like motion of the oil droplets which was only observed at the conjunction of the three outlets. The snapshot of the video 
Movie E11) is shown in Figure E.7 depicting vortex of SO droplets in SDS100 solution. This behaviour is expected to happen because of boundary layer streaming.

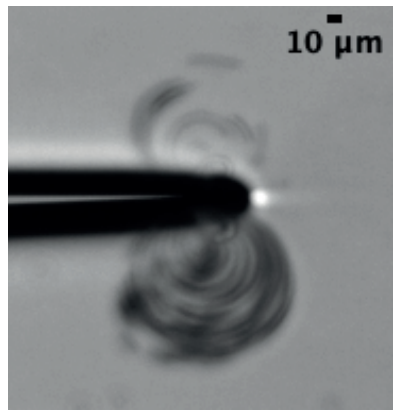

Figure E.7: Snapshot of the microchannel at the conjunction of the three outlets showing vortex-like movement of SO droplets in SDS100.

Acoustic streaming is a flow-generated force as a result of gradient in the time-averaged acoustic momentum flux in a fluid. In ideal fluids the net fluid flow is zero throughout the fluid. In real fluids an acoustic wave loses energy due to scattering and viscosity of the fluid, i.e. acoustic attenuation, which causes a net displacement of the fluid. In other words, acoustic streaming is a steady fluid flow formed by acoustic attenuation [5]. Stokes' was the first to derive an expression for the acoustic attenuation coefficient for a plane-sound wave as

$$
\alpha=\frac{2 \mu(2 \pi f)^{2}}{3 \rho_{m} c^{3}}
$$

where $f$ is the applied frequency, $\mu$ is the dynamic viscosity of the medium and $c$ is the speed of sound in the medium [6]. The particles are only influenced by primary and secondary acoustic radiation forces, however the entire fluid is affected by acoustic streaming. The main types of acoustic streaming are Rayleigh streaming and Schlichting streaming which are also known as outer and inner boundary layer streaming respectively. These types of acoustic streaming differ in length sacle. Rayleigh streaming happens in the small scale similar to the wave length (scale $\sim \lambda$ ) and Schlichting happens in microscale (scale $\ll \lambda)$. In general streaming is noticeable for smaller particles $(<1 \mu \mathrm{m})$ and higher frequencies $(>1 \mathrm{MHz})$ 4, 5. Schlichting streaming is observed as boundary layer vorticity caused by friction between wall and medium. This flow generates counter rotating vortexes in the bulk of the fluid 
between pressure nodes and anti-nodes [5]. According to Landau and Lifshitz, boundary layer streaming is most noticeable under the following condition

$$
\lambda \gg l \gg \delta \quad \delta=\sqrt{2 \eta / \omega}
$$

where $\lambda$ is the wavelength, $l$ is the characteristic length of the microfluidic chip, i.e. the channel width, $\delta$ is the viscous penetration depth, $\eta$ is the kinematic viscosity and $\omega$ is the angular frequency [7. Boundary layer streaming is prominent in microchannels with length scales that are fractions of the ultrasonic wavelength. Thus, this is the case for half-wavelength resonators which are typically applied in acosutophoretic experiments [3]. In our halfwavelength microchannel $(w=\lambda / 2)$, there is a sudden decrease in the channel width from $600 \mu \mathrm{m}$ to $200 \mu \mathrm{m}$ in the outlets (see Figure 6.2 in Chapter Five). The length scale at the conjunction of the outlets is then $1 / 6$ of the applied wavelength. Therefore, boundary layer streaming is likely to happen at this positions which observed as vortex-like motion of the oil droplets (see Figure E.7).

\section{E.7 Fabrication of the microfluidic chip}

The microfluidic chip was fabricated using standard photolithography and deep reactive ion etching (DRIE) techniques at $\mathrm{MESA}^{+}$Nanolab/clean room at the University of Twente. The process can be divided in to three steps, namely etching of the main channel into the silicon ( $\mathrm{Si}$ ) wafer, etching the access holes through the Si wafer and finally bonding the finished $\mathrm{Si}$ wafer to a Pyrex wafer. The photolithography was done twice using two masks to make the channels and the access holes respectively. Before starting the photolithography, the $\mathrm{Si}$ wafers were thermally oxidized to get a $\mathrm{SiO}_{2}$ layer of 1 $\mu \mathrm{m}$, i.e. hard mask. This was done by wet oxidation of Si wafer at temperature of $1150^{\circ} \mathrm{C}$ for 2 hours and 30 minutes. After coating the Si wafer with a photoresist layer, the first mask was aligned with the wafer and the main channel pattern is transferred to the layer by exposure to UV light and resist development. The developed resist layer is then annealed at temperature of $120^{\circ} \mathrm{C}$ for 10 minutes using a hot plate. The extra $\mathrm{SiO}_{2}$ layer and the main channels were then etched to a depth of $50 \mu \mathrm{m}$ using DRIE technique (Bosch process recipe was used). The photoresist and fluorocarbon were stripped after DRIE Bosch process using $\mathrm{O}_{2} / \mathrm{CF}_{4}$ plasma for 60 min (power $=800 \mathrm{~W}$, pressure $=0.5$ mbar) and a protection foil (Dupont MX 5020 foil) was applied 
to the top side. By the same procedure, a positive photo resist layer was developed using the second mask on the backside of Si wafer. The access holes are etched and the photoresist and foil were stripped away. The remaining $\mathrm{SiO}_{2}$ layer was removed by dipping the wafer in buffered HF solution (BHF (1:7)) for 30 minutes. Finally, the wafer was cleaned using piranha $\left(\mathrm{H}_{2} \mathrm{SO}_{4}: \mathrm{H}_{2} \mathrm{O}_{2}\right.$ $(3: 1)$ vol.\%) and dried. The finished Si wafer was anodically bonded to the Pyrex wafer.

\section{References}

[1] A. A. Maan, K. Schroën, and R. Boom, "Spontaneous droplet formation techniques for monodisperse emulsions preparation - perspectives for food applications", Journal of Food Engineering 107, 334 - 346 (2011).

[2] F. J. Trujillo, P. Juliano, G. Barbosa-Cánovas, and K. Knoerzer, "Separation of suspensions and emulsions via ultrasonic standing waves - a review", Ultrasonics Sonochemistry 21, 2151-2164 (2014), aOSS 2013.

[3] T. Leong, L. Johansson, P. Juliano, S. L. McArthur, and R. Manasseh, "Ultrasonic separation of particulate fluids in small and large scale systems: A review", Industrial \& Engineering Chemistry Research 52, 16555-16576 (2013).

[4] I. U. Vakarelski, E. Q. Li, A. I. Abdel-Fattah, and S. T. Thoroddsen, "Acoustic separation of oil droplets, colloidal particles and their mixtures in a microfluidic cell", Colloids and Surfaces A: Physicochemical and Engineering Aspects 506, 138-147 (2016).

[5] M. Wiklund, R. Green, and M. Ohlin, "Acoustofluidics 14: Applications of acoustic streaming in microfluidic devices", Lab Chip 12, 2438-2451 (2012).

[6] G. Stokes, "On a difficulty in the theory of sound", The London, Edinburgh, and Dublin Philosophical Magazine and Journal of Science 33 (111), 3490-356 (1848).

[7] L. Landau and E. Lifshitz, Fluid Mechanics, 2 edition (Pergamon press, Oxford) (2006). 


\section{Appendix F}

\section{F.1 Comparison between the designed and fabri- cated fibrous microstructures}

The pictures of the designed cells and the corresponding scanning electron microscopy (SEM) images of the fabricated unit cells for the microstructures with porosity 0.6 and 0.85 are shown in Figure F.1. It is worth mentioning that the shown SEM images concern the same region as the corresponding unit cell. The original SEM images for porosity 0.6 and 0.85 are taken at magnification $70 \mathrm{x}$ and $270 \mathrm{x}$ respectively. That is why the pillars in the chip with porosity 0.85 look a bit larger than the designed picture. The zoomed-in SEM and designed images of the top view of all the chips are shown in Figures F.2 and F.3.

The inlet/outlet of the microfluidic chips are shown in the tilted side view SEM images of the microfluidic chips with porosity 0.55 and 0.85 (Figure F.4). The zoomed-in SEM images of the side view of all the fabricated microfluidic chips are shown in Figure F.5illustrating the corrugated pillar wall structure.

\section{F.2 Algorithm for calculation of $2^{\text {nd }}$ nearest neigh- bor $\left(\gamma_{2}\right)$}

$\gamma_{2}$ can be calculated based on Equation 7.3 in Chapter Seven which requires the measurement of the mean second nearest neighbor distance from a pillar i.e. $\left\langle D_{2}\right\rangle$. The following methodology can be adopted to evaluate this parameter. This algorithm is a general one which can be used in any software, such as MATLAB, Mathematica or Python. 


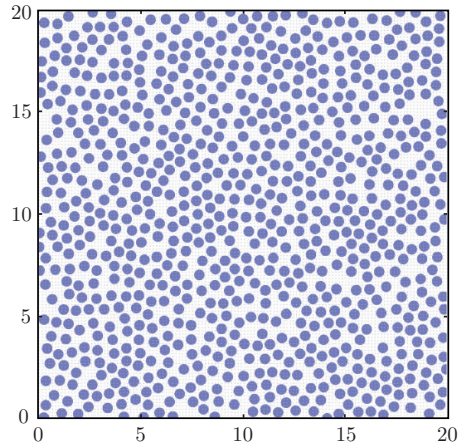

(a)

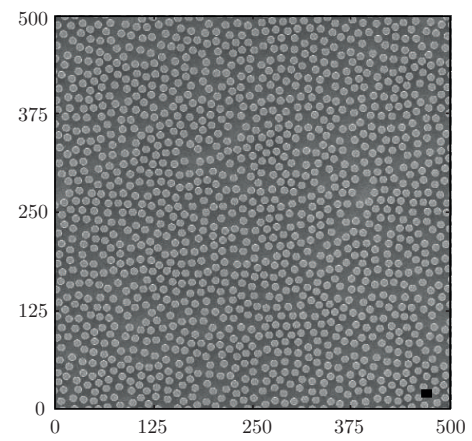

(c)

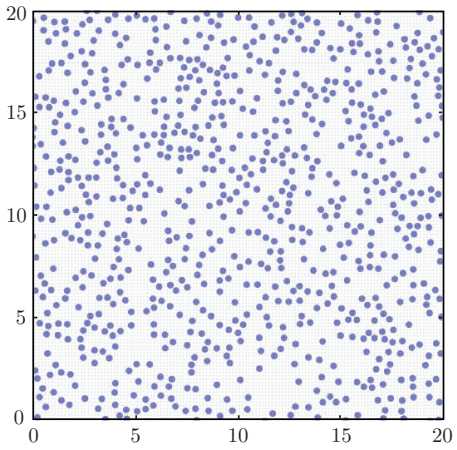

(b)

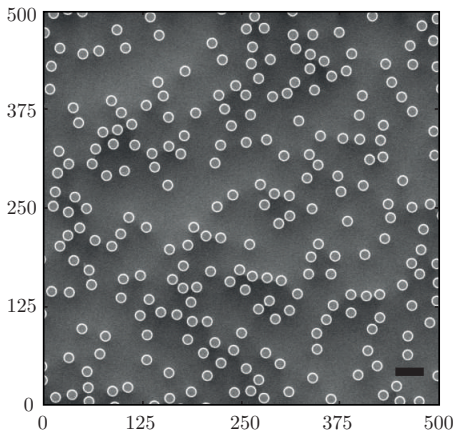

(d)

Figure F.1: Pictures of simulated unit cell of the microstructure with porosity (a) 0.6 and (b) 0.85 using MC algorithm. The corresponding fabricated unit cells in the microfluidic chip are shown respectively in (c) and (d) (both axis are in $\mu \mathrm{m}$ and scale bar is $20 \mu \mathrm{m})$. 


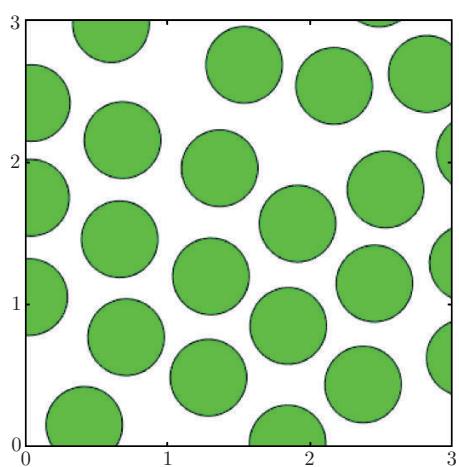

(a)

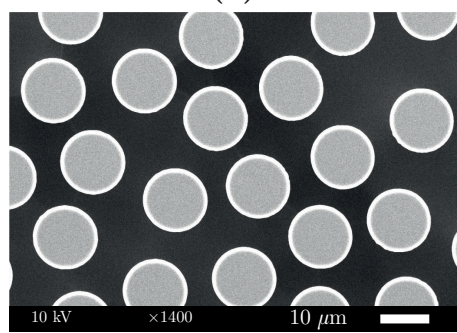

(c)

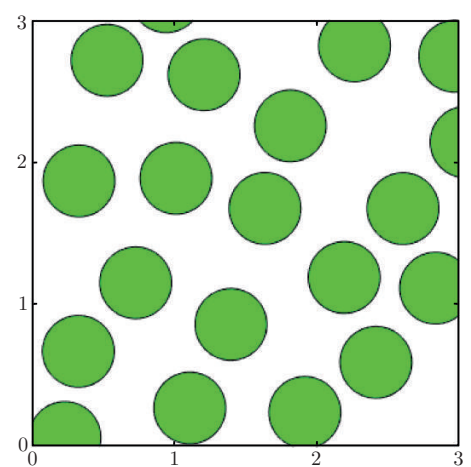

(b)

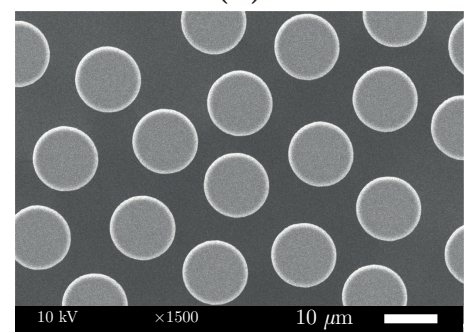

(d)

Figure F.2: Zoomed in pictures of the designed cell for porosity (a) 0.55 and (b) 0.6. The corresponding SEM images of the fabricated microfluidic chips are shown respectively in (c) and (d). 


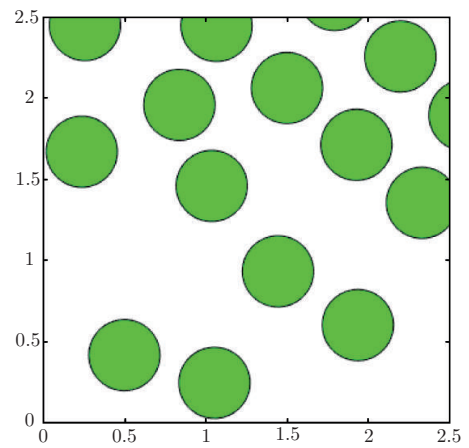

(a)

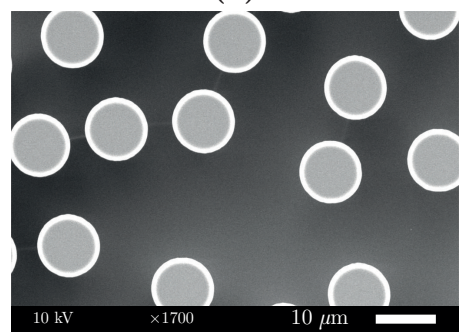

(c)

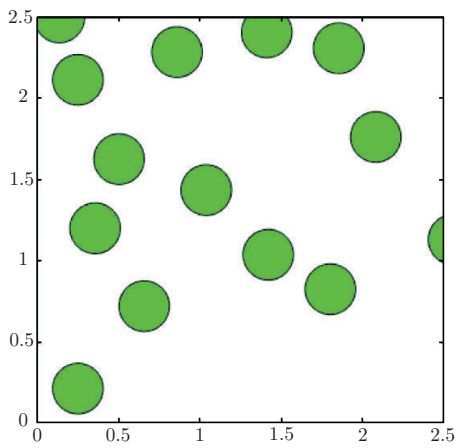

(b)

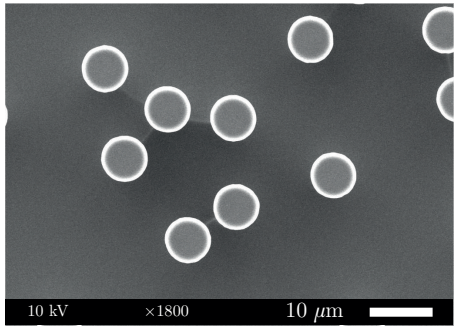

(d)

Figure F.3: Zoomed in pictures of the designed cell for porosity (a) 0.7 and (b) 0.85. The corresponding SEM images of the fabricated microfluidic chips are shown respectively in (c) and (d).

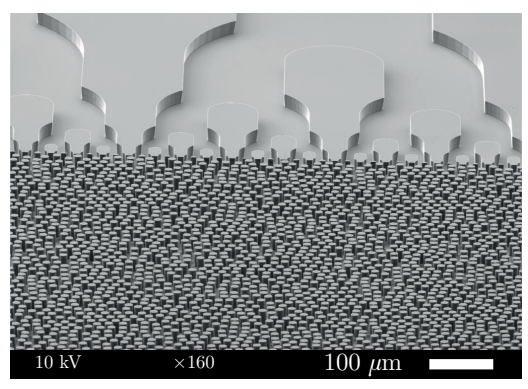

(a)

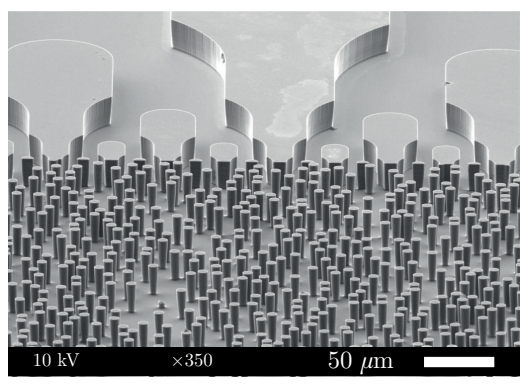

(b)

Figure F.4: The side view SEM images showing the inlet/outlet of the microfluidic chips with porosity (a) 0.55 and (b) 0.85 . 


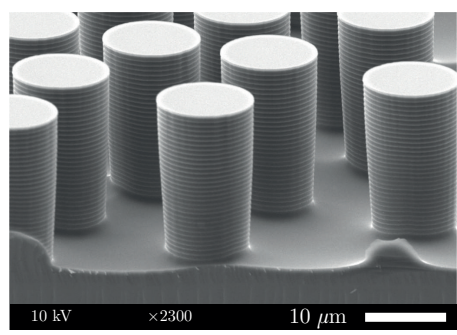

(a)

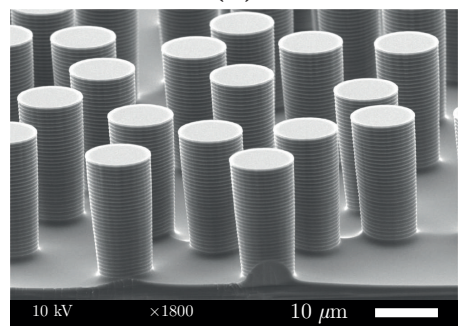

(c)

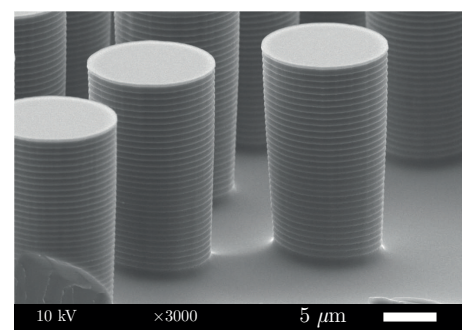

(b)

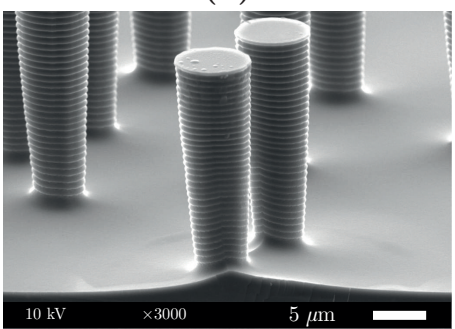

(d)

Figure F.5: Zoomed in SEM images of the side view of the fabricated microfluidic chips with porosity (a) 0.55 , (b) 0.6 , (c) 0.7 and (d) 0.85 .

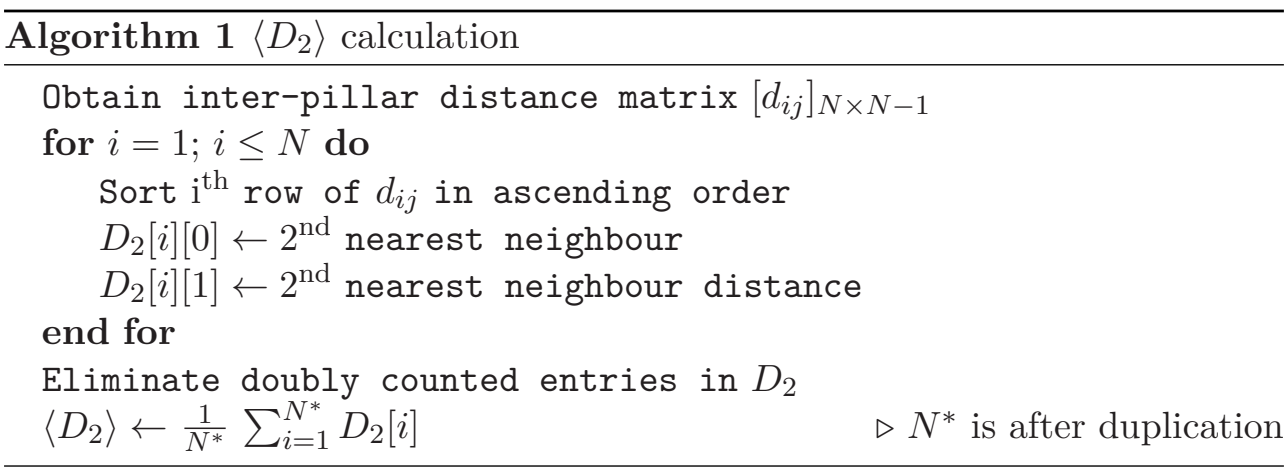

\section{F.3 Error analysis in calculation of $\gamma_{2}$}

The simulated pillar configuration for each porosity was used to calculate $\gamma_{2}$. according to the above algorithm, for instance if we consider 10 pillars, the distance between pillar 1 and the other 9 pillars can be calculated and the $2^{\text {nd }}$ nearest neighbor can be chosen. This procedure should be done for all 800 pillars and the overall mean value should be taken leading to $\left\langle D_{2}\right\rangle$. This 
gives rise to mean, upper and lower values for calculation of $\gamma_{2}$ from which the corresponding standard deviation can be calculated (see Table F.1). From now on, the calculated $\gamma_{2}$ from simulation is called $\gamma_{2, \mathrm{sim}}$. In the fabricated pillar configurations, the actual pillar diameter was different than the simulated value (see Tables 7.1 and 7.2 in Chapter Seven). This can correspondingly lead to a different $\gamma_{2}$ value based on actual the parameters (this will be called $\gamma_{2 \text {,act }}$ ). By assuming no change in center to center distance between pillars during fabrication procedure, mean $2^{\text {nd }}$ nearest neighbor distance $\left\langle D_{2}\right\rangle$ remains the same as that calculated based on the simulation results (algorithm). Thus, according to Equation 7.3 in Chapter Seven, $\left\langle D_{2}\right\rangle$ can be defined as

$$
\left\langle D_{2}\right\rangle=d_{\operatorname{sim}}\left(\gamma_{2, \operatorname{sim}}+1\right),
$$

and

$$
\left\langle D_{2}\right\rangle=d_{\text {act }}\left(\gamma_{2, \text { act }}+1\right),
$$

based on simulated and actual pillar diameters respectively.

Parameter $R$ can be defined as the ratio between $d_{\text {sim }}$ and $d_{\text {act }}\left(R=\frac{d_{\text {sim }}}{d_{\text {act }}}\right)$ such that in the case of unity, $\gamma_{2}$,sim is equal to $\gamma_{2}$,act. Based on the assumption that $\left\langle D_{2}\right\rangle$ remains the same in both simulation and fabricated pillar configuration, Equations F.1 and F.2 lead to

$$
\gamma_{2, \text { act }}=R\left(\gamma_{2, \text { sim }}+1\right)-1 .
$$

The standard deviation in measurement of ratio $R$ (see Table F.1) stems from the corresponding standard deviation in measurement of actual pillar diameter $\left(d_{\text {act }}\right)$ (see Table 7.2 in Chapter Seven). Calculation of the overall standard deviation in measurement of $\gamma_{2 \text {,act }}$, requires considering standard deviations in both $R$ and $\gamma_{2, \text { sim. }}$. For the corresponding error analysis, Equation F.3 can take the general form of

$$
A=(B \times C)+B-1,
$$

where $A=\gamma_{2 \text {,act }}, B=R$ and $C=\gamma_{2, \text { sim. }}$. For the sake of simplicity in calculation of the combined errors, $B \times C$ can be taken as $D$ which is $R \times \gamma_{2}$,sim.

For a variable $D=B \times C$, the corresponding error can be defined as [1]

$$
\left(\frac{\Delta D}{D}\right)^{2}=\left(\frac{\Delta B}{B}\right)^{2}+\left(\frac{\Delta C}{C}\right)^{2},
$$


Table F.1: Mean and standard deviation values of $R, \gamma_{2, \text { sim }}$, variable $D$ and $\gamma_{2 \text {,act }}$

\begin{tabular}{lcccc}
\hline$\varepsilon_{\text {sim }}$ & $R=B=\left.\frac{d_{\text {sim }}}{d_{\text {act }}}\right|_{\text {Mean }}$ & $C=\left.\gamma_{2, \text { sim }}\right|_{\text {Mean }}$ & $\left.D\right|_{\text {Mean }}$ & $A=\left.\gamma_{2, \text { act }}\right|_{\text {Mean }}$ \\
\hline 0.55 & $1.035 \pm 0.024$ & $0.288 \pm 0.006$ & $0.298 \pm 0.009$ & $0.333 \pm 0.026$ \\
0.6 & $1.066 \pm 0.024$ & $0.333 \pm 0.009$ & $0.354 \pm 0.012$ & $0.420 \pm 0.027$ \\
0.7 & $1.051 \pm 0.027$ & $0.470 \pm 0.016$ & $0.494 \pm 0.021$ & $0.544 \pm 0.034$ \\
0.85 & $1.078 \pm 0.039$ & $0.939 \pm 0.041$ & $1.012 \pm 0.058$ & $1.091 \pm 0.070$ \\
\hline
\end{tabular}

where $B$ and $C$ are the mean values of $R$ and $\gamma_{2}$ sim respectively and $D$ is mean value calculated from multiplying $B$ and $C . \Delta B$ and $\Delta C$ and $\Delta D$ are the corresponding standard deviations (see Table F.1).

By knowing the corresponding error in variable $D=B \times C(\Delta D)$, the overall error in variable $A$ can be defined as [1]

$$
(\Delta A)^{2}=(\Delta D)^{2}+(\Delta B)^{2}
$$

where $A$ is the mean value of $\gamma_{2 \text {,act }}$ calculated from Equation F.3. $\Delta A$ (see Table F.1 is the overall standard deviation which should be considered for $\gamma_{2}$ stemming from the calculation method (algorithm) and the fabrication procedure.

\section{F.4 Permeation of water and hexadecane through fabricated microstructures}

Movie F1, Movie F2 and Movie F3 display permeation of hexadecane through fabricated pillar microstructures with porosity $0.55,0.6$ and 0.7 respectively. Permeation of water through the microstructure with porosity 0.85 is displayed in Movie F4.

\section{F.5 Fabrication procedure of the microfluidic chip}

The microfluidic chip is fabricated using standard photolithography and deep reactive ion etching (DRIE) techniques at $\mathrm{MESA}^{+}$Nanolab at the University of Twente. The process can be divided in to three steps, namely etching of the structure into the silicon ( $\mathrm{Si}$ ) wafer, etching the access holes through the Si wafer and finally bonding the finished Si wafer to a Mempax (Schott) wafer. The photolithography is done twice using two masks to make the pore network (pillars) and the access holes respectively. Before starting the 
photolithography, the $\mathrm{Si}$ wafers are thermally oxidized to get a $\mathrm{SiO}_{2}$ layer of $1.7 \mu \mathrm{m}$, i.e. hard mask. This is done by wet oxidation of Si wafer at a temperature of $1150^{\circ} \mathrm{C}$ for 6 hours. After coating the Si wafer with photoresist, the first mask pillar pattern is transferred to the layer by exposure to UV light and resist development. The next step is to etch the protection $\mathrm{SiO}_{2}$ layer and then the pillar pattern into the Si wafer (to a depth of $20 \mu \mathrm{m}$ ) using DRIE technique (Bosch process recipe is used). Then the photoresist layer is stripped using oxygen plasma. A dicing foil is applied to the top of the wafer to protect it during powderblasting. On the back a powderblast foil is applied (Harke I-HE dryresist) and the access holes are defined via photolithography using the second mask. The access holes are generated using powderblasting. After powderblasting the foils are removed and the wafer is ultrasonically cleaned to remove any residual powder. Afterward the wafer is cleaned using piranha $\left(\mathrm{H}_{2} \mathrm{SO}_{4}: \mathrm{H}_{2} \mathrm{O}_{2}(3: 1)\right.$ vol.\%) to remove any residual foil and rinsed with $\mathrm{H}_{2} \mathrm{O}$. The remaining $\mathrm{SiO}_{2}$ layer is removed by dipping the wafer in buffered HF solution (BHF (1:7)) for 25 minutes and dried. The finished Si wafer is anodically bonded to the Mempax (Schott) wafer and diced into individual chips.

\section{References}

[1] R. Hogan, "How to combine errors", (2006). 


\section{Acknowledgments}

Being born and raised in a developing country taught me a lot of things which I am eternally grateful for. From childhood, I was placed in situations wherein there were always competitions which helped me try harder and realize my inner potential. I learned to continually push myself to be my best. Every day in the country was a new challenge in terms of social, economical and political matters making the life of people difficult. However, I learned to become resistant and resilient towards minor pitfalls. Entering highly-ranked universities for higher educations required competing with more than one million applicants made me realize that hard work will be always paid off. Being underprivileged and not having the equal opportunities as the other people in the world taught me to try harder and harder to obtain what I deserve. With that said, I personally believe that in $21^{\text {st }}$ century, after more than 70 years from formation of United Nations Human Rights Council, every human being deserves equality and freedom in all aspects of life. I hope to be alive to see the world with a thorough peace and freedom in which people are not discriminated and judged just because of their nationality.

Completion of this thesis would not have been possible without the help of many people and I would not stand at the position that I am without the support of my family, friends and colleagues. My first and foremost appreciation goes to my supervisor and promotor Rob Lammertink who believed in me and gave me the opportunity to work as a researcher and later as a $\mathrm{PhD}$ at Soft matter, Fluidics and Interfaces (SFI) group. I am sincerely thankful for all your helps and supports throughout these five years. I learned a lot in the research work, since you let me make mistakes and gave me the freedom to try different research fields. Whenever I felt stressed in my work, you were always there to discuss things over and find a solution. Your critical questions and comments helped me try my best to achieve as much as I can from my $\mathrm{PhD}$ project. Not only from the work point of view, but also in soft skills such as supervision of students, I learned a lot from you. I am grateful for this since it 
guided me find my strengths and capabilities which further helped me choose my future career. It is hard to express my appreciation in words, but I am wholeheartedly happy that you were my supervisor.

Next person who helped me during my project, although he was not involved in the project, was Jeff Wood. I am grateful to you that you were critical on my research work. It really helped me find my weaknesses and try to improve them. Apart from our scientific discussions, I enjoyed our non-scientific ones as well, commander Shepard ;).

I would also like to thank my daily supervisor from Wetsus, Slawomir Porada. Your kind and supportive character helped me find my way faster when I started my PhD at Wetsus. You were always there for me whenever I needed help. Even after I moved to University of Twente to do the rest of my $\mathrm{PhD}$ at SFI, you continued helping me and coming up with new ideas for the work. I appreciate all your efforts to do the biofouling work (Chapter Five) at Wetsus although I was not there anymore.

Five chapters of this thesis are the result of collaboration with other groups and researchers. Chapter Two was performed together with Sirus Javadpour from department of Materials Science and Engineering at Shiraz University, Iran. Sirus was also my supervisor during my master. I appreciate all your helps, constructive comments and warm encouragements. Chapter Three would not exist without my collaboration with Physics of Fluids (POF) group at University of Twente. I would particularly like to thank Detlef Lohse for giving me the opportunity to work at POF for a while. I also want to thank Guillaume Lajoinie for introducing confocal microscope at POF to me and allowing me using it despite its full agenda. My special appreciation goes to Pengyu Lv former post doctoral researcher at POF, who helped me further with the confocal microscope and image analysis of the obtained results. You were always available for helping me and doing experiments with me. I never forget the very last experiment which we did together on Friday afternoon till around 09:00 pm. I appreciate your time and dedication to the work which we did together. I am glad that we continued our collaboration even after you moved to China which led to another successful work (Chapter Six). Additionally, I would like to thank Yanshen Li post doctoral researcher at POF for his help on confocal microscope as well as Gabriela Berenice Diaz Cortes from Delft University of Technology for invaluable advice on Buckley-Leverett analysis using MATLAB reservoir simulation tool box.

Chapter Five was performed together with Slawomir Porada and Linya Xu, internship student, in collaboration with Rik de Vries at Wetsus. I would 
like to offer my thanks to you for introducing your biofouling set-up to us and helped us with the experiments although you were busy writing your thesis.

Chapter Six was conducted in collaboration framework with Food Process Engineering (FPE) group at Wageningen University and Research. My appreciation goes to Karin Schroën who introduced Edge-Based Droplet Generation (EDGE) set-up to me for making monodisperse emulsions and gave me the opportunity to work there for a week. Advice and comments given by you has been a great help in this work. I appreciate that you also accepted to be a member of my defence committee. It was a great pleasure for me. I owe my gratitude to Maurice Strubel, technical assistant at FPE group, without whom I was not able to do my experiments there. You have been greatly tolerant and supportive during my work and helped me learn how to work with the EDGE set-up and later on characterize the emulsions. I would also like to show my appreciation to you for coming to Enschede and helping me make the EDGE set-up at UT. That was a great help for me. I am also grateful to David Fernandez Rivas from Mesoscale Chemical Systems (MCS) group at University of Twente for his invaluable advice on acoustic systems.

Chapter Seven was a result of collaboration with Multiscale Mechanics (MSM) group at University of Twente. I would like to express my gratitude to Stefan Luding for initiating the idea and all the insightful comments and suggestions throughout the work. I would also like to offer my thanks to Wouter den otter for all his support and encouragement in this work. Greatest and deepest appreciation goes to Thejas Hulikal Chakrapani, PhD at MSM group, whom I was collaborating with for this work. Your dedication and hard work led to a successful outcome which I am proud of. Thanks for always being available for meetings and discussions. I enjoyed working with you and I am happy that apart from collaboration, we made a good friendship as well. I wish you best of luck in your future life and career.

This thesis would never have been possible without the help and support of technical staff. Special thanks to Jan van Nieuwkasteele, process engineer at SFI. I have benefited from your advice and support on my microfluidic experiments and all the chips which you fabricated for me. I am also grateful for your assistance on making the acoustic set-up. I would also like to acknowledge Ineke Punt, technical staff at SFI. You were the first person who introduced membrane fabrication to me and helped me make my first membrane. Your advice and comments on working with the contact angle device have been a great help for me. Special thanks also to Bob Siemerink, technical assistant at membrane cluster. You helped me with my zeta potential measurements. 
Your sense of humor made working environment in the lab so "gezellig";). Next person that I would like to show my appreciation to, is Iske Achterhuis research assistant at membrane cluster. Your support with the Osmo Inspector set-up and UV-Vis was an enormous help to me and my student. In addition, thanks to people from TCO workshop at UT who helped me with fabrication of my experimental set-ups. Sip Jan Boorsma, Roy Kooijman former support staff at glass workshop, and Rob Dierink.

First year of my $\mathrm{PhD}$ was done at Wetsus where I made my first set-up. I would like to offer my special thanks to Harm van der Kooi and Wim Borgonje who helped me make the set-up. I would like to express my gratitude to Maarten Biesheuvel, coordinator of the concentrate theme, who helped me strengthening my weaknesses in my research work as well as my Dutch language. I want to also thank Martijn Wagterveld, scientific project manager, for coming up with the idea of application of acoustic field for movement of oil droplets towards membrane. I also appreciate the help of Hakan Kandemir, $\mathrm{PhD}$ at Wetsus, on this topic. Additionally I want to thank my other colleagues at Wetsus such as Heleen Sombekke, former project manager, Nynke Broekens, HR manager, Anke de Graaf, HR secretary, Casper Borsje, Terica Sinclair, Tania Mubita and Victor Ajao former PhDs, Janneke Dickhout, and Victor Torres Serrano, former PhDs and my office mates, for all their kind help and support during my work at Wetsus. I enjoyed working with all of you.

I extend my sincere gratitude to all my students who contributed to the accomplishment of this work. Jaap Eijsker, my first student who worked on the effect of surfactants on the retention of oil in liquid-infused membranes. Noor van de Beek and Julia Peper whose works contributed in Chapters Four and Six respectively. Work of Jomuel Velandres on the electro-filtration helped me obtaining the reflections and perspectives to the work (Chapter Eight). Without all your hard work and dedication, a great part of this thesis would not have been possible. I wish you all best of success.

I wish to also thank other people at membrane cluster who supported me during my PhD work. Antoine Kemperman, Herman Teunis, Harmen Zwijnenberg and Cindy Huiskes from inorganic membrane group.

Further I would like to give my appreciation to the secretaries at SFI and membrane cluster. Lidy Harryvan, former secretary of SFI who helped me before and after my first arrival to The Netherlands. The nice dinner which I and Amir had at your place is so memorable for me. I would like to express my gratitude to Audrey Haarnack, MST secretary who helped me with my 
Dutch language. I enjoyed our "wandelingen" in which you encouraged me to talk in Dutch. Special thanks to Brigitte Boogaard, current secretary of SFI.

A great part of $\mathrm{PhD}$ life is interaction with other $\mathrm{PhD}$ colleagues, with whom I have shared moments of deep anxiety but also of big excitements. A warm word for my colleague and good friend Mandakranta Ghosh, who always managed to make me feel unique and with whom I had the best conference trips ever. I would like to offer my thanks to Nicole Timmerhuis, who helped me with reviewing the Dutch translation of the summary. I enjoyed working with you during your master and I am happy that you started a PhD at SFI and became my colleague and office mate. I am glad to have the support of both of you as my paranymphs during my PhD defence. Another colleague of mine with whom I made a nice friendship was Pim Bullee. Working with you in the lab for hydrohpobization of mucrofluidic chips was a lot of fun which I never forget ;). "Je bent geweldig en ik kijk ernaar uit je binnenkort weer te zien :)". I specifically appreciate Burak Akdeniz who has recently started his PhD at SFI. Without your help I could not be able to finish all my lab and office cleanings in a day. Thanks for your kind helps and supports. I wish you best of success with your PhD. I would like to also thank the other PhDs at SFI and MST cluster such as Abimbola Ashaju, Arputha Paul, Khalid El Tayeb El Obied, Ameya Bysani, Özlem Demirel, Elif Nur Durmaz and Pelin Karakiliç whom their presence was very important during my $\mathrm{PhD}$ life. I enjoyed Pelin's wedding ceremony in Turkey. It was such a unique and nice experience for me. I am glad to meet all of you.

I am particularly happy to meet Aura Visan, former PhD at SFI, whom I enjoyed sharing scientific as well as non-scientific thoughts and issues. Thank you also for the design and fabrication of the microfluidic chip which I used for the work in Chapter Six. One of the other former PhDs at SFI, whom I really enjoyed working with was Anne Benneker. SFI lab atmosphere was always happy and energetic with the presence of you, Anne. I liked our discussions in the lab and I am happy you learned some Persian sentences ;). Sander Haase was another former PhD at SFI who was also my office mate. I learned a lot of things from you. Thanks for all your help and encouragements. I would also like to show my gratitude to the other former PhDs at SFI, Damon Rafieian, Joeri de Valença and Yali Zhang for their warm welcome and support at the start of my work at SFI.

I wish to also thank the members of my defence committee, Arian Nijmeijer, Frieder Mugele, Xu Hou, Karon Schroën and Anke Lindner for 
generously offering their time, support and guidance throughout the review of this thesis.

I also owe much gratitude to my family, my mother, my sisters and brother. As Goerge Santayana says, "the family is one of nature's masterpieces" and I am so lucky to have an incredible one. Your devotion, unconditional love and support, patience, optimism and advice despite the long distance between us, were more valuable than you could ever imagine. Thanks for always being there for me.

Lastly, but above all, my deepest appreciation and love goes to my husband, Amir Saadat who has supported me throughout my PhD work and has constantly encouraged me during the tough and inconvenient moments of my $\mathrm{PhD}$ life. Thanks for patiently listening to all my complains and wisely directing me. I appreciate your kind endurance when I was impatient and irritable which happened a lot during my PhD. You are always there to calm me down and talk to me. You are the most important person for me and words cannot express how grateful I am to have you by my side for the rest of my life.

This work was part of the Vici project STW 016.160.312 which was financed by The Netherlands Organisation for Scientific Research (Nederlandse Organisatie voor Wetenschappelijk Onderzoek (NWO)). This work was performed in the cooperation framework of Wetsus, European Centre of excellence for sustainable water technology (www.wetsus.nl). Wetsus is co-funded by the Dutch Ministry of Economic Affairs and Ministry of Infrastructure and Environment, the European Union Regional Development Fund, the Province of Fryslân and the Northern Netherlands Provinces. This work has also received funding from the European Union's Horizon 2020 research and innovation program under the Marie Skłodowska-Curie [grant agreement No. 665874]. The author would like to thank the research theme 'Concentrates' for the fruitful discussions.

With love,

Hanieh

February 2020 


\section{About the author}

Hanieh Bazyar was born on March 25, 1988 in Shiraz, Iran. After graduating from high school in the field of mathematics, she started bachelor in Materials Science and Engineering at Shiraz University. During her bachelor studies, she gained some teaching experience as teaching assistant (TA) in different courses. She did her bachelor internship at FARASSAN composite company in Shiraz, where she leaned

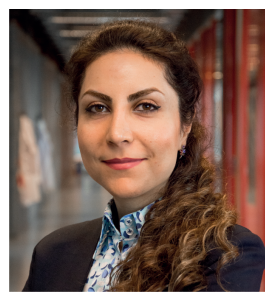
about glass-reinforced polymer (GRP) composite tubes and vessels. She did her bachelor thesis in collaboration with the same company, on the fabrication and analysis of GRP composite materials.

Directly after bachelor, she started her master in 2010 in the same field at Shiraz University. During her master studies she was also part-time involved in teaching as TA. She did her master thesis as an industrial project with FARRASAN and South Zagros Oil \& Gas Production company under supervision of prof. dr. Sirus Javadpour. The subject of her master thesis was about rehabilitation and reinforcement of metallic gas pipes using GRP composites.

After obtaining her master degree in 2012, she started working as full time TA and research assistant in the same department at Shiraz University. In 2015, she came to The Netherlands, University of Twente, to conduct research work on membranes at Soft matter Fluidics and Interfaces (SFI) group. Her research work was about fabrication and characterization of liquid-infused membranes. After a year, on March 2016, she started a PhD on the same topic at SFI group, in collaboration with Wetsus, under supervision of prof. dr. ir. Rob G. H. Lammertink.

On March 2020, she started working as a tenure tracker at TU/Delft, department of Process and Energy. In her spare time, she likes sports such as fitness and running as well as painting, doing puzzles and travelling. 



\section{About the cover}

On October 2018 I did a project with first year bachelor students on "chemistry and food". The goal of the project was investigating the stability of food emulsions with the presence of kitchen salt and sugar. The food emulsions were prepared by dispersing sunflower oil in aqueous solutions of xanthan gum and soy lecithin as a food emulsifier. For visualization purposes, a fluorescent food dye was added to the oil phase prior to the emulsion preparation. A small droplet of each emulsion was observed under an inverted fluorescent microscope. The observations were done on the day of the emulsion preparation and the day after as well.

The picture on the front side of the cover shows the emulsion prepared with xanthan gum and salt after one day (at magnification of $2.5 \mathrm{x}$ ). Since the initial emulsion droplet was small (around $20 \mu \mathrm{l}$ ), water was already evaporated after one day and crystals of salt can be observed as long and short cubes. The oil droplets were already coalesced and attached to the salt crystals (white bright regions).

The picture on the backside of the cover shows the emulsion prepared with xanthan gum and salt after 3 hours (at magnification of $2.5 \mathrm{x}$ ). Water has been already evaporated and salt crystals are distinguishable. The oil droplets can be also clearly observed in the middle and attached to the salt crystals.

The original pictures were black and white and they are colourized as you can see. The cover design and picture colourizing are done in Adobe Illustrator by Phoenix Technologies graphic design company in Agra, India (www.phoenix-technologies.net).

This thesis is printed by IPSKAMP printing company, Enschede, The Netherlands (www.ipskampprinting.nl). 



\section{Scientific output}

\section{Publications}

- prepared for submission: Acoustophoresis of monodisperse oil droplets in oil-in-water $(\mathrm{O} / \mathrm{W})$ emulsions

H. Bazyar, J. Peper, P. Lv, K. Schröen, R. G. H. Lammertink

- prepared for submission: Permeability prediction of porous media

H. Bazyar, T. Hulikal Chakrapani, W. K. den Otter, S. Luding, R. G.

H. Lammertink

Physical Review Fluids

- submitted: Application of liquid-infused membranes to mitigate biofilm growth

H. Bazyar, L. Xu, R. de Vries, S. Porada, R. G. H. Lammertink Environmental Science: Water research and Technology

- 2019: Liquid-infused membranes with oil-in-water (O/W) emulsions

H. Bazyar, N. van de Beek, R. G. H. Lammertink

Langmuir, 35, 9513-9520

- 2018: Liquid-liquid displacement in slippery liquid-infused membranes H. Bazyar, P. Lv, J. Wood, S. Porada, D. Lohse, R. G. H. Lammertink Soft Matter, 14, 1780-1788

- 2016: On the gating mechanism of slippery liquid-infused porous membranes

H. Bazyar, S. Javadpour, R. G. H. Lammertink

Advanced materials interfaces, 3,1600025 


\section{Selected presentations in conferences}

- 2020: Adaptive pores in next generation membranes: anti-biofouling performance

H. Bazyar, S. Porada, R. G. H. Lammertink

$12^{\text {th }}$ International Congress on Membranes \& Membrane Processes (ICOM), London, UK

- 2019: Interface-controlled oil permeation using liquid-infused membranes

H. Bazyar, N. van de Beek, R. G. H. Lammertink

The $33^{\text {rd }}$ Conference of the European Colloids and Interface Society (ECIS), Leuven, Belgium

- 2019: Adaptive pores for oil permeation from oil-in-water emulsions

H. Bazyar, T. Hulikalchakrapani, W. den Otter, S. Luding, R. G. H. Lammertink

The $11^{\text {th }}$ International Conference on Porous Media (InterPore), Valencia, Spain

- 2018: Liquid film retention in slippery liquid-infused membranes

H. Bazyar, P. Lv, J. Wood, S. Porada, D. Lohse, R. G. H. Lammertink Euromembrane, Valencia, Spain

- 2017: Immiscible displacement in slippery liquid infused membranes H. Bazyar, S. Porada, R. G. H. Lammertink $9^{\text {th }}$ International Conference on Porous Media (InterPore), Rotterdam, The Netherlands 


In this thesis a novel class of polymeric membranes known as slippery liquid-infused membranes are studied. In these membranes pores are filled with an infusion liquid which is typically an oil. Liquid-infused pores act like a gate that can open and close in response to the system - pressure, thus called "Adaptive pores". Once appropriate pressure is applied, certain species can be transferred through the pores while others are being retained. This is called gating capability which can be used for efficient sorting of immiscible fluids from a mixture in separation applications.

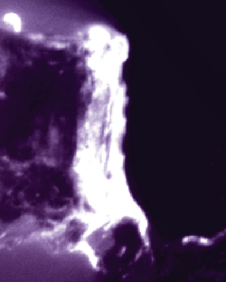

(n)

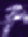
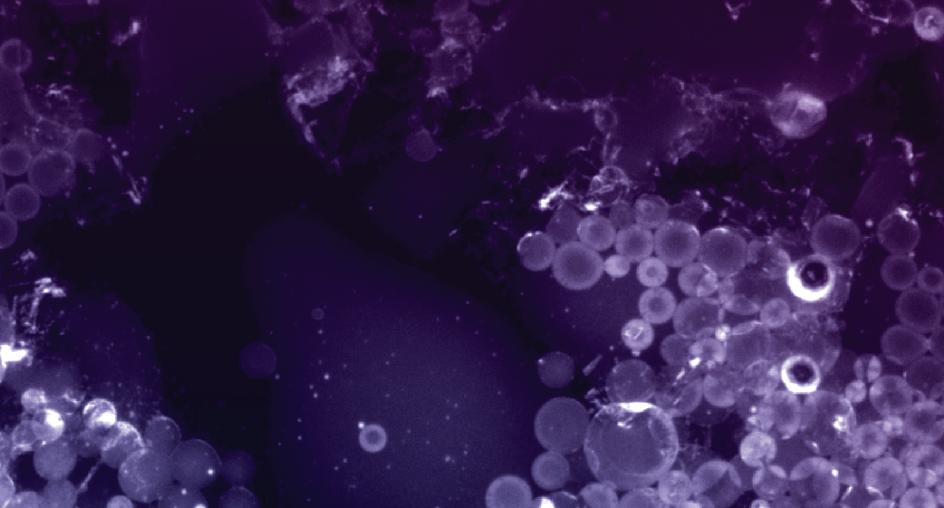

6.8
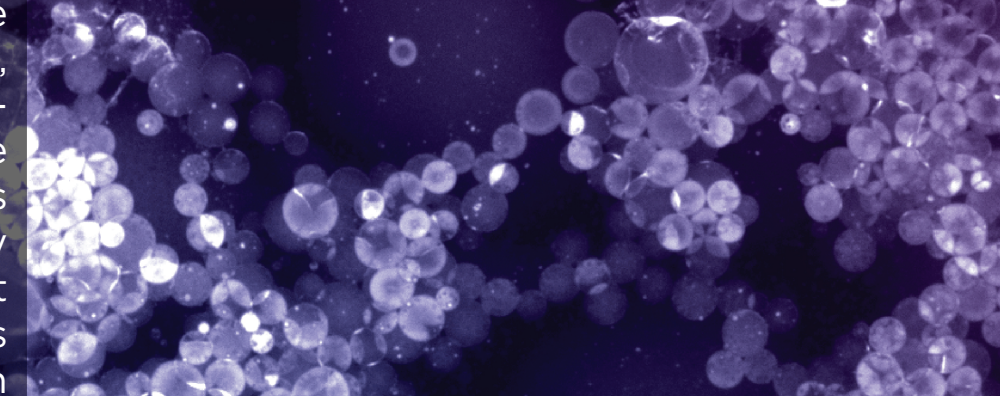